\title{
ELITE QUALITY
}

\section{INDEX}

(O) EQx2020

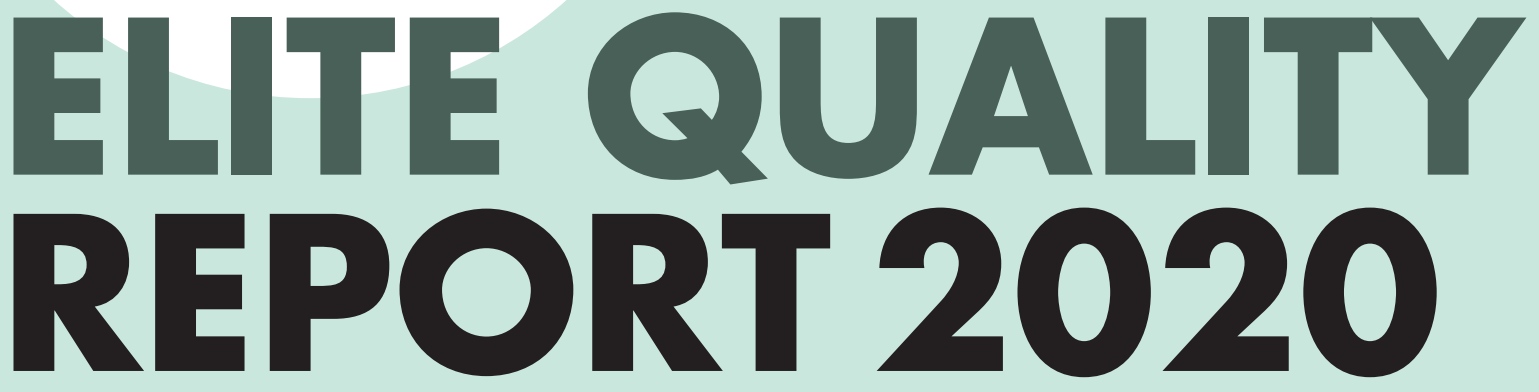

32 COUNTRY SCORES

AND GLOBAL RANK

Value Creation fundamentals in societies:

Global metrics for long-term economic and human development
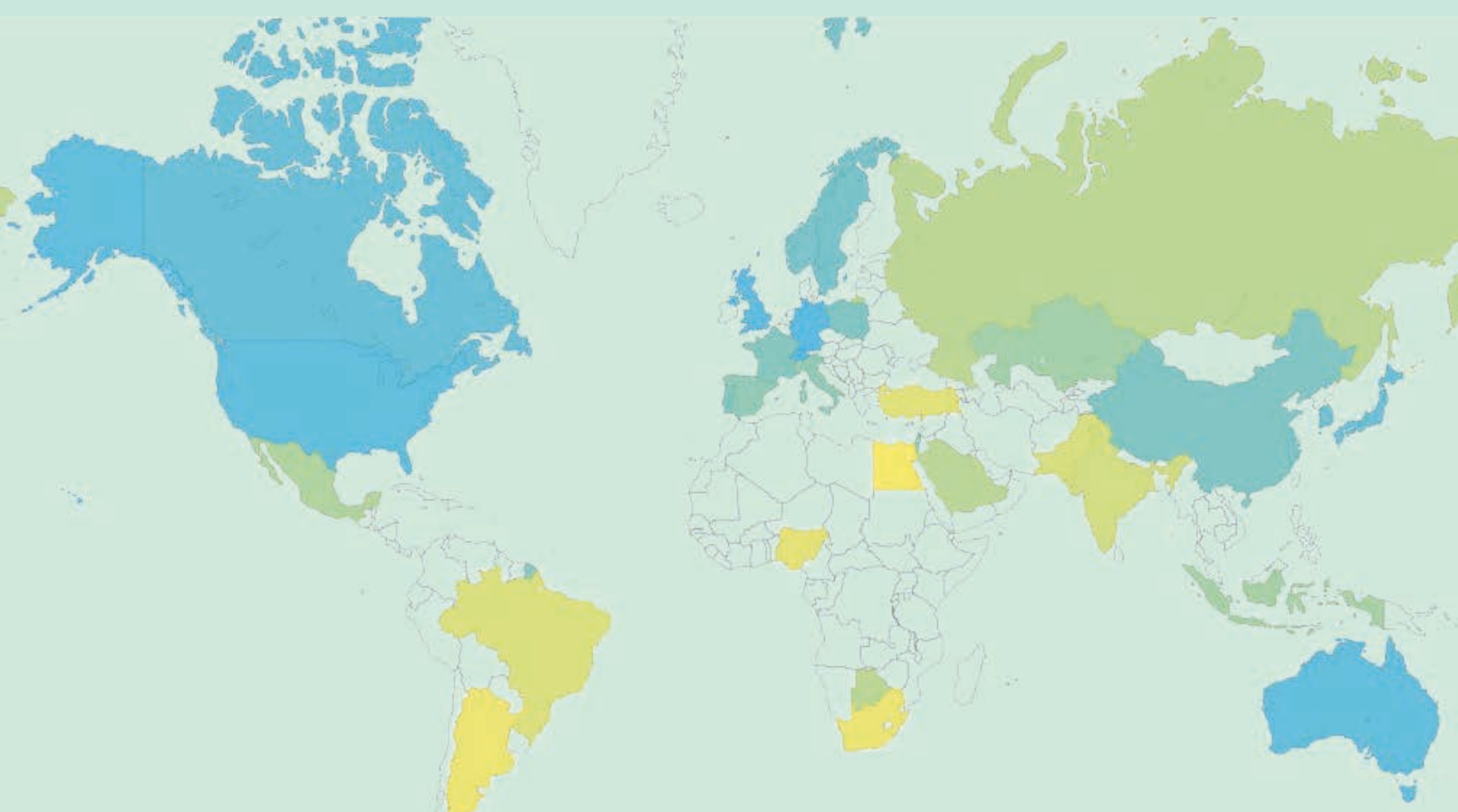

EQx Country Scores

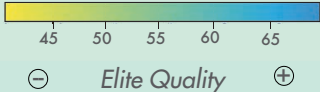




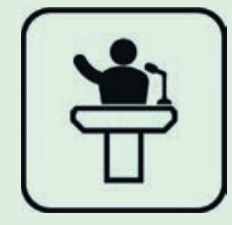

Political

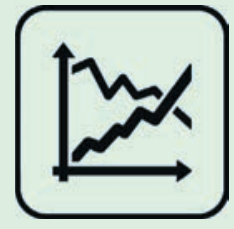

Economic

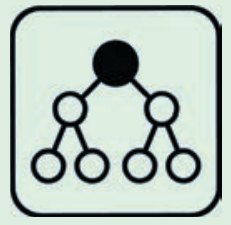

Power

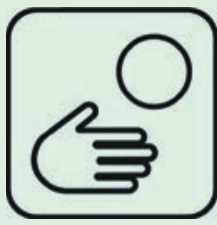

Value

This report is the result of a collective research and writing effort by its editors and authors. Substantial discrete contributions are recognized in the corresponding sections of the report.

The report was edited by Tomas Casas and Guido Cozzi, and authored by Tomas Casas, Guido Cozzi, Céline Diebold, Diana van der Watt and Camille Zeller.

If you wish to reference the report use the following citation format: Casas, T. \& Cozzi, G. (2020). Elite Quality Report 2020: 32 Country Scores and Global Rank. Zurich: Seismo. doi: 10.33058/seismo.30750

(C2020 the Foundation for Value Creation, St.Gallen, Switzerland, distributed under the terms and conditions of the Creative Commons license CC BY-NC-ND (http:/creativecommons.org/licenses/by-nc-nd/4.0/).

Published by Seismo Press AG, Zurich and Geneva in partnership with the Foundation for Value Creation

978-3-03777-240-9 (Print)

978-3-03777-750-3 (EBook)

https://doi.org/10.33058/seismo.30750

Available at SSRN: https://ssrn.com/abstract=3676776

Parties interested in the commercial use of the Elite Quality Report 2020 32 Country Scores and Global Rank, parts thereof, Country Scores data or Global Rank data, should obtain written permission by contacting at rights@elitequality.org

printed in

switzerland by Niedermann Druck AG, St.Gallen 


\section{ELITE QUALITY \\ REPORT 2020}

32 COUNTRY SCORES

AND GLOBAL RANK

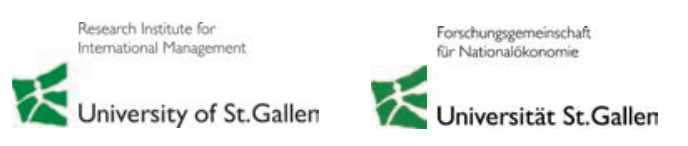


The Elite Quality Index (EQx) and the Elite Quality Report: 32 Country Scores and Global Rank (a.k.a. EQx2020 Report, EQx2020 or Report) represent a unique interpretation of national economies and their mid- to long-term prospects. The EQx2020 is based on a methodology which starts with the collection and collation of relevant, up-to-date datasets from a variety of organizations and sources (see herein section 7.2 References, for the complete list). The datasets conceptually fit the EQx White Paper (Casas, 2020).

The EQx methodology is described in Measuring Elite Quality (Casas, Cozzi, Diebol, \& Zeller, 2020) (a.k.a. EQx Methodology Paper). It was developed and inspired by a team of academics and practitioners with the aim of supporting national elites Value Creation business models and incentivizing political economy tenets that foster such models". Analysis and interpretations of the EQx results contained in this Elite Quality Report, such as the commentaries on the Country Scorecards, are the result of individual or collective work and do not necessarily represent the position of the editors, the project team and other project participants.

ELITE QUALITYTM, the Elite Quality Index® $(E Q x)$ and its underlying methodologies are the exclusive intellectual property of the Foundation for Valve Creation (FVC) protected internationally by copyright and/or trade mark registration. All rights reserved. 2020

This EQx2020 is the first of a series of reports and insights derived from the Elite Quality Index. Its purpose is to elicit a discussion among academics and initiate conversations with a broad range of interested parties. The $E Q x$ project is innovative and timely in our age of disruption, with its position at the intersection of academia, business and policy. The $E Q \times 2020$ is an initial, experimental expression of the project, and we aim to release a full report annually, starting with the EQx2021 publication next January.

The EQx2020 was produced from datasets collected, collated and transformed by a committed and international research team. The Report's underlying dataset and all included information is subject to change without notice. For the country classification the Report uses the ISO 3166-1 alpha-3 country codes defined by the ISO 3166 Maintenance Agency. The terms "country" and "nation" - as used in this Report - do not always refer to a territorial entity/state as understood by international law and practice. The term might refer to self-contained economic areas that are not states, but for which statistical data are maintained on a separate and independent basis.

The Report's editors, contributors and research team cannot guarantee that information in the underlying dataset is correct, that there are no errors, or that calculations and described methodologies have been consistently applied. We are not responsible for the suitability - or fitness for any purpose - of the contents and supporting information, interpretation and analysis found in the Report. The research team, project, partners, contributors, editors and the Foundation for Value Creation accept no liability for any content of the Report or its parts, nor for any implications, nor decisions made, or actions taken on the Report's basis.

The research team, project, partners, contributors, editors and the Foundation for Value Creation might not own nor control the rights of underlying datasets or information ("Data \& Information") used in the Report. They are not responsible for uses that any party might make of the Data \& Information.

Unless formally licensed, acquisition of the Report implies no authorization of third-party products or services derived from any Data \& Information or any content referred to or included in the EQx2020 Report.

The research team, project, partners, contributors, editors and the Foundation for Value Creation are not responsible for the transformation by any third parties of information in this Report, who might infringe upon the integrity of the Report or underlying data and information. Any transformation of the Report and its related information has to be clearly, visibly acknowledged together with the mandatory source citation.

Data \& Information as well as the datasets that were compiled for the Report from third parties, all of which have been duly credited in the References chapter, are subject to these third parties' terms of use.

While every care has been exercised in preparing, compiling and publishing the data contained in these pages and this report, no responsibility can be accepted whatsoever in respect to any such information, data, analysis or opinion, any loss arising out of any use, or inability to use such, as well as for any error or omission contained herein.

When the EQx2020 Report, parts thereof, its Country Scores or Global Rank, directly or indirectly obtained, is distributed or reproduced, the source attribution shall be cited as: Casas, T. \& Cozzi, G. (2020). Elite Quality Report 2020: 32 Country Scores and Global Rank. Zurich: Seismo. doi: 10.33058/seismo.30750

Any readers and users of the Report, whether obtained via download or otherwise, agree to make all reasonable efforts to comply with these terms themselves and to promote compliance with their own end users.

Parties interested in partnering with the Foundation for Value Creation can email us at: foundation@elitequality.org. 


\section{ELITE QUALITY}

INDEX

\section{Value Creation fundamentals in societies}

Global metrics for long-term economic and human development 


\section{Table of Contents}

\section{INTRODUCTION}

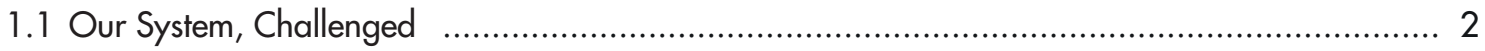

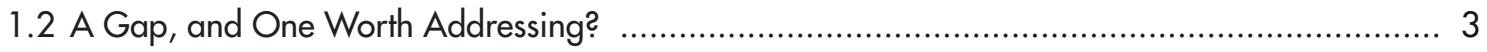

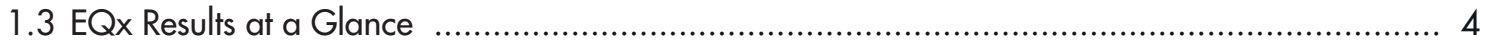

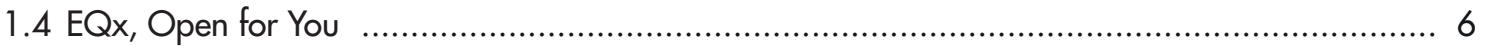

\section{HOW 'ELITE QUALITY' BECAME A GLOBAL INDEX}

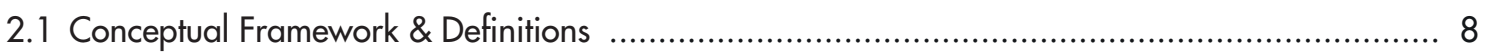

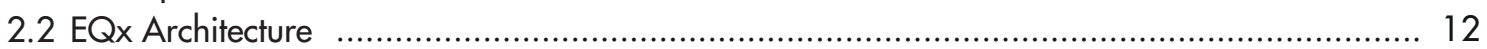

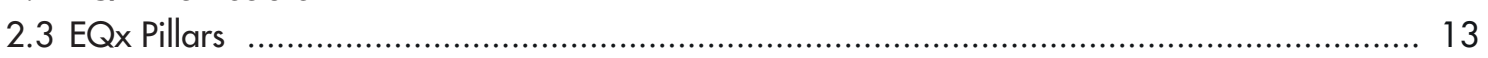

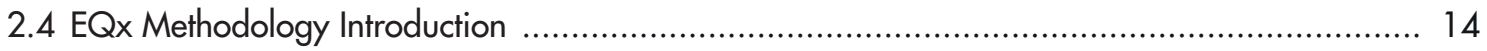

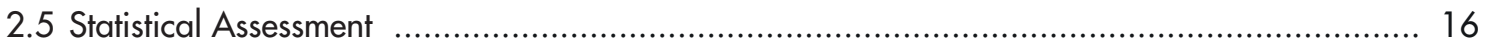

\section{EQX RESULTS}

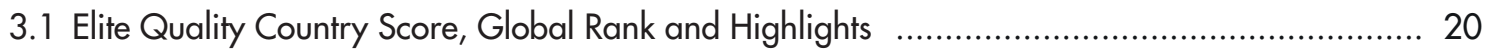

3.2 State of Elites Framework: Country Mapping and Highlights ............................................ 22

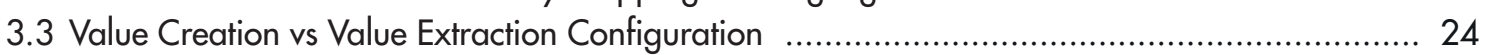

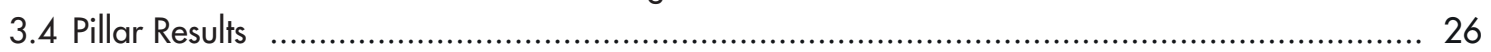

\section{EQX COUNTRY ANALYSIS}

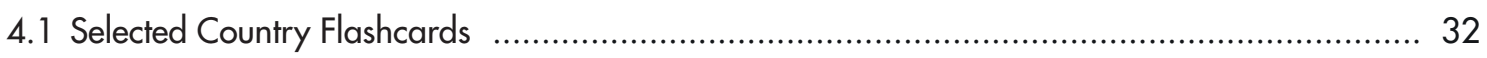

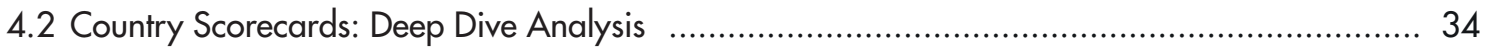

4.3 Extreme Country Performances by Pillar ...................................................................... 52

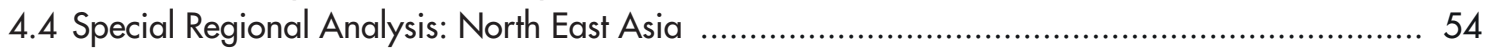

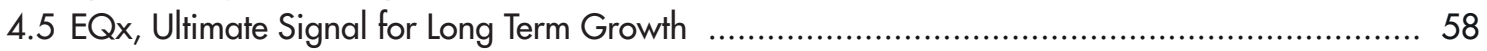

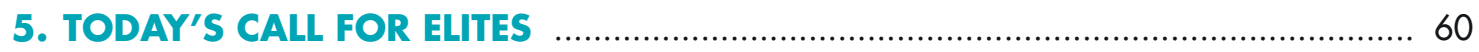

\section{EXHIBITS}

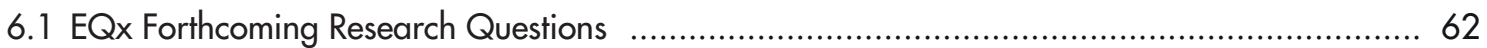

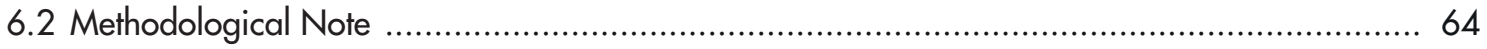

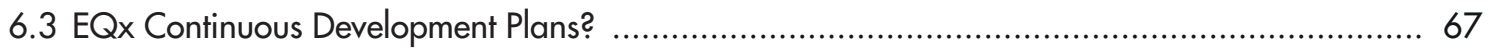

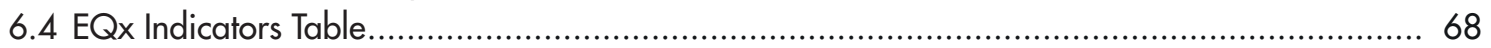

\section{REFERENCES}

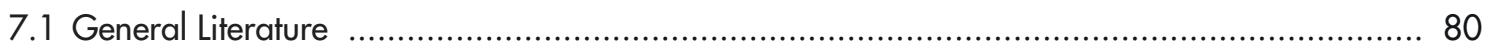

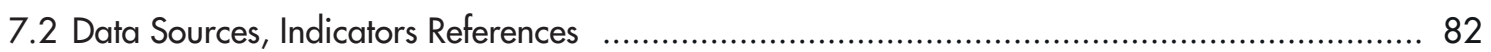

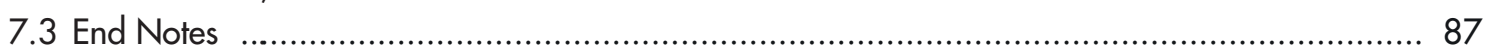




\section{List of Visuals}

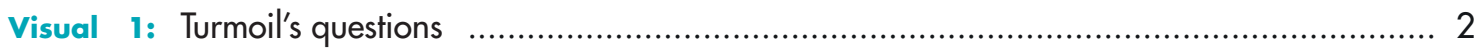

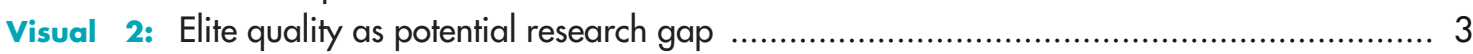

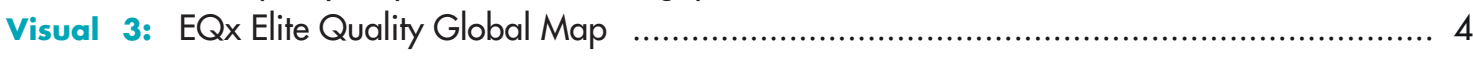

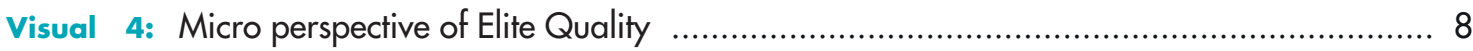

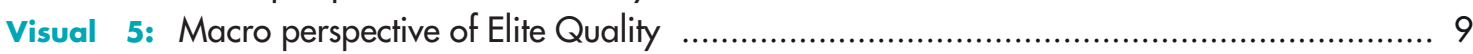

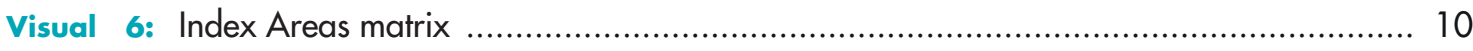

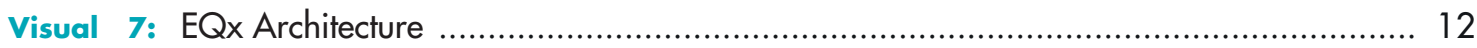

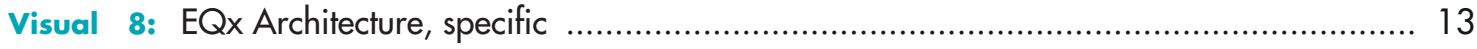

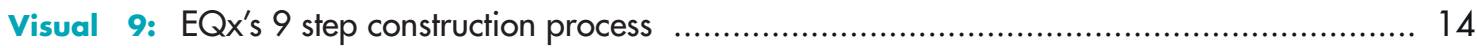

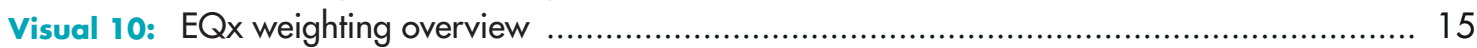

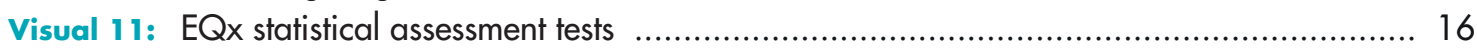

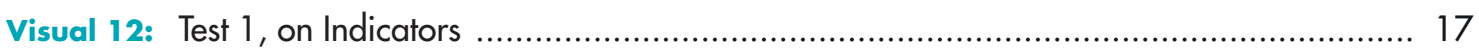

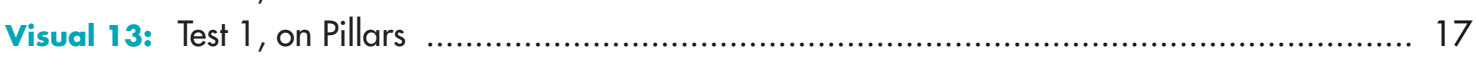

Visual 14: EQx2020 table of Country Scores and Globa Rank ............................................... 20

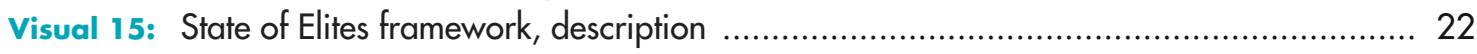

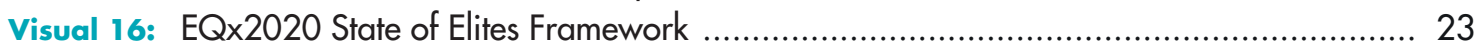

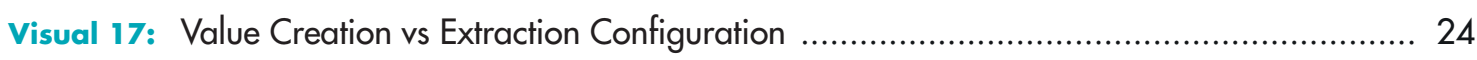

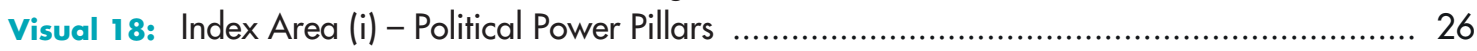

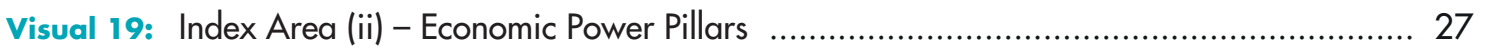

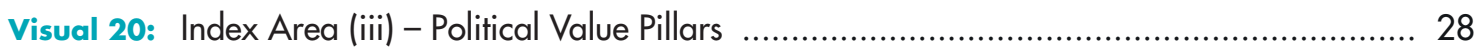

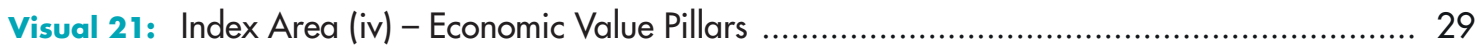

Visual 22: Table of complete EQx Pillars by Country Scores ..................................................... 30

Visual 23: Table of complete EQx Pillars by Global Rank ...................................................... 31

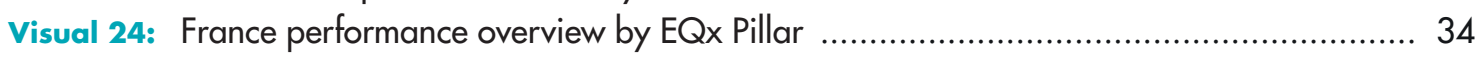

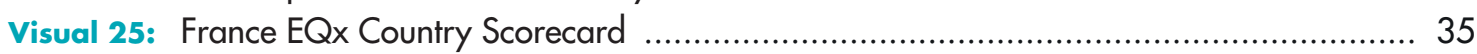

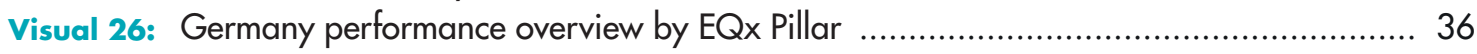

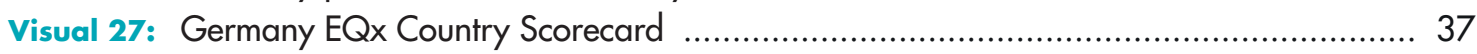

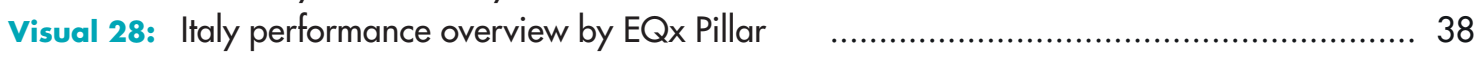

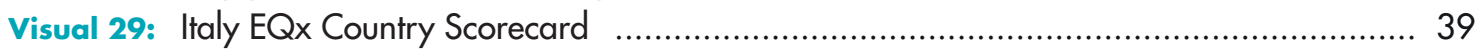

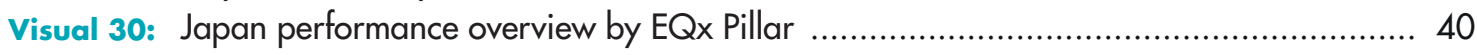

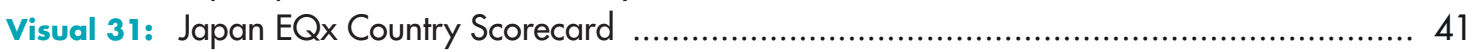

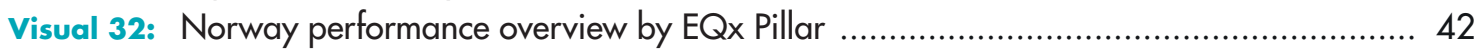

Visual 33: Norway EQx Country Scorecard ........................................................................... 43

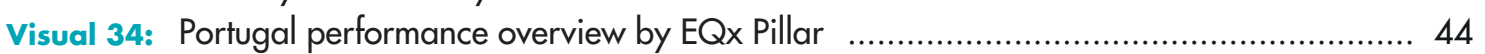

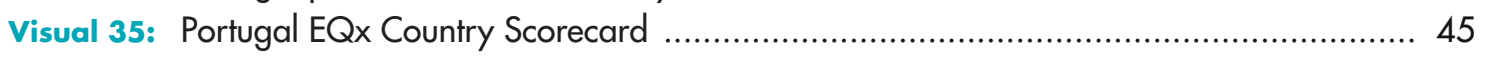

Visual 36: Russian Federation performance overview by EQx Pillar ....................................... 46

Visual 37: Russian Federation EQx Country Scorecard .................................................... 47

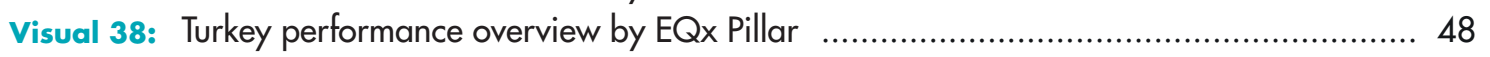

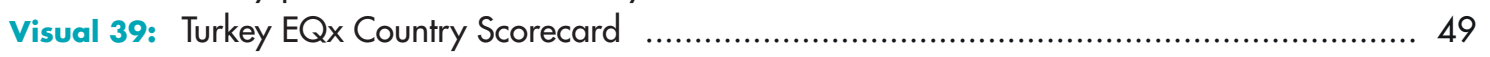

Visual 40: United States performance overview by EQx Pillar ............................................... 50

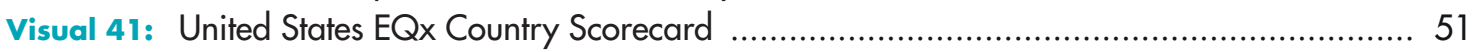

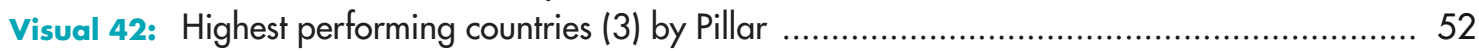

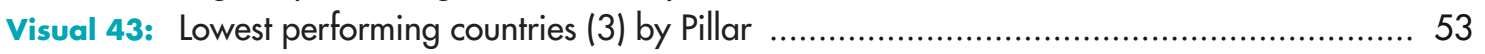

Visual 44: Japan, Korea, China - Regional Comparison ........................................................... 55

Visual 45: EQx's correlation with GDP per capita PPP ..................................................... 58

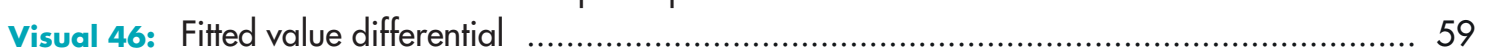

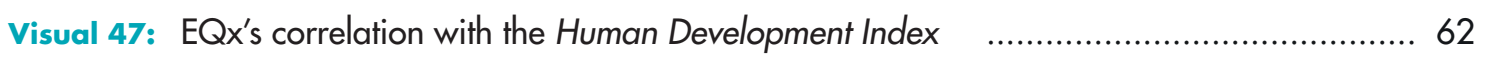

Visual 48: EQx's correlation with the WEF Global Competitiveness Index $\quad$...............................63 63

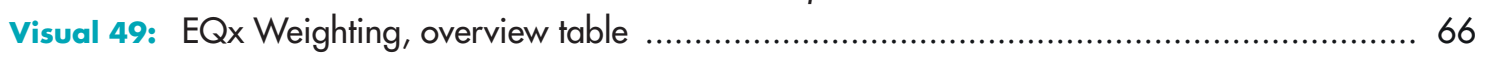

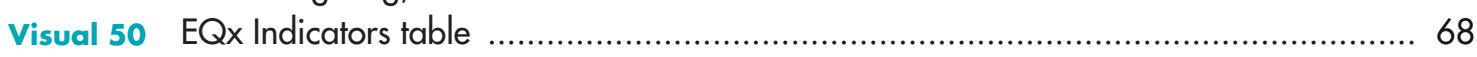

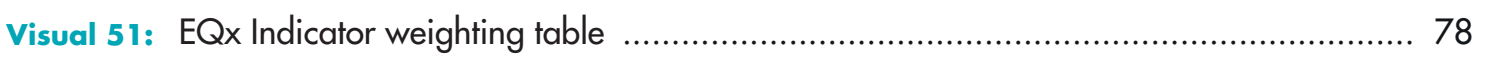




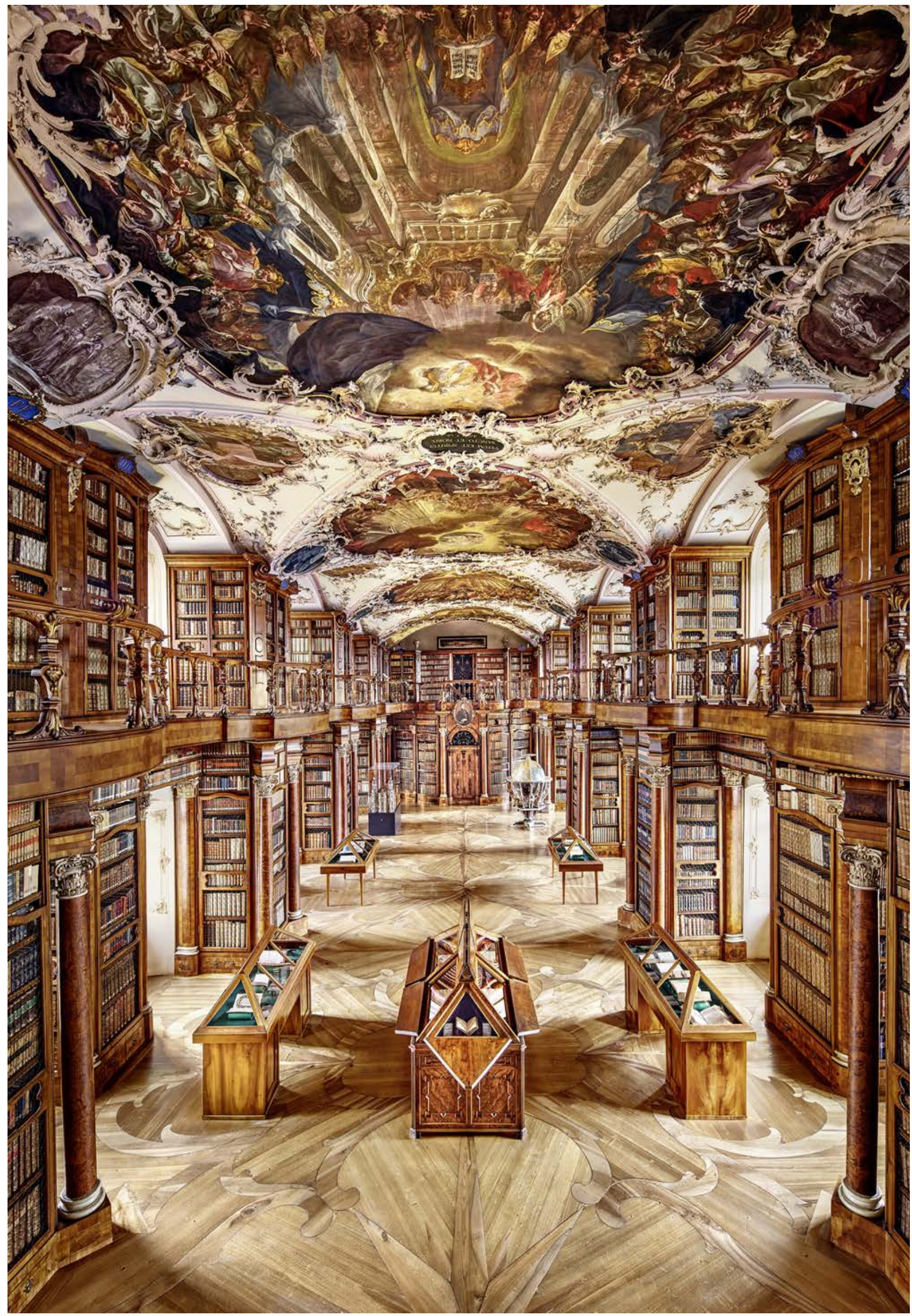

The Abbey Library of St.Gallen (Stiftsbibliothek) in Switzerland has its roots tracing back to medieval times having for over a millennia served as a repository of knowledge Luca Zanier Photography, Corridors of Power Project 


\section{Executive Summary}

\section{Elite Quality determines human and economic development}

- Elites are an empirical inevitability, dominating all political economies. They provide necessary coordination capacity for the economy's resources, whether human, financial or knowledge-based.

- By determining institutions that enable coordination, elites shape human and economic development, the destiny of societies, the wealth of nations, and their rise and fall.

- To sustain their position, elites run business models that accumulate wealth. High-quality elites run Value Creation business models that give more to society than they take. Low-quality elites do the opposite and operate Value Extraction models.

\section{What did the EQx2020 research discover?}

1. There exist substantial differences in the states of Elite Quality around the world.

2. Singapore is number one. While its score is penalized on account of high Power, the city state's elites are by far the highest value creators on the planet.

3. The successful Germanic elite model employed in Switzerland $\left(2^{\text {nd }}\right)$ and Germany (3rd) fosters a high-level of Value Creation, notwithstanding improvement potential in various areas.

4. We find Anglo-Saxon elites to be high-quality and are led by the U.K. $\left(4^{\text {th }}\right)$ and the U.S. $\left(5^{\text {th}}\right)$. Interestingly, American and British elites manage to rent seek more than their top Power Sub-Index scores $\left(1^{\text {st }}\right.$ and $\left.2^{\text {nd }}\right)$, derived from excellent institutions, seem to warrant.

5. Emerging superpower China has super elites coming in $12^{\text {th }}$, at a level much higher than its peers in the middle-income category, and outperforming many advanced E.U. countries.

6. BRIS countries are clustered in the lower levels. Russia, India, Brazil and South Africa - in that order - rank between $23^{\text {rd }}$ and $30^{\text {th }}$.

7. Many African elites are rent seekers, approximately as powerful as elites in China or Poland but scoring lowest of all surveyed countries because of high Value Extraction activities.

8. The E.U. is split by Elite Quality, with Country Scores varying significantly. Behind top-scorer Germany there is the cluster of Sweden (10 th) , Poland $\left(13^{\text {th }}\right)$, Portugal $\left(14^{\text {th }}\right)$, France $\left(15^{\text {th }}\right)$, followed by a lagging one with Italy $\left(17^{\text {th }}\right)$ and Spain $\left(18^{\text {th }}\right)$.

\section{EQx measures Elite Quality}

- We present the first ever international measurement of Elite Quality, the Elite Quality Index (EQx) for 32 countries. We use 72 Indicators describing Value Creation/ Extraction. The Index architecture includes Power (Sub-Index I), a measurement of future Value Extraction potential, and Value itself (Sub-Index II) and 12 Pillars (e.g. Creative Destruction, Human Capture or Producer Rent).

- Elite Quality is an analytical framework based on economic and management theory designed to interpret - and possibly transform - the state of the world and its future.

- This EQx2020 Report is the first, experimental version of what will be an annual publication. In early January 2021 we are launching the EQx2021 on the theme of Elite Value Creation and Covid-19.

\begin{tabular}{|c|c|c|}
\hline Country & $\begin{array}{c}\text { Global } \\
\text { Rank }\end{array}$ & $\begin{array}{c}\text { Country } \\
\text { Score }\end{array}$ \\
\hline Singapore & 1 & 68.5 \\
\hline Switzerland & 2 & 64.9 \\
\hline Germany & 3 & 64.2 \\
\hline United Kingdom & 4 & 63.9 \\
\hline United States & 5 & 63.4 \\
\hline Australia & 6 & 63.2 \\
\hline Canada & 7 & 61.9 \\
\hline Japan & 8 & 61.6 \\
\hline Korea, Rep. & 9 & 61.2 \\
\hline Sweden & 10 & 59.7 \\
\hline Norway & 11 & 58.6 \\
\hline China & 12 & 58.4 \\
\hline Poland & 13 & 58.3 \\
\hline Portugal & 14 & 58.0 \\
\hline France & 15 & 57.4 \\
\hline Israel & 16 & 56.9 \\
\hline Italy & 17 & 55.5 \\
\hline Spain & 18 & 55.5 \\
\hline Kazakhstan & 19 & 52.7 \\
\hline Indonesia & 20 & 52.0 \\
\hline Mexico & 21 & 50.7 \\
\hline Saudi Arabia & 22 & 49.2 \\
\hline Russian Federation & 23 & 48.9 \\
\hline Botswana & 24 & 48.9 \\
\hline India & 25 & 45.4 \\
\hline Pakistan & 26 & 44.5 \\
\hline Brazil & 27 & 44.1 \\
\hline Turkey & 28 & 43.3 \\
\hline Nigeria & 29 & 42.4 \\
\hline South Africa & 30 & 41.7 \\
\hline Argentina & 31 & 41.6 \\
\hline Egypt, Arab Rep. & 32 & 40.0 \\
\hline
\end{tabular}




\section{Introduction:}

\section{Measuring Value in the Political Economy}

More value had been created by early 2020 than at any other time in economic history. Material improvements resulting from Value Creation through pioneering science, innovative services and smart business models are still enormous and evident. Humanity's relentless ingenuity yields increasing benefits for all, enabled by the consolidation of phenomenal global coordination mechanisms such as narratives' ${ }^{1}$ and, yes, the elites. Yet, despite the accelerating prodigious output of our collective work, values and creativity, discontent, disorder and distress are on the rise.

\subsection{Our System, Challenged?}

Since 2008, nations - their political and business leaders, narratives and core values - have faced vigorous challenges on multiple and largely unforeseen fronts. Numerous voices claim that we are undergoing, even before the $21^{\text {st }}$ century's inflection pandemic year of 2020, an assault on order of a ferocity not seen since the 1930s. Social, economic and political forces might be gathering momentum to disrupt or even destruct in ways we cannot seem to predict. A glance at the current world situation demonstrates this:

- Protest movements and escalating riots, especially by the young and the disenfranchised

- Unchartered combinations of secular stagnation, stagnant wages, and sub-zero interest rates, along with increasing inequality

- Trade wars, sanctions, technology embargoes and deglobalization

- The extinction rebellion and rapid real-time environmental degradation, confronting us with irreversible losses
- One-off high-impact events like Brexit and black swans of all kinds lurking across emerging markets, Wall Street, the South China Sea and in health systems worldwide

- Populist and anti-establishment politicians, on the Far Right and on the Radical Left

- The rampant invasion of fake news and disinformation campaigns, as well as targeted cyber attacks

- The human tragedy of refugees and the hard responses of those who feel threatened by immigration and the 'other'

- Raging debates within our societies and across the world over how to define our obligations and relations to one another, especially during the crisis caused by Covid-19

Within the top echelons of the political economy, there is no president, no CEO, no technology tycoon, nor general who purports to know the full impact and extent of the disruptions in store. The coming years promise to be interesting, and there is a keen awareness that unwelcome transformations, very costly to many groups in society, are on the horizon. We face takeovers by extremist political leadership with nationalist narratives, destruction of business of the non-creative kind, the breakdown of health care and even of public order. Partial systemic collapse, while still very unlikely, is indeed no longer unthinkable.

It is critical to understand the deep causes of discontent if we are to address them. We are familiar with the generally accepted narratives for what is wrong, all amply discussed in the public domain.

Visual 1: Turmoil's questions: Beginning or end? The beginning of what? What are the causes?

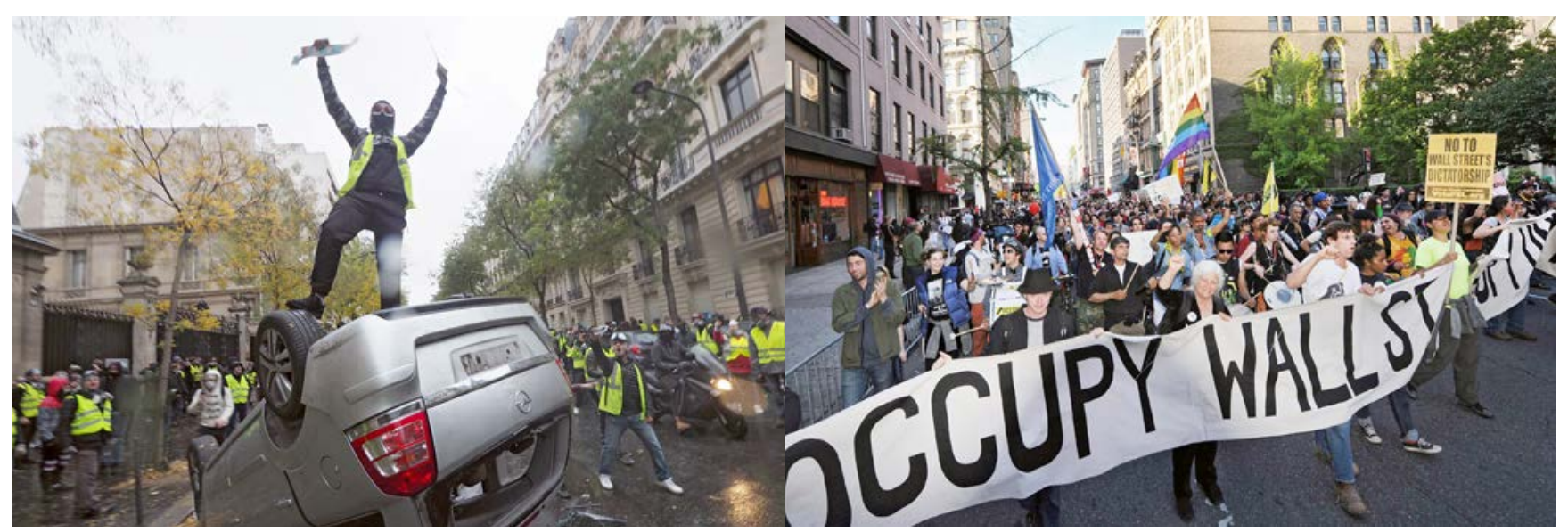




\section{What are 'elites'?}

Definition: Elites are narrow, coordinated groups with business models that successfully accumulate wealth; they are an empirical inevitability and exist in every society on earth. In short:

Surprise 1: Elites are a mathematical certainty; they are inevitable

Surprise 2: Elites supply essential coordination capacity to society
Fact 1: Elites can be

high-quality value creators

Fact 2: Elites can also be

low-quality value extractors
Hypothesis: Elite Quality determines economic and human development

Action: We measure Elite Quality by the Elite Quality Index (EQx)

Takeaway: EQx is a political economy index that measures the ability of the business models of the elite in a country - on aggregate - to create value, rather than rent seek

Generally accepted causes of discontent that stand out include:

- Technology, automatization destroys jobs and creates a new digitally illiterate underclass

- Globalization, produces the losers of the "flat world" who react and push for fragmentation

- Demographics, the onset of aging societies makes the economy irremediably less productive

- Geopolitics, sees big power rivalries reconfigure and lessen business spaces at significant costs

- Irrational behaviors, as in populism, racism, business short-termism or police brutality, harm the public interest

- Black Swan events, like new viruses, water emergencies or financial crises erode institutions

What if the above diagnosis is incomplete? These mainstream factors might bear less than full responsibility for human development and declining relative prosperity levels that significant segments of society in many countries experience.

\subsection{A Gap, and One Worth Addressing?}

The Elite Quality Index (also the Index or EQx) proposes an alternative analytical framework to interpret - and possibly transform - the state of the world and its future prospects. It is based on a simple idea.

$E Q x$ holds that the business models chosen and run by elites are at the origin of a causal chain that leads to economic and human development. Elites (the 'who') affect human and economic development outcomes (the 'what'), sometimes directly and mostly indirectly via their sway on institutions (the 'how') that lay down the rules of the game. Rules give elites the 'license to operate'. Both the 'how' and the 'what' are amply measured. For instance, the World Bank's Ease of Doing Business Index (DBI) measures the latter while the World Economic Forum's Global Competitiveness Index (GCl) or the United Nations' Human Development Index (HDI) measures the former.

Measuring the 'who' of the political economy is the research gap which we seek to pursue. We do so at the national aggregate level, i.e. the elites in terms of their business models' Valve Creation and Value Extraction choices.

Addressing the identified research gap will, as a next step, involve linking what we term 'Elite Quality' to economic and social outcome Indicators, such as growth, competitiveness, total factor productivity (TFP) and human development. Sections 4.5 and 6.1 discuss the larger research project associated with $\mathrm{EQx}$ including its medium-term growth predictor potential.

Visual 2: Elite Quality as potential research gap Source: Casas, 2020, Figure 7 (modified)
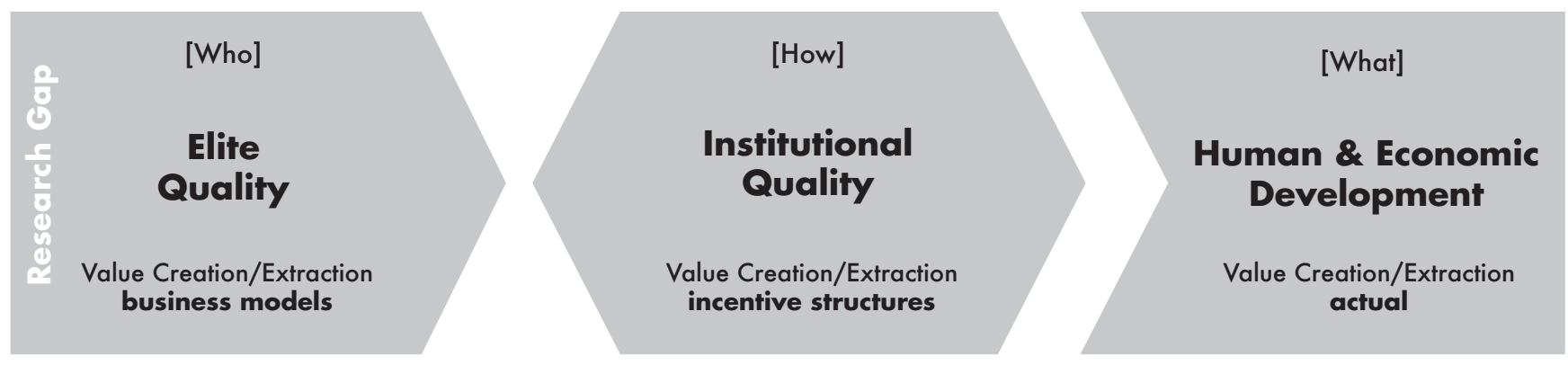


\subsection{EQx Results at a Glance}

Visual 3: EQx Elite Quality Global Map, color-adjusted Country Scores

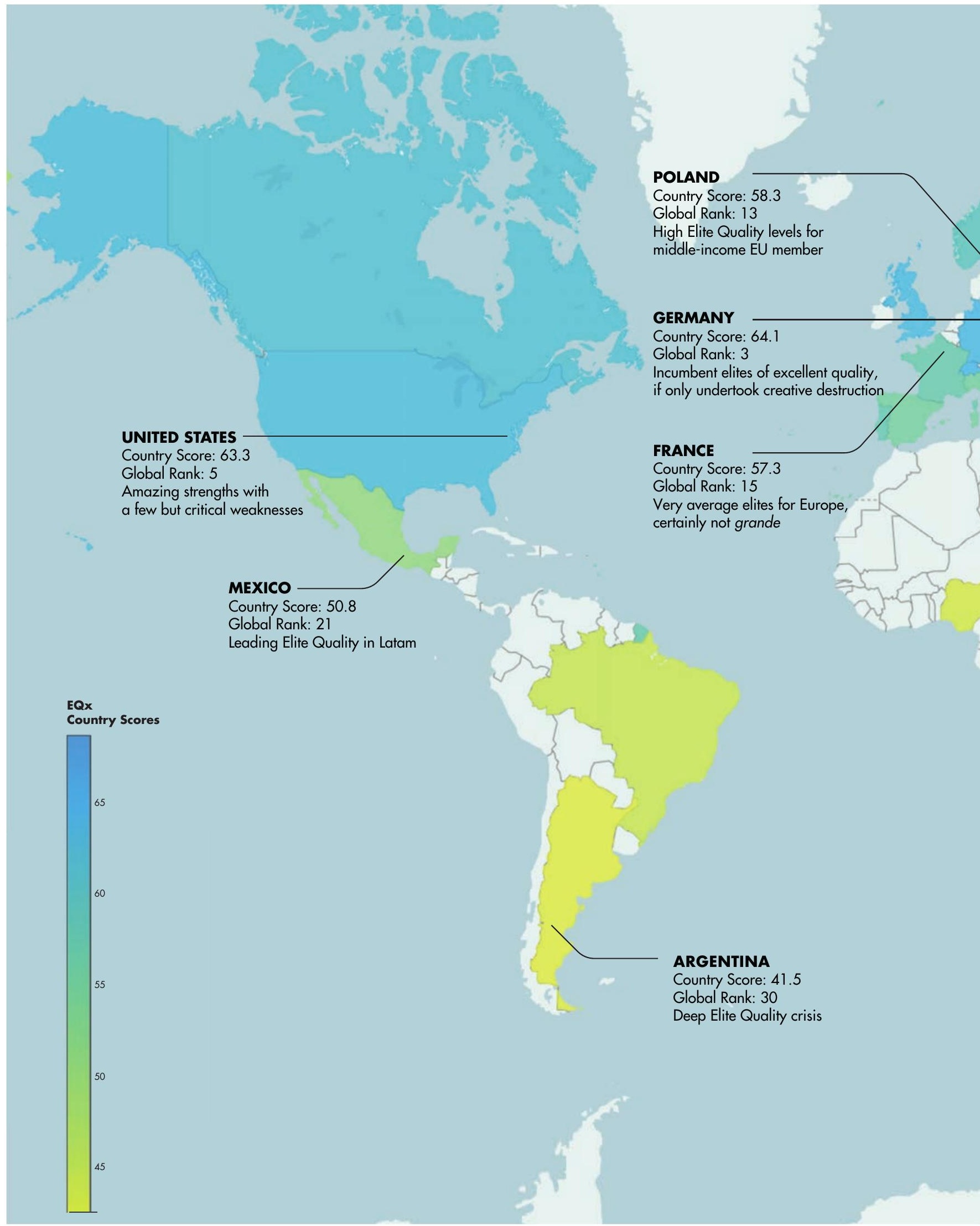




\subsection{EQx, Open for You}

The EQx research project is open and participative. We are designing the infrastructure for a vibrant community that is inspired by the subject of Elite Quality and its potential impact. The motivation behind the online EQx Index
Management Platform (IMP) is to solicit and organize potential inputs and ideas. Future project stakeholders can be users, dataset contributors, researchers or partners.

\section{Who are EQx users?}

The EQx project is inclusive by definition, and welcomes anybody who is curious about the economy, the political economy, global comparative indices, business models, power, the idea of value, the future of society, or even current affairs.

$E Q x$ is setting up the IMP infrastructure so users can make the index their own, carry out hands-on online simulations with the $E Q x$ dataset and reach their very own insights and conclusions, beyond those supplied by EQx Reports.

The IMP will be available soon at www.imp.elitequality.org

\section{Call to dataset contributors}

Who can become EQx Dataset Contributor?

We encourage submission of original ideas for Indicator data. All ideas for novel, measurable Indicator constructs are considered as long as they describe Value Creation/Extraction phenomena in the economy. Moreover, we are open to switch existing datasets with higher-quality sources. Contributions will be duly acknowledged and credited.

Contact us with your original thoughts and suggestions at datasets@elitequality.org

\section{Call to researchers}

The EQx project's ethos is that of an open global research community. The EQx2020 Report is a call to parties interested in jointly developing $E Q x$ academic projects of a theoretical or empirical nature that aim at leading peer reviewed publications.

Our purpose is to develop practical insights, including for policy. In this regard we look to research partners wishing to take responsibility for a country or region, including the integrity of local data and the interpretation of local results.

Reach us at research@elitequality.org and let's discuss collaboration. 


\section{Do you wish to partner with the Foundation for Value Creation (FVC)?}

The Foundation provides the coordination that brings to life $E Q x$, much of its underlying research and related publications. You might want to engage and associate your institution - or yourself personally - with our non-profit Foundation for a variety of reasons. These might include social engagement, the development of public discourse or the design concrete policy proposals. You might also wish to become a benefactor.

Whether you are running an elite business model or are a concerned citizen, there are many motivations for establishing strategies to "grow the pie" in your political economy. We encourage you to shape your country's institutions and the narratives on Value, possibility in partnership with FVC.

Start a conversation with us at benefactor@valuecreation.org

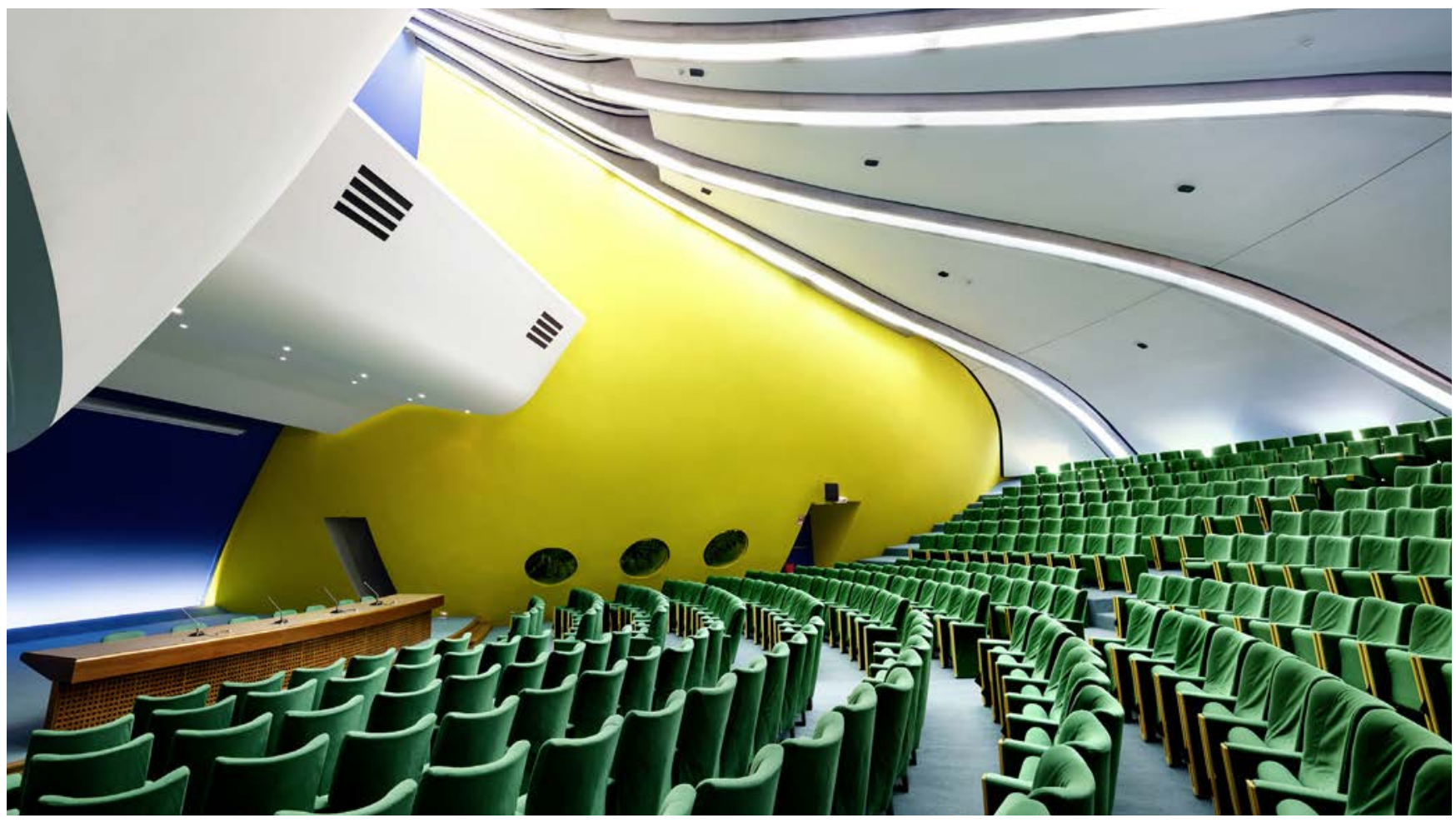




\section{How 'Elite Quality' Became a Global Index}

\subsection{Conceptual Framework \& Definitions}

The Elite Quality Index (EQx) proposes an alternative analytical framework to interpret - and possibly transform - the state of the world and 'available futures'. Our key conceptual underpinning is that elites are a central observable phenomenon in political economies, a mathematical certainty existing in every society on earth.

In this study, elites are defined as the relevant leaders possessing the strongest coordination capacity over society's key resources, such as human, financial and other capital. Elites, as rational economic agents, must aim to maximize their wealth, utilizing their talent, resources and coordination capacity. Elites are thus the narrow, coordinated groups within countries that implement business models which successfully accumulate wealth.
Crucially, as part of their wealth accumulation, elites choose business models that either create value or rent seek. As summarized by Hillman and Ursprung (2015, p.3), "in the rent seeking literature, a rent is an unearned reward sought through a quest for privilege. The seeking of rents is personally beneficial... but social loss is incurred because resources are used in non-productive distributive quests". The 2 concepts are antagonists (Value $\neq$ Rent) but they are also 2 sides of the very same coin. In their fundamental form, Value and Rent are at the 2 ends of the business model spectrum, which $E Q x$ names Value Creation and Value Extraction. From the micro perspective, where the unit of analysis is the individual organization or the decision-maker, value creating 'high-quality' elites run business models that create more value than they capture. 'Low-quality' elites do the opposite.

Visual 4: Micro perspective of Elite Quality: EQx icons representing elites' business model choice "Capture more or capture less value than create"

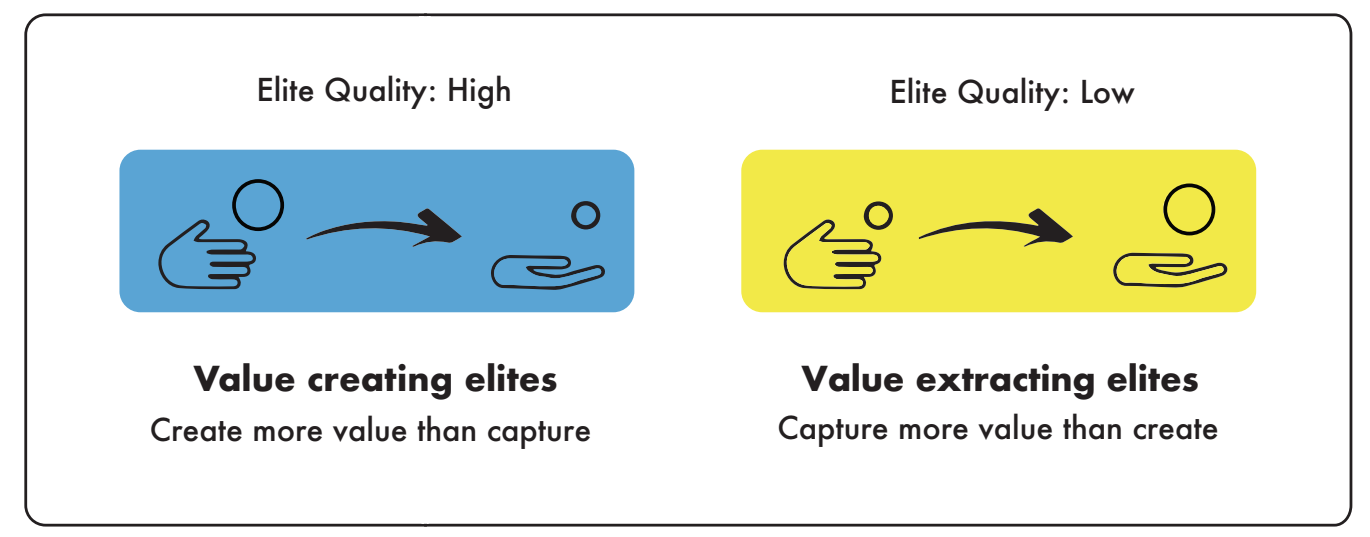

The choices made at the micro-level have an impact on the macro, i.e. the level of the economy as a whole. In simple terms, rent seeking is the means by which low-quality elites increase their own slice of the (economy's) pie at the expense of the non-elites. This happens when business models are based on monopolies, certain subsidies, trade tariffs or even on the most appalling phenomenon of slavery (which regrettably still exists in the $21^{\text {st }}$ century, as the Global Slavery Index annually reports). Elites can also choose a business model that predominantly creates value, rather than extracts value. We call elites that grow the whole pie to increase their own wealth and in doing so enrich their own country, 'high-quality'.
Prosperity for the wider nation, we claim, depends mainly on the nature of the business models chosen by elites. Specifically, whether elites allocate society's key resources like savings, talent, or land to value boosting (or reducing) projects. At one extreme, "rentier capitalism" is the state where "economic and political power allows privileged individuals and businesses to extract a great deal of such rent from everybody else" (Wolf, 2019). Rent seeking policies pursued by low-quality elites result in less competition and thus lower efficiency (Clements \& Parry, 2018, p.56). By contrast, high-quality elites have a transformative role in the political economy and on society in general - because by definition they give more than they take. 
Visual 5: Macro perspective of Elite Quality: Economic impact of elites' business model choice "To grow my own slice or the whole pie?"2

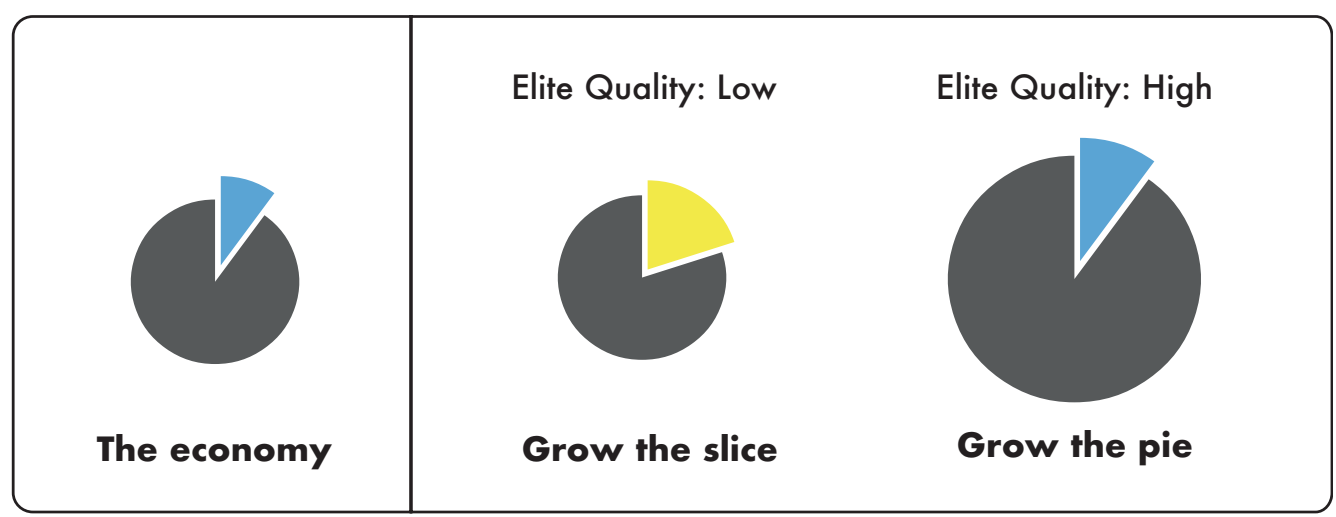

As policies, leaders and circumstances change, so too do Elite Quality and economic and human development outcomes. Often, decisions are made by elites to transition their interests from one business model to the opposite. A rentier elite in the traditional energy sector might take a risk and invest in $4^{\text {th }}$ industrial revolution technologies, while a value creating elite in an advanced industrial sector might leverage political power for a trade barrier or force a regulation that pre-empts innovative new entrants. Voilà! A value creating business model is transformed into a rent seeking one, or vice versa. This fluidity motivates the annual release of the EQx Index and exposes the ability for constructive changes by elites themselves and policymakers based on the information gathered herein.

Equally, a political economy may be shaken by highly disruptive episodes. For instance, in the $21^{\text {st }}$ century we have seen the $4^{\text {th }}$ Industrial Revolution, China's rise and even a pandemic. As technological and social contexts evolve, business models that once created value are naturally overtaken by more innovative models, as human creativity and ingenuity never cease. When the prevalent business models in an economy do not keep up with possibilities afforded by technological and social advancement, stagnation occurs. Elite business models can also, using a Keynesian analogy, be 'sticky'.

Elites can face disruption by using their coordination capacity to accomplish Schumpeterian creative destruction with innovative business models, thereby creating value, or they can do the opposite and become reactionary, seeking rents. Transformations aiming at long-term economic and human development revolve around concrete, industry-by-industry reforms and incentives. These reforms should galvanize a country's existing coordination capacity toward Value Creation business models, while disincentivizing rent seeking Value Extraction.

$E Q x$ holds that the operation of Value Creation business models is in the long-term best interests of the elites, their families and associates. By creating value, not only does the elite's own wealth grow not at the expense of others', but the process of wealth accumulation also accrues social legitimacy, as it infuses society with public goods and inclusive economic growth.

On the other hand, if elites fail to progress out of an impasse, such as one caused by technological changes, discontent or even revolutionary forces may ensue and partially or completely demolish the system, often with symbolic and non-symbolic acts intended to punish or vanquish elites. The rise (and fall) of nations is therefore primarily a function of changes in Elite Quality. That is, whether national elites - on aggregate - increasingly create more value than they capture.

The EQx Index - with its Country Score and Global Rank - is a heuristic that aims to measure these changes, by operationalizing the discussed political economy concepts and equating them to actual levels of Value Creation and Value Extraction. $E Q x$ is then a macro signal, or possibly a fundamental independent indicator, determining long-term economic growth and the wealth of nations which result from high-quality elites. We operationalize Elite Quality by developing Sub-Indices I and II: Power and Value. 
The Value Sub-Index II is anchored in the ideas of Value Creation developed in management and in rent seeking theories of economics. Value Creation and rent seeking Value Extraction are on opposite sides of the same continuum. Elite business models are somewhere in the range between Value Creation, at one extreme, and Value Extraction on the other. The EQx mandate is to incorporate datasets that supply evidence of Value Creation/Extraction, even though the latter might be easier to ascertain and measure, because rent seeking results are visible and affected via concrete interventions in politics.

How is power in the Power Sub-Index I measured? Distortions that enable rent seeking business models require power. Since there is no rent seeking without power, power is conceptualized as rent seeking potential. Power is not rent seeking per se, since power is a necessary, but not sufficient condition. In some countries, elites enjoying high degrees of power invest in and run Value Creation business models.

Given that EQx is a political economy index, the Power Sub-Index I and the Value Sub-Index II each possess the corresponding 2 Dimensions: Political and Economic. While these 2 political economy terms might be self-explanatory, the definitions of all 4 Index terms are conveniently provided on the next page.

Combining the 2 Sub-Indices with the 2 Dimensions brings forth EQx's 4 Index Areas. Each EQx Index Area is brought to life by 3 conceptually related Pillars, which are the direct host of the different datasets - the Indicators - that feed the Index with data. The matrix from which the $4 \mathrm{EQx}$ Index Area quadrants emerge is presented below.

Visual 6: Index Areas matrix, where Power and Value Sub-Indices meet Political and Economic Dimensions
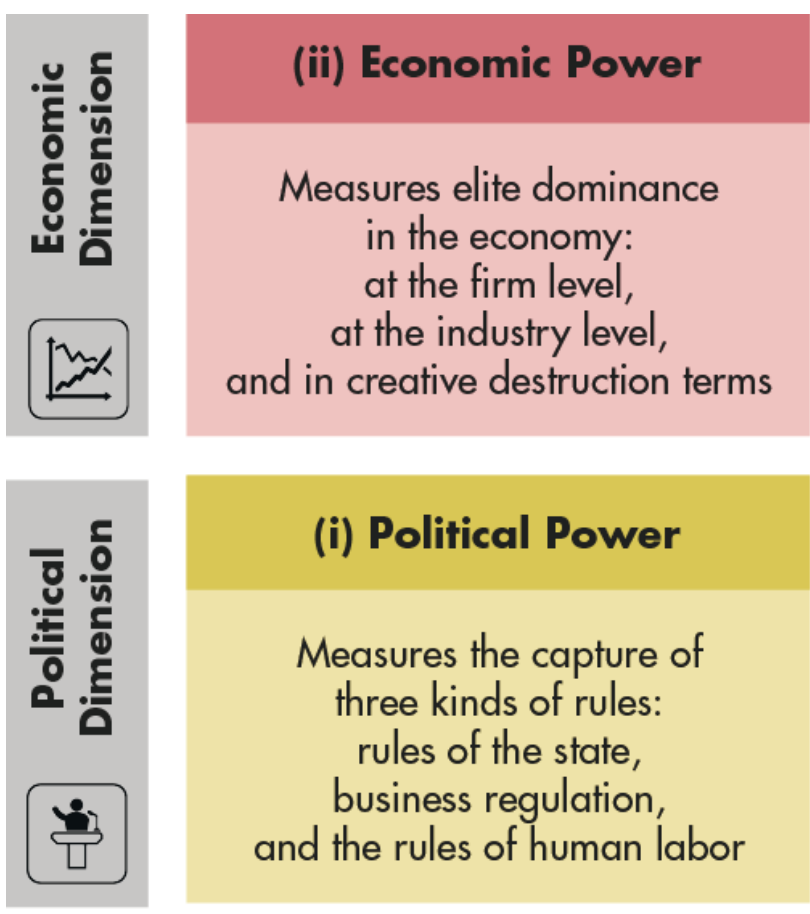

\section{(i) Political Power}

Measures the capture of three kinds of rules: rules of the state, business regulation, and the rules of human labor

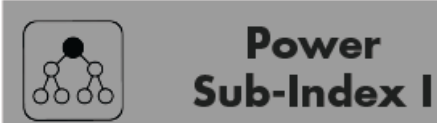

\section{(iv) Economic Value}

Measures Value Extraction from the economy's three markets: products and services, capital markets, and labor markets

\section{(iii) Political Value}

\section{Measures Value Extraction in} the political dimension:

as the state's unearned income, its taking of income, and its giving of income

\section{Value \\ Sub-Index II}




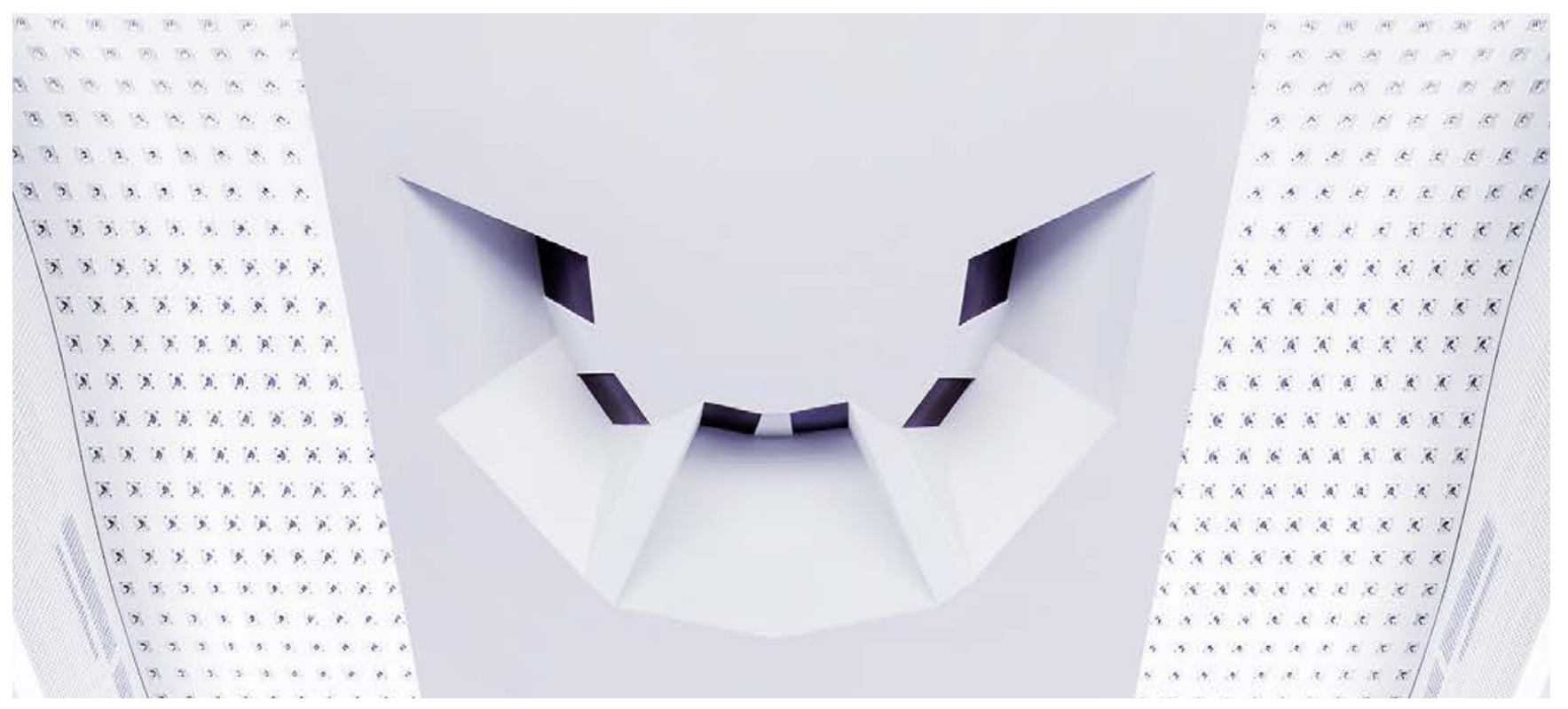

\section{What is Power?}

The capacity to enforce one's preferences; Power is also Value Extraction potential

\section{What is Value?}

The outcome of productive activities; its creation increases the overall economic pie

\section{What is Political?}

The dimension where business model rules are determined, and Value Creation/Extraction is enabled

\section{What is Economic?}

The dimension where Value Creation/Extraction is implemented via suitable business models

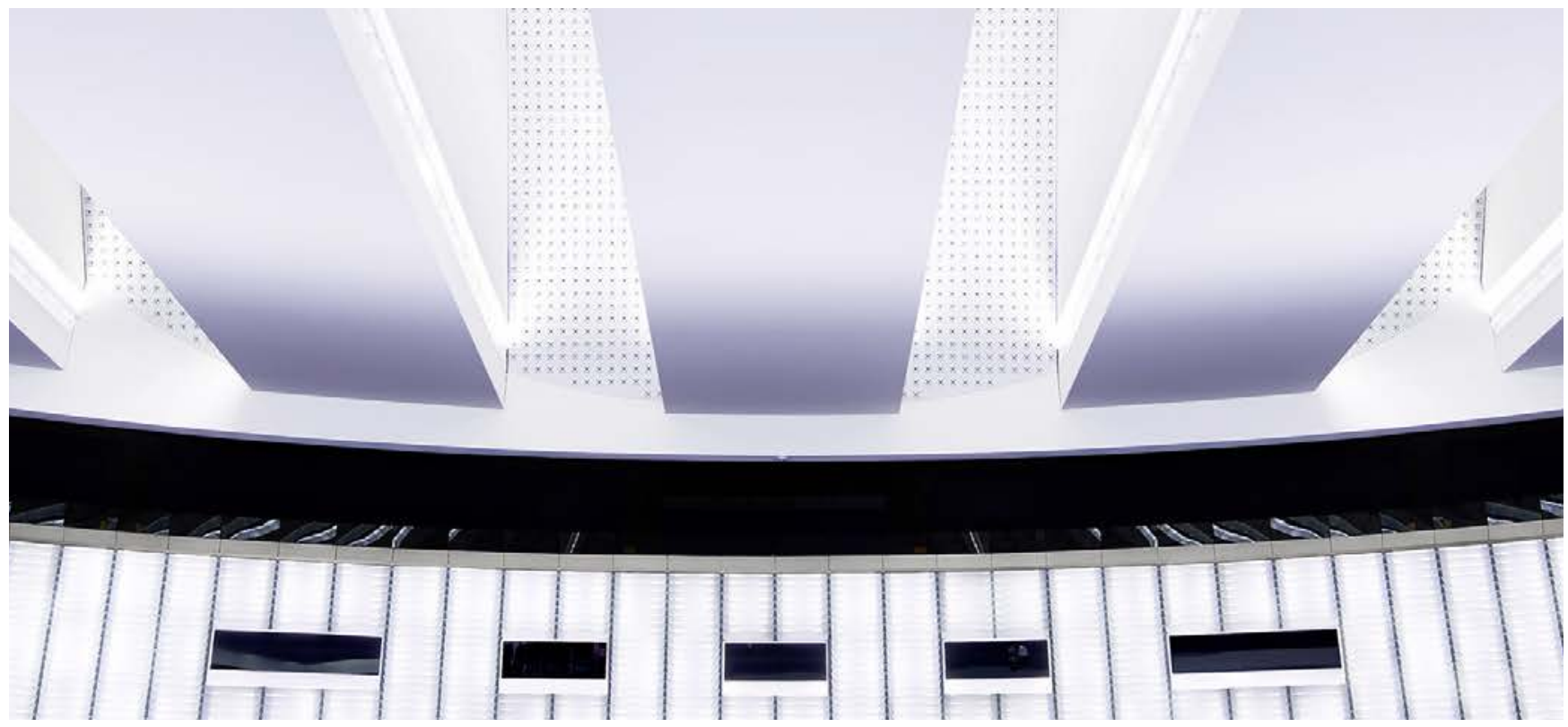




\subsection{EQx Architecture}

The architectural design of EQx has been conceived of as a 4-level structure (Casas, 2020).

From the bottom up, EQx is based on a transparent series of selected datasets, operationalized as indivisible Indicators (Level 4). The respective datasets are collected, conceptually validated, collated and referenced (see section 7.2). They come from open, government and varied sources including the World Bank, the IMF, the finance industry or other indices. Selected Indicators are developed by the EQx team of researchers and collaborators. For each EQx Indicator and its underlying dataset there is a clear rationale of how they reflect Value Creation or its opposite, Value Extraction (see Indicators table in section 6.4).

Each of the (currently) 72 Indicators is logically connected to a corresponding Pillar (Level 3), which are described in detail in sections 2.3 (conceptually) and 3.4 (results). The 12 Pillars
(Level 3) are - in turn - grouped according to 4 Index Areas (Level 2). The 4 Index Areas are the product of a $2 \times 2$ matrix where the Power Sub-Index I and the Value Sub-Index II meet the Political Dimension and the Economic Dimension. For the Power Sub-Index I and Value Sub-Index II and for all the 12 Pillars, EQx provides both Country Scores and the Global Rank.

At the top of the EQx architecture, the 4 Index Areas come together to produce the Elite Quality Index, EQx (Level 1), with its Country Scores and Global Rank.

The index architecture provides the methodological structure for the $E Q x$ construction, which is detailed in-depth in the $E Q x$ Methodology Paper. The document can be downloaded at: https://elitequality.org/methodology_paper. Various methodological aspects of EQx are available in sections 2.4 (Methodology Introduction), 2.5 (Statistical Assessment), 6.2 (Methodological Note).

Visual 7: EQx Architecture Source: Casas, 2020, Figure 9 (modified)

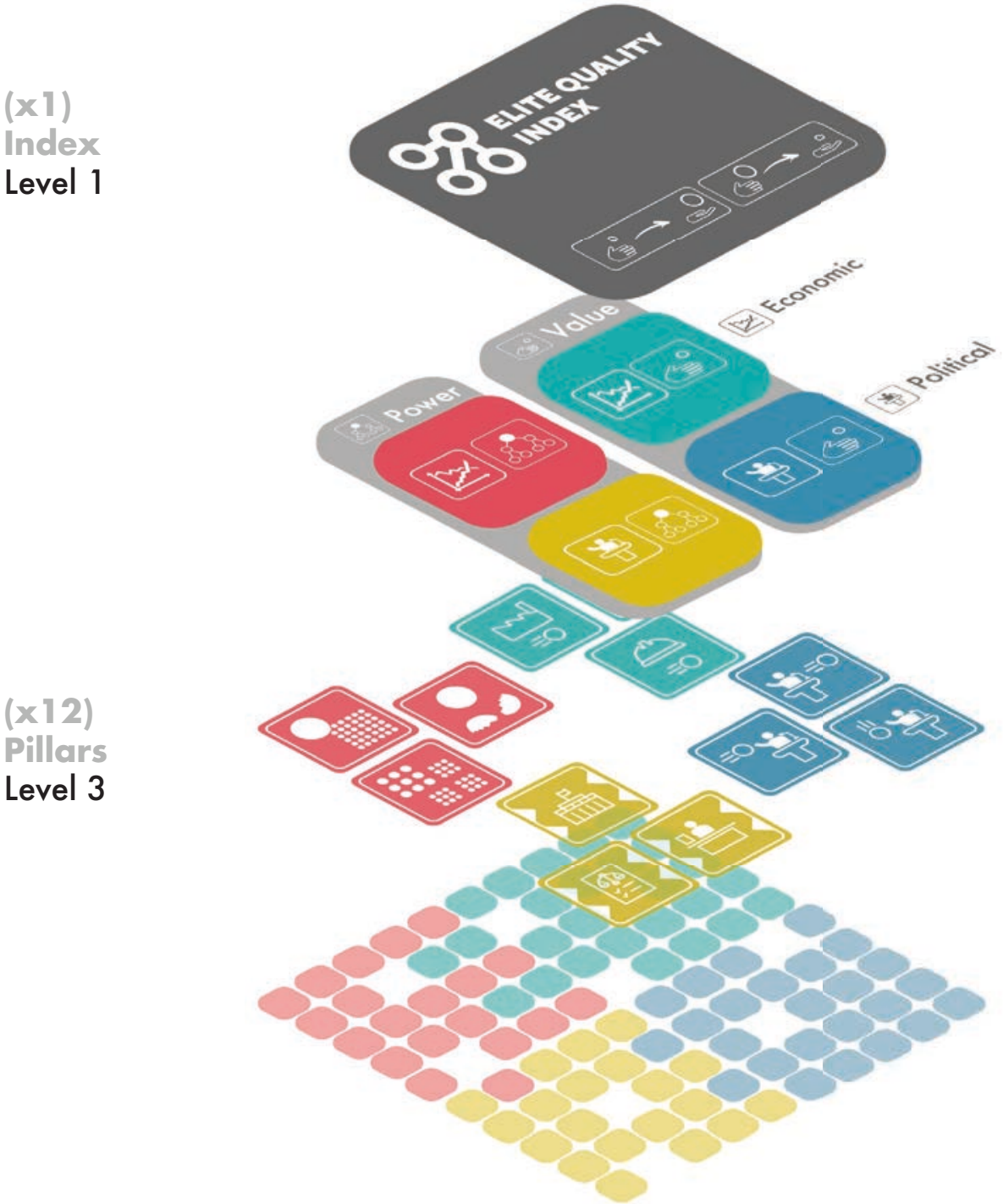

(x2)

Sub-Indices

Level 2 (x72)

Indicators

Level 4 


\subsection{EQx Pillars}

The 12 EQx Pillars each capture a specific element of the Economic and Political Power/Value complex present in countries. The purpose of the Pillars is to define and form conceptual lenses through which we can approach, understand and measure specific phenomena. They comprise a weighted sum of expertly chosen Indicators which numerically evidence present or potential future Value Creation or rent seeking.

The Political Power Pillars were selected to address the capture of 3 kinds of rules: the rules of the state via the 'State Capture' (i. 1) Pillar, the rules of business regulation via 'Regulatory Capture' (i.2), and the rules for labor markets and civil service jobs via 'Human Capture' (i.3). 'State Capture' addresses how distributional coalitions capture the state and its government branches like with Political corruption (COR, i. 1). 'Regulatory Capture' suggests the extent to which rules and regulation, both in terms of process and output, have been captured by interest groups. 'Human Capture' accounts for the power of labor and civil service coalitions, including any privileges in the political system, as well as their ability to influence wages and working conditions.

The Economic Power Pillars measure elite 'Industry Dominance' (ii.4) and 'Firm Dominance' (ii.5) within the economy, as well as the opposite: the extent of 'Creative Destruction' (ii.6). 'Industry Dominance' measures the dominance of leading industries by measuring the degree of diversity in an economy. 'Firm Dominance' measures the power of single businesses within the economy, with Indicators such as Antitrust exemptions (ATX, ii.5). We borrow Schumpeter's (1942) concept of 'Creative Destruction' - the replacement of outdated by innovative structures - for the third Economic Power Pillar which includes measures of Entrepreneurship (ENT, ii.6) and VC finance (VCK, ii.6). The aim is to measure the pressures for renewal and disruption in the economy which fuel Value Creation.
The Political Value Pillars are named 'Giving Income' (iii.7), 'Taking Income' (iii.8) and 'Unearned Income' (iii.9), and reflect policy decisions in the political sphere that concern redistribution in the broadest sense, as in Acemoglu and Robinson (2012, p.76) "from one subset of society to benefit a different subset". An important point here is that we only consider the merits of such redistribution in terms of Value and try to assess for each surveyed Indicator whether it is extracted or created. 'Giving Income' measures how the government uses and manages public finances, looking at the provision of public goods such as education or the amount of subsidies distributed in an economy. 'Taking Income' addresses how the state collects such income, as in Delta capital gains tax vs income tax (DKI, iii.8), or whether it allows income or the ultimate value - life - to be taken as in Homicide rate (HOM, iii.8). The 'Unearned Income' Pillar focuses on the exploitation of natural resources such as Dutch disease propensity (DUT, iii.9), or of the future at the expense of the present like Government debt as \% of GDP (DBT, iii.8). Political Value offers a picture of the degree to which production has been channeled into or shifted away from innovative and wealth-creating sectors of the economy (Porter, 1990).

The Economic Value Pillars directly measure the extent of Value Creation (or Extraction) from the economy's 3 markets: the products \& services markets, the capital markets and the labor markets. 'Producer Rent' (iv. 10) estimates the rents extracted by producers and suppliers in the market for goods and services, whilst 'Capital Rent' (iv. 11) measures the rents extracted both directly and indirectly as a result of financial market participation. 'Labor Rent' (iv. 12), which includes Indicators such as Unemployment rate (UEM, iv. 12) and the Gender wage gap (GVG, iv. 12), allows us to assess the rents arising within a country from interventions by both supply and demand forces in the labor market.

Visual 8: EQx Architecture, specifying Level 2 and 3 constituents

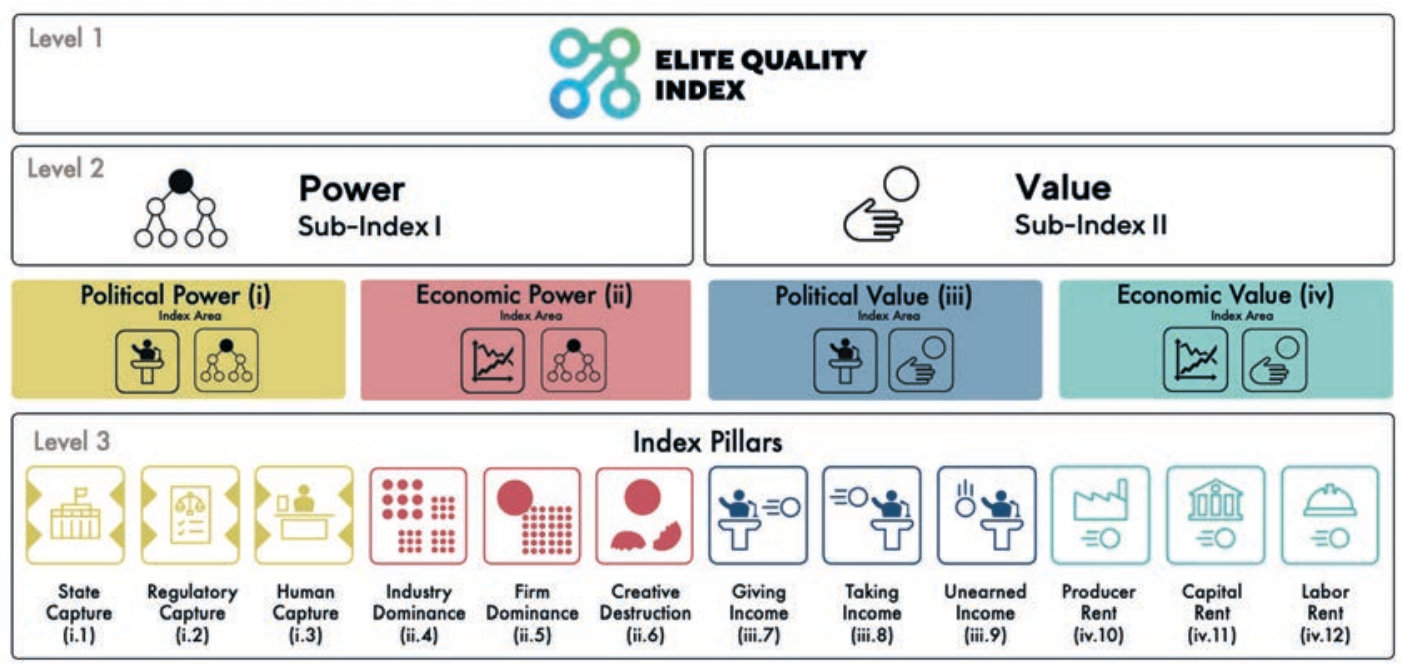




\subsection{EQx Methodology Introduction}

$E Q x$ aims to be an academically grounded and statistically valid measure of Elite Quality. At the same time, judgement calls are inevitable during the process of index construction (Mazziotta \& Pareto, 2013, p.74). Therefore, EQx's overarching objective is to make the procedure as clear and transparent, and hence as justifiable as possible (Santeramo, 2017, p. 135). In consequence, the underlying assumptions and methods used for index construction are presented and evaluated in detail in Measuring Elite Quality (Casas, Cozzi, Diebold, \& Zeller, 2020), a.k.a. the EQx Methodology Paper.

The steps underlying the $E Q x$ Index construction are shown in Visual 9 below. Steps 1 and 2 are detailed in the EQx White Paper (Casas, 2020) and summarized in sections 1 to 3 of this report. Steps 3 to 8 are developed in detail in the EQx Methodology Paper, and a brief summary is supplied in the Exhibit section 6.2. In this report we focus on the construction process and the weighting, and provide a brief summary of the main methodological steps for reference purposes. The weighting part of Step 6 is examined in this section, while the statistical assessment, Step 8 , is concisely summarized in the next section, 2.5. The results of Step 7 are presented in the report which is the realization of Step 9.

\section{Weighting Scheme}

The Indicator weighting scheme of any index is decisive, determining scores and rank. Best practices in index construction see weights explicitly made consistent with the index concept and made transparent. In other words, first, a weighting scheme must reflect what the index aims to measure. Second, each of the datasets that constitute the index must see their weight assigned in a documented and traceable manner.

In $E Q x$, the fundamental datasets are the Indicators, and they all denote present or future Value Creation ( $\neq$ Extraction) phenomena. For instance, Indicators considered include Firm Concentration (HH, ii.5), Global Pluralism Index (PLU, i. 1), Trade freedom (TRF, iv. 10), Firm exit ratio (EXR, ii.6), Crony capitalism (CRO, i.2), Natural interest rate deviation from optimum (DNI, iv. 1 1), or Corporate tax rate deviation from optimum (DCT, iii.8) (for the full EQx Indicators list, see Exhibit 6.4). The weight of each Indicator in $E Q x$ depends on the weight of that Indicator (Level 4) within its Pillar (Level 3), the weight of the Pillar (Level 3) within the Index Area, and the weight of the In$\operatorname{dex}$ Areas (Level 2) within the EQx Index (Level 1).

What does the EQx Index aim to measure? Again, the overall Elite Quality of nations in terms of the Value Creation caused by the nation's elite business models as evidenced by aggregated datasets. Generally speaking, indices, in terms of what they measure, lay on a spectrum ranging from established to emerging concepts. On one hand, indices advance and measure well established constructs like competitiveness, innovation, multidimensional poverty, the gender gap or prosperity, and on the other, novel constructs like ease of doing business, happiness, attractiveness or economic complexity. Elite Quality is a novel construct and, as such, has necessitated a weighting method that combines both conceptual and expert-led approaches.

\section{EQx Concept}

\section{Step 1}

Theoretical grounding and framework

EQx Input

\begin{tabular}{|c|c|c|}
\hline Step 3 & Step 4 & Step 5 \\
\hline $\begin{array}{l}\text { Dataset } \\
\text { collection and } \\
\text { transformation }\end{array}$ & $\begin{array}{l}\text { Imputation of } \\
\text { missing data }\end{array}$ & $\begin{array}{l}\text { Normalization } \\
\text { of Indicators }\end{array}$ \\
\hline \multicolumn{3}{|l|}{ EQx Output } \\
\hline Step 7 & Step 8 & Step 9 \\
\hline $\begin{array}{l}\text { Determination } \\
\text { of Country } \\
\text { Score \& } \\
\text { Global Rank }\end{array}$ & $\begin{array}{l}\text { Robustness and } \\
\text { sensitivity }\end{array}$ & $\begin{array}{l}\text { Results } \\
\text { visualization \& } \\
\text { publication }\end{array}$ \\
\hline
\end{tabular}

\section{Step 2}

Theoretical consistent Indicator selection

\section{Step 6}

Weighting and aggregation 
Elite Quality is measured at present by $72 \mathrm{EQx}$ Indicators, each of which is evidence of Value Creation (or its opposite, Value Extraction) in the political economy, at present or potentially in the future.

The EQx notion sees Power as a necessary condition for Value Extraction and rent seeking. The Power Sub-Index I is thus the indicator of potential future Value Extraction. Therefore, the relative weighting for the 2 Sub-Indices Power and Value is conceptual and determined by the authors after thorough deliberation: the Power Sub-Index I has a weight of $34 \%$ whereas the Value Sub-Index II is weighted at $66 \%$. Further research will determine the extent to which Power leads to future Value Creation/Extraction, and is one of the factors that might lead to the re-calibration of weights. Incidentally, the Elite Power Sub-Index I can be construed as an independent index in its own right.

The EQx could have been christened Political Economy Index because it measures Power and Value in the political economy. Each of EQx's 2 Sub-Indices contain a Political and an Economic Dimension, as discussed earlier. The weights of these 2 Dimensions within the Power Sub-Index I and the Valve Sub-Index II respectively are also the result of the conceptual $E Q x$ design and of the authors' judgement: the weights for both are established at roughly $1 / 3: 2 / 3$ (conceptual de- liberations 2 and 3). For the Power Sub-Index I, the rationale is that Economic Power is supreme, while Political Power only reflects potentially extractive processes if it transitions to the economic arena. For the Value Sub-Index II, the rationale is the higher significance - in terms of direct impact on citizens and economic agents - of the economic over the political in the overall Value Creation processes of the political economy.

One can imagine a matrix with the 2 Sub-Indices intersecting the 2 Dimensions, thereby yielding 4 quadrants. Each is an EQx Index Area (see Visual 10). Their nomenclature is discernible: Political Power (PP), Economic Power (EP), Political Value (PV) and Economic Value (EV). The conceptual deliberation weighting 1,2 and 3 just described extends a specific weight to each Index Area: $11.6 \%$ (PP); $22.4 \%$ (EP); $22.4 \%$ (PV) and $43.6 \%$ (EV).

While the weights of Level 2 elements (the 2 Sub-Indices, their 2 Dimensions, and the 4 derived Index Areas) are determined by conceptual deliberation, the weights of $E Q x$ structure levels 3 and 4 are established by a panel of experts employing Budget Allocation Process (BAP) methodology. BAP establishes the weighting of Pillars (Level 3) within each of the 4 Index Areas, as well as the weighting of the Indicators (Level 4) within each of the 12 Pillars.

Visual 10: EQx weighting overview

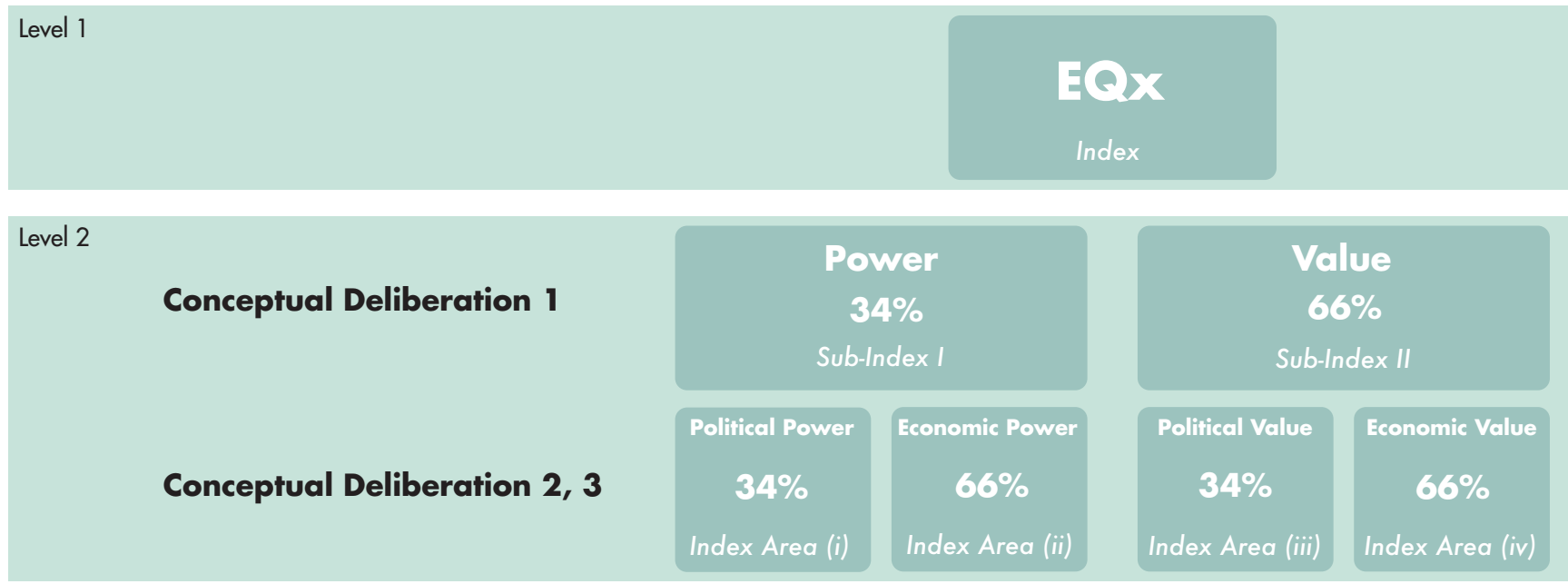

Level 3

Budget Allocation Process

12 Pillars

Individual Pillar within Index Area weigths

Level 4

Budget Allocation Process

72 Indicators

Individual Indicators within Pillar weights 


\subsection{Statistical Assessment}

As the previous steps highlight, the $E Q x$ is based on several judgement calls and is the result of a multilevel calculation exercise. This raises the question: how reliable and meaningful is the $E Q x$ ?

Evidence of the reliability of the Index is obtained by a range of robustness tests, presented and discussed in detail in the EQx Methodology Paper and summarized hereinafter. The tests aim at validating the previously presented judgement calls by gauging the sensitivity of the Index to modifications of its set-up, and, in particular, investigating how sensitive the $E Q \times$ Country Rank is, ceteris paribus, to changes in key modelling assumptions. 5 statistical tests assess the Index's robustness in different regards, as summarized in Visual 11.

In summary, the 5 tests performed on $E Q \times 2020$ data suggest that EQx Country Scores and the implied Global Rank are not driven by (i) individual Indicators, (ii) data quality or availability, and are robust to a range of alternative (iii) normalization (iv) weighting and (v) aggregation schemes.

\section{Test 1 - Leave-one-out robustness}

Test 1 assesses the sensitivity of the Index to the selection of underlying Indicators and aims at showing the balanced structure of the EQx. Are all of the 72 Indicators equally important? Are some redundant, or, on the contrary, dominating Index scores? To answer these questions, we test the impact of each Indicator on EQx Country Scores and Global Rank, by excluding one Indicator at a time. Visual 12 shows the effect on EQx Country Scores. The distribution of differences in EQx Country Scores is illustrated by vertical lines for each excluded Indicator. A small box and short vertical line close to the zero-difference horizontal red dashed line indicate that the respective Indicator does not significantly affect EQx Country Scores. Thus, Visual 12 shows that while all Indicators contribute somewhat to the final EQx Scores, most Indicators differ only moderately in their influence. Furthermore, considering the impact on the Global Rank, in almost all cases excluding an Indicator does not change the rank of a country at all, or only by one rank (the visual is presented in the EQx Methodology Paper).

Visual 1 1: EQx statistical assessment tests, overview table

Test Nr.

\begin{tabular}{|l|l|}
\hline \hline 1 & Leave-one-out robustness \\
\hline $\mathbf{2}$ & Sensitivity to data availability \\
\hline $\mathbf{3}$ & Sensitivity of the normalization scheme \\
\hline $\mathbf{4}$ & Robustness to the weighting scheme \\
\hline $\mathbf{5}$ & Robustness to the aggregation scheme \\
\hline
\end{tabular}

EQx has a balanced structure. While all Indicators and Pillars contribute to final scores, none dominates the ranking.

Differences in $E Q x$ scores between countries are not significant with respect to the number of Indicators used for Index calculation.

$E Q x$ is stable to changes in the trimming threshold used for the normalization of Indicator values (e.g. highly significant Kendall Tau b correlation coefficient of 0.95 , when comparing $E Q x$ ranking to a ranking using no trimming during the normalization).

$E Q x$ ranking is largely robust to slight and even far-reaching modifications in the weighting scheme (e.g. highly significant Kendall Tau b correlation coefficient of 0.77 , when comparing $E Q x$ ranking to a ranking using equal weighting at every aggregation level).

$E Q x$ ranking is largely robust to modifications in the aggregation scheme (e.g. highly significant Kendall Tau b correlation coefficient of at least 0.96 , when comparing the $E Q x$ ranking to a ranking using geometric aggregation at one of the aggregation levels). 
Visual 12: Test 1, on Indicators: Deviation from baseline scores, excluding one Indicator at a time

Note: Boxes represent $50 \%$ of all countries; the horizontal line within a box indicates the median

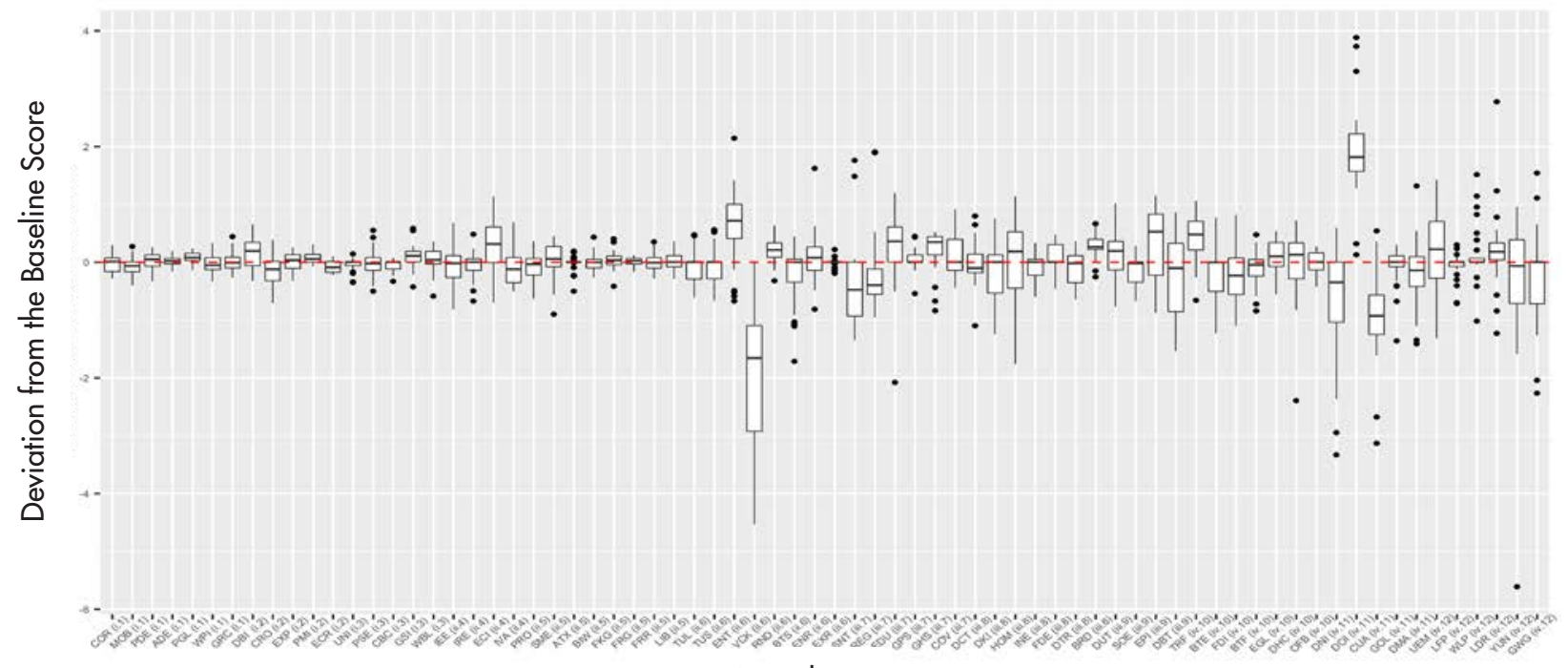

$\mathrm{EQx}$ Indicators

To assess whether EQx has a balanced conceptual structure, we re-run Test 1 but this time by examining the effect of omitting one Pillar at a time on the Global Rank. Visual 13 shows the subsequent distribution of the differences in the Global Rank, which is illustrated by the vertical lines for each excluded Pillar. Pillar 12 (Labour Rent) is the highest-impact Pillar, since its omission shifts countries' Global Rank the most. However, for $50 \%$ of countries, omitting one Pillar affects their Global Rank by only up to one position for the majority of Pil- lars. The median deviation from the baseline EQx Global Rank is zero in almost all cases. Omitting one of the Pillars 1, $2,3,5$ or 9 does not affect the Global Rank position for nearly all countries.

Thus, the results suggest that while all Indicators and Pillars contribute to the $E Q x$, with some having a larger impact than others, no single Indicator and no single Pillar dominates the final EQx Global Rank.

Visual 13: Test 1, on Pillars: Deviation from baseline ranking when excluding one Pillar at a time Note: Boxes represent $50 \%$ of all countries; the horizontal line within a box indicates the median

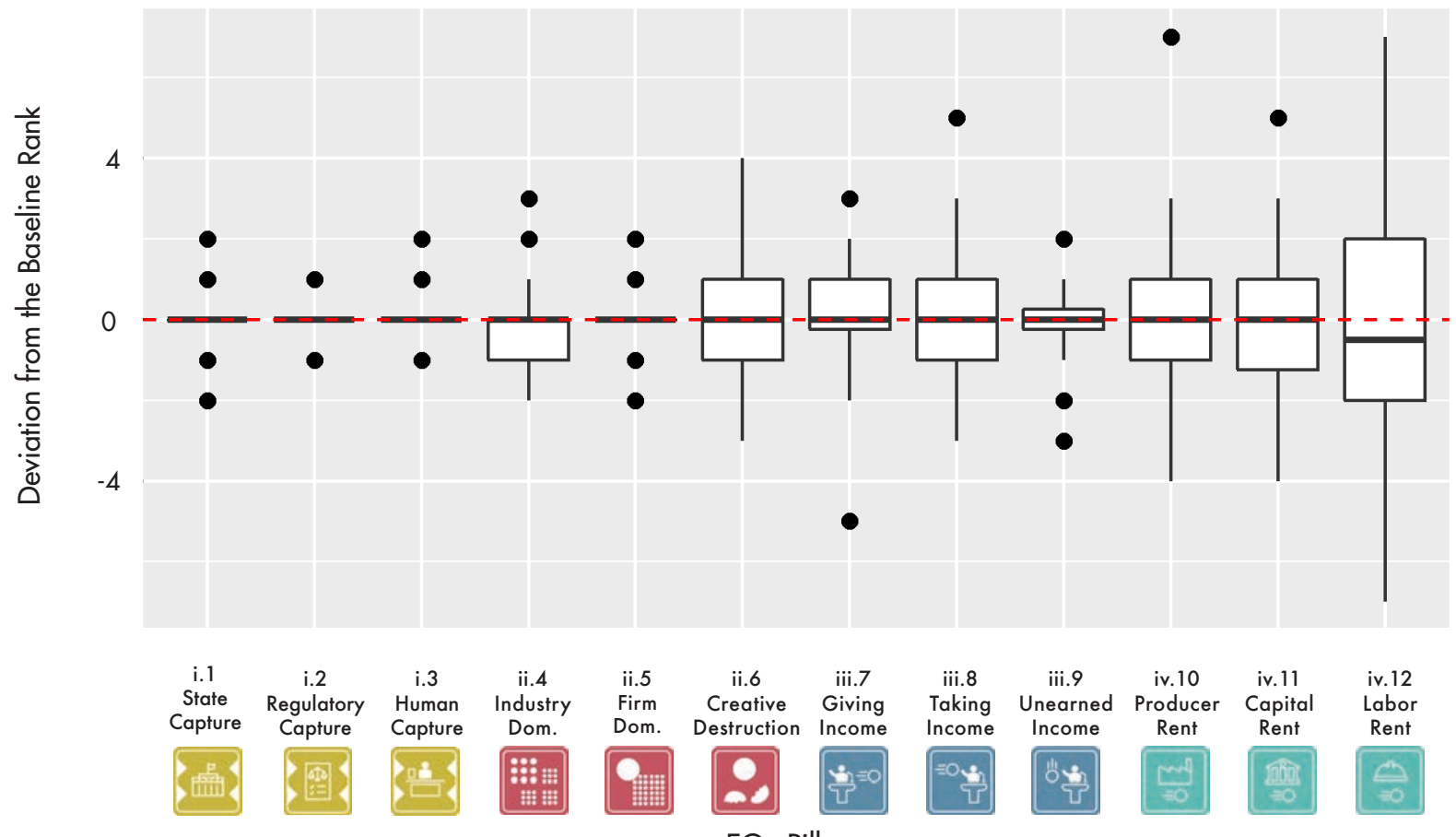

EQx Pillars 


\section{Test 2 - Sensitivity to data availability}

Test 2 gauges the meaningfulness of the EQx in terms of the data used, by investigating whether missing data points follow a completely random pattern or a systematic pattern (the latter being a problematic indication of bias). In other words, are Country Scores related to the availability of data? Indeed, countries with more data tend to score higher in the EQx. However, this relationship is not deemed to be particularly strong. That is, differences in EQx Country Scores are not significant with respect to the number of Indicators. Furthermore, provided the considered Indicators are unbiased, the state of Elite Quality is depicted using less, but nevertheless correct information. In view of the high-quality data constituting the $E Q x$, we thus do not expect $E Q x$ scores to be biased in terms of data availability.

\section{Test 3 - Sensitivity of the normalization scheme}

The mean and standard deviation underlying the Indicators' standardization are calculated from the $95 \%$ trimmed datasets. Test 3 evaluated the sensitivity of the EQx to this method, by calculating Index values using several thresholds for the computation of means and standard deviations during the normalization process, and comparing the resulting ranking to the baseline $E Q x$ ranking. The rankings using different trimming thresholds are highly correlated with the baseline ranking. For instance, when applying no trimming at all, the resulting ranking is still highly and significantly correlated with the baseline ranking, with a Kendall Tau-b correlation coefficient of 0.95 (Spearman correlation coefficient: 0.99).

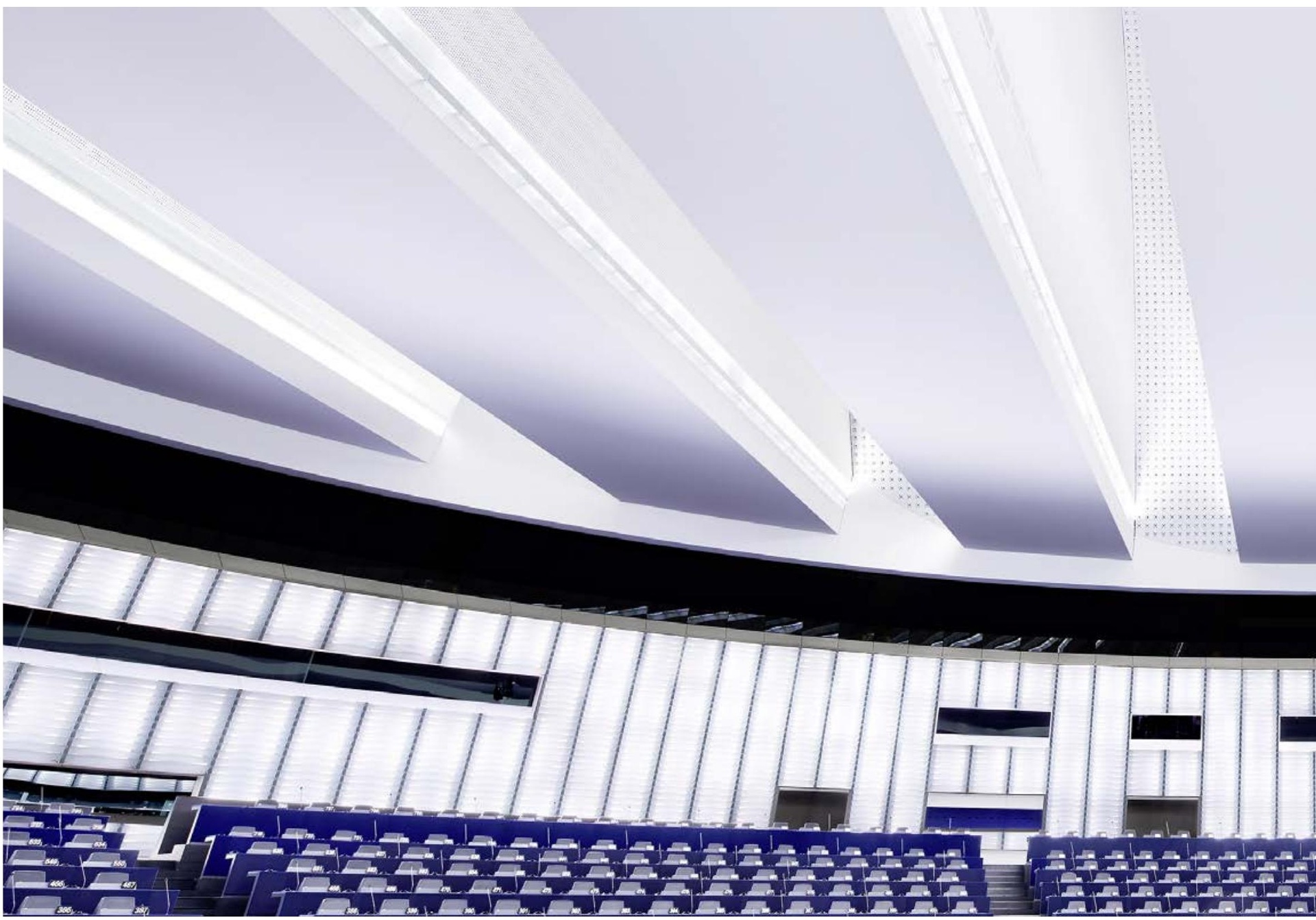




\section{EQx Results}

\subsection{Elite Quality Country Score, Global Rank and Highlights}

Visual 14: EQx2020 table of Country Scores and Global Rank with Power and Rent Sub-Indices

\begin{tabular}{|c|c|c|c|c|c|c|}
\hline \multirow[b]{3}{*}{ Country } & \multicolumn{2}{|c|}{$E Q x$} & \multicolumn{4}{|c|}{ Sub-Indices } \\
\hline & \multirow[b]{2}{*}{ Rank } & \multirow[b]{2}{*}{ Score } & \multicolumn{2}{|c|}{ Power (I) } & \multicolumn{2}{|c|}{ Value (II) } \\
\hline & & & Rank & Score & Rank & Score \\
\hline Singapore & 1 & 68.5 & 15 & 59.2 & 1 & 73.4 \\
\hline Switzerland & 2 & 64.9 & 5 & 63.8 & 2 & 65.5 \\
\hline Germany & 3 & 64.2 & 3 & 65.0 & 3 & 63.7 \\
\hline United Kingdom & 4 & 63.9 & 2 & 70.6 & 7 & 60.5 \\
\hline United States & 5 & 63.4 & 1 & 70.7 & 8 & 59.6 \\
\hline Australia & 6 & 63.2 & 8 & 63.4 & 4 & 63.1 \\
\hline Canada & 7 & 61.9 & 9 & 62.7 & 5 & 61.5 \\
\hline Japan & 8 & 61.6 & 10 & 62.0 & 6 & 61.4 \\
\hline Korea, Rep. & 9 & 61.2 & 4 & 65.0 & 9 & 59.3 \\
\hline Sweden & 10 & 59.7 & 11 & 61.8 & 10 & 58.6 \\
\hline Norway & 11 & 58.6 & 13 & 60.2 & 13 & 57.8 \\
\hline China & 12 & 58.4 & 19 & 58.2 & 11 & 58.5 \\
\hline Poland & 13 & 58.3 & 17 & 58.5 & 12 & 58.2 \\
\hline Portugal & 14 & 58.0 & 12 & 61.4 & 15 & 56.3 \\
\hline France & 15 & 57.4 & 7 & 63.4 & 16 & 54.3 \\
\hline Israel & 16 & 56.9 & 6 & 63.5 & 19 & 53.5 \\
\hline Italy & 17 & 55.5 & 16 & 58.6 & 18 & 53.9 \\
\hline Spain & 18 & 55.5 & 14 & 59.9 & 21 & 53.2 \\
\hline Kazakhstan & 19 & 52.7 & 28 & 43.5 & 14 & 57.5 \\
\hline Indonesia & 20 & 52.0 & 22 & 49.2 & 20 & 53.5 \\
\hline Mexico & 21 & 50.7 & 25 & 47.4 & 22 & 52.4 \\
\hline Saudi Arabia & 22 & 49.2 & 30 & 40.0 & 17 & 53.9 \\
\hline Russian Federation & 23 & 48.9 & 24 & 48.3 & 25 & 49.2 \\
\hline Botswana & 24 & 48.9 & 29 & 42.7 & 23 & 52.0 \\
\hline India & 25 & 45.4 & 23 & 48.4 & 27 & 43.8 \\
\hline Pakistan & 26 & 44.5 & 32 & 32.5 & 24 & 50.7 \\
\hline Brazil & 27 & 44.1 & 20 & 50.2 & 28 & 41.0 \\
\hline Turkey & 28 & 43.3 & 21 & 49.2 & 29 & 40.3 \\
\hline Nigeria & 29 & 42.4 & 31 & 34.7 & 26 & 46.4 \\
\hline South Africa & 30 & 41.7 & 18 & 58.5 & 32 & 33.1 \\
\hline Argentina & 31 & 41.6 & 26 & 47.1 & 30 & 38.7 \\
\hline Egypt, Arab Rep. & 32 & 40.0 & 27 & 44.2 & 31 & 37.8 \\
\hline
\end{tabular}


Beyond academia, the aim of the Elite Quality Index (EQx) is to become a tool for thought leaders and front-runners in business, government and broader areas of social engagement. EQx is an instrument that aims to support national elites' Value Creation business models and incentivize political economy tenets that foster such models.

The main findings as we interpret the EQx2020 results are discussed below:

\section{What do EQx scores tell us?}

\section{Finding 1: Singapore}

The clear leader, so successful that it is a stand-alone outlier. Singaporean elites base their business models on Value Creation. They are also significantly more powerful than their Western counterparts; precisely because of this feature, Singapore's EQx Country Score is strongly penalized (because Power is potential Value Extraction). Yet, Singaporean elites refrain from rent seeking activity. Thus, despite its middling rank in the Power Sub-Index I, the country comes in well ahead of all others in the overall Global Rank, thanks to a stellar showing in the Value Sub-Index II. The Asian city state is the gold standard of elite governance. One must then ask: how can the world learn from Singapore's elite governance?

\section{Finding 2: U.S. and U.K.}

$E Q x^{\prime}$ s most thought-provoking result might be the $4^{\text {th }}$ and $5^{\text {th }}$ place of the Anglo-Saxon economies. The surprise starts with the excellent scores attained in the Power Sub-Index I; American and British elites are the least powerful of all. This comes with a twist: despite their relative weakness, they manage to rent seek. We see a political economy configuration opposite to that in Singapore. The question emerges: on the back of their strong showing, will the U.S. and the U.K. model result in higher economic growth and human development rates than other advanced economies in continental Europe and East Asia?

\section{Finding 3: China}

The emerging superpower's aggregate Elite Quality Country Score is at the high end of the spectrum. China's performance is all the more extraordinary given its middle-income status. As a matter of fact, China's Elite Quality is comparable to European advanced economies like Norway or Sweden. At a level much higher than its peers in the middle-income category, China manages to stimulate Value Creation, while keeping rent seeking business models under control. The question thus emerges; what accounts for China's success - is it its large economy, authoritarian political governance, or institutions that favor competition?

\section{Finding 4: E.U. core economies}

The E.U.'s leading countries vary significantly in their Country Scores. Germany is well ahead of France, while Italy and Spain place a couple of steps lower. One must ask: do dissimilar Value Creation elite business model configurations point to divergent long-term growth prospects for individual E.U. countries, and do we have multiple political economy models within Europe?

\section{Finding 5: BRICS}

The often-discussed BRICS split between China and the other 4 countries is clearly visible in the EQx, although with a nuance. Russia, India, Brazil and South Africa (in that order) cluster around relatively low levels. A rung below Russia we find Brazil and India at similar levels, with the latter's lower GDP per capita implying future growth potential. An important question emerges: how can the 'BRIS' elites transition to higher Value Creation business models on aggregate and so advance their long-term growth prospects? 


\subsection{State of Elites Framework: Country Mapping, Elite Typology and Highlights}

The State of Elites framework revolves around EQx's 2 Sub-Indices, Power and Value. Both represent the degree of Value Creation along a spectrum ranging from high to low. The rationale for Value Creation $\neq$ Extraction is described in Section 2.1.

It is important to emphasize that the State of Elites framework sees the interaction of the present with the future, as it reflects the fact that Power converts to Value Extraction. Value Extraction business models require Power to operate and thus Power is described as future Value Extraction potential in the Visual 15. In the framework, the 2 axes represent the 2 temporal perspectives and so every country finds itself in a position that captures information about the present (via Value) and the future (via Power).

The State of Elites is best apprehended through 4 possible conditions that describe a country's elites in terms of their business models on aggregate: 'competitive', 'enlightened', 'rentier' and 'striving'. The Power Sub-Index I and Value Sub-Index II Country Scores serve as the $x$-and $y$-axis of the $2 \times 2$ matrix which provide the coordinates that not just locate each political economy in the framework, but most importantly serve as a starting point for interpretive work. A country's position is a unique and important source of insights to analyze its present situation as well as to understand its prospects, especially givVisual 15: State of Elites framework, description of the 4 states

Source: Casas, 2020, Figure 10 (modified)

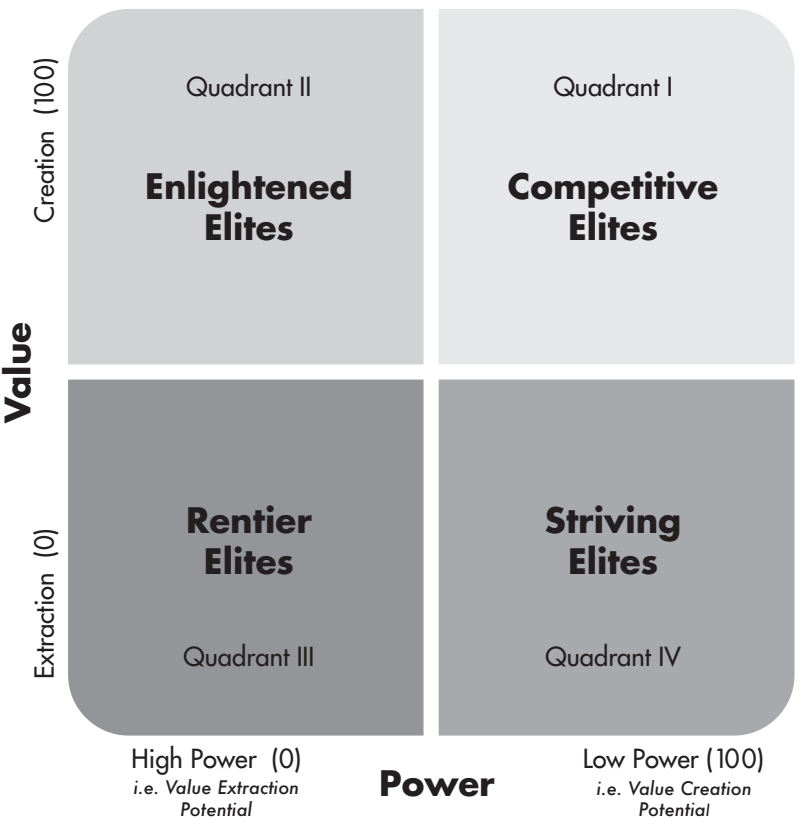

en our aim to support the development of prescriptive views.

\section{Description of the 4 States of Elites}

Quadrant 1 sees 'competitive elites' in a situation which most resembles a free market. This state is characterized by short-lived cycles of highly innovative and profitable elites that rise to the top in quick succession. If contests between elites is civil, that competition will produce a plethora of public goods, including human and economic development. Technological possibilities are seized, and long-term economic growth is maximized and limited only by human capacity to innovate.

Quadrant 2 sees powerful elites that dominate the political economy. These dominant coalitions, however, refrain from Value Extraction despite their ability to obtain rents, and instead choose to run value creating business models. The 'enlightened elites' state is one where elites are very powerful and nonetheless create substantial value.

Quadrant 3 exhibits 'rentier elites'. Countries with economies in this state are characterized by highly dominant and powerful elites that have consolidated value extracting business models. Having captured the levers of power and overcome the resistance of productive forces, the elites have designed institutions that favor their business models at the expense of increasingly demoralized non-elites who have little incentive to invest in Value Creation activities.

Quadrant 4 sees free-for-all Value Extraction by a multitude of diverse agents. Low power elites compete for rents and Value Creation business models are absent, challenged by all sides. The 'striving elites' state is an "Absent Leviathan" situation (Acemoglu, \& Robinson, 2019) and a rather unstable one, with aspirational elites whose extractive rent seeking is real but has not (yet) scaled. Emerging interest groups engage in struggles of all kinds for dominant positions that will enable them to shape institutions that will in turn protect and consolidate their business models. 


\section{EQx2020 State of Elites, results}

Employing the Power Sub-Index I and Value Sub-Index II

Country Scores, we position each of the 32 covered countries

in this Report in the State of Elites Framework.

Visual 16: EQx2020 State of Elites Framework: Country positions based on EQx Sub-Indices Power and Value

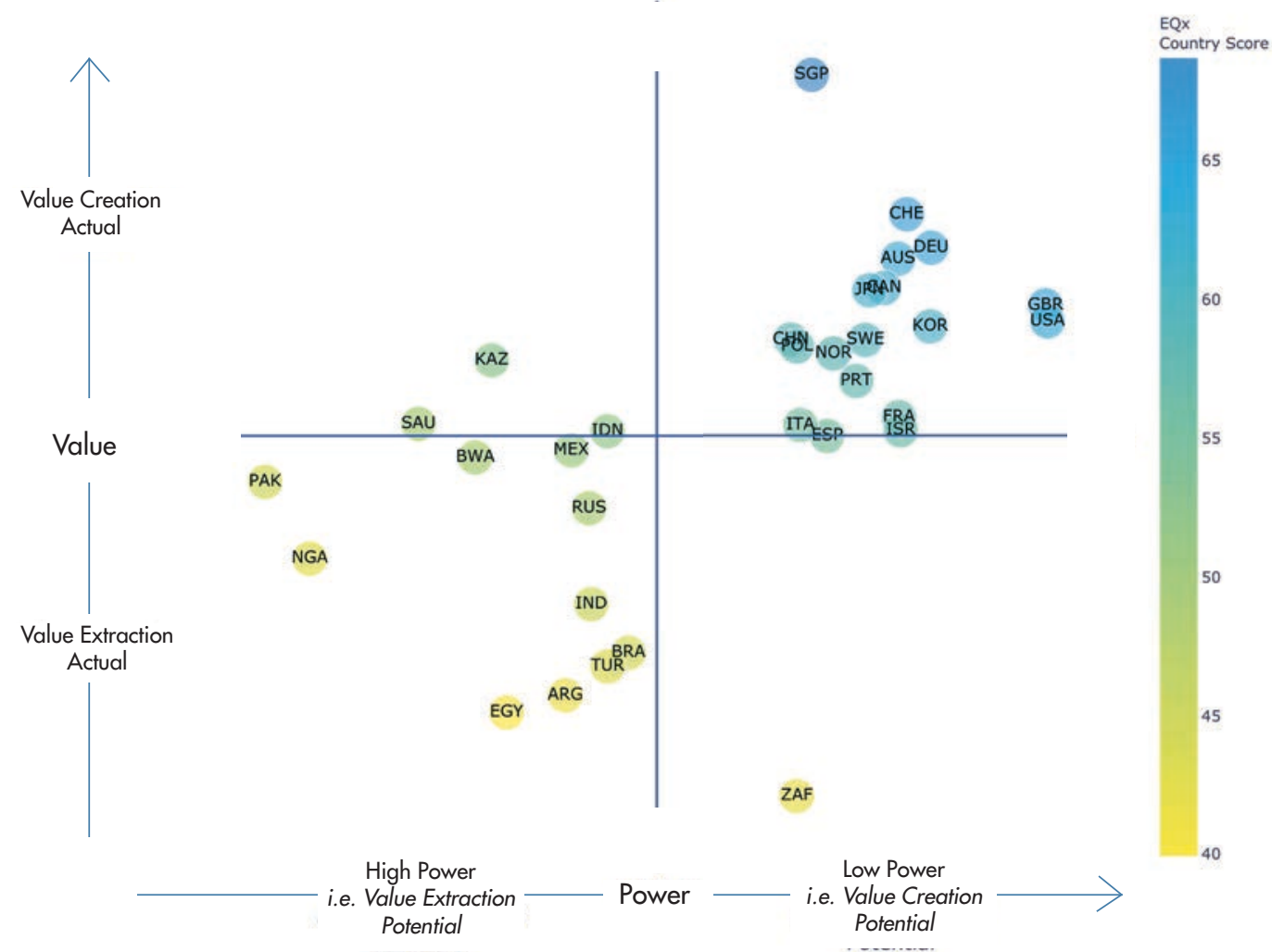

\section{EQx2020 State of Elites, highlights}

The high-level State of Elites analysis has most of the 32 $\mathrm{EQ} \times 2020$ surveyed countries as either 'rentier' or 'competitive', and we detect a developmental relationship between the quadrants. Within each quadrant, however, the picture that emerges is more complex. Each cluster, development level or region can be analyzed on its own terms. Such a perspective then yields an understanding of each of the 4 State of Elites in terms of tendencies: the variance from one political economy to another, even when quadrants are shared, is significant.

For instance, India and Pakistan have similar Country Scores, both being in the overall 'rentier' quadrant. The EQx interpretations and policy implications diverge greatly: while Pakistani elites tend towards the 'enlightened', the aggregate of Indian elites is disposed to the 'striving'. That is, Pakistan elites are much more powerful but extract less value than their Indian counterparts, which on aggregate are more dispersed and yet manage to rent seek more effectively.
In the 'competitive' quadrant we see a relationship between the leading countries at the frontier of Elite Quality (Singapore, Switzerland, Germany, U.K. or U.S.) that runs perpendicular to the trendline in the overall sample. That is, Singapore tends toward the 'enlightened' space given its relatively powerful elites (more than compensated for by the actual Valve Creation of its elites). On the other hand, the U.S. or the U.K. score highest in terms of Power but manage to rent seek with Value scores at the levels of countries in the next cluster where we find Korea, Sweden or China.

The 3 countries in the 'enlightened' quadrant restrain their Power (and Value Extraction potential) to actually create moderate levels of value. Saudi Arabia, Indonesia, and especially Kazakhstan fall in this category. The question is, will they (i) follow the path of Singapore, or instead (ii) monetize their power, or even (iii) decline and tend towards the 'striving' positioning of Brazil or Turkey? After all, weakening elites could lead to a free-for-all rent seeking situation, as seems to be the case in South Africa. 


\subsection{Value Configuration Framework: Economic Activity as Shares of Value Creation/Extraction}

EQx ranks countries on Elite Quality. That is, each country has a score that represents a point on the Value Creation to Value Extraction spectrum of the political economy. The Country Scores are normalized to a range of 1 to 100 , with 100 being the highest score, i.e. the best, in terms of Value Creation.

To make concrete the abstract aggregate notion, to support policy and social debates, and to facilitate the connection of the macro (country-level) EQx to the micro (company-level), we introduce the Value Configuration framework. The Value Configuration suggests the relative proportion of Value Creation vs Value Extraction business models within a given economy on a relative and comparative basis. A simple conversion turns $E Q x$ scores into Value Creation percentages, where the distance from a theoretical perfect $100 \%$ is assumed to be economic activity derived from Value Extraction business models. While figuratively speaking Country Scores represent a point on a continuum, the Value Configuration is a heuristic where the range up to the Country Score spot is determined to be Value Creation and the reminder to be Value Extraction. If the total economic pie is measured by GDP, Value Creation and Value Extraction jointly add up to $100 \%$ of national income.

Value Configuration is a rendition of the political economy position of a given country in relation to others, reflecting the respective proportions of value creating and rent seeking business models. For any given political economy, the ratio between the 2 business models is not an absolute, but instead qualified by the same metric of the other countries in the Index. Derivate work on the Value Configuration heuristic is currently being tested at the firm-level, where a method is being developed to assess the percentage of revenue (and profits) generated by firms from Value Creation business models and their value extracting opposite. This assessment is also performed in comparative terms, the benchmark in this case being other firms.

Visual 17: EQx Value Creation vs Value Extraction Configuration, based on EQx Country Scores

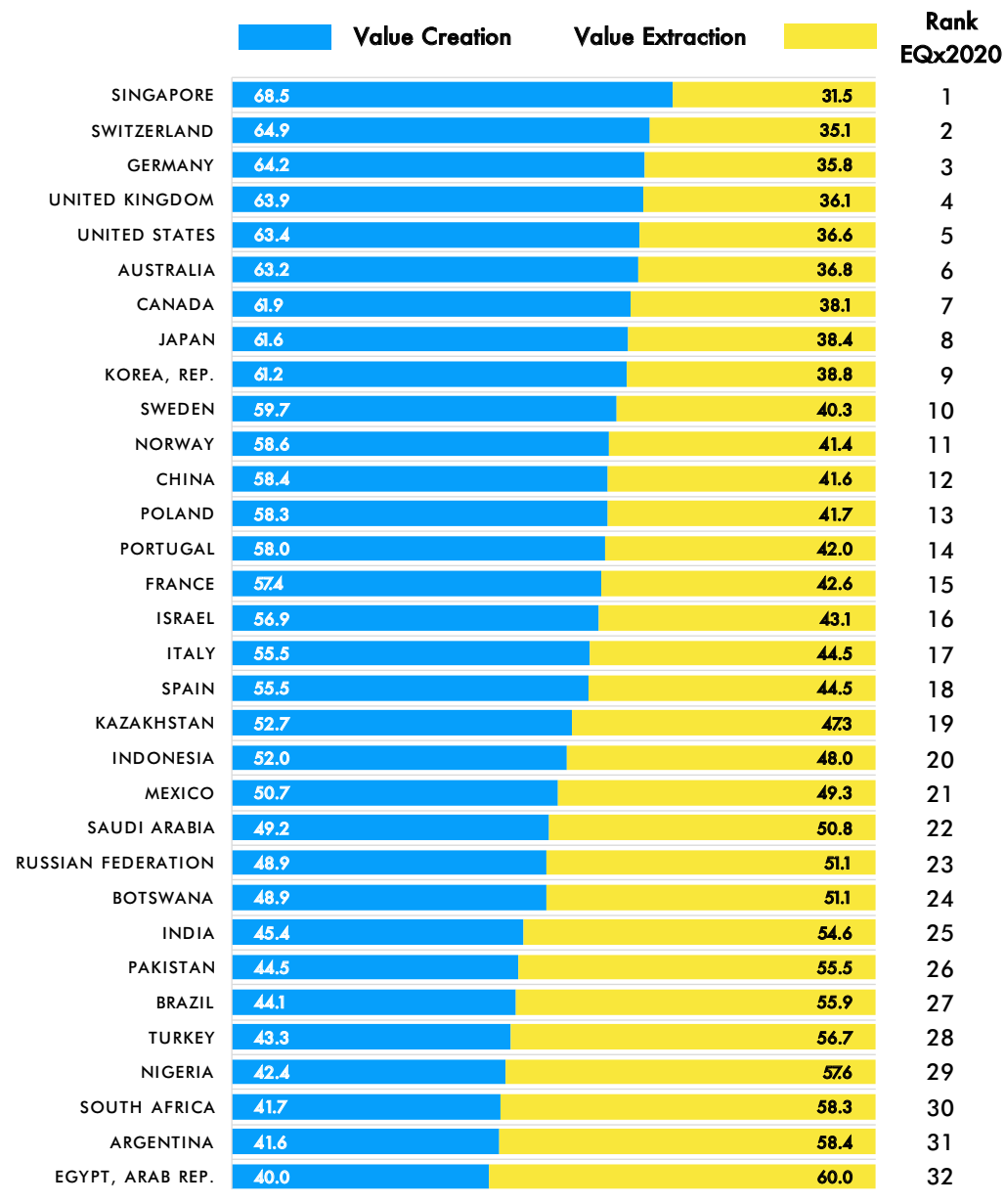




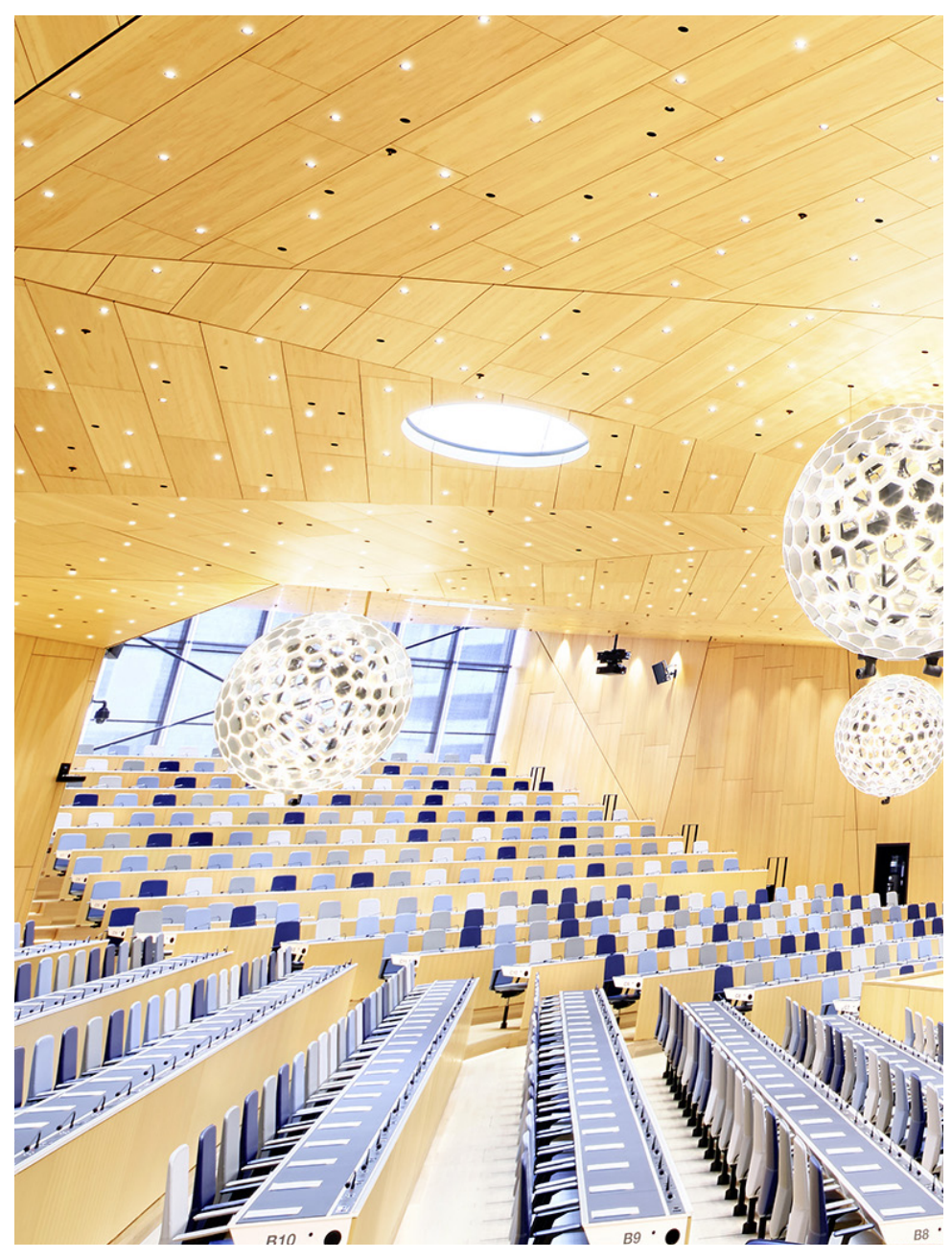




\subsection{Pillar Results}

The Pillars are the specific and integer constructs that host the EQx Indicators and their datasets. Categorized and color-coded along the 4 Index Areas, they are presented next. Conceptually, the Pillar Country Scores and Global Rank measure where exactly in the political economy Value is being created and if the pie (versus the slice) is being enlarged.

\section{Political Power Pillars, Index Area (i)}

The Political Power Pillars measure the capture of 3 kinds of rules: The rules of the state, the rules of business regulation, and the rules for labor markets and civil service jobs. The terminology is borrowed from Stigler's Capture theory (1971).

Pillar i.1, State Capture focuses on the direct capture by distributional coalitions of the state and its government branches. This Pillar measures diverse manifestations of elite power ranging from political centralization to gender parity at the state's top echelons. Specific Indicators measure Social Mobility (MOB, i. 1) and any evidence that the state has been captured, as for instance evidenced by Political corruption (COR, i. 1) or in the planned Indicator, Political turnover (TUP, i. 1), which aim to reflect the degree of 'creative destruction' in politics.

Pillar i.2, Regulatory Capture measures the extent to which rules and regulation, or the making thereof, have been captured by special interests. The Pillar includes Administrative decentralization (AED, i.2) and Crony capitalism (CRO, i.2), derived from an index proposed by The Economist ("Comparing crony capitalism", 2016), which measures wealth derived by billionaires from rent-heavy industries as a signal of the successful capture of regulators or legislators. It also incorporates the World Bank's widely-recognized Ease of Doing Business Index - coined in the EQx as Institutional quality (DBI, i.2) - which measures the quality of a country's institutions and regulatory environment.

Pillar i.3, Human Capture attempts to measure the power of labor and civil service coalitions, including their privileges in the political system. This might be reflected by their ability to influence their own wages and working conditions. In this Pillar, evidence of their Political Power is measured by Unionization rates (UNI, i.3), or Public sector employees as \% of total employment (PSE, i.3). Other areas of human capture are operationalized by the Women, Business and the Law (WBL, i.3) Indicator, or the extreme phenomenon of modern slavery by the Global Slavery Index (GSI, i.3).

Visual 18: Index Area (i) - Political Power, Pillars with Country Score and Global Rank

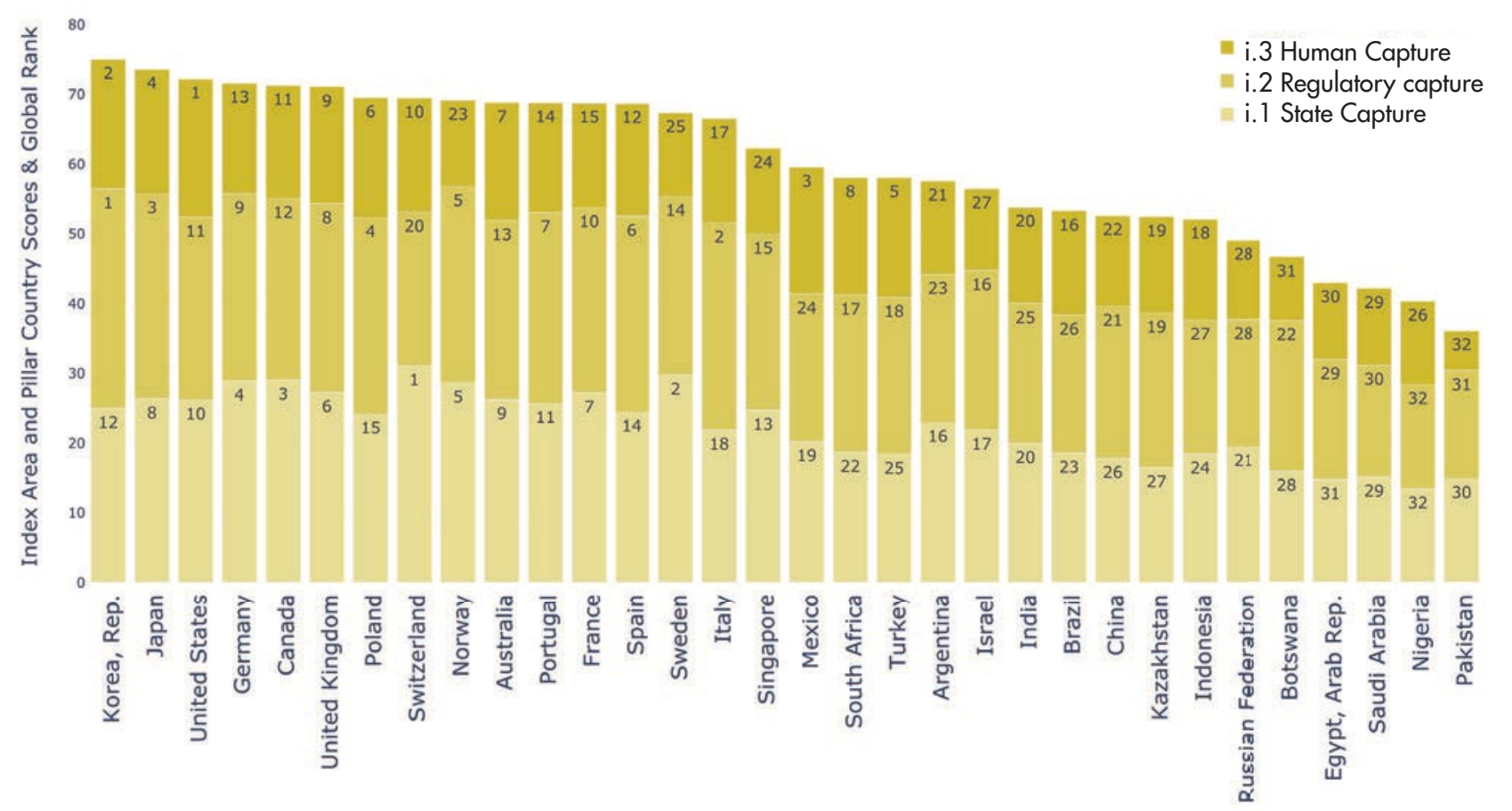




\section{Economic Power Pillars, Index Area (ii)}

The Economic Power Pillars measure elite dominance in the economy: First at the industry level, then at the single business level, and lastly, the opposite of dominance, i.e. creative destruction.

Pillar ii.4, Industry Dominance measures a national economy's diversity. Influence of a country's dominant industries in the political economy is assessed by Indicators measuring, for instance, the relative export volumes, revenues, or profits of leading industries as percentage of GDP. The Pillar also includes Indicators like the Economic Complexity Index (ECl, ii.4) measuring the "amount of productive knowledge" (Hausmann, et al., 201 1, p.63) implied in a country's export structures.

Pillar ii.5, Firm Dominance measures the degree of power concentration in the hands of a nation's leading firms. To that effect, the Pillar examines, for instance, the Top 10 firms market capitalization as \% of GDP (FKG, ii.5), as well as the number of Small and mediumsized enterprises per 1,000 people (SME, ii.5). Indicators further considered will be measurements of policies designed to maintain healthy levels of competition and limits to Economic Power.

Pillar ii.6, Creative Destruction estimates the pressures for renewal and disruption in an economy. Borrowing Schumpeter's concept, one focus is entrepreneurs whose role is to challenge incumbents and drive economic growth. The Pillar first considers the "destruction" part of the process for instance by measuring the Listed firms turnover, long run 15 years / short run 3 years (TUL/TUS, ii.6) and the Firm entry/exit ratio (ENR/EXR, ii.6). Then, it considers the forces fostering "creation" in the economy, such as the all-important level of Entrepreneurship (ENT, ii.6) or VC (venture capital) finance (VCK, ii.6).

Visual 19: Index Area (ii) - Economic Power, Pillars with Country Score and Global Rank

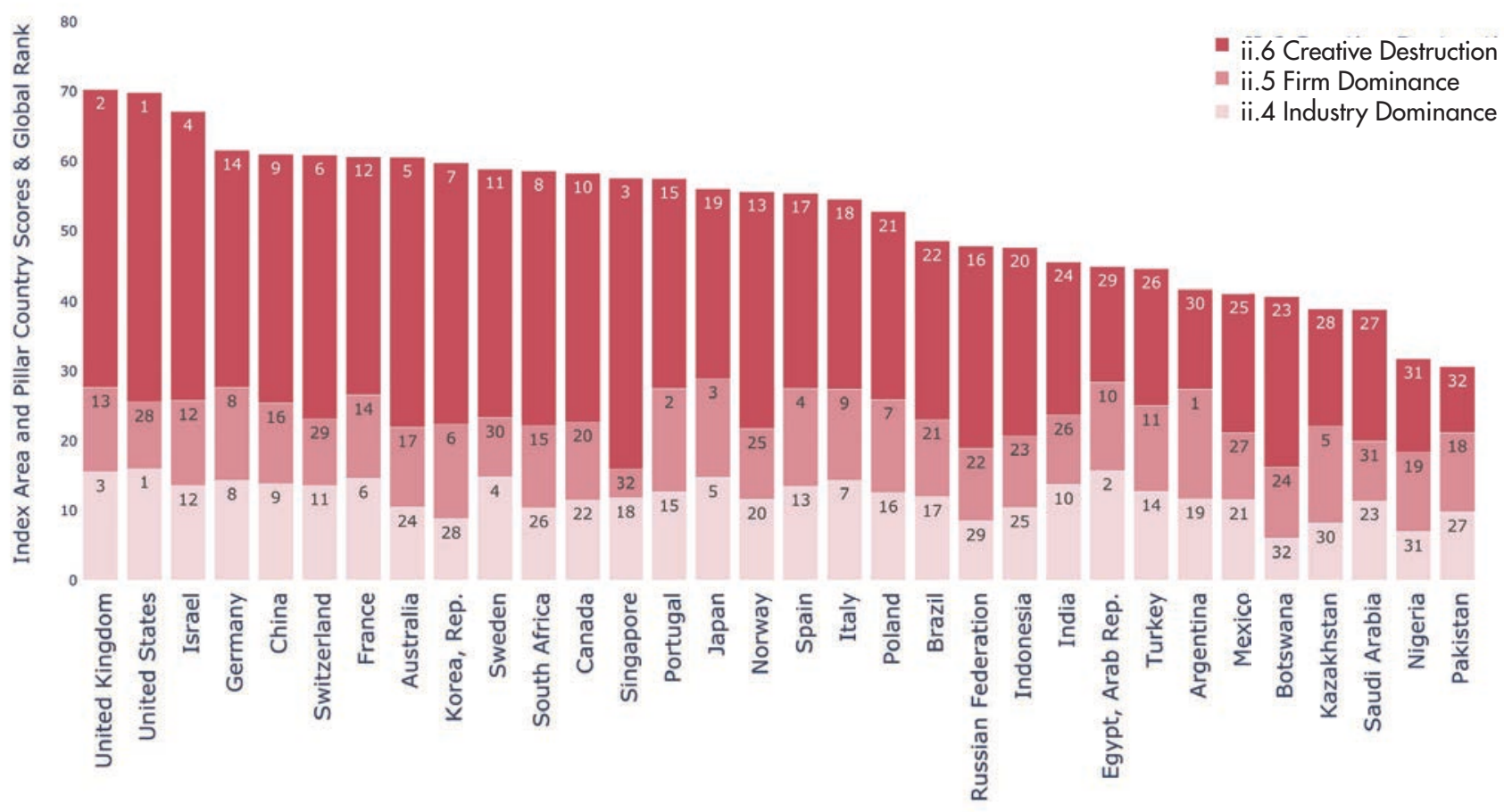




\section{Political Value Pillars, Index Area (iii)}

The Political Value Pillars measure Value Creation $(\neq$ Extraction) in the political dimension: Political rent is conceptualized as the state's unearned income, as well as the state's taking and giving of income.

Pillar iii.7, Giving Income focuses on how the government uses and manages public finances. Redistribution of state income in the form of Subsidies and transfers as \% of expenses (SNT, iii.7) is an important Indicator of this Pillar; many of these processes often divert resources away from most efficient uses and create hidden costs (Clements \& Parry, 2018). The Pillar also evaluates Indicators conducive to Value Creation, like public education provision or health including Covid-19 safety (COV, iii.7), that increase competition in many markets and act to curb rent seeking behaviors.

Pillar iii.8, Taking Income measures rent extraction occurring as the state collects income from productive citizens and other wealth generators, fails to protect these, or endorses wealth transfers carried out by powerful coalitions. The Pillar includes tax system properties such as the Corporate tax rate deviation from optimum (DCT, iii.8). Plans for future Indicators include a Housing affordability survey (HAS, iii.8) since land prices are often determined by the government on behalf of narrow coalitions with pernicious effects on the young and working classes, or measures related to the challenging tasks of establishing a security optimum: the absence of security encourages proliferation of extractive (criminal) business models and an over-investment is a sign of rent seeking.

Pillar iii.9, Unearned Income mainly focuses on the exploitation or Value Extraction of natural and various resources, including the future. For instance, environmental footprints are conceptualized as wealth provided by nature - i.e. wealth that is not earned in full. Accordingly, a low Environmental Performance Index (EPI, iii.9) represents intergenerational wealth transfers, as does Government debt as \% of GDP (DBT, iii.9). State ownership, control and involvement in business (SOE, iii.9) is another Indicator here - the license to operate is self-issued rather than earned.

Visual 20: Index Area (iii) - Political Value, Pillars with Country Score and Global Rank

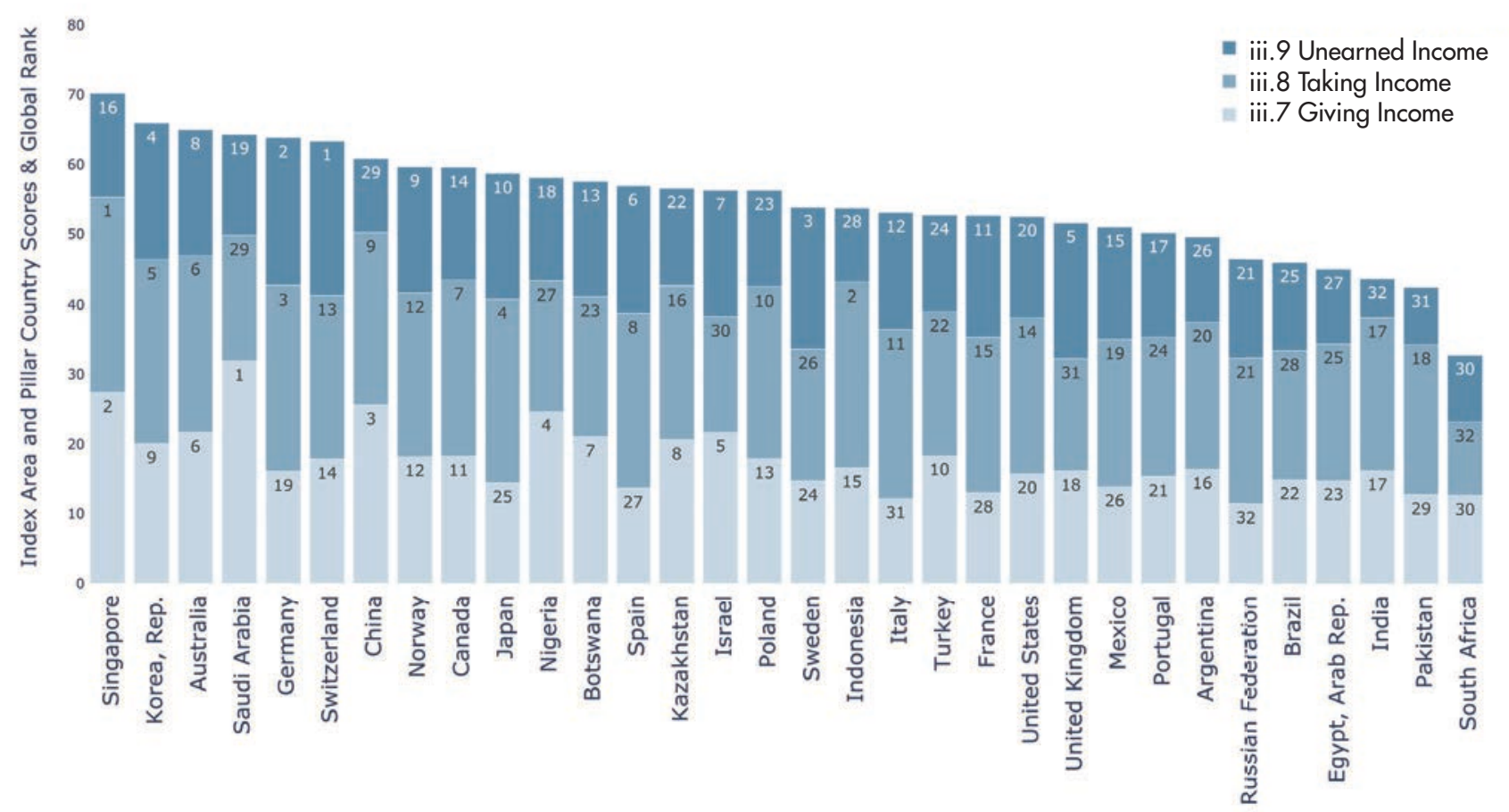




\section{Economic Value Pillars, Index Area (iv)}

The Economic Value Pillars measure Value Creation ( $\neq$ Extraction) in the economy's 3 markets: The products and services market, the capital market and the labor market.

Pillar iv.10, Producer Rent identifies rents extracted by producers and suppliers in the market for goods and services. Rents are extracted, for example, through barriers as implied in Trade Freedom (TRF, iv. 10), Barriers to entry (BTE, iv. 10) or Foreign direct investment as \% of GDP (FDI, iv. 10). Protectionist measures against entry enable Value transferring business models to be established, usually to the benefit of domestic producers and investors, inducing welfare losses well-documented in economics.

Pillar iv. 11 , Capital Rent focuses on rents extracted though direct or indirect financial market participation. Data from markets, including Neutral interest rate (DNI, iv. 11), M\&A as \% of GDP (DMA, iv. 1 1), Gold demand as \% of GDP (GOL, iv. 11 ) or Currency appreciation (CUA, iv. 11 ), are assessed to determine Value Extraction. Controversial positions which require further research are taken - for example, considering rent deviations from theoretical free-market 'optimal values'. More complex forms of rent seeking in capital markets will also be considered in the future, like the difference between return on assets (ROA) and total factor productivity (TFP).

Pillar iv.12, Labor Rent seeks to determine all rents arising from interventions in or related to labor markets by participants on both supply and demand sides. For this purpose, the Pillar includes the Unemployment rate (UEM, iv. 12) and other measures which often are the result of intra-labor rent seeking. Value Extraction phenomena in which rent seeking can a priori occur on either the employers or employees side are also measured, like the Delta real wage vs labor productivity (WLP, iv. 12). More clear-cut Value Extraction models considered are the Gender wage gap (GWG, iv. 12) and the planned Cost of Thriving Index (CTI, iv. 12).

Visual 21: Index Area (iv) - Economic Value, Pillars with Country Score and Global Rank

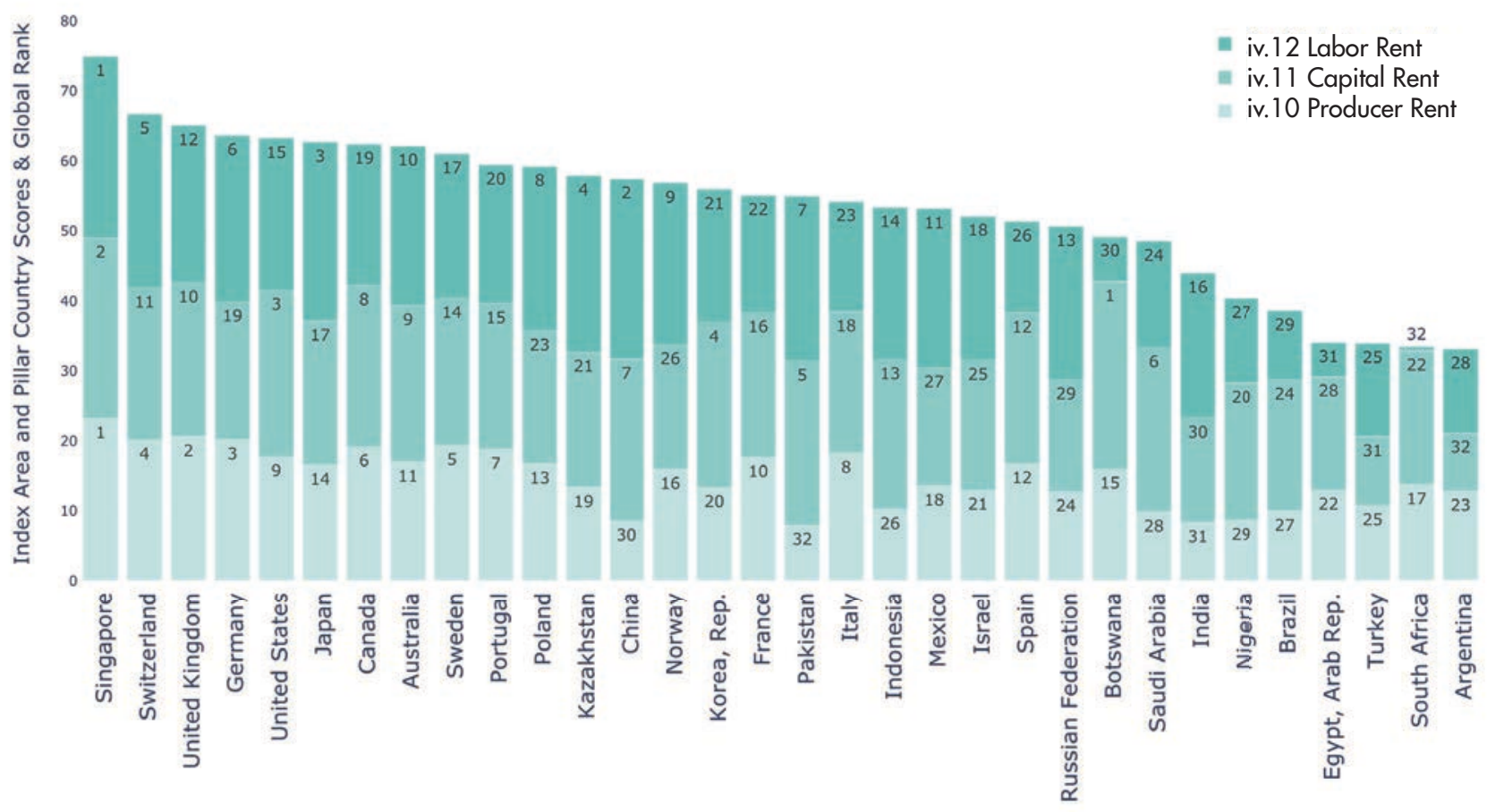


EQx2020: By Pillar Country Scores

Visual 22: Table of complete EQx Pillars by Country Scores, color-coded

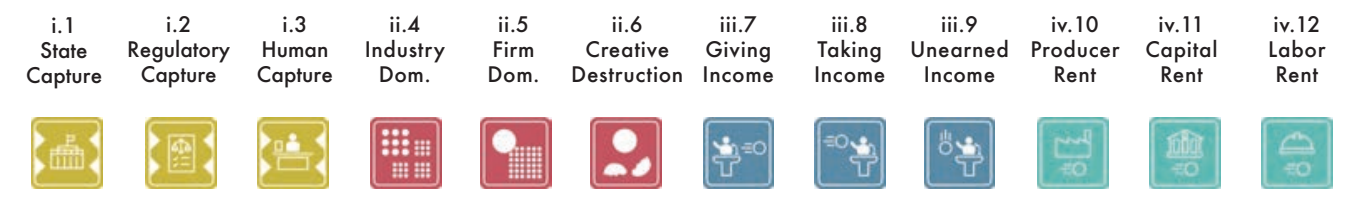

\begin{tabular}{|c|c|c|c|c|c|c|c|c|c|c|c|c|}
\hline Singapore & 68.6 & 68.3 & 45.7 & 56.2 & 18.0 & 74.3 & 75.2 & 76.8 & 54.6 & 80.1 & 75.8 & 70.3 \\
\hline Switzerland & 86.3 & 59.6 & 60.5 & 64.7 & 41.5 & 67.4 & 49.1 & 64.3 & 81.2 & 69.5 & 64.0 & 67.1 \\
\hline Germany & 80.3 & 72.6 & 58.7 & 68.3 & 57.9 & 60.6 & 44.2 & 72.9 & 77.9 & 69.6 & 57.9 & 64.3 \\
\hline United Kingdom & 75.8 & 73.1 & 62.1 & 74.1 & 52.6 & 76.2 & 44.3 & 44.2 & 71.3 & 71.1 & 64.7 & 60.8 \\
\hline United States & 72.8 & 70.9 & 73.4 & 76.3 & 41.6 & 79.1 & 43.2 & 61.4 & 53.0 & 61.2 & 70.1 & 58.7 \\
\hline Australia & 72.8 & 69.4 & 62.8 & 49.9 & 49.8 & 69.0 & 59.5 & 69.4 & 66.4 & 58.5 & 65.8 & 61.6 \\
\hline Canada & 80.7 & 70.4 & 60.1 & 54.8 & 48.6 & 63.6 & 50.1 & 69.3 & 59.3 & 66.0 & 67.9 & 54.7 \\
\hline Japan & 73.1 & 79.5 & 66.2 & 70.0 & 61.7 & 48.4 & 39.7 & 72.3 & 65.9 & 57.0 & 60.6 & 69.1 \\
\hline Korea, Rep. & 69.3 & 85.2 & 68.8 & 42.1 & 58.9 & 66.7 & 55.1 & 72.3 & 72.0 & 45.9 & 69.5 & 51.4 \\
\hline Sweden & 82.7 & 69.2 & 44.6 & 70.4 & 37.1 & 63.6 & 40.4 & 51.9 & 74.4 & 66.8 & 61.9 & 55.7 \\
\hline Norway & 79.7 & 76.0 & 45.8 & 55.1 & 44.1 & 60.6 & 50.0 & 64.4 & 66.2 & 54.9 & 52.5 & 62.5 \\
\hline China & 49.4 & 58.9 & 48.3 & 66.0 & 50.2 & 63.6 & 70.5 & 67.6 & 38.9 & 29.5 & 68.0 & 69.7 \\
\hline Poland & 67.2 & 76.1 & 63.7 & 59.9 & 57.9 & 48.0 & 49.3 & 67.5 & 50.7 & 57.6 & 55.9 & 63.6 \\
\hline Portugal & 71.4 & 74.0 & 58.3 & 60.3 & 64.5 & 53.6 & 42.1 & 55.1 & 54.6 & 64.8 & 61.3 & 53.6 \\
\hline France & 75.7 & 71.7 & 55.6 & 69.6 & 52.0 & 60.9 & 35.7 & 61.3 & 63.7 & 60.8 & 60.9 & 45.4 \\
\hline Israel & 60.8 & 61.8 & 43.4 & 64.6 & 53.1 & 73.9 & 59.6 & 45.5 & 66.4 & 44.7 & 54.6 & 55.6 \\
\hline Spain & 67.9 & 75.9 & 59.9 & 64.2 & 60.9 & 49.9 & 37.5 & 68.9 & 66.9 & 57.7 & 63.4 & 35.2 \\
\hline Italy & 60.8 & 80.3 & 55.4 & 68.4 & 56.6 & 48.5 & 33.4 & 66.5 & 61.5 & 63.0 & 59.4 & 42.6 \\
\hline Kazakhstan & 45.8 & 60.0 & 51.2 & 38.8 & 60.5 & 30.1 & 56.7 & 60.4 & 51.4 & 46.0 & 56.9 & 68.3 \\
\hline Indonesia & 51.3 & 51.9 & 53.5 & 49.7 & 44.7 & 48.1 & 45.6 & 73.0 & 39.0 & 35.2 & 63.0 & 58.9 \\
\hline Mexico & 56.2 & 57.2 & 67.4 & 54.9 & 41.8 & 35.6 & 38.1 & 58.0 & 58.9 & 46.7 & 49.7 & 61.5 \\
\hline Saudi Arabia & 42.0 & 43.3 & 40.9 & 54.2 & 37.0 & 33.8 & 87.7 & 49.2 & 53.3 & 33.9 & 69.1 & 41.2 \\
\hline Botswana & 44.2 & 58.4 & 34.0 & 28.6 & 44.3 & 43.7 & 57.8 & 55.1 & 60.5 & 55.0 & 78.8 & 17.4 \\
\hline Russian Federation & 54.1 & 49.2 & 42.3 & 40.4 & 45.3 & 51.7 & 31.5 & 57.2 & 51.9 & 43.9 & 47.1 & 59.3 \\
\hline India & 55.4 & 54.2 & 51.2 & 65.4 & 43.5 & 39.0 & 44.6 & 59.8 & 20.6 & 28.7 & 44.0 & 56.0 \\
\hline Pakistan & 41.3 & 41.9 & 21.2 & 46.4 & 49.6 & 16.8 & 35.2 & 58.8 & 30.2 & 27.4 & 69.1 & 63.6 \\
\hline Brazil & 51.6 & 53.4 & 55.4 & 57.1 & 47.9 & 45.7 & 41.1 & 50.3 & 46.6 & 34.2 & 55.3 & 26.7 \\
\hline Turkey & 51.2 & 60.7 & 63.8 & 60.6 & 53.4 & 34.9 & 50.4 & 56.7 & 50.6 & 37.0 & 29.0 & 36.1 \\
\hline Nigeria & 37.2 & 40.5 & 44.3 & 33.0 & 49.5 & 24.0 & 67.8 & 51.3 & 54.3 & 29.9 & 57.7 & 32.7 \\
\hline South Africa & 51.9 & 61.0 & 62.5 & 49.5 & 51.3 & 65.1 & 34.8 & 29.0 & 34.8 & 47.4 & 56.2 & 1.6 \\
\hline Argentina & 63.8 & 57.4 & 49.6 & 55.5 & 68.3 & 25.6 & 45.1 & 58.0 & 44.5 & 44.1 & 24.4 & 32.5 \\
\hline Egypt, Arab Rep. & 40.8 & 46.6 & 40.8 & 75.0 & 55.0 & 29.5 & 40.7 & 53.5 & 39.4 & 44.6 & 47.7 & 13.2 \\
\hline
\end{tabular}




\section{EQx2020: By Pillar Global Rank}

Visual 23: Table of complete EQx Pillars by Global Rank, color-coded

\begin{tabular}{|c|c|c|c|c|c|c|c|c|c|c|c|c|}
\hline & $\begin{array}{c}\text { i. } 1 \\
\text { State } \\
\text { Capture }\end{array}$ & $\begin{array}{c}\text { i.2 } \\
\text { Regulatory } \\
\text { Capture }\end{array}$ & $\begin{array}{l}\text { i.3 } \\
\text { Human } \\
\text { Capture }\end{array}$ & $\begin{array}{c}\text { ii.4 } \\
\text { Industry } \\
\text { Dom. }\end{array}$ & $\begin{array}{l}\text { ii. } 5 \\
\text { Firm } \\
\text { Dom. }\end{array}$ & $\begin{array}{c}\text { ii.6 } \\
\text { Creative } \\
\text { Destruction }\end{array}$ & $\begin{array}{l}\text { iii.7 } \\
\text { Giving } \\
\text { Income }\end{array}$ & $\begin{array}{l}\text { iii.8 } \\
\text { Taking } \\
\text { Income }\end{array}$ & $\begin{array}{c}\text { iii.9 } \\
\text { Unearned } \\
\text { Income }\end{array}$ & $\begin{array}{l}\text { iv. } 10 \\
\text { Producer } \\
\text { Rent }\end{array}$ & $\begin{array}{c}\text { iv. } 11 \\
\text { Capital } \\
\text { Rent }\end{array}$ & $\begin{array}{c}\text { iv. } 12 \\
\text { Labor } \\
\text { Rent }\end{array}$ \\
\hline & 量 & 象 & $\frac{a^{2}}{2}$ & 啉: & Q 带 & 0 & $\overrightarrow{⿱ ⺌ 冖}^{2}=0$ & $=0 \frac{2}{\vec{v}}$ & & $m$ & $\int_{00}$ & $\sum_{00}^{0}$ \\
\hline Singapore & 13 & 15 & 24 & 18 & 32 & 3 & 2 & 1 & 16 & 1 & 2 & 1 \\
\hline Switzerland & 1 & 20 & 10 & 11 & 29 & 6 & 14 & 13 & 1 & 4 & 11 & 5 \\
\hline Germany & 4 & 9 & 13 & 8 & 8 & 14 & 19 & 3 & 2 & 3 & 19 & 6 \\
\hline United Kingdom & 6 & 8 & 9 & 3 & 13 & 2 & 18 & 31 & 5 & 2 & 10 & 12 \\
\hline United States & 10 & 11 & 1 & 1 & 28 & 1 & 20 & 14 & 20 & 9 & 3 & 15 \\
\hline Australia & 9 & 13 & 7 & 24 & 17 & 5 & 6 & 6 & 8 & 11 & 9 & 10 \\
\hline Canada & 3 & 12 & 11 & 22 & 20 & 10 & 11 & 7 & 14 & 6 & 8 & 19 \\
\hline Japan & 8 & 3 & 4 & 5 & 3 & 19 & 25 & 4 & 10 & 14 & 17 & 3 \\
\hline Korea, Rep. & 12 & 1 & 2 & 28 & 6 & 7 & 9 & 5 & 4 & 20 & 4 & 21 \\
\hline Sweden & 2 & 14 & 25 & 4 & 30 & 11 & 24 & 26 & 3 & 5 & 14 & 17 \\
\hline Norway & 5 & 5 & 23 & 20 & 25 & 13 & 12 & 12 & 9 & 16 & 26 & 9 \\
\hline China & 26 & 21 & 22 & 9 & 16 & 9 & 3 & 9 & 29 & 30 & 7 & 2 \\
\hline Poland & 15 & 4 & 6 & 16 & 7 & 21 & 13 & 10 & 23 & 13 & 23 & 8 \\
\hline Portugal & 11 & 7 & 14 & 15 & 2 & 15 & 21 & 24 & 17 & 7 & 15 & 20 \\
\hline France & 7 & 10 & 15 & 6 & 14 & 12 & 28 & 15 & 11 & 10 & 16 & 22 \\
\hline Israel & 17 & 16 & 27 & 12 & 12 & 4 & 5 & 30 & 7 & 21 & 25 & 18 \\
\hline Spain & 14 & 6 & 12 & 13 & 4 & 17 & 27 & 8 & 6 & 12 & 12 & 26 \\
\hline Italy & 18 & 2 & 17 & 7 & 9 & 18 & 31 & 11 & 12 & 8 & 18 & 23 \\
\hline Kazakhstan & 27 & 19 & 19 & 30 & 5 & 28 & 8 & 16 & 22 & 19 & 21 & 4 \\
\hline Indonesia & 24 & 27 & 18 & 25 & 23 & 20 & 15 & 2 & 28 & 26 & 13 & 14 \\
\hline Mexico & 19 & 24 & 3 & 21 & 27 & 25 & 26 & 19 & 15 & 18 & 27 & 11 \\
\hline Saudi Arabia & 29 & 30 & 29 & 23 & 31 & 27 & 1 & 29 & 19 & 28 & 6 & 24 \\
\hline Botswana & 28 & 22 & 31 & 32 & 24 & 23 & 7 & 23 & 13 & 15 & 1 & 30 \\
\hline Russian Federation & 21 & 28 & 28 & 29 & 22 & 16 & 32 & 21 & 21 & 24 & 29 & 13 \\
\hline India & 20 & 25 & 20 & 10 & 26 & 24 & 17 & 17 & 32 & 31 & 30 & 16 \\
\hline Pakistan & 30 & 31 & 32 & 27 & 18 & 32 & 29 & 18 & 31 & 32 & 5 & 7 \\
\hline Brazil & 23 & 26 & 16 & 17 & 21 & 22 & 22 & 28 & 25 & 27 & 24 & 29 \\
\hline Turkey & 25 & 18 & 5 & 14 & 11 & 26 & 10 & 22 & 24 & 25 & 31 & 25 \\
\hline Nigeria & 32 & 32 & 26 & 31 & 19 & 31 & 4 & 27 & 18 & 29 & 20 & 27 \\
\hline South Africa & 22 & 17 & 8 & 26 & 15 & 8 & 30 & 32 & 30 & 17 & 22 & 32 \\
\hline Argentina & 16 & 23 & 21 & 19 & 1 & 30 & 16 & 20 & 26 & 23 & 32 & 28 \\
\hline Egypt, Arab Rep. & 31 & 29 & 30 & 2 & 10 & 29 & 23 & 25 & 27 & 22 & 28 & 31 \\
\hline
\end{tabular}




\section{EQx Country Analysis}

\subsection{Selected Country Flashcards}

\section{Switzerland}

EQ×2020 Global Rank: 2 ${ }^{\text {nd }}$

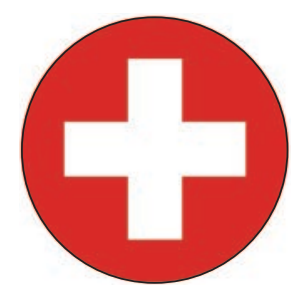

As a result of strong decentralization and direct democracy, rent seeking in Switzerland is limited, notwithstanding particular exceptions such as the $5 \%$ of annual budget expenditure allocated to agricultural sector subsidies (Federal Chancellery, 2019, p.9). While the business elites have amassed quite high levels of economic dominance (as evidenced by the Power Sub-Index), this has not as yet been converted into domestic rent seeking. The high Elite Quality outcome is attributable to the international orientation of Swiss firms'

\section{United States \\ EQx2020 Global Rank: $5^{\text {th }}$}

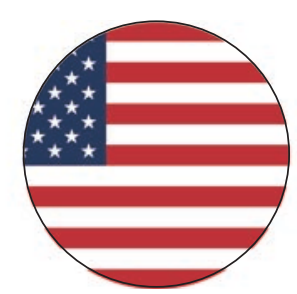

The strong rank of the U.S. befits a country that has maintained robust domestic demand growth for so many decades, with curbed market and political power restraining rents on both Sub-Indices. The rise of populism and movements such as Occupy and the June 2020 protest movement and riots, however, demonstrate how sensitive democracies can be to low-quality on just a few Pillars. The U.S. ranks well almost across the board, but notable outliers - including high Billionaires' wealth as a percent of GDP (BIW, ii.5), School life expectancy (EDU, iii.7), the Homicide rate (HOM, iii.8) or Health Care as \% of GDP deviation from optimum (DHC, iv. 10) - should ring alarm bells regarding future stability.

By Freya Beamish

\section{Kazakhstan}

EQx2020 Global Rank: $19^{\text {th }}$

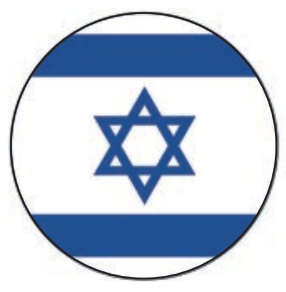

Elites in Israel score well on elements tied to the leading IT sector; leading the Creative Destruction (ii.6) Indicators including Entrepreneurship (ENT, ii.6), VC finance (VCK, ii.6), and $R \& D$ as \% GDP (RND, ii.6). The strong democratic tradition of Israel and its entrenched openness to globalization have created a very open and competitive society. However, long-term challenges remain for political stability, including political sclerosis, uneasy social relations between the majority and minorities, and dominance of billionaires in the economy.

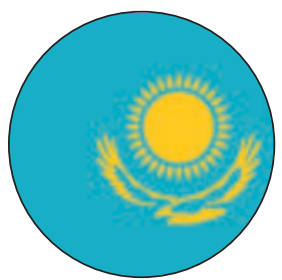

The former Soviet Republic turns in a strong performance, and its Elite Quality is such that future growth can be expected (Visual 46). Blessed by oil, but being the most landlocked country on earth, Kazakhstan has managed to maintain trade and investment relationships with Russia, China, the West and the Arab world. The elite configuration under its first President, Nursultan Nazarbayev, was modelled after Singapore. Yet, with the recent energy crisis and the closing that value creating elites start to take center stage. acts of the founding father era beginning, it is imperative
By Prof. Shlomo Weber 


\section{China}

\section{EQx2020 Global Rank: 12}

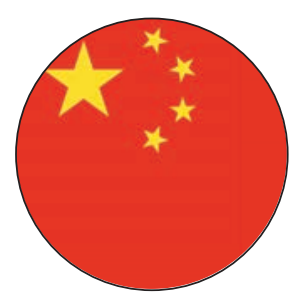

China is the top performer of all surveyed countries relative to its GDP, scoring higher than large E.U. economies like France or Spain. This extraordinary performance for a middle-income country also comes with inconsistency, as China scores between $3^{\text {rd }}$ and $30^{\text {th }}$ place across the EQx Pillars. China's state capitalism model is consistent with the high levels of Political Power recorded. In order to keep its high growth path over the longer-term, policymakers should want to contain any future Value Extraction potential that Power implies. Singapore shows how such a feat is realized.

by Freya Beamish

\section{Brazil}

EQx2020 Global Rank: 27 $^{\text {th }}$

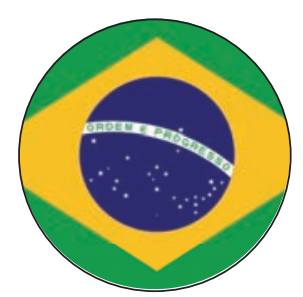

Brazil has made progress since the 1985 restoration of its democracy, especially regaining and largely holding control of inflation. However, at present, faith needs to be restored in the government, with the country scoring below average across all Index Areas. In order to secure a robust long-term growth path, and catch up with its BRIC peers, elites should transition to Value Creation business models, while providing conditions conducive to business and entrepreneurship in the economy.

\section{Russia}

EQx2020 Global Rank: $\mathbf{2 3}^{\text {th }}$

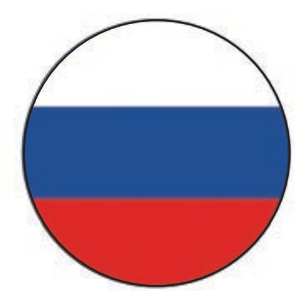

Russian elites find themselves in a difficult position in their relations with political authorities, as excellent scores on Entrepreneurship (ENT, ii.6), Barriers to start-ups (BTS, ii.6), and Political globalization (PGL, i. 1) stand in contrast to the realities of poor scores on Administrative decentralization (ADE, i. 1), Economic globalization (EGL, iv. 10), and Barriers to FDI (BTF, iv. 10). Political risk from domestic realities and external geopolitical pressure have pushed elites closer to the government, leaving less opportunity for Value Creation and more for rent seeking in an environment wary of globalization.

by Prof. Shlomo Weber

\section{South Africa}

EQx2020 Global Rank: 30 nd

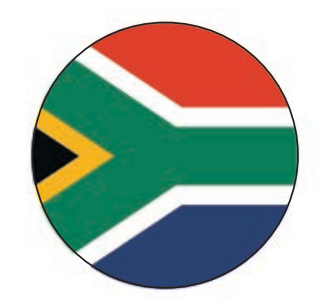

South Africa seems entangled in a vicious circle of rent extraction rooted in the Apartheid era, with new elite agents and their business models having joined the fray. Reforms reduced wealth transfers and power concentration, helping the country reach the middle ranges of the Power Sub-Index. Yet rent seeking levels are among the world's highest, and thus most economic growth translates into inequalities. This is mainly driven by the revolving door between business and politics, leading to favorable rules for rent seeking, private contracts and even bribery. The low degrees of aggregate Economic Power, fostered by a strong startup ecosystem, is a bright spot. 


\subsection{Country Scorecards: Deep Dive Analysis}

\section{France: Able to increase Elite Quality - but no signs it will do so across the board}

France's relatively low EQx position, ranking $15^{\text {th }}$ overall, is all the more disheartening when compared with Germany's $3^{\text {rd }}$ place - the lower quality levels of French elites relative to those of their Northern neighbors means that the gap between the 2 largest E.U. economies is destined to widen, unless bold reforms addressing elite business models are undertaken.

That France is in disarray, and has not regained its footings in the aftermath of 2008, is in many people's minds, with the images of "les gilets jaunes" literally setting streets on fire. The protest movement which began in October 2018 might reemerge with renewed force after the quarantine of Spring 2020. The movement started as a demonstration against a planned tax on diesel and petrol, intended to encourage the country to reach its green energy targets faster. However, quickly the movement began to encapsulate a number of additional grievances. Understanding these dynamics is not straightforward. For instance, the Elite Quality Index ranks France $25^{\text {th }}$ in terms of Tax revenue as \% of GDP (DTR, iii.8), but it is unclear if the protesters in their calls for a total tax system reform would reduce France's systemic levels of Value Extraction, or on the contrary would lead to new forms of rent seeking. An additional source of discontent motivating the movement is the apparent lack of economic prospects in France. Whilst 2019 saw a 10year low of unemployment, it still performs poorly in the Index, ranking $24^{\text {th }}$ for Unemployment rate (UEM, iv. 12), and 23rd for Youth unemployment rate (YUN, iv. 12).

As part of efforts to defuse the protests and appease the public, Macron announced EUR 25bn of tax cuts and extra spending in order to increase the disposable income of households'. These measures included EUR $5 \mathrm{bn}$ of cuts to income tax for low- er and average earners, as well as an increase in pensions for the same group ${ }^{2}$. Does this loosening of the purse strings mean that France's vast public debt, which sees the country rank $27^{\text {th }}$ for Government debt as \% of GDP (DBT, iii.9), is extracting valve from the future to solve the problems of the present? Even the IMF described levels as "too high for comfort"3.

In other areas France is exemplary, refraining from extracting rents from the future. Macron's concession to protestors in cancelling the fuel tax has not compromised his promise to "make our planet great again". Ranking at the top of the Environmental Performance Index (EPI, iii.9), France voted into law in July 2019 a climate and energy package that commits itself to becoming carbon neutral by $2050^{4}$.

Innovative new policy responses with respect to women's rights are an additional example of France's elites rejecting rent extraction business models - benefitting at least half of the population no less! As the November 2019 femicide protests demonstrate, there remains much work to be done on the subject, but France's elites are resolute, and used the country's G-7 presidency to establish a new Women 7 engagement group. The aim of this group is to ensure commitments will be made to gender equality throughout the $G 7$ process ${ }^{5}$. EQx reflects these steps forward, ranking France at the top in both the Women's Power Index (WPI, i. 1) and the Women, Business and the Law (WBL, i.3) Indicators. If France is capable of hampering value destruction at the all-important gender and environmental levels, why not in the other areas of our Index?

Diana van der Watt \& Céline Diebold University of St.Gallen

Visual 24: France performance overview by EQx Pillar vs overall distribution

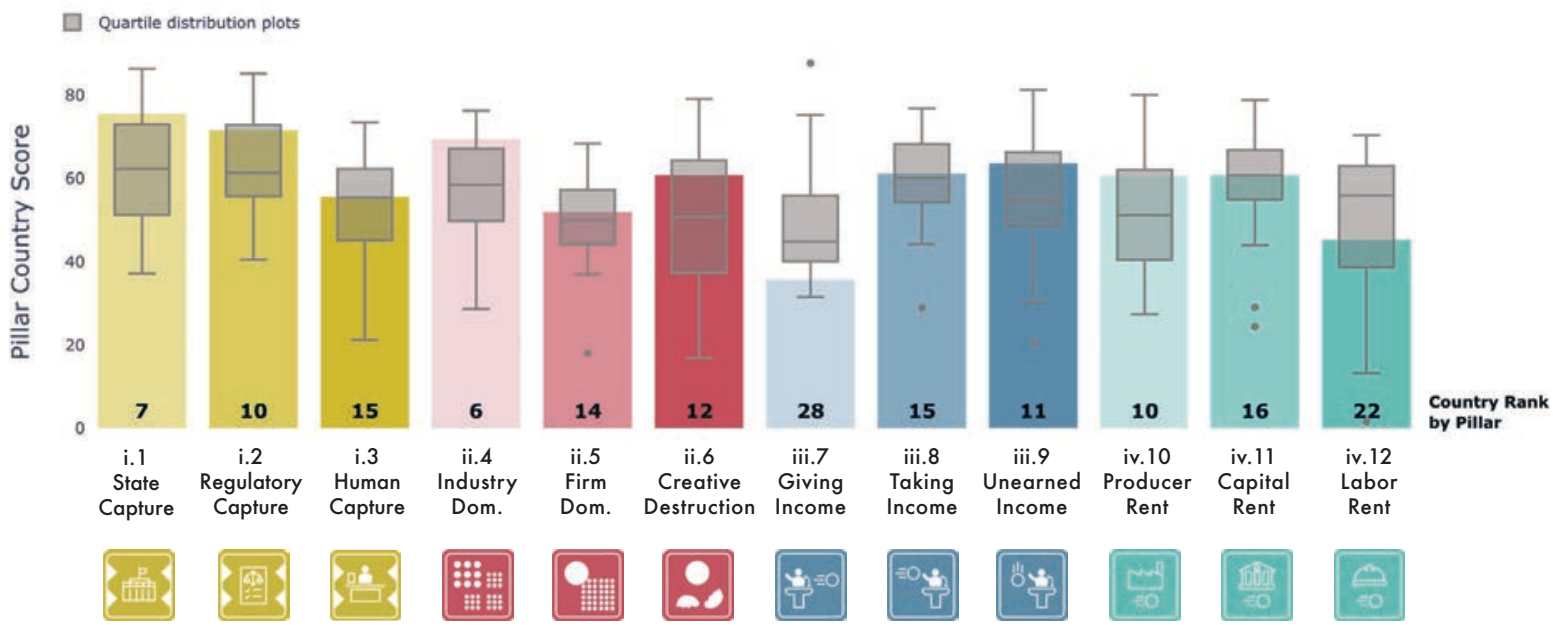




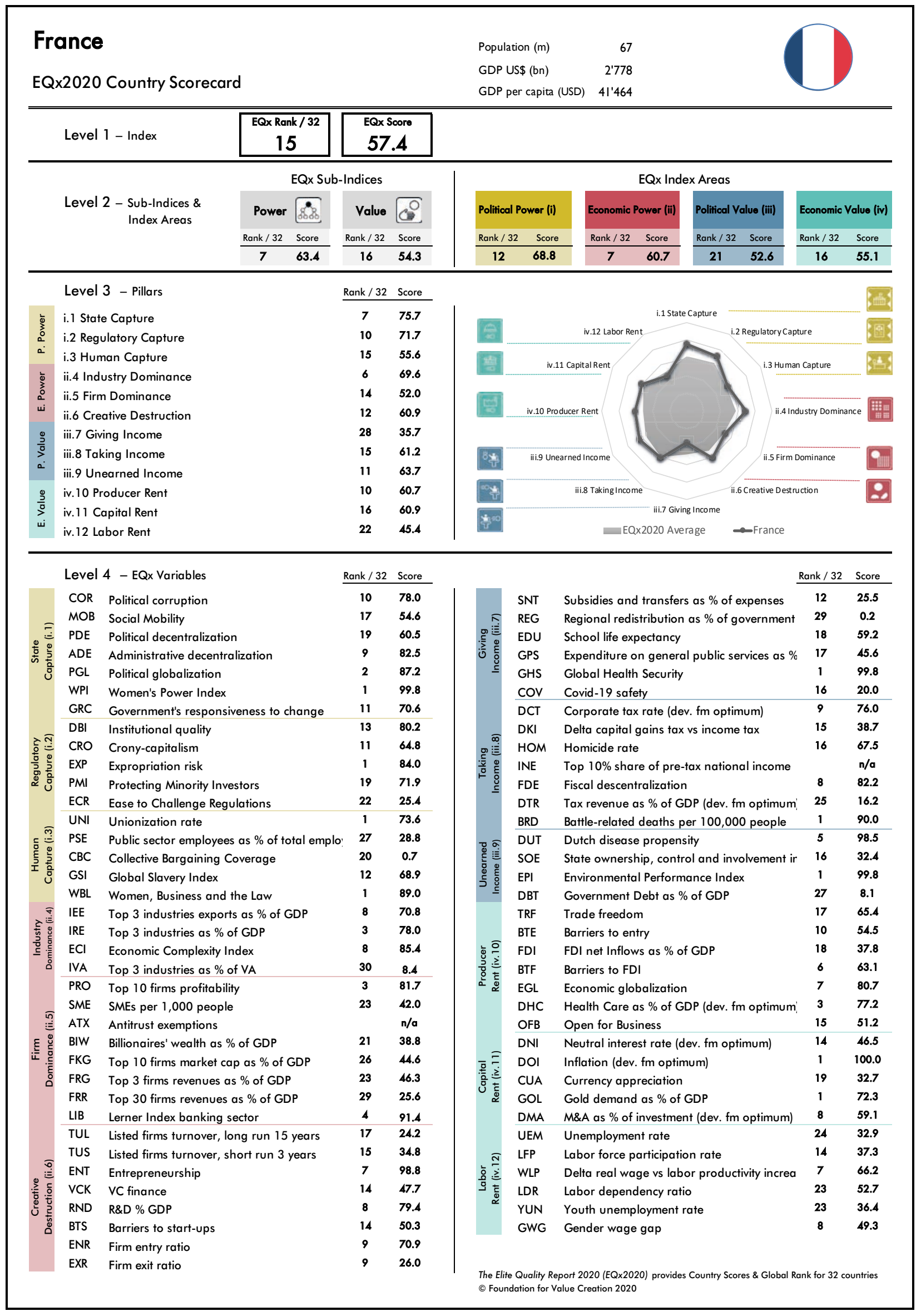


Germany's $30^{\text {th }}$ anniversary of the fall of Berlin Wall was celebrated last year. Reflecting back on this milestone, Germany's elites have managed to transform the country into the diverse and open economic powerhouse of Europe, with nearly a quarter of its population having an immigrant background ${ }^{6}$. On the other hand, there are challenges too. Asset inflation and stagnant wages might account for the discontent reflected in the rise of the far-right Alternative for Germany (AfD), which emerged top in the European Parliament election in Brandenburg and Saxony, both states in the former Communist East Germany. Moreover, the last 18 months saw the country flirt with a technical recession and confront the realization that, in terms of the $4^{\text {th }}$ Industrial Revolution, a technology gap with the U.S. and China is widening. That Tesla was at one point more valuable than all German automotive companies combined is telling ${ }^{7}$. Voices in Germany Inc. have started to plead for protectionist measures - are elites afraid of competing with Chinese rivals?

The EQx Index nevertheless acknowledges German inclusivity and modernity, and ranks it $3^{\text {rd }}$ overall. The youth of today's Germany have good reason to feel optimistic about their future, demonstrated tangibly by ranking $3^{\text {rd }}$ in Youth unemployment (YUN, iv. 12) and $8^{\text {th }}$ in School life expectancy (EDU, iii.7). One ranking sure to capture attention is the $2^{\text {nd }}$ place score of Germany's Covid-19 safety (COV, iii.7) Indicator, earning international praise for agile and decisive policy responses $^{8}$. In the Spring of 2020, Germany outshone its neighbors, with far fewer per capita deaths than most other European countries, owing to the country's earlier roll-out of extensive testing'. With fears of a second wave of the virus later in the year, any celebration is premature, but this is a very strong signal of Germany protecting the broad-based Value Creation potential of its citizens. The Covid-19 safety Indicator in next year's $E Q x$ will be telling.
There is not only a need for medical elites to flatten the epidemiological curve and prevent value destruction, but also for economic elites to address any recessionary curve and prevent rent seeking as the state invests in reconstruction. Germany's top score in the Economic Complexity Index $(\mathrm{ECl}$, ii.4) indicates diversification throughout the economy, and together with earning the $6^{\text {th }}$ spot in R\&D \% of GDP (RND, ii.6), we would hope that the German economy is well placed to tackle the challenge. Furthermore, the country's number 1 rank in Expropriation risk (EXP, i.2) underscores how Germany is an attractive place to do business. With the Firm Dominance (ii.5) Pillar at $7^{\text {th }}$, it seems unlikely that the German government, with its $4^{\text {th }}$ place ranking in State ownership, control and involvement in business (SOE, iii.9), will subsidize national heroes at the cost of the majority.

Another German icon is of course Angela Merkel. Her gradual retreat as Chancellor of Germany, scheduled for 2021, naturally draws attention to the legacy she leaves behind. For a country led by the world's most powerful woman ${ }^{10}$, Germany ranks a respectable yet disappointing $9^{\text {th }}$ place in the Women's Power Index (WPI, i. 1) Indicator and $12^{\text {th }}$ place in the Gender wage gap (GWG, iv. 12). Furthermore, despite the rhetoric about climate change ${ }^{11}$, Germany lags behind European peers, United Kingdom and Spain, on the Environmental Performance Index (EPI, iii.9) Indicator. Another fundamental issue is found at the Creative Destruction Pillar (ii.6), ranking at $14^{\text {th }}$. Here, elites might pre-empt new value creators from getting real traction, whilst disruptive value remains in the purview of incumbents, notwithstanding the promise of Berlin as a start-up capital. Germany can and might, in other words, do much better.

Diana van der Watt \& Camille Zeller University of St.Gallen

Visual 26: Germany performance overview by EQx Pillar vs overall distribution

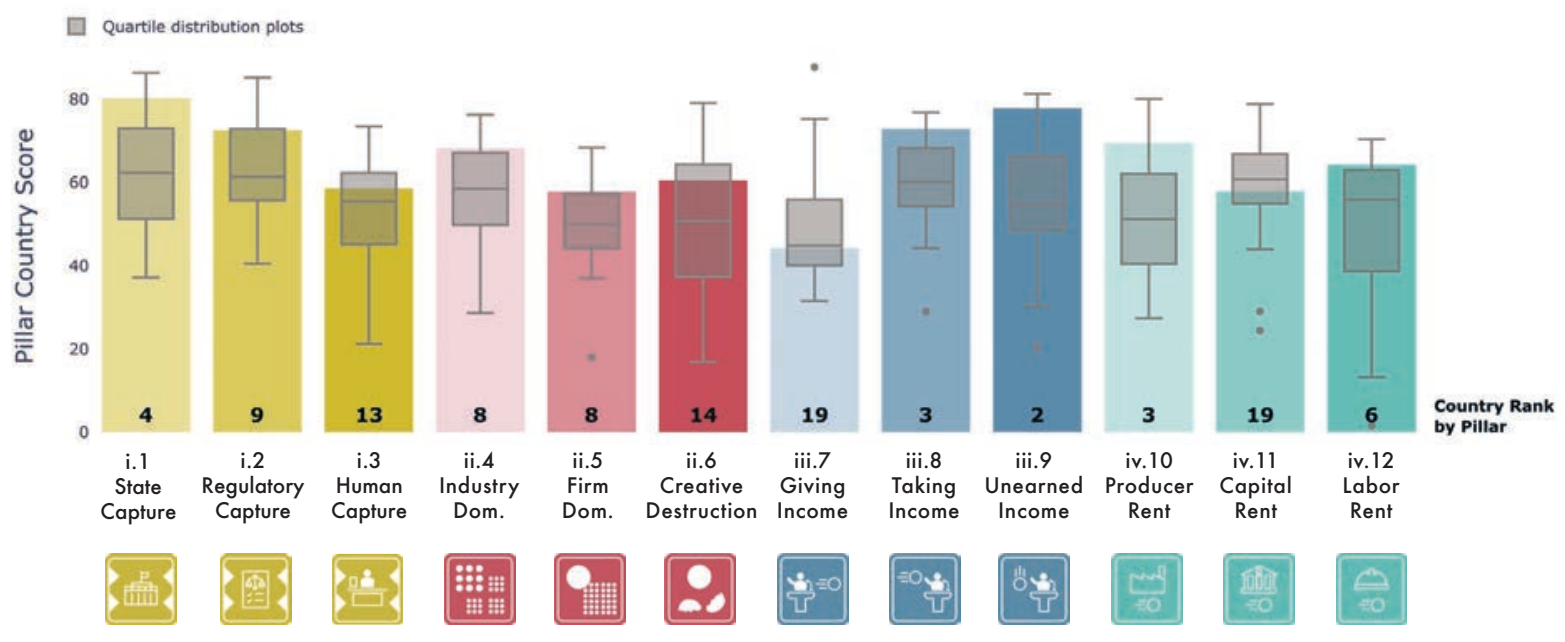




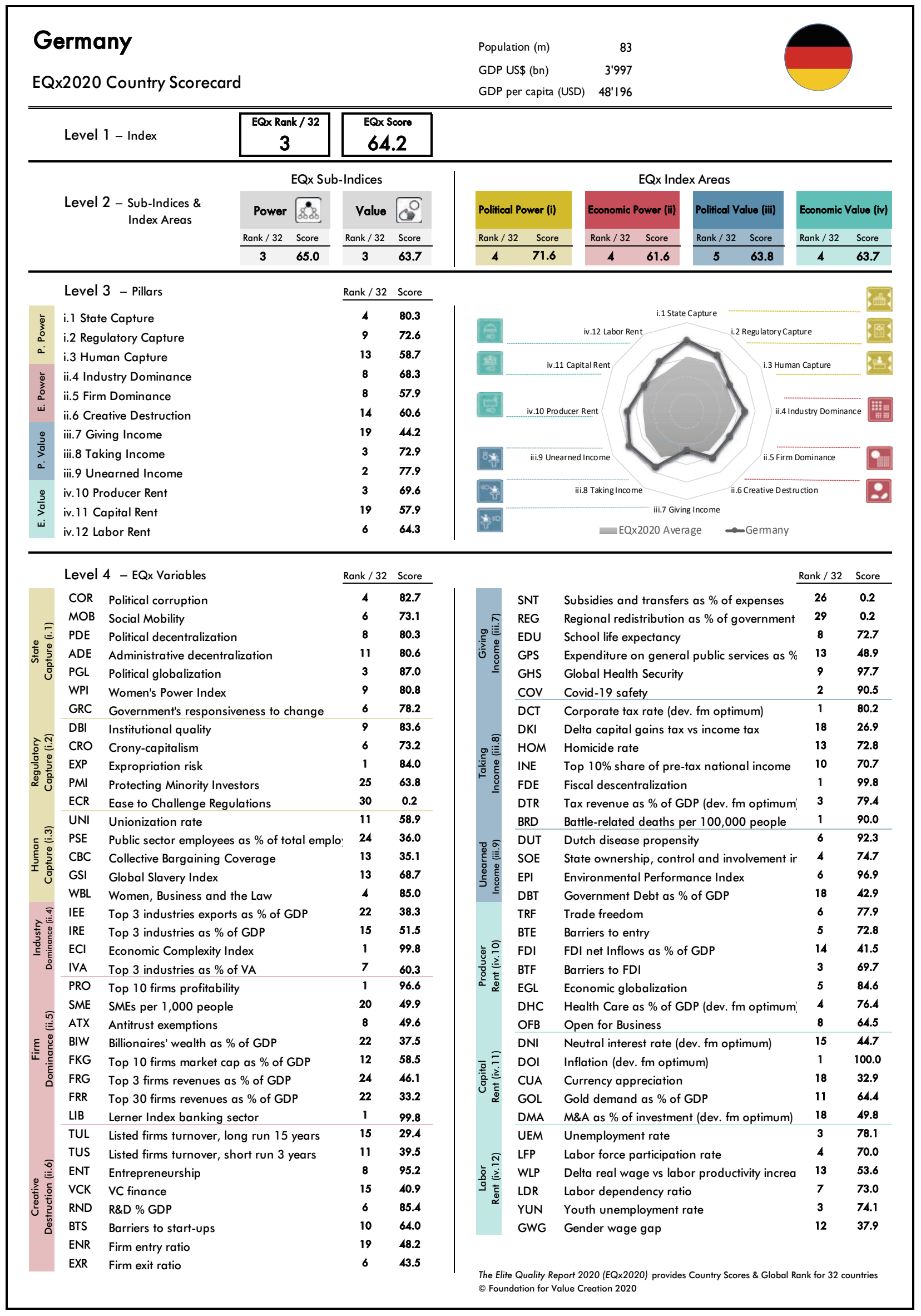




\section{Italy: Change needed, not in sight}

Italian elites have a middling score across Sub-Indices, but their Pillar performances vary greatly. Whilst Italy comes $2^{\text {nd }}$ in the Regulatory Capture Pillar (i.2), it comes $2^{\text {nd }}$ to last in Giving Income (iii.7), dragged down by government redistribution, with the North-South divide being a textbook case study of divergence in development. As one of the most affected countries in Europe by Covid-19, with levels of debt and unemployment looming large, the ability of its economy and citizens to recover depends on the government creating incentives for Value Creation by small, medium and family businesses, reducing debt and unemployment, and rooting out extractive business models.

In terms of political elite dynamics, August 2019 saw the end of the government formed in 2018 between the 5 Star Movement (M5S) and the League. The change was the result of the League's leader Salvini's dash for a snap election to capitalize from an expected vote redistribution away from M5S and to the League, which was forecasted by pollsters. However, the gamble backfired as the M5S persuaded the Democratic Party (PD) to join a coalition government, which is still in force today (mid-2020). Hence the new populist elite, victorious in the 2018 elections, crashed, due to one of its 2 main parties attempting to increase its share of the pie. That enabled a comeback of the older elite (represented by the PD), now leading a semi-populist government. These dynamics are well reflected in the EQx, and in the State of Elites framework (Visual 16). Italian elites are shown as relatively weak and disinterested in Value Creation, being all too ready to capture rents as soon as the opportunity arises.
A Salvini-led centre-right coalition won the regional election in Umbria last November, a historically PD-dominated region. This attests well to Political decentralization (PDE, i. 1), in which Italy ranks the highest in our Index. The political power of regions is strong, and indeed the League, in opposition to the central government, controls Italy's richest region, Lombardy. An important weakness of the system is the inability of the government to respond to change, which sees Italy ranking last at $32^{\text {nd }}$ on this Indicator (GRC, i. 1) despite the inclusion of much poorer countries in our EQx2020 sample. Its mediocre ranking at $19^{\text {th }}$ in Global Health Security (GHS, iii.7) and in Covid-19 safety (COV, iii.7) is consistent with the exceptional collapse of the health system as a result of the pandemic. The dysfunctional Administrative Decentralization ( $A D E, i .1)$ in Italy is depicted by rank 22, which suggests why completely differently affected regions reacted the same way as Lombardy, resulting in several controversies.

Italy's inability to respond to change was unfortunately confirmed by the debacle experienced with the Covid-19 attack and the related economic crisis. Transformation in the transalpine country has proven elusive, making it likely that elite business models based on Value Extraction endure. Yet, a pain threshold was exceeded in 2020, so could this be the catalyst for the reform necessary to crush decades of inertia?

Prof. Guido Cozzi, University of St.Gallen

Visual 28: Italy performance overview by EQx Pillar vs overall distribution

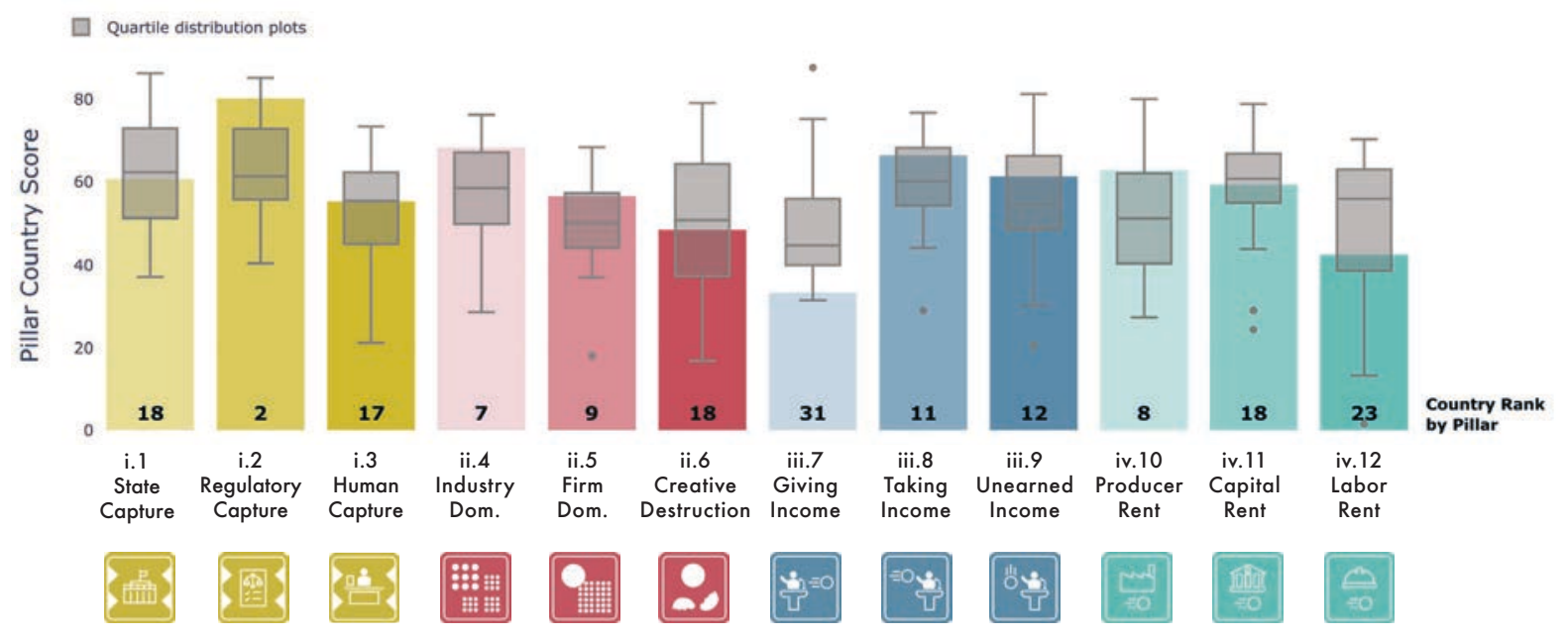




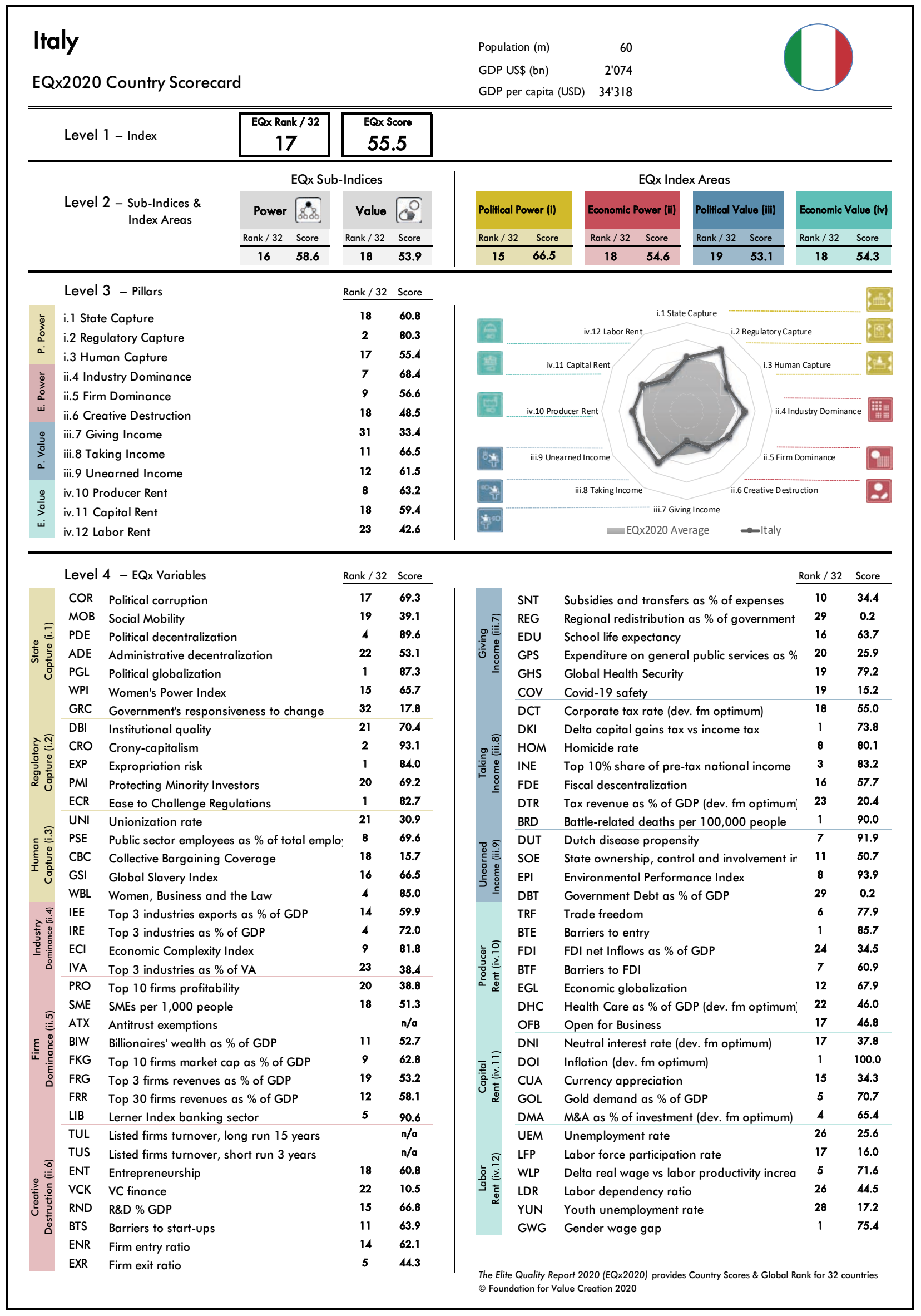




\section{Japan: Will elites finally shift gears in the Reiwa era of "beautiful harmony"?}

In May 2019, the ascension of Emperor Naruhito to the throne of Japan saw the closing of the Heisei era, meaning "achieving peace". Starting in 1989 - the same year the Nikkei reached its peak - the Heisei period turned out peaceful, maybe even excessively so at a time when the disruptions associated with the $4^{\text {th }}$ Industrial Revolution created new value elsewhere. With peace and stability being one of Japan's strengths, we aptly see it rank at the top in Indicators for external peace, measured by Battle-related deaths (BRD, iii.8), and internal peace, measured by the Homicide rate (HOM, iii.8). Overall Japan sits in $8^{\text {th }}$ place, slightly ahead of its Asian peers.

Japan's analysis requires deep contextual understanding. In some areas where Japan scores well, such as in the Firm Dominance Pillar (ii.5), there might be factors not fully captured, like interlocking shareholdings. For instance, and as mentioned in the North East Asia special regional analysis (Section 4.4), the power of Japan Inc. seems reflected in the operative part of the Abenomics program. This effectively depreciated the yen, and in turn increased the profits of Japanese companies, but not their competitiveness (as seen in export market shares). This could be construed as an indirect subsidy or a form of corporate rent seeking at the cost of the general public.

Also of note, is that Japan started massive Value Extraction at the end of the 1990's with low interest rate (and ZIRP) policies. Yet today, and in light of similar policies by central banks in advanced economies (especially by the ECB), such Value Extraction does not stand out from its developed nation peers in the Capital Rent Pillar (iv. 11 ).

The Giving Income Pillar (iii.7) seems to reflect, correctly, Japanese politicians' preference toward regional income redistribution. On the other hand, the Taking Income Pillar (iii.8) ranks Japan $2^{\text {nd }}$ in
Tax revenue as a \% of GDP (DTR, iii.8). While commendable, it points to an imbalance between government revenue and outlays. Hence, ranking 29th on Government debt as a \% of GDP (DBT, iii.9), Japan is burdened with the industrial world's largest public debt, sitting in 2019 at double its USD 5trn economy ${ }^{12}$. Value is extracted from the patient Japanese population and from future generations - an extreme view would see low fertility rates as a protest of sorts against rent seeking by elites.

Japan could grow by further opening up. A lot, for instance, would be gained by improving on Trade freedom (TRF, iv. 10), where it currently ranks $18^{\text {th }}$, and on Economic globalization (EGL, iv. 10) where it ranks $15^{\text {th}}$. Japan already showed commendable leadership with the ambitious CPTPP (Comprehensive and Progressive Agreement for Trans-Pacific Partnership) trade deal, which over the long run might compensate for lost corporate earnings hit by the trade conflict between the U.S. and China, its 2 most important export markets.

Raising productivity is a priority for Japan's elites, and the labor market is hence an important space that brings together demographics and growth. The Labor Rent Pillar (iv. 12) sees Japan performing very well including a low Unemployment rate (UEM, iv. 12). However, labor turnover is low, and upward mobility of non-regular workers is limited, meaning that the extent of subtle but persistent distortions might be underestimated. Moreover, demographic trends threaten to create serious labor shortages in the future, with the number of workers set to deplete by almost 8 million in $2030^{13}$. While Japan scores rather low on all $3 \mathrm{EQx}$ gender Indicators, if the Prime Minister's "Abenomics is womenomics" is truly implemented and Japan breaks with tradition here, the country will witness a growth and productivity boost in the coming years.

Visual 30: Japan performance overview by EQx Pillar vs overall distribution

Anonymous authors

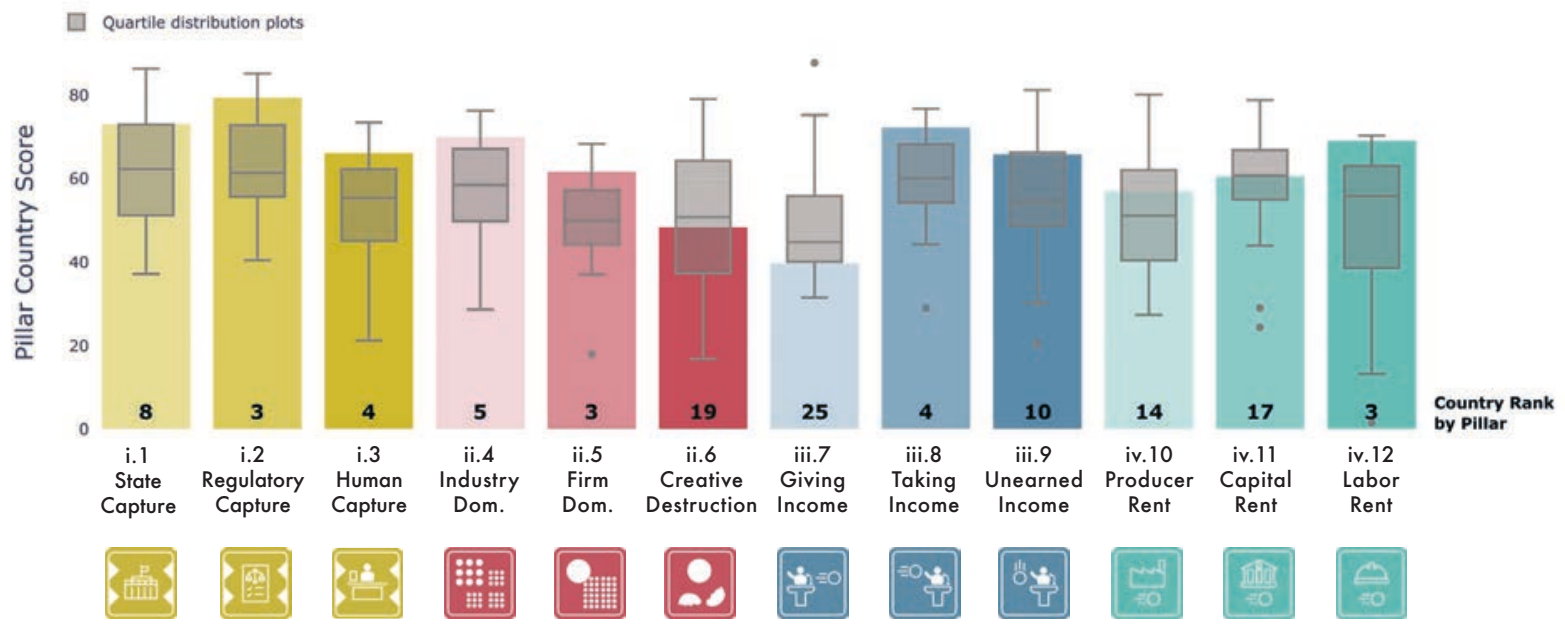




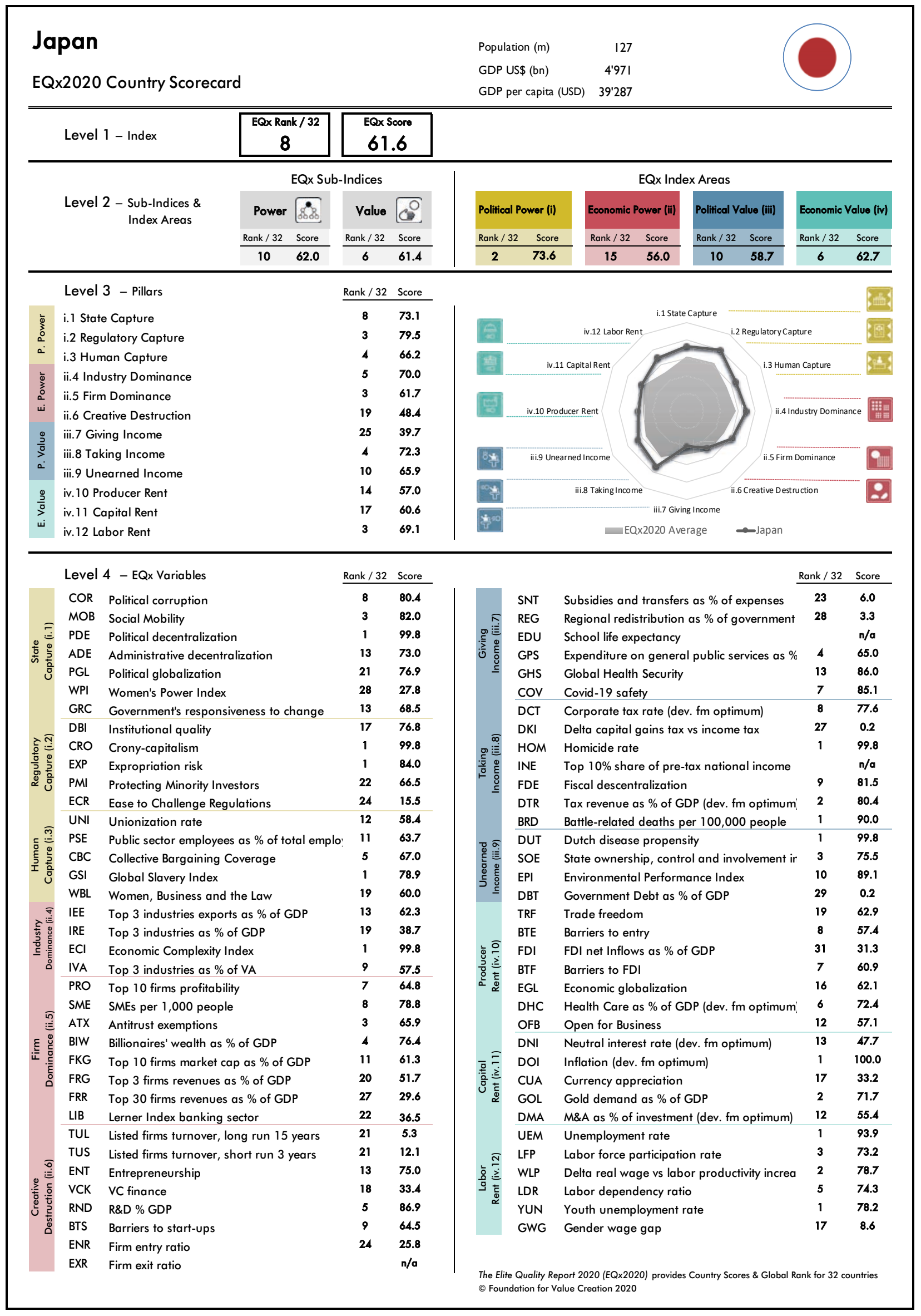




\section{Norway: Traversing peaks and valleys}

The Norwegian numbers on the 72 Indicators of the EQx are, like the country itself, a profile of peaks and valleys. A recognizable picture emerges of the Norwegian economy at present, excelling in egalitarian taxation (rank 1 in indicator Delta capital gains vs income tax (DKI, iii.8)) and labor participation (rank 5 in the Labor force participation rate (LFP, iv. 12)), and a society relatively free of violence and social unrest (rank 4 in Homicide rate (HOM, iii.8)) is depicted. Conversely, Norway scores at the bottom on FDI net Inflows as \% of GDP (FDI, iv. 10) with another low score on Dutch disease propensity (DUT, iii.9). These are unique national characteristics of the Norwegian economy and political system.

Norway's profile is partially explainable through the country's historical dependence on natural resources. Other characteristics are linked to a political governance system loosely referred to as the "Nordic Model". The mixture of characteristics poses some uncomfortable questions to the country's elites about future strategic choices.

Norway has historically been dependent on dominant industries, strongly tied to its natural resources: A once world-dominant merchant fleet was replaced in turns by a hydro-powered electrochemical industry, paper mills, petroleum and offshore technologies. This is mirrored by rank 30 in Pillar 'Firm Dominance' (ii.5). One may call this an "all-in type" of economy where the labor force is consumed by dominant industries, raising labor costs and rendering the country vulnerable to international market disruptions. A few large companies dominate and indicate the identity and characteristics of elites.

The petroleum economy sees labor costs at levels that make Norway an unlikely recipient of foreign investments, along with other signs of Dutch disease. Reflected in EQx too, is the tradi- tional skepticism against foreign acquisition of natural resources - which kept Norway out of the EU - to protect energy, fisheries and fish farming. Additionally, the world's biggest sovereign fund has made Norway a net exporter of capital, with little need for FDI, potentially preempting some of the Dutch disease's worst effects.

This situation is new, as Norway traditionally lacked private capital concentrations and economic transitions were facilitated by the country's political system. The "Nordic Model" is basically social-democratic in its outlook, consisting of a high acceptance of government regulation, publicly financed healthcare and education and a high level of co-operation between employers and labor unions. As the EQx data shows, this model comes with high-hquality institutions (rank 5 in Institutional quality (DBI, i.2)), income equality (rank 1 in Top 10\% share of pretax national income (INE, iii.9)), and high levels of work force participation (rank 5 in Labor force participation rate (LFP, iv. 12)). However, it also tends to come with an inflated public sector (rank 26 in Tax revenue as \% of GDP (DTR, iii.8)).

At present, the Nordic Model seems to be an advantage in weathering the Covid-19 pandemic. In the long run, however, ranking at the extreme ends on some indicators may indicate some political rigidity in policy choices. In a more diversified economy, Norway may need higher levels of FDI (and venture capital investment), openness to entrepreneurship and a transparent business environment. At the same time political promises to the population must be kept. While until now Norway has been able to traverse peaks and valleys, a more digitized and technology-based world poses challenges to the predominant business models of Norway.

Prof. Jan Ketil Arnulf, Prof. Janicke Rasmussen

\& Prof. Dag Morten Dalen

BI Norwegian Business School

Visual 32: Norway performance overview by EQx Pillar vs overall distribution

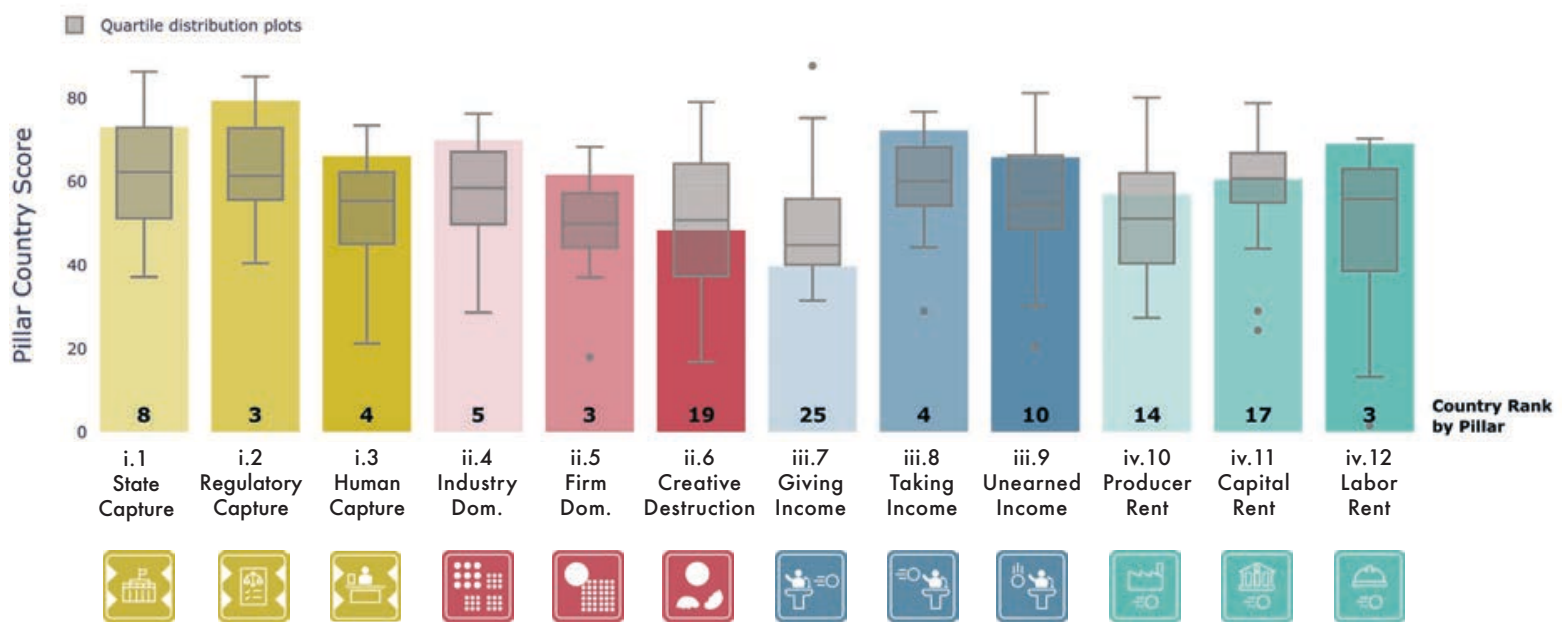




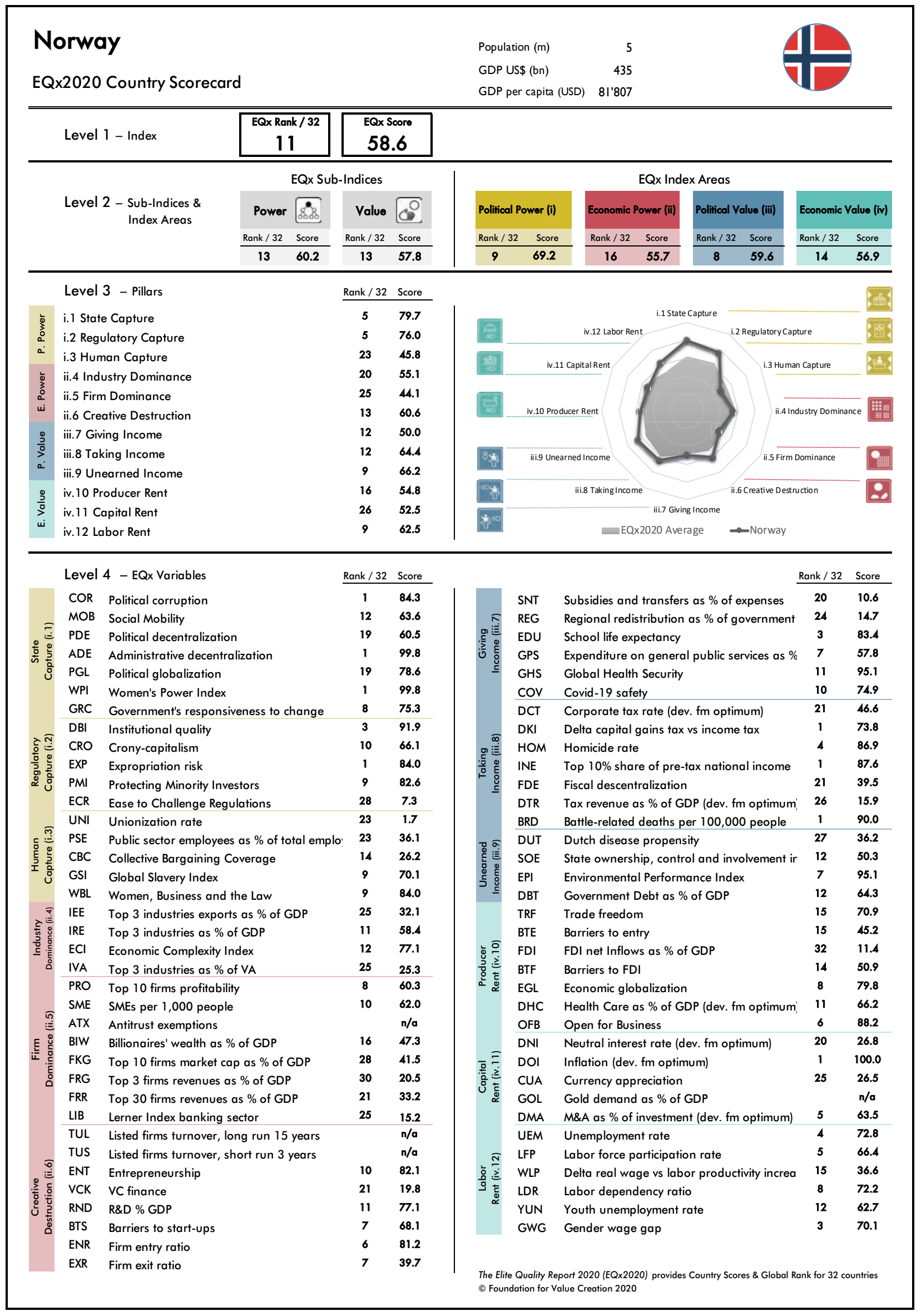




\section{Portugal: Strong Southern European perfor- mance, and plenty of work ahead}

After joining the European Community in 1986, Portugal experienced a period of real convergence with its European partners until 2000. Since then, with the single currency, its economic performance deteriorated to the point that, after the 2008-10 crisis, it had to call upon external aid to meet its commitments. Today Portugal grows below the E.U. average, it is not competitive, and it is one of the most indebted member states, heavily dependent on the external sector - tourism in particular.

Despite this economic context, Portuguese elites have a middling score (rank 14 $4^{\text {th }}$ ) in the group of the sampled countries, ranking better than others in southern Europe such as Italy (rank 1 $7^{\text {th }}$ ) or

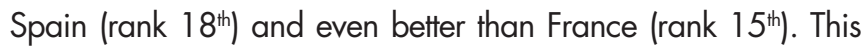
could be a catalyst for a new phase of real convergence with the E.U., already initiated before the current pandemic crisis, but which has caused a major setback in such endeavour.

However, this overall score hides great disparities in the four In$\operatorname{dex}$ Areas, revealing a better performance in terms of Value Creation by the economic elites (iv, rank 10 ${ }^{\text {th }}$ ) and worse in terms of Political Value (iii, rank $25^{\text {th}}$ ).

Emphasis should be placed on the good performance in terms of Trade freedom (TRF, iv. 10, rank 6 $6^{\text {th }}$ ), Barriers to entry (BTE, iv. 10,

rank $7^{\text {th }}$ ), foreign direct investment attraction (FDI and BTF, iv. 10, rank $7^{\text {th }}$ and $1^{\text {st }}$, respectively) and Economic globalization (EGL, iv, rank $6^{\text {th }}$ ). These results are in line with the fact that Portugal is a small economy open to the exterior, that promoted a series of privatizations (SOE, iii.9, rank $9^{\text {th }}$ ) and a "golden visa" programme as a form of external financing. The country has also been able to attract several technological investments due to the competitive value of its qualified labour.
Despite the good performance in terms of Economic Value, there are still great opportunities for improvement such as unemployment (EMU, iv. 12, rank 22 $\left.{ }^{\text {nd }}\right)$, and in particular Youth unemployment (YUN, iv. 12, rank 20 ${ }^{\text {th}}$ ), and the health care services (DHC, iv. 10, rank $20^{\text {th}}$ ). The covid-19 pandemic crisis has made the need to correct the weaknesses of the health system all the more evident.

The worse performance in terms of Political Value stems from significant regional disparities (REG, iii.7, rank $25^{\text {th}}$ ), the low quality of public services (GPS, iii.7, rank 19th), the huge corporate tax burden (DCT, iii.7, rank $\left.25^{\mathrm{t}}\right)$, all which contribute to the weak competitiveness of the Portuguese economy and low level of investment along with the high and extractive general tax burden (DTR, iii.7, rank $21^{\text {st) }}$. In this respect, the mediocre nature of public expenditure (DBT, iii.9, rank 29th), which represents a strong extraction of value from future taxpayers' generations, should also be highlighted.

As for political and the economic power, Portugal outperforms the average of surveyed countries. Small countries are often at risk to be at the mercy of powerful elites, yet Portugal boasts high competition due to the good firm entry and exit dynamics in several markets. In this context, the number of large companies is small, contributing to a low concentration of the economic power.

The results at the level of Political Power derive mainly from E.U. membership (Political globalization (PGL, i. 1), rank $8^{\text {th }}$ ) and from the effective institutional arrangements of municipalism, regional coordination commissions and its autonomous regions (Political decentralization (PDE, i. 1), rank $8^{\text {th }}$ ). Additionally, the imposition of quotas for gender diversity in public offices, in the state-owned business sector and in public companies contributes to the good performance in this area (WBL, i.3, rank $\left.4^{\text {th }}\right)$.

Prof. Cláudia Ribeiro \& Prof. Óscar Afonso School of Economics and Management,

Visual 34: Portugal performance overview by EQx Pillar vs overall distribution

University of Porto

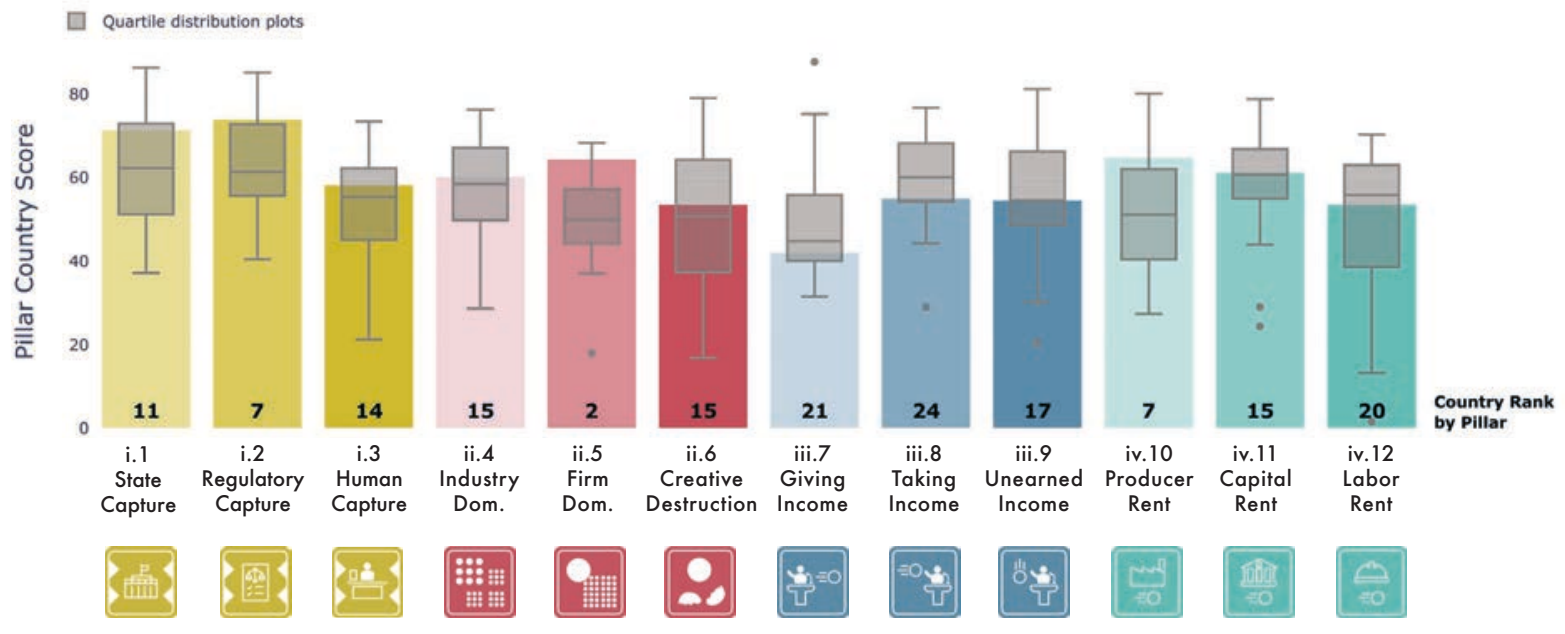




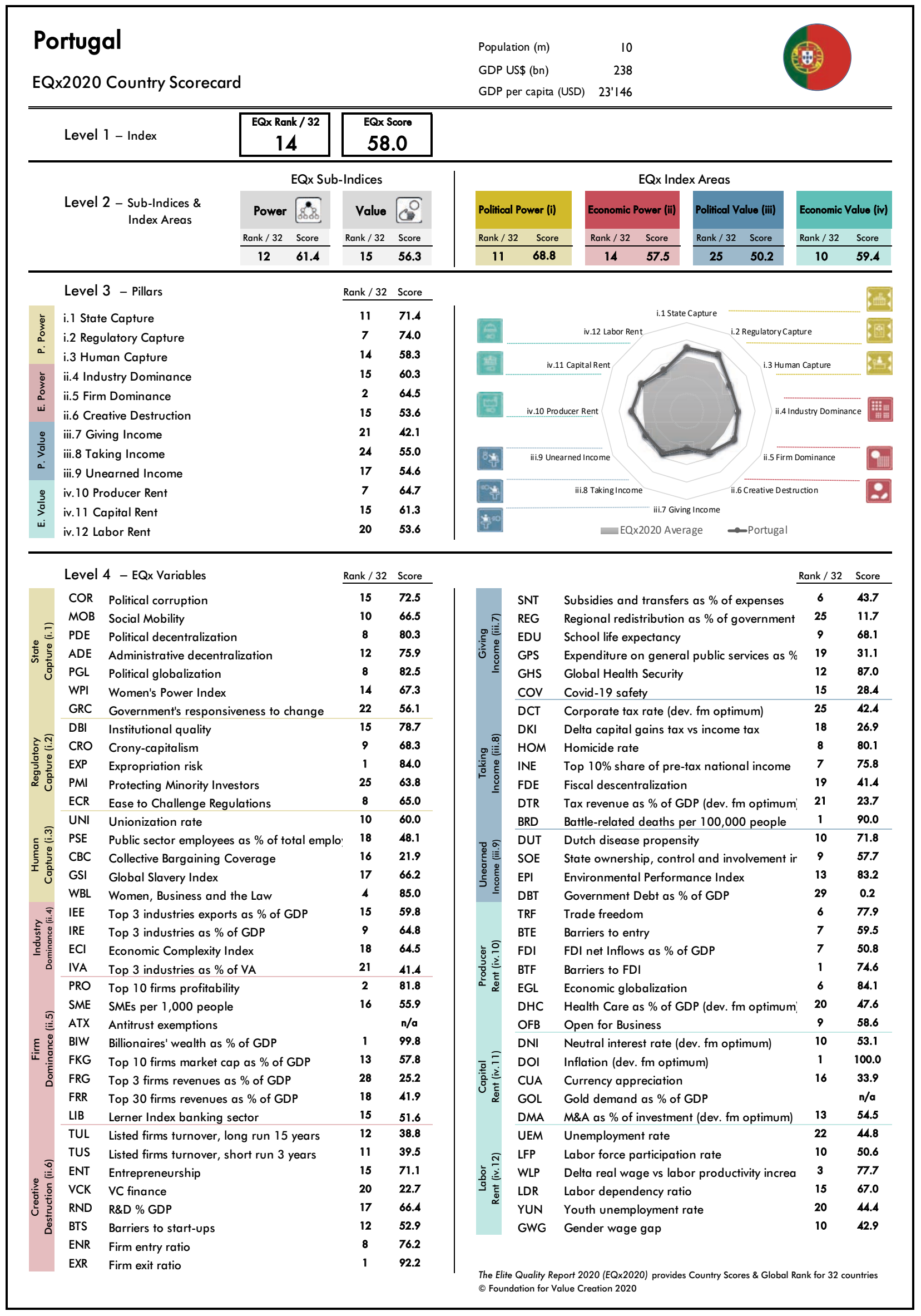




\section{Russia: To unleash true potential}

For over 70 years, the Soviet Union was a non-market economy. Over the 30 years of Russia's new history, the country has made significant progress on many fronts, including the legalization of private property, large-scale privatization, restructuring of the main natural monopolies, liberalization of capital controls, the emergence and strengthening of antitrust policy, and almost complete repayment of public debt. However, since the mid 2000s the role of the state in the economy and the share of government-controlled firms has increased, and is now reaching problematic levels. Issues with the protection of property rights and rule of law persist and manifest themselves in the lack of judicial independence, lack of equality before the law, and unfair competition practices, ultimately leading to the exploitation of non-elites. These themes see the overall score for Russia below the sample mean in rank 23. It is higher than other BRICS countries, except China (rank 12 $12^{\text {th}}$, and it ranks lower than the only other post-soviet country in the ranking - Kazakhstan (ranked 19't).

Russia exhibits significant variation across different dimensions. On 11 out of 72 Indicators Russia's rank is in the top 10 of countries in the sample, but on 38 of Indicators it is in the bottom half of the list and on 16 Indicators it is in the bottom fifth of the countries. It scores higher on economic dimensions (rank $21^{\text {st }}$ for Economic Power, and $23^{\text {rd }}$ for Economic Value) than on political dimensions (rank $27^{\text {th }}$ for both Political Power and Political Value).

The highest scores come from dimensions that reflect sound macroeconomic policies, such as Inflation (DOI, iv. 11 , rank $1^{\text {st }}$ ) and Government Debt as \% of GDP (DBT, iii.9, rank $2^{\text {nd }}$ ), as well as some aspects of tax policies (Delta capital gains tax vs income tax, DKl, iii.8, rank 1 ${ }^{\text {st }}$ ) and a competitive banking sector (Lerner Index banking sector, LIB, ii.5, rank 1 ${ }^{\text {st }}$. Low public debt is especially important, as it reflects restraint of elites in rent seeking by placing an unfair financial burden on future generations. Higher than average scores in the category of Institutional Quality (DBI, i.2, ranked $12^{\text {th }}$ ) reflect progress on the measure included in World Bank's Doing Business rating, where Russia has jumped from the 130-140 division to the 30-40 division in 7 years.

The lowest scores come from Indicators reflecting Regulatory Capture (i.2). Persistent problems with the protection of property rights in Russia are reflected in Protecting minority investors (PMI, i.2, ranked 29th) and Expropriation risk (EXP, i.2, ranked $28^{\text {th }}$ ). Low ranking in terms of Crony-capitalism (CRO, i.2, ranked $29^{\text {th }}$ ) reflects the fact that a large share of Russian billionaires come from industries that are prone to monopolization, or rely on close connections with the government. Relatedly, problems with firm dominance (ii.5) caused by high concentration of wealth are reflected in low ranking for such measures as Billionaires' wealth as \% of GDP (BIW, ii.5, ranked $29^{\text {th }}$ ) and Top 3 firms revenues as \% of GDP (FRG, ii.5, ranked 29th). The Dutch disease propensity (DUT, iii.9, ranked $30^{\text {th }}$ ) and political corruption are also widely known problems. Less attention is usually paid to problems with gender inequality reflected in low scores for Women's Power Index (WPI, i. 1, ranked 29th) that reflects the share of women in top echelons of power.

One of the main problems in Russia, that is both a cause and a consequence of limited Elite Quality, is pervasive lack of trust: the government does not trust citizens and businesses; citizens and businesses do not trust each other and together they do not trust the state. This increases the costs of doing business, pushes private business into the arms of the state as a means of protection and as a means of rent extraction, reduces the effectiveness of institutions, replacing them with personalistic rule, and ultimately squeezes capital and brains out of the country. Unleashing the true potential of Russia will not be possible without addressing this widespread issue.

Prof. Ruben Enikolopov \& Andrei Sharonov, Respectively Rector New Economic School \& President SKOLKOVO Moscow School of Management

Visual 36: Russian Federation performance overview by EQx Pillar vs overall distribution

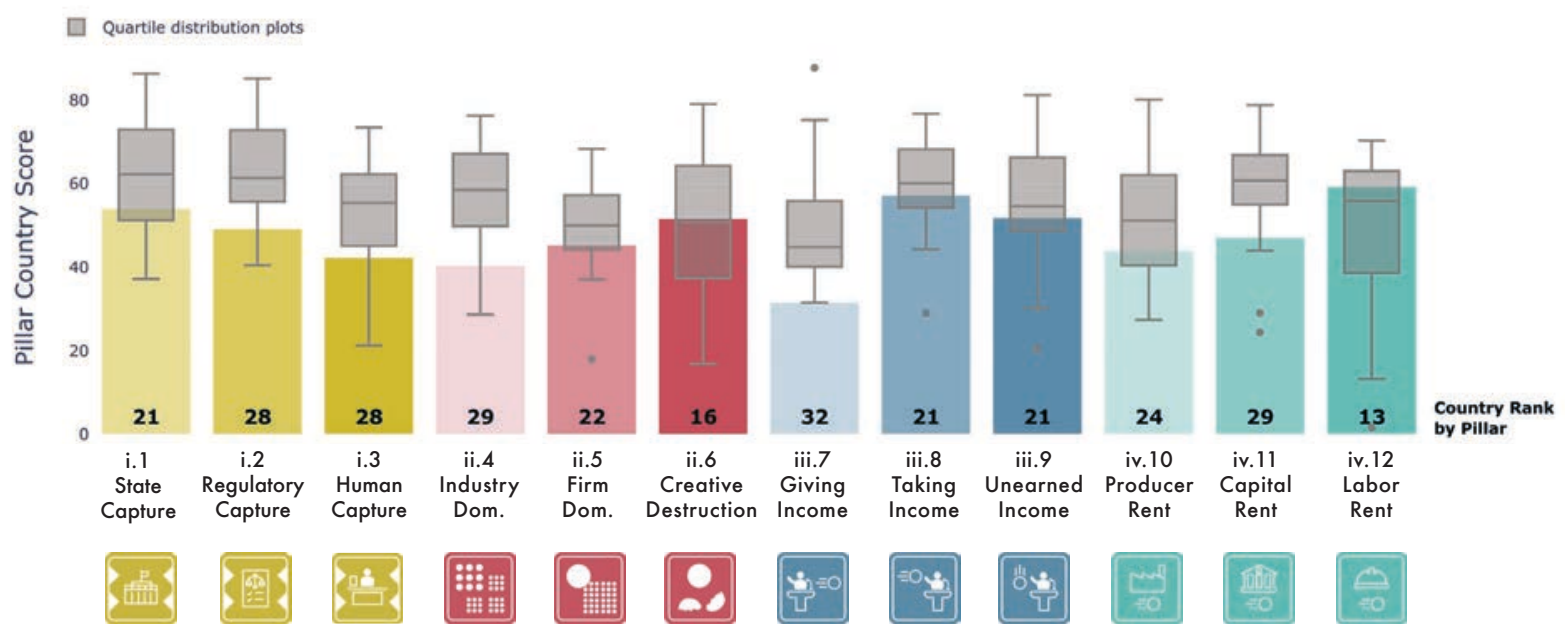




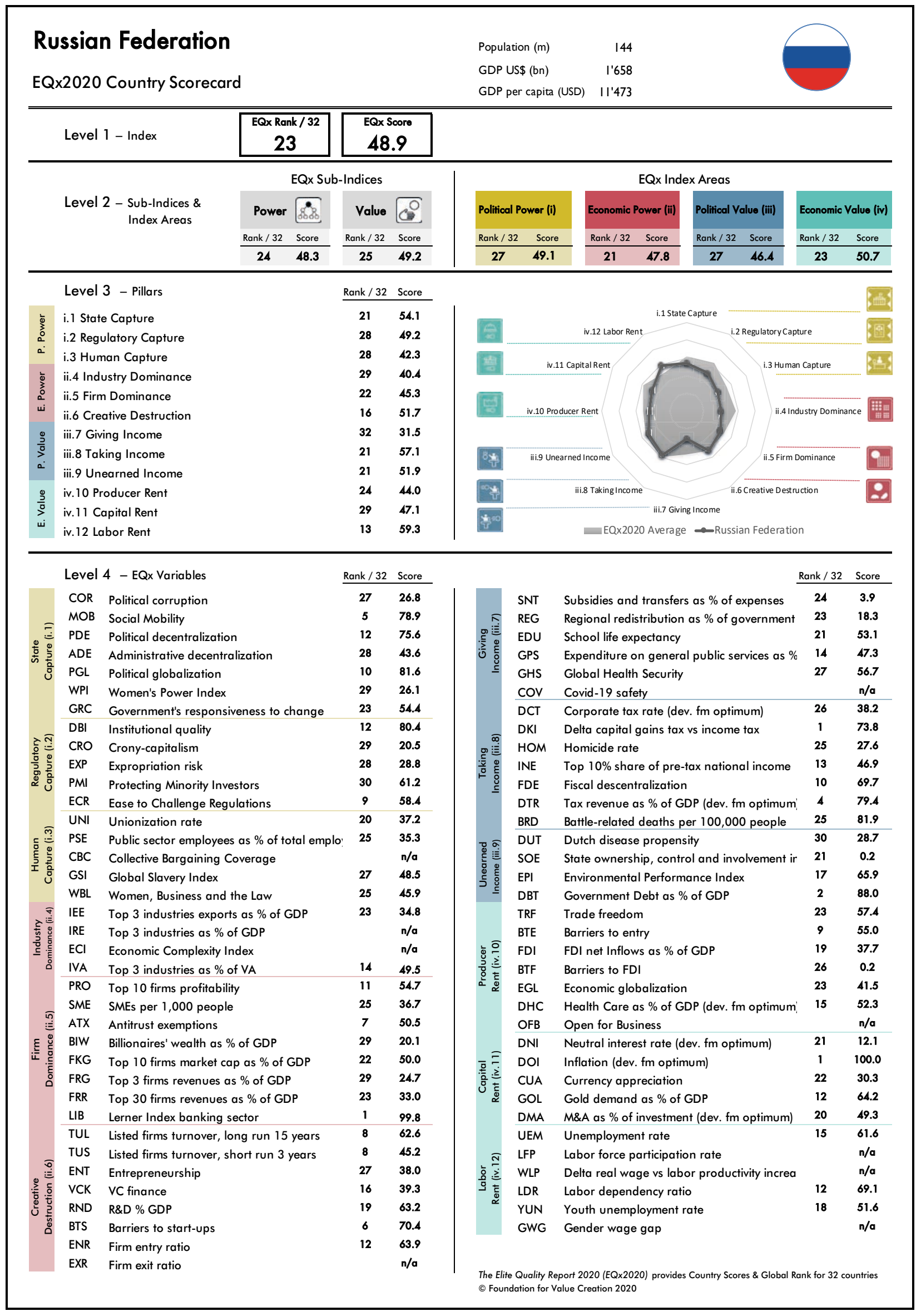




\section{Turkey: Rentier models bereft of power, or reactivating convergence with Europe?}

Turkish elites have a long history of domestic power struggles, especially after the long-dominating "White Turks" military elite was challenged and then replaced by the popular Erdogan-led A.K.P. in the early 2000s. The political elites' tussle for power wrecked their E.U. entry hopes about a decade ago, leaving Erdogan to impose a despotic regime and to resort to the help of the Gülen's minoritarian religious elite, which then turned inimical in the failed coup of 2016 and ensuing repression. A part of the business elite maintained their privileges and rents associated with traditional models. Yet these are not secure and can be taken away from them at any time, which is consistent with the high Expropriation risk (EXP, i.2) Indicator. In the State of Elites framework, we see them in the area where 'striving' elites meet 'rentier' elites (Visual 16).

Business elites will, however, not be challenged by new innovative and emerging players with more efficient business models. The Creative Destruction Pillar (ii.6) is at rank 26 very low. SMEs are not encouraged (SME, ii.5, rank 27) despite Turkey's resilient entrepreneurial traditions.

The state itself might distract business elites away from market-oriented productive activities, as it is a source of rents.

The State Capture Pillar (i.1) is problematic (rank 25), plagued by vast corruption (COR, i. 1, rank 25), low administrative decentralization (ADE, i. 1, rank 25), and minimal women power (WPI, i. 1, rank 25), which deprives the economy of important resources.

High unemployment (UEM, iv. 12, rank 27) co-exists with the lowest collective bargaining coverage rate and the sec- ond-lowest labour unionization rate in our sample. The labour market is among the most severely affected by slavery (GSI, i.3, rank 30) and by labour dependency (LDR, iv. 12, rank 28). Moreover, wars are terrifying human capital Value Extraction models and our proxy for external peace, Battle-related deaths (BRD, iii.8), shows Turkey among the worst performers in the sample (rank 29). Overall Turkey comes in at a very commendable $5^{\text {th }}$ in the Human Capture Pillar (i.3), and while the Health Care as \% of GDP (DHC, iv. 10) is low, fortunately it fares far better in Covid-19 safety (COV, iii.7, rank 12).

The Capital Rent Pillar (iv. 1 1) is another story where Turkey scores $2^{\text {nd }}$ to last, dragged down by the massive lira depreciation and debt crisis of 2018, which weakened the popular support for the new A.F.K. elite. This could generate further instability, or hopefully more pluralism.

The Chinese development model might have been attractive to Turkey, visible in rapid modernization projects like the double-deck Eurasia Tunnel. But the transplant has only been partial and left out some of the Value Creation aspects of East Asian state capitalism. Looking forward, should growth continue to rely on projects like the Kanal Istanbul connecting the Black Sea to the Marmara Sea with its environmental risks?

Turkey's potential should not be underestimated: The country could try to capitalize on its education (EDU, iii.7, rank 4) to build up a better educated, more innovative and inclusive elite, able to get closer to the European trade partners and hopefully reactivate a convergence process.

Prof. Guido Cozzi, University of St.Gallen

Visual 38: Turkey performance overview by EQx Pillar vs overall distribution

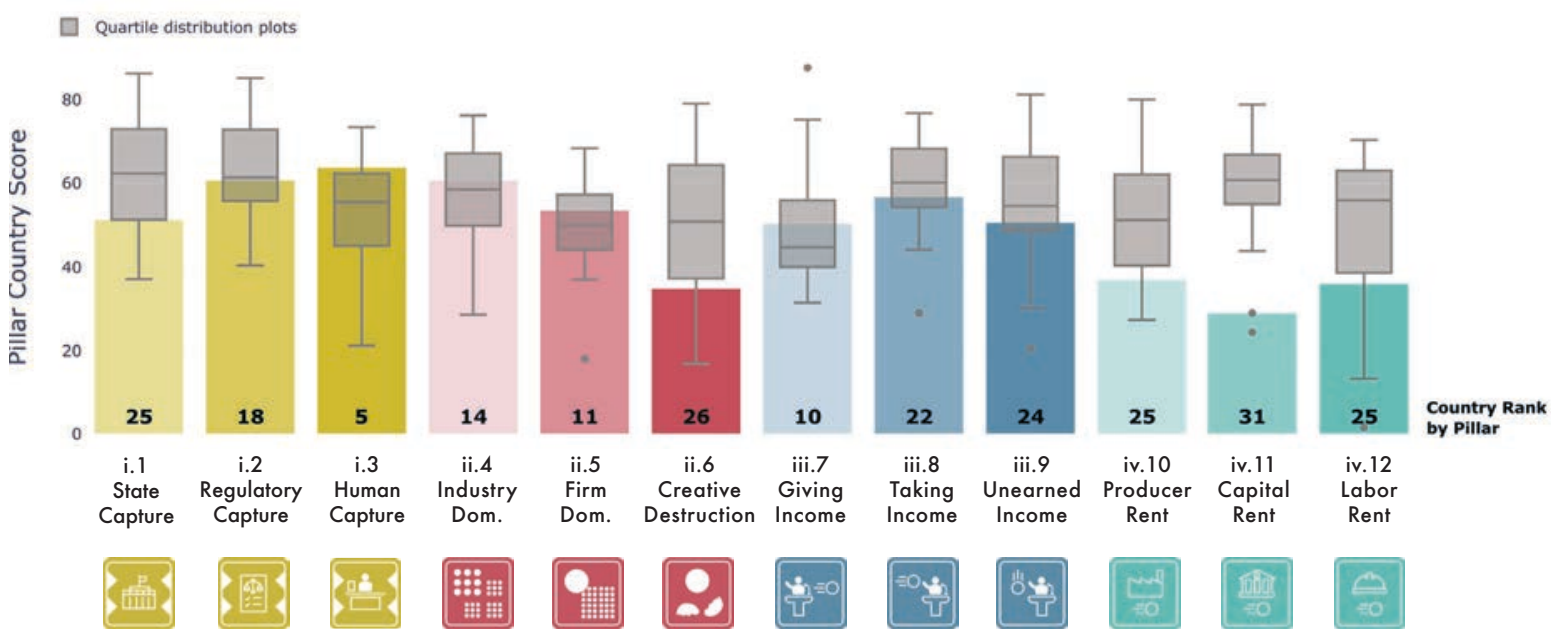




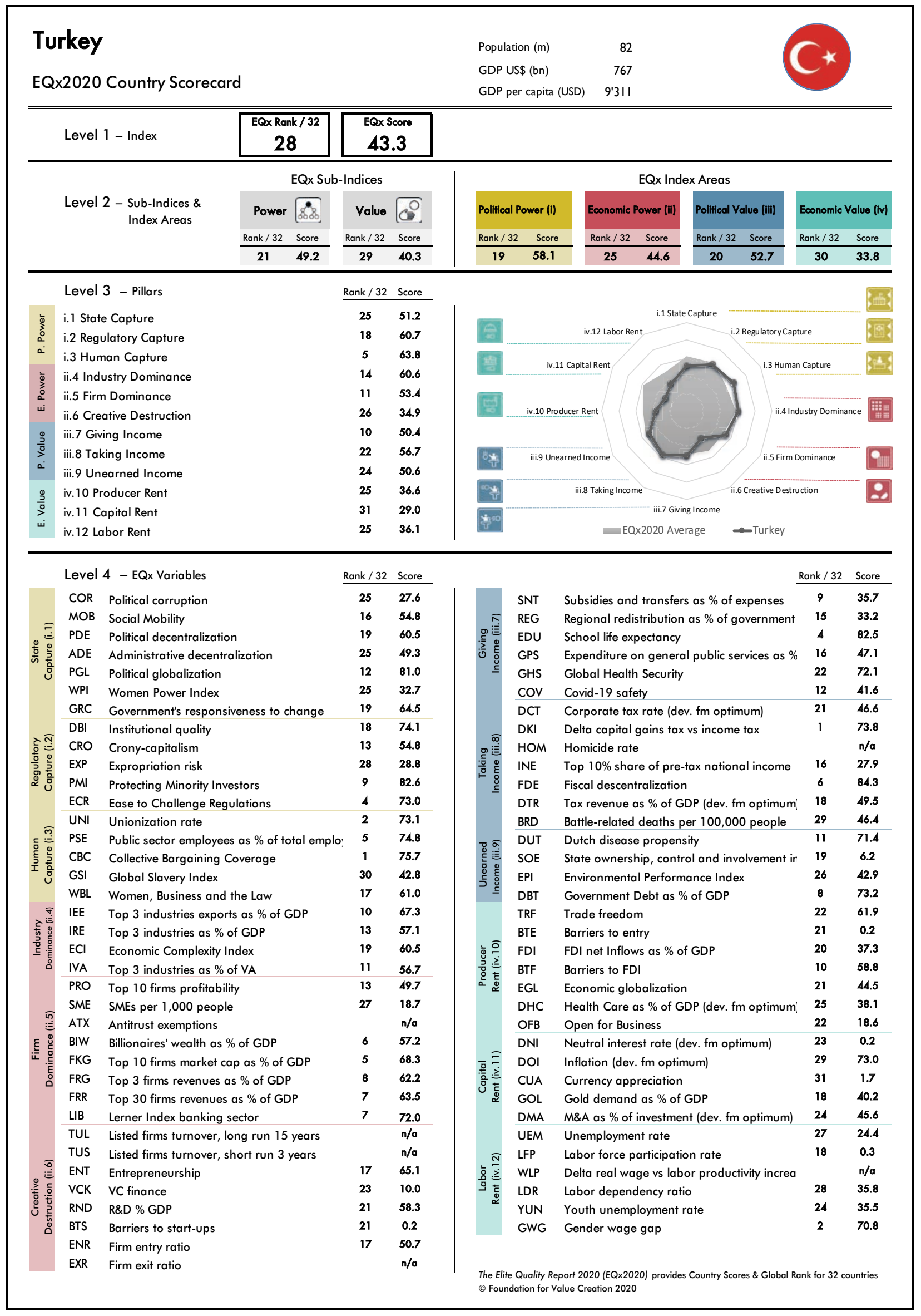


United States: Low elite power for a great future, and surprisingly high Value Extraction

U.S. elites are value creators second to none: consider GAFA, Wall Street or the energy industry, innovative powers and competitiveness have made them global leaders. Many across the world are watching the rising capabilities of Chinese elites with anticipation and trepidation, with Value Creation similar to their American counterparts in key areas like artificial intelligence, e-commerce or new materials. However, looking forward, the U.S. seems to have a decisive advantage over all other countries in the Index: it ranks $1^{\text {st }}$ in the Power Sub-Index, an indication of future Value Creation potential.

At the same time, it seems paradoxical that U.S. elites place only $8^{\text {th }}$ in the second Sub-Index: Value. This is certainly a high score, but not the level of excellence found with the Power Sub-Index. One might wonder how American elites manage, despite having so little power (compared to elites in other political economies), to succeed at rent seeking?

Perhaps an indication of how value is extracted - certainly not yet reflected in the $5^{\text {th }}$ rank seen in Trade freedom (TRF, iv. 10) - is President Trump's trade war not only against China, but at one time even against European and North American allies. Steel or Aluminum tariffs are a license to engage in Value Extraction activities - from other Americans no less! U.S. citizens are now forced to pay higher input prices when manufacturing cars or beer kegs (or when consuming these). Maybe the discontent reflected in the election of President Trump, the subsequent scandals, and the George Floyd protests and riots, all relate to the U.S. $13^{\text {th }}$ place for Political corruption (COR, i. 1$)$, or to the appalling $28^{\text {th }}$ rank in Government debt as \% of GDP (DBT, iii.9), which make social relief and spending on health care highly unlikely.
At a domestic level, the American people seem increasingly concerned about inequality. While the index places the U.S. $24^{\text {th }}$ for Billionaire's wealth as \% of GDP (BIW, ii.5), itself a measure of dominance and not of Value Extraction, it could still serve as proof of the worrisome rising narrative of the death of the American dream ${ }^{14}$. Alarming in this regard is for example the U.S.'s $21^{\text {st }}$ place in Social mobility (MOB, i. 1), meaning that many value creators don't have the opportunity to realize their potential.

EQx scores suggest that the United States is in an unparalleled position to succeed if elites have the will to stop cold rent seeking tendencies. The $1^{\text {st }}$ place ranking in the Creative Destruction Pillar (ii.6), and in the Entrepreneurship (ENT, ii.6) Indicator is evidence that America is loaded with wealth creation potential. Although 2019 was characterized as a year that "unicorns stumbled"15, with some of Silicon Valley's most famous creations such as Uber and Lyft disappointing upon IPO, the tech hub remains the envy of countries worldwide. It is there where Value Creation, if encouraged appropriately and inclusively, can further boost the U.S. EQx ranking.

In conclusion, any problems the U.S. has are fixable. The top Power Sub-Index rank means that the U.S. is a self-correcting system. If elites would only unleash the full potential of America's institutional strengths for the sake of creating new value, while stopping pork and other Value Extraction rackets, the U.S. could easily climb atop the world's Elite Quality ranking, while the inclusive American Dream of opportunity for all might be realized.

Prof. Tomas Casas \& Diana van der Watt University of St.Gallen

Visual 40: United States performance overview by EQx Pillar vs overall distribution

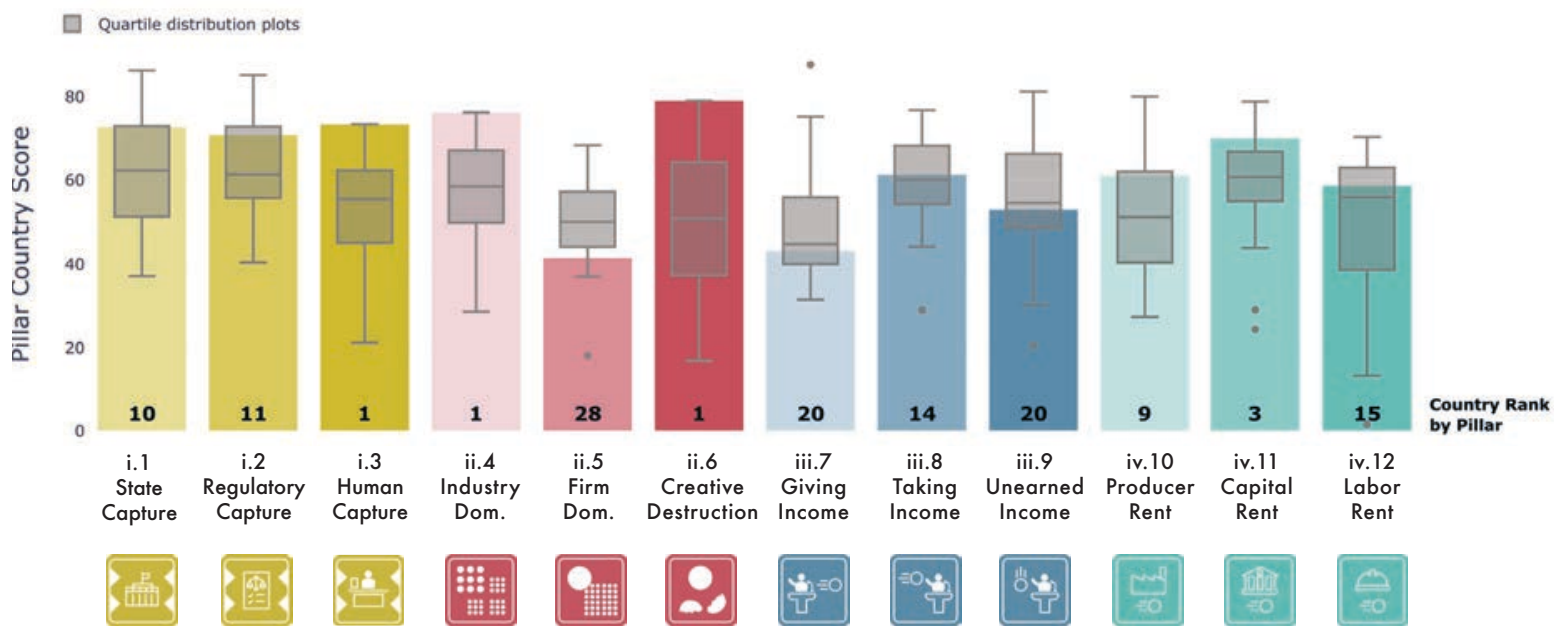




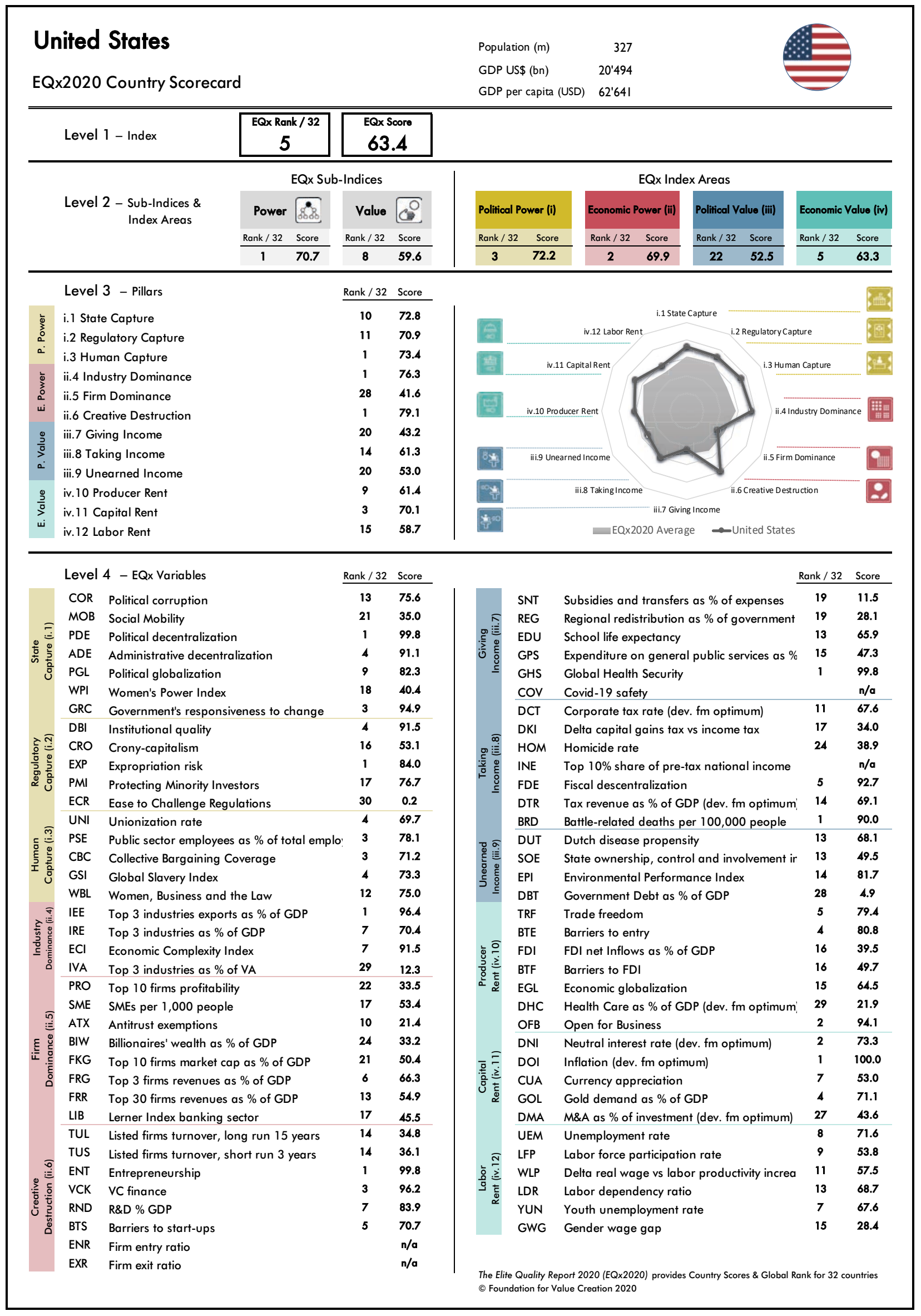




\subsection{Extreme Country Performances by Pillar}

\section{The leaders}

Visual 42 displays the podium results of each Pillar, drawing our attention to the countries which might provide inspiration for others in terms of Pillar specific value creating business models.

The performance of Singapore is exceptional, ranking $1^{\text {st }}$ place overall and featuring no less than 6 times in Visual 42. Singaporean elites dominate the Economic Value Index Area, the only country to come on top on all 3 Pillars which comprise this Index Area. The country is notably missing from the Political Power Pillars, despite having leading scores in Indicators including Institutional quality (DBI, i.2) and Government's responsiveness to change (GRC, i. 1).

The variation in scores between the top 3 scoring countries by Pillar is consistently small. For instance, the Creative Destruction (ii.6) Pillar shows a closely fought race run by the United States, Great Britain and Singapore. However, there are 2 clear exceptions illustrated by the graph. In the Producer Rent Pillar (iv. 10), Singapore outperforms the rest with outstanding Value Creation by producers and suppliers in goods and services markets. Saudi Arabia has a trailblazing score for Giving Income (iii.7), yet this has to be put into perspective due to missing data.
3 notable performances which deserve special attention are the successes in Capital Rent (iv. 11) by Botswana, Human Capture (i.3) by Mexico, and Firm Dominance (ii.5) by Argentina, despite the overall rankings in the aggregate Index. Whilst Botswana's score might be affected by a lack of availability of data, Argentina dominates the Indicators that measures market capitalization and revenues as percentages of GDP, indicating a lower potential for rent seeking by large firms. Mexico's high scores for Collective Bargaining Coverage (CBC, i.3) and Unionization rate (UNI, i.3) will perhaps be short lived, given the introduction of a law allowing workers to form independent labor unions.

Success within a Pillar is not restricted to a certain type of country. Taking a deep dive into Industry Dominance (ii.4), for example, we see that the U.S. leads in Top 3 industries exports as \% of GDP (IEE, ii.4), and the United Kingdom gets its boost from Top 3 industries as \% of GDP (IRE, ii.4), despite the heavy weight of financial services. Egypt, by contrast, scores well in Top 3 industries as \% of VA (IVA, ii.4), in which the U.S. and U.K. score $29^{\text {th }}$ and $31^{\text {st }}$ respectively.

Visual 42: Highest performing countries (3) by Pillar

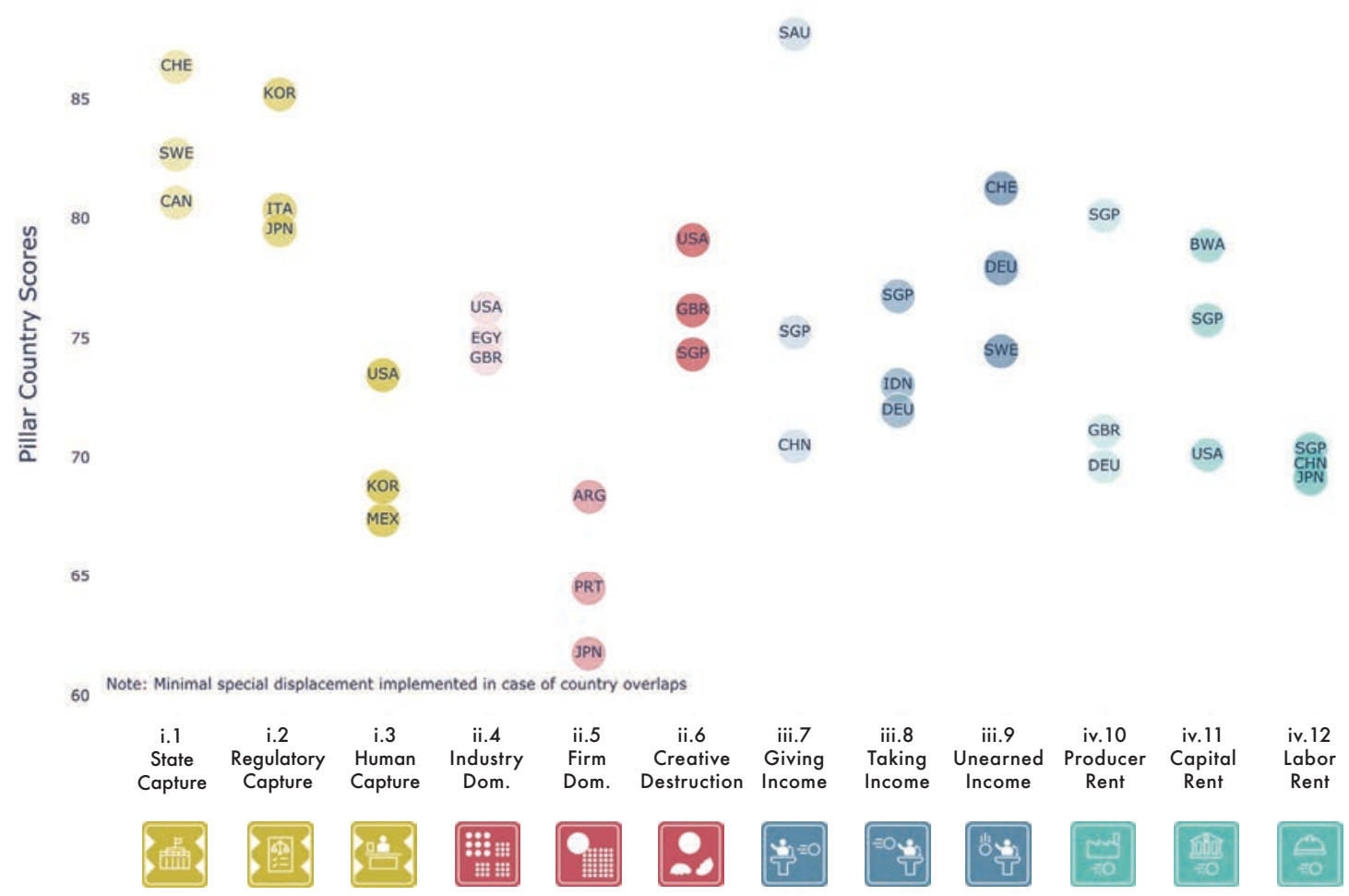




\section{Highest improvement potential}

The raison d'être of this index is to identify areas in which the business models of country elites could be improved to create more value. In Visual 43, the countries with the greatest potential for such progress are shown by Pillar, providing a number of enriching insights. For instance, in some areas, such as Producer Rent (iv. 10), Pakistan, India and China, while all sharing borders, have arrived at their low scores though very different political economy routes. Here, especially further to anticipated opening up and liberalization, China and even India, could see its overall scores improve markedly in the coming years.

The purpose of this specific graph is to trigger elites to transform existing business models towards increased Value Creation - they and their countries are poised to benefit the most from such changes. Indeed, a number of overall highly scoring countries are identified here as having great room for improvement. Even Singapore, which ranks first for its stellar performance in the Index, finds itself lagging in Firm Dominance (ii.5). Great Britain, one of the top countries in the overall EQx, also finds itself in the bottom 3 for Taking Income (iii.8), mostly due to its tax policies.

Visual 43: Lowest performing countries (3) by Pillar
This chart is particularly revealing in terms of political leadership for Pakistan and South Africa, as the countries feature in the bottom 3 of all Pillars making up the Sub-Indices Political Power (i) and Political Value (iii) respectively. Pakistan might have a relatively easier job, since its main challenge is to address potential future Value Extraction, meaning elites can pre-emptively tackle and amend the rules that allow the capture of the state, of business regulation, and of jobs. By contrast, South Africa is already in the midst of political Value Extraction, with urgent reforms needed at the government level itself to redress the vast rents associated with Giving Income (iii.7), Taking Income (iii.8) and Unearned Income (iii.9).

A particularly interesting point exemplified by this display of the Giving Income Pillar (iii.7), is that countries may score similarly poorly but for different underlying reasons. Whilst Italy's score is decreased by its high Regional redistribution as \% of government budget (REG, iii.7), South Africa trails in School life expectancy (EDU, iii.7), and Russia's performance is skewed by a low Global Health Security (GHS, iii.7) score. In short, concrete policy implications must be sought at the Indicator level.

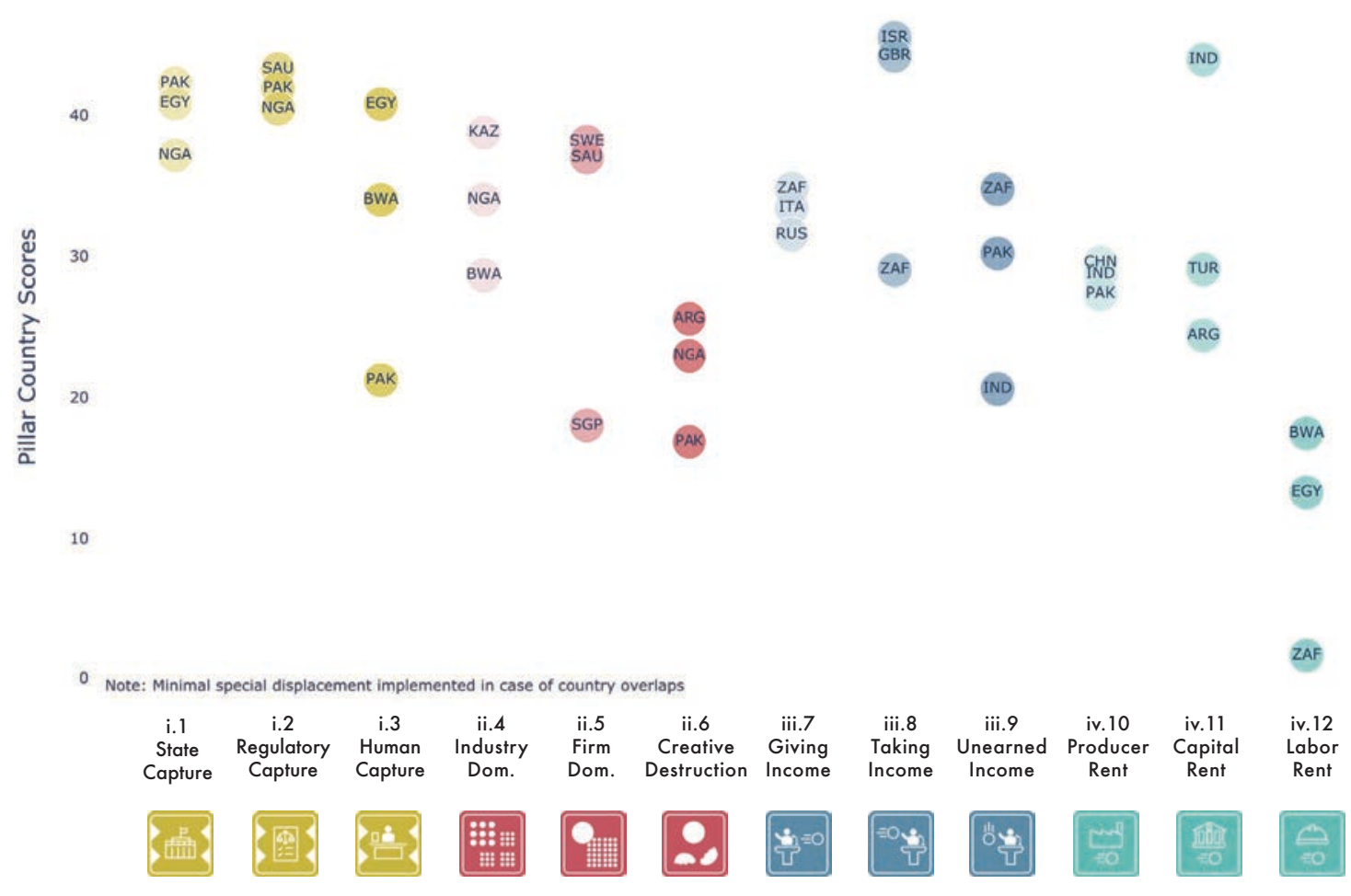




\section{The Elite Quality narrative linking the economies of China, Japan and Korea}

One of the most fruifful ways to use the EQx Index is through cross-country comparison. Cross-country analysis is particularly informative in cases such as China, Japan and Korea, which could be said to capture the same economic model at different stages of development, alluding to a time series analysis.

The Index shows China at a historic turning point, as leaders of the country well know. It highlights how China has benefitted from inefficiencies and rent extraction during its fast growth period, ranking $12^{\text {th }}$, with a similarly middling performance on both Sub-Indices, at $19^{\text {th }}$ on Power, and $10^{\text {th }}$ on Valve. The precedents set by its North-East Asian neighbors show that these scores will have to improve as China's growth slows, and suggests that delayed reform comes at a cost.

Korea, which still enjoys relatively fast GDP growth, ranks at 9th overall, but recent elections have shown dissatisfaction with the system, with "economic democratization" even becoming a campaign slogan. In contrast, Japan has had to reform to curb both power and rent seeking as its economy slowed, meaning that the growth in the size of the pie was no longer big enough to allow for such wealth extraction. All the same, curbing rents and power has not been enough to prevent GDP growth slowdown, and Japan lags many developed economies in our sample, in $10^{\text {th }}$ place for Power and $6^{\text {th }}$ for Value. Together, this all suggests small differences in power and rent can create a significant drag on activity.

Korea's performance suggests that China could get away with allowing rent extraction to linger on, even as its economy slows. Chinese growth could easily fall below $5 \%$ on a structural basis in the next few years. While this is low by historical standards, the Korean precedent suggests that the size of the pie would still be growing rapidly enough for elites to continue carving an outsized share for themselves, while the rest of the country can be bought off with the remainder. Japan's performance, however, suggests that this would be a perilous path; there seems to be a limit to Value Extraction capacity, as the growth in the pie slows. However, leaving it too late to curb power and rent could stunt long-term growth.
Can the shiffing of political power to business be stopped in the transition process?

President Xi Jinping's anti-corruption drive suggests that the Chinese authorities are somewhat aware of the task at hand. But the recent increase in Party power, and deviation from previous Party convention on term limits, could be storing up trouble for the future. Political Power is already the biggest drag on China's overall performance, with a rank of $24^{\text {th }}$ out of the 32 surveyed countries. That power could turn out to be damaging as growth slows, tempting politicians to seek to carve out a bigger share of the pie, where previous data suggests that officials have refrained from using the full extent of their power to maximize rents.

The ranking for Korea and Japan on Political Power is of much higher quality, at $1^{\text {st }}$ and $2^{\text {nd }}$ places respectively. We are unconvinced, however, that power hasn't simply transferred from politicians to business leaders through a privatization process, with industrial organization little changed. Our Index suggests this is a problem in Korea, with a middling performance on Economic Power, and with the Economic Value performance dragged down by a number of key Indicators across Pillars. High Industry Dominance (ii.4), coming in $28^{\text {th }}$ of the 32 surveyed countries, also demonstrates this point, reflecting the power of the export sector lobby. Japan performs better in this sense but falls down on the Indicator Top 3 industries as \% of GDP (IRE, ii.4). Our index also unveils the concentration of industry revenues in the Firm Dominance (ii.5) Pillar, with Japan and Korea ranking highly in these Indicators. On the face of it, Korea's number 1 ranking on SMEs per 1,000 people (SME, ii.5) within this Pillar should be lauded, but we fear that the large number of SMEs merely reflects the dual nature of the labor market; in black and white, those that cannot obtain employment in the mega firms then turn to starting their own small businesses. These small businesses, however, are not the drivers of innovation, but often micro businesses, run by older age people, in the low productivity catering sector, and are a driver of high "household" debts in Korea. This should serve as a warning to China to strengthen efforts to avoid a dual labor market. 
China receives an encouraging above average rank on Industry Dominance (ii.4), though the relatively poor performance from Korea should alert the authorities to the potential for slippage here. The Creative Destruction (ii.6) Pillar will be of paramount importance to maintaining sufficient GDP growth as the old growth model recedes to make way for the new. If the elites, whom currently hold power, cling onto it, or don't manage to transfer their resources, then the remnants of the old model will stifle the full establishment of the new. China's performance is above average here.

\section{Facing down the demographic cliff?}

Japan's experience is also informative as far as demographics go, with China facing the challenge of rapid reform to cater for the ballooning ranks of the old age population as the working age population dwindles. Japan ranks $25^{\text {th }}$ on the Giving Income (iii.7) Pillar, its lowest quality performance, thanks to high Subsidies and transfers as \% of GDP (NT, iii.7) and Regional redistribution as \% of government budget (REG, iii.7), probably thanks in part to its aged rural population. Like Japan, the older population in China is well represented in rural areas, with the need for reform even more pressing due to the land ownership system. In China, the older farmers don't technically own the land which they work, potentially depriving them of an exit into retirement. Left untackled, these factors could exacerbate the already grave challenge of organizing fiscal transfers in a massive country, with many provinces tied to the oldguard model at risk of being left behind.

\section{Where is China headed on openness?}

China's worst performance is in the Producer Rent (iv. 10) Pillar, ranking $30^{\text {th }}$ due to the relatively high tariff barriers, other barriers to entry, and a relatively closed capital account. The authorities in the last few years have made the critical realization that tariffs on imports are generally bad for consumers and hinder the transition to private consumption-led growth. The trade war with the U.S. may have slowed down the process of reducing tariff barriers, as China retaliated against measures taken by the Trump administration. We expect to see progress on this front, as well as on capital inflows, in the near future, though another flare up of tensions and a tit-for-tat escalation is a real threat.

Admittedly, China and the U.S. have secured a Phase One trade deal, but much of this was focused on the low-hanging fruit. China's purchase commitments seem likely to do damage to the international trading system, with imports from the U.S. displacing those from elsewhere simply by fiat. The knottier issues remain unresolved. If anything, the period since the financial crisis has given the world a false sense of security, with China playing a greater role in driving global

Visual 44: Japan, Korea, China - Power and Rent Sub-Indices, Regional Comparison

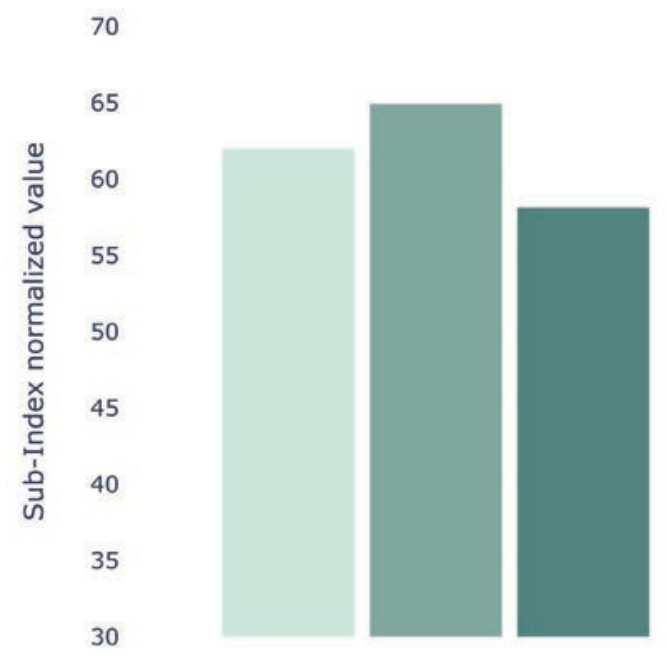

Power Sub-Index I

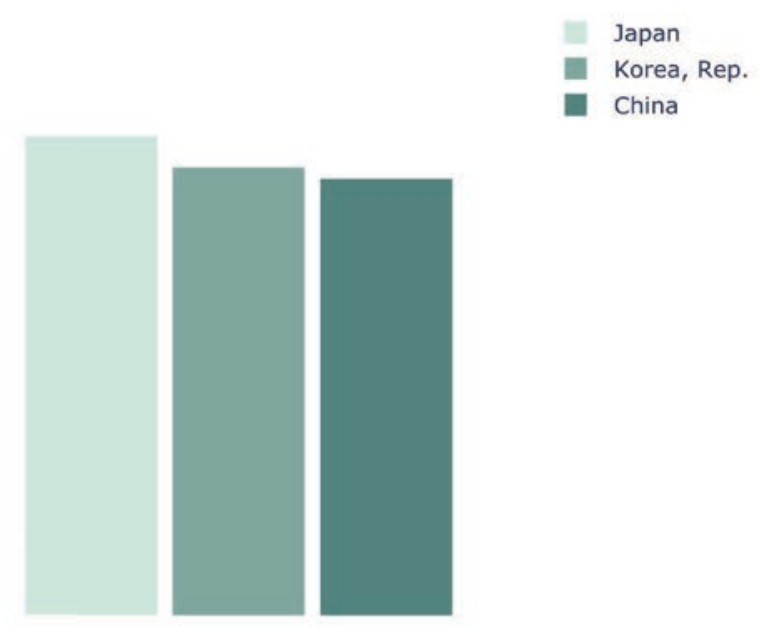

Value Sub-Index II 
growth. But this contribution was fueled by an unsustainable debt build up. China now faces the burden of a multi-year deleveraging process, during which, it is likely to need to rely more on external demand. The temptation, therefore, will soon be to continue skewing resources towards the export sector, which essentially equates to rent extraction. Our Index suggests that Japan and Korea, predecessors in this sense, did not manage fully to avoid this temptation.

With the authorities already taking steps to increase foreign involvement in China, there seems to be less movement on allowing Chinese capital to flow out and gain the benefits of diversification. For now, the recent announcement that the benchmark deposit rate will remain unchanged, since October 2015, is also an ill omen that the authorities intend to keep Chinese savers locked up at home, subsidizing the industrial sector, a factor not fully picked up yet by our Index.

Capturing capital rent extraction in the North East Asian model...

Future iterations of the Index will work on refining the Capital Rent (iv. 11) Pillar, in which China appears to perform well. There might, however, be some misgivings as to this result, as some Indicators are in their preliminary stages, and the Pillar does not yet include the full list of planned Indicators. Whilst this may matter less for developing countries, in the case of China it impacts its performance, boosting it to a better position in the ranking. In short, the Indicators Neutral interest rate (deviation from optimum) (DNI, iv. 11) and Inflation (deviation from optimum) (DOI, iv. 11) are both calibrated for developed markets, which could give China an advantage; with the assumed neutral interest rate and optimal inflation rate lower than the likely reality, China's undershooting is not picked up. In the future, we may also need to think about the differences across countries in how interest rates and money growth interact.

Another Indicator in the capital rents front is Currency appreciation (CUA, iv. 11). China performs very well here, largely thanks to appreciation early in the sample period. We may want to consider capturing intervention, rather than the pure moves in the currency, which can reflect necessary structural adjustments between a country and the rest of the world. Measuring intervention would be difficult though, as the North East Asian case demonstrates. China now uses state-owned banks to intervene, generally to support the currency at this stage, rather than merely relying on the central bank.
In any case, the Index accurately paints a picture of China at a turning point. The deleveraging China must now undergo probably entails real effective depreciation, meaning the country is likely to join its North East Asian neighbors on this front over the next decade. Japan's direct intervention, however, would be minimal. But the operative part of its Abenomics program was effectively to depreciate the yen, through a flood of Bank of Japan created money, so looking at pure yen depreciation is justified here. Korea's situation is equally complicated. It's $23^{\text {rd }}$ place performance partly reflects a sharp drop during the financial crisis. This was due to large amounts of short-term dollar debts built up in the years before 2008, largely as a result of hedging by the export sector. Should that macroprudential failure be penalized? As we noted above, the Index picked up excessive industry concentration, and the strength of the export lobby. So maybe this penalization is fair, reflecting the hazards of elites becoming too dependent on one business model. At the same time, historically, the country has tried to keep the currency on a cheap footing to support this export sector, at the expense of domestic consumers.

The future inclusion of asset inflation deviation from optimum as an $E Q x$ Indicator would also likely pull China down the ranks on the Capital Rent Pillar, and again will show China at a turning point. The effects of its closed capital account and previously loose monetary policy likely will show up here. Similarly, data on housing affordability probably would probably damage China's score in the Political Value area.

\section{... and capturing labor market rents}

All 3 countries perform well on the Labor Rent (iv. 12) Pillar, but picking up rent extraction here is tricky, and may require more country-specific thinking. Poor quality data in China's case is difficult to get around. Japan's quasi-feudal labor market, meanwhile, performs well on our current metrics, but harbor Value Extraction in reality, for instance on the intergenerational front.

Freya Beamish, Chief Asia Economist at Pantheon Macroeconomics 


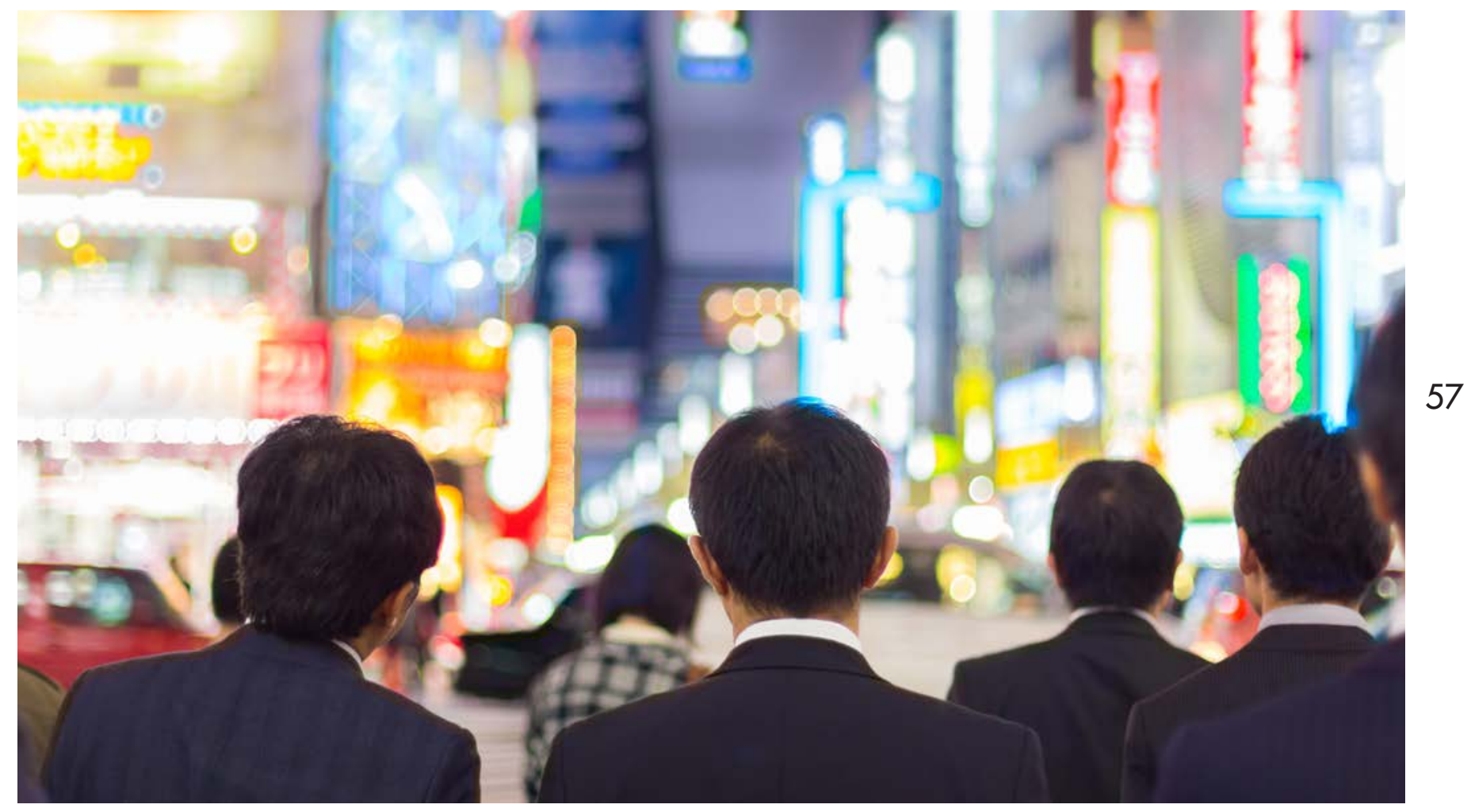




\subsection{EQx, Ultimate Signal of Medium-term Growth (with Implications for Economic Responses to Covid-19)}

Further to statistical assessment, the properties and robustness of the EQx dataset and its aggregated markers enable the pursuit of falsifiable hypotheses relevant to various research questions within the fields of economics and management science, and possibly other fields like political science or even ethics.

An initial question for testing is the establishment of $E Q x$ as a tentative leading indicator for economic growth. The underlying assumption is that elite business models based on Value Creation (rather than extractive rent seeking activities) generate broad and sustainable economic growth. 'Medium-term' time frames to be evaluated could range from 3-year to 15year time horizons. EQx constructs and data would thus be introduced to econometric models of growth, either as a single variable, or better, decomposed into its Pillars at different levels of aggregation. In fact, depending on their exact focus and data availability, several growth regressions could benefit from our Index's ability to meaningfully aggregate or disaggregate different components of Power and Value Creation. As econometric model adjustments are developed by the extended $E Q x$ research team, individual $E Q x$ components like Sub-Indices or Pillars and their respective weights might be finetuned according to predictive contribution. Candidate dependent variables worth exploring in the modeling context include human development, competitiveness, total factor productivity (TFP) or innovation.
Visual 45 below underscores an interesting relationship: the higher the EQx Country Score (i.e. the more prevalent the Valve Creation business models and the lower their rent seeking antagonists), the higher the levels of economic development in terms of real GDP per capita.

Beyond the correlation (correlation coefficient 0.807), much is revealed by considering the individual countries' residuals below the common intercountry line. China, the U.K. and Korea have a large vertical. These countries' Elite Quality on aggregate is the highest relative to their GDP per capita. This visualization points to the idea that Elite Quality is a signal for falsifiable long-term economic growth performance.

The big question is whether these residuals result from cumulative temporary deviations from a long-term relationship common to all countries and represented by the line, or whether they mirror the "fixed-effects" of socio-cultural characteristics of the country that cannot disappear in the medium-term. In other words, are the EQx Country Scores associated with negative vertical distances in Visual 45 (countries sitting below a hypothetical common trendline) a 'signpost' for higher future income levels (and higher economic growth rates)? Interestingly, Singapore sits above the trendline, meaning that it could perhaps regress, to the still astonishing high level of about USD 85,000 (PPP). The signal from China on account of Elite Quality is one

Visual 45: EQx's correlation with GDP per capita PPP - 2018 data (The World Bank), lagging causality?

Correlation coefficient $=0.807$, R-squared $=0.651$

Note: Minimal spatial displacement implemented in case of country overlap

100

范

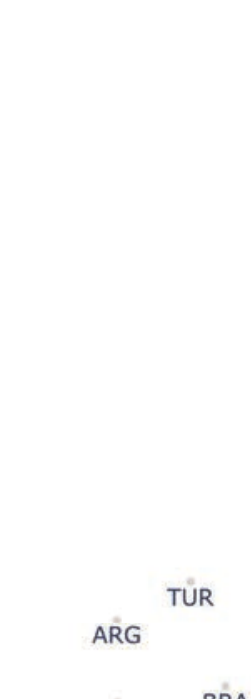

50

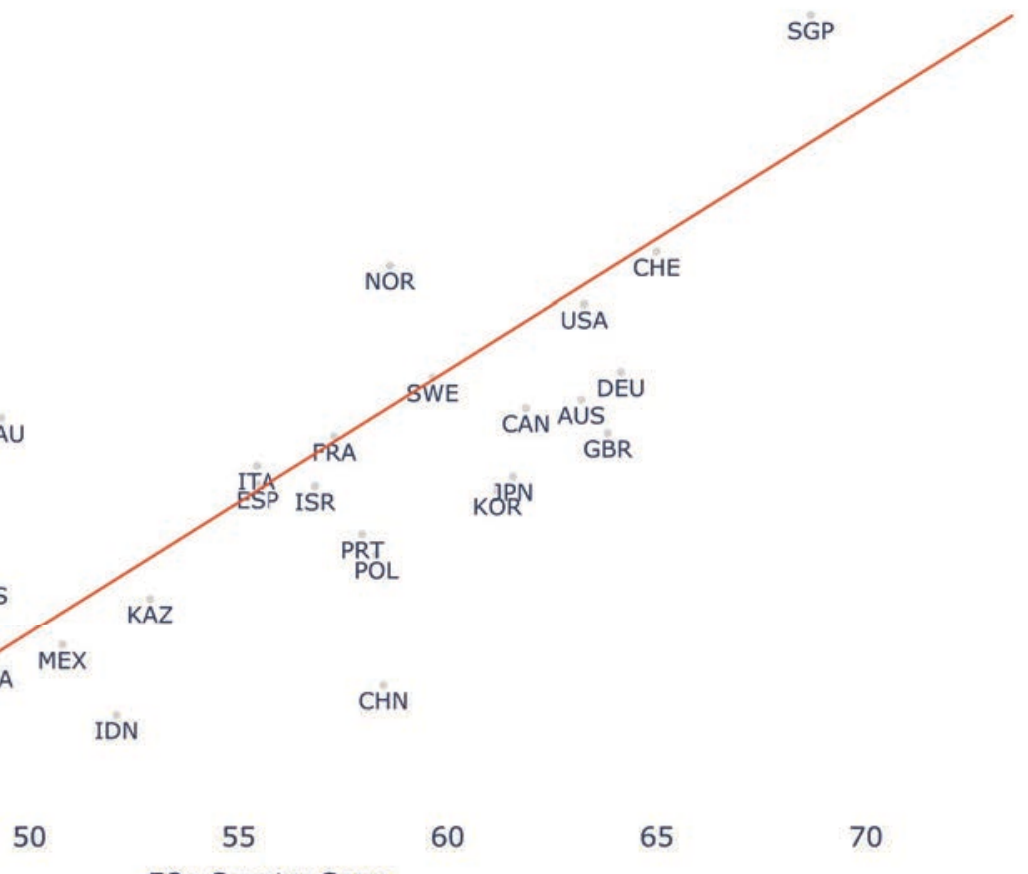

Countries - Trendline 
of USD 45,000 GDP per capita (PPP), close to 3 times its current level. In Europe the U.K., Poland, Israel, Germany or Portugal are also set to grow their purchasing power GDP.

On the other hand, Argentina and Turkey point to substantial negative growth ahead, if the large positive distances (to the trendline) persist. Furthermore, Italy, France and Sweden might stagnate, albeit these countries are already relatively and very prosperous. The previous discussion about time-horizons leads to the 'if' and 'when' question, i.e. will all or most countries ultlimately transition towards the trendline and how long will the shift take? In other words, how forward-looking is EQx?

The determination of signaling effects, and the potential hysteresis (where historical elite business models endure and determine national development trajectories) of Elite Quality bring forth practical policy dimensions. Can inflection points that redirect economic and human development trajectories be detected? EQx is designed to draw from financial markets and other dynamic data; the real-life EQx data subset, properly modelled and interpreted, could be the core signals which, however weak, anticipate larger future movements of economic variables.

A case in point of great topicality is the dissimilar policy responses to the Covid-19 crises. Any response, ranging from helicopter money and looser monetary policies, to 'Coronabonds', or to specific industry rescue packages and subsidies, will lead to updated Value Creation vs Extraction Configurations (see Visual 17). That is, to new proportions of inclusive vs extractive business models in the economy. The EQx2021 report will aim to capture the effects of Covid-19 policies in terms of Value Creation and hence long-term economic prospects.

In summary, weak signals for conceivable economic trajectory inflection points might, once properly modelled, call for revising a country's medium and long-term growth prospects. After all, emerging elite business model configurations are the central - albeit often overlooked - fact of any political economy. Their effects certainly require longer horizons to fully play out in the economic and social spheres. For this very reason, EQx plans on initiating an econometric modelling research program to capture different economic growth and political economy aspects. We will enlarge the dataset by increasing the number of countries and years, so that we are able to mobilize a variety of methods, ranging from static and dynamic panels, to instrumental variable estimations, to important causation methods such as the propensity score, along the lines of important recent studies (such as Acemoglu, Naidu, Restrepo, \& Robinson, 2019).

Visual 46: Fitted value differential as indication of future growth prospects (based on Visual 45) Note: Fitted value differentials are calculated as the difference between the fitted value and the actual GDP per capita value, as $\%$ of the actual GDP per capita value

60 


\section{Today's Call to Elites}

In times of crisis, Elite Quality is paramount. During the final stages of the 18-month preparation of this Report, the world has been confronted by the Covid-19 health emergency. This Call to Elites attempts to provide a framework to tackle the evolving economic and social crises.

1. Coordination. Elites are scarce and critical coordination capacity. Without elite coordination capacity a nation cannot successfully hope to prosper, innovate, or tackle a crisis.

2. Choice. Elites have the choice to configure their business models between 2 poles: Value Creation and Value Extraction.

3. Policy. Optimal policies for economic and human development are those that crystalize in institutions that incentivize Value Creation business models. Rules with teeth must close doors to Value Extraction and rent seeking, because these constitute value transfers away from the original value producers and eventually lead to stagnation and in the extreme, to social breakdown.
4. Transparency. It is extremely difficult to assess at the micro or firm level, and even for the elites themselves, whether and to what degree a given operation or business model is value creating or extracting. An important reason for the obscurity is that both models are profitable and generate wealth. While elites and non-elites alike are keen on frameworks for transparency, elites seeking sustainability and the long-term perspective are expressly interested.

5. Diversity. Countries experience different levels of Elite Quality. There will be debates about the right Elite Quality levels. For instance, it is argued that countries in initial stages of development should tolerate rent seeking models to enable capital accumulation and finance elite coordination capacity. Once the economy develops, those elites should transition to Value Creation models. On the other hand, the richer a country is, the higher the demands on Elite Quality: operating on the efficiency frontier leaves scant margin for the allocative inefficiencies accruing from Value Extraction business models.

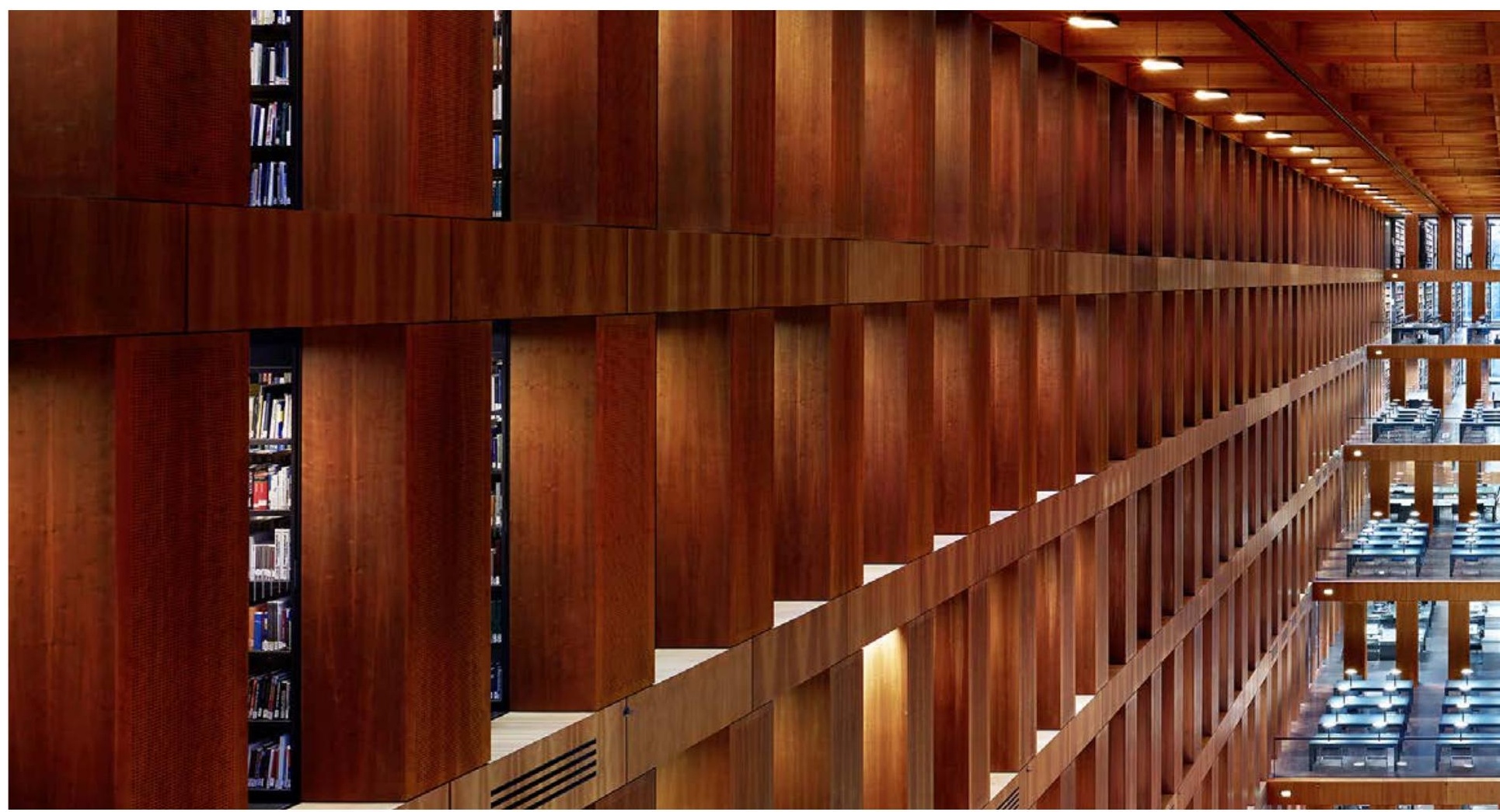




\section{Exhibits}

\subsection{EQx Forthcoming Research Questions}

The EQx2020 Report's Country Scores and Global Rank are part of a cross-disciplinary research project. Both macro-, meso- and micro-level research questions derive from the Elite Quality conceptualization and the measurements of the Index. A set of fundamental and inclusive research questions are outlined below.

\section{Fundamental research questions}

Predictability: As discussed, Elite Quality is purportedly an independent variable leading to economic and human development, a leading indicator for mid- or long-term economic growth. The core of the $E Q x$ research project is to test falsifiable hypotheses by empirical means. In this context, econometric models might be developed to address reverse causality issues at the highest of standards of economics. By highest of standards, we mean the issues tackled in the econometric works of people like the recent Nobel prize winners Banerjee and Duflo; we cannot run experiments, but our causal inference could reach a similar reliability based on observational data.

Longitudinal study: Can we compare countries to themselves over time? The annual EQx is a global comparative index. That is, every country is ranked and qualified in relation to other countries. At the same time, we know that scoring high or low in the Global Rank is not as important as improving a given country's Elite Quality over time. Research with longitudinal panel data will address - at the individual country level - the progress towards higher/lower levels of Elite Quality. The EQ×2021 Report plans to first address the question by presenting a benchmark comparison capturing pre-2007 Great Recession data.

Theoretical diligence: Is Elite Quality an internally consistent and falsifiable construct which explains that which established theories do not? Does EQx and its supporting methodology truly measure Elite Quality as conceived? The question of whether Value Creation business models for the national aggregate are properly measured will be theoretically diligenced for the 4 levels of the Elite Quality architecture, including for each Indicator.

\section{Extended research questions}

International business: Elite Quality captured by EQx could well be a relevant contextual factor for a variety of firm decisions on internationalization, such as foreign market entry mode choice. Elite Quality could be determinant of foreign

Visual 47: EQx's correlation with the Human Development Index - 2018 (UNDP, 2019) Correlation coefficient $=0.778$, R-squared $=0.605$

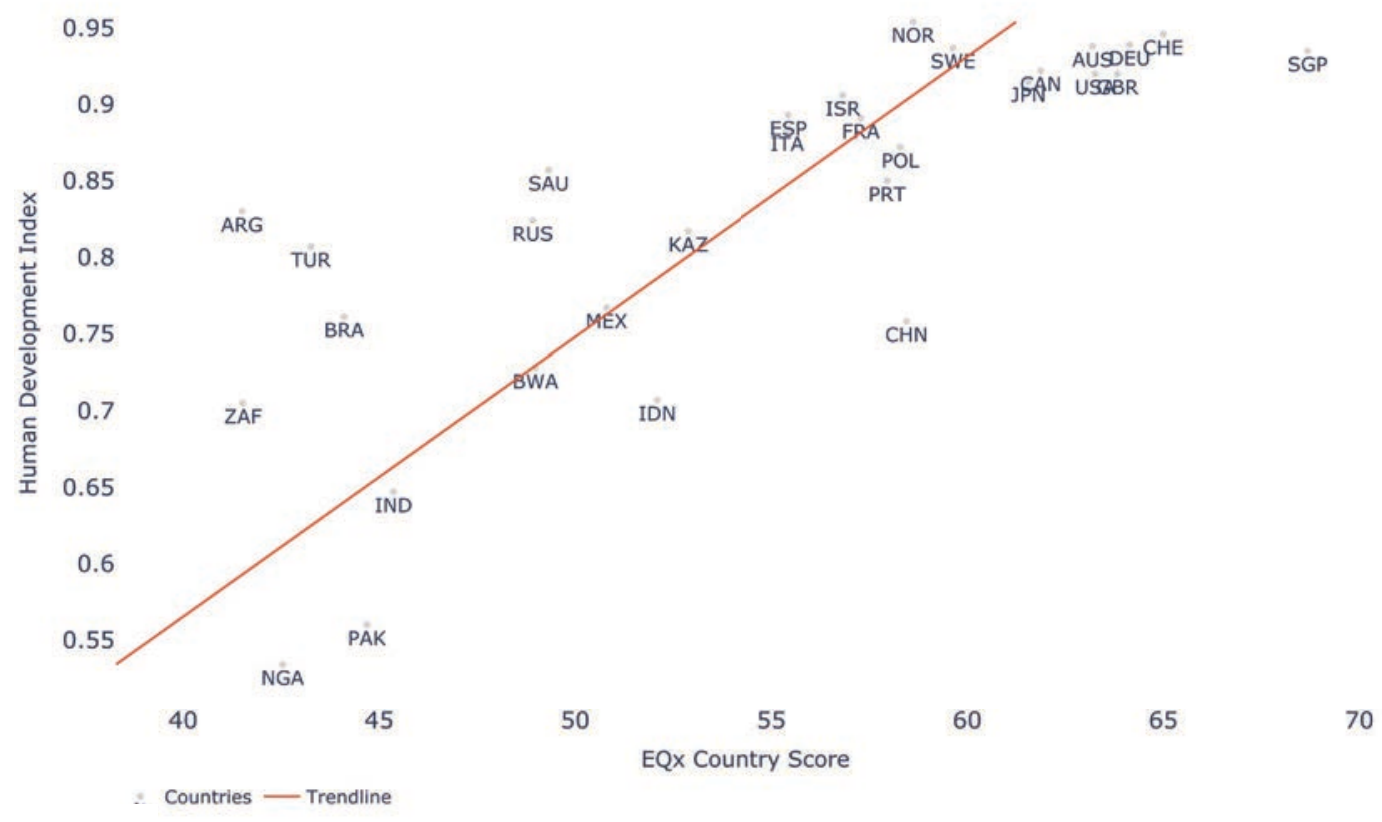


direct investment (FDI) performance, and might have a signaling effect for host countries wishing to attract FDI.

Business models: While the EQx Index is built primarily on macro datasets measuring Value Creation on the aggregate, a transition (back) to the micro-level will be made. Ample literature exists on Value Creation at the level of organizations. The idea is to utilize existing EQx concepts and approaches to establish whether firm (or industry) profits are the result of Value Creation or of extractive business models.
Corporate governance: The agency of boards, especially those at leading and system-relevant organizations, is increasingly being scrutinized from a stakeholder perspective. Assessing a business model's Value Creation might in the future be part of Corporate Social Responsibility (CSR). Along similar lines, the Environmental, Social, and Governance (ESG) investor perspective might reference $E Q x$ as it measures the sustainability and societal impact of business models associated with specific investment decisions.

\section{Selected research questions for the EQx project team}

\section{(i) Future EQx Reports plan to propose mid- and long-term economic growth predictions.}

(ii) Development of an EQx Liquid indicator to assess how changes in financial market and other 'real-time' data impact growth, risk, economic forecasts and general human welfare indicators.

(iii) What is the overall "state of elites" in the world? An EQx World Score plans to answer this question by establishing an aggregate Elite Quality metric that takes into account the scores of all nations. Whether the $E Q \times$ World Score is on a rising or on a falling trend will be studied. The impact on the World EQx of events such as Covid-19 and related policy responses also merits inquiry.

Visual 48: EQx's correlation with the WEF Global Competitiveness Index (WEF, 2018) Correlation coefficient $=0.883, \mathrm{R}$-squared $=0.779$

6

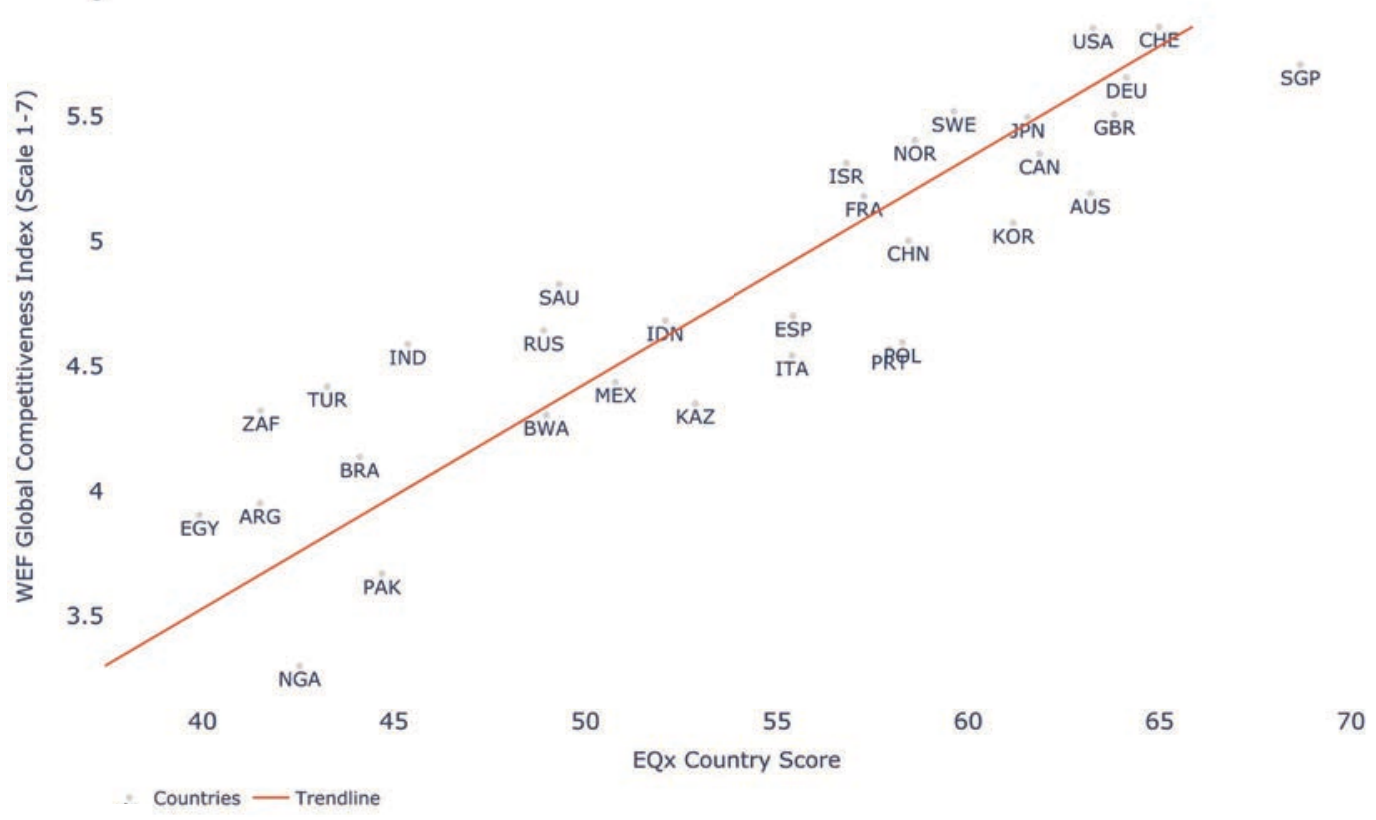


This brief provides a synopsis of methodology steps (Steps 3 to 6 and 8, as in Visual 9) and reference parts of this report (Sections 2.4 Methodology Introduction and 2.5 Statistical Assessment). For a full methodology discussion consult the latest version of the EQx Methodology Paper.

\section{Dataset collection and transformation (Step 3)}

As basis for the EQx's 72 Indicators, datasets are collected from renowned international organisations. By using these various datasets and sources, the EQx aims to capture and measure all relevant aspects of Elite Quality. Section 7.2 lists the data source for each Indicator. Datasets can be categorized, according to whether and how they are transformed before yielding EQx Indicators. For instance, some Indicators are obtained directly from the original data (e.g. Indicator Institutional quality (DBI, i.2) uses the final score of the World Bank Ease of Doing Business Index). Other Indicators are obtained after some basic transformation of the source dataset, e.g. by setting absolute numbers in relation to the countries' number of inhabitants or GDP. Another set of Indicators is obtained after more complex transformations, implying data cleaning and more extensive data transformations, as was the case with the Top 3 Industries as \% of VA (IVA, ii.4) Indicator.

Whenever possible, the most recently available data is used to compute EQx Indicators. That is, if available, the Index uses 2019 or 2020 data. Considering the geographic coverage of the $E Q x$, the future aim is to measure Elite Quality for as many countries as possible, even if severe limitations exist in pursuit of this objective. For the EQx2020, Index valves are computed for a set of 32 countries.

\section{Imputation of missing data (Step 4)}

Fortunately, the datasets considered for the EQx are generally characterized by relatively good completeness. However, roughly $10 \%$ of Indicator-level datapoints are missing. The EQx approach to missing values is designed to avoid systematic upward or downward biases as a result of missing valves. That is, a lack of data should not penalize or favour any country but should solely influence the accuracy of its score.

High data quality is achieved through 2 angles. First, minimum requirements in terms of data availability are defined. Datasets are only included in the EQx analysis if they cover a minimum of $30 \%$ of the countries under consideration (for the EQx2020 this corresponds to 9 countries) and provide recent information on countries' Elite Quality, i.e. by 2016 or later (although there might be some exceptions to this rule). Additionally, Pillars need to be based on a minimum of 4 Indicators.

Secondly, the EQx implements an "available-case analysis" (Little \& Rubin, 2002, p. 54), where Indicators are not omitted when having missing values, but are used if they fulfil the above minimum requirements. In cases where the most recent data is not available for a specific country, missing values are imputed from the latest available data for this country, up to 3 years prior to the most recent year. When an Indicator is missing for a country entirely, the weight of the missing Indicator is split between the remaining Indicators of the same Pillar, proportionally to their weight. The $E Q x$ methodology thus builds on the premise that Indicators within the same Pillar measure similar aspects of Elite Quality. For the EQx2020, a country's Index score is derived from a minimum of 40 Indicators in the case of Botswana and, on average, from 61.7 Indicators.

An obvious concern is that missing values are not missing completely at random but based on a systematic pattern (OECD, 2008, p. 24): data availability might be related to a country's Elite Quality. This could represent an important endogeneity bias for the EQx. However, we found that differences in $E Q x$ scores are not significant with respect to the number of Indicators. Furthermore, a positive relation between country scores and data availability would not necessarily be an indicator for bias: provided the existing Indicators are unbiased, Index scores would not be biased, but less precise. The state of Elite Quality would be depicted using less, but nevertheless correct information. We are confident that this argument would apply here, since the EQx uses data of renowned and trustworthy international organisations.

Still, data constraints might hamper the cross-country comparability of EQx country scores: some Indicators stem from different years, and some Indicators cover a heterogenous set of countries. The latter implies that each Country Score relies on a different set of Indicators (Little \& Rubin, 2002, p. 54), which might limit the meaningfulness of the international ranking. However, while these important limitations should be kept in mind, we are confident that the EQx offers valuable insights on aggregate Elite Quality in the considered countries. Reassuringly, a range of robustness tests suggest that the EQx ranking is largely robust to modifications in key modelling assumptions. 


\section{Normalization of Indicators (Step 5)}

Because the Indicators have different scales and measurement units, normalization is necessary prior to aggregating the data to "avoid adding up apples and oranges" (OECD, 2008 , p.27). In a first step, a logarithmic transformation is applied to some source datasets (12 of the $72 \mathrm{EQx}$ Indicators are based on a log-transformation) when this is deemed to improve the distribution of the data and thus yield more meaningful Indicator scores. Then, before aggregating Indicator values to Country Scores, data is standardized, i.e. converted to a common scale (with mean zero and standard deviation one) by calculating $z$-scores $\left(z_{c, i}\right)$. This improves the comparability of datasets with large differences in scales and units, as is the case with EQx Indicators. The standardization is done using the $95 \%$ trimmed mean and standard deviation, in order for the standardization process to be less susceptible to outliers. In a further step, the datasets are rescaled such that the Indicator scores all range between 0 and $100\left(x_{c, i}^{n}\right)$. Lastly, if necessary, Indicators are transformed such that - consistently across all datasets - a value close to 100 indicates a high level of Elite Quality, and a valve close to 0 represents a low level of Elite Quality.

\section{Weighting and Aggregation (Step 6)}

By weighting the individual Indicators, varied relevance can be attributed to them. As outlined in section 2.4, Casas' (2020, forthcoming) framework provides a clear structure to the Index. The weights applied at each level (Indicator, Pillar, Index Area, and Sub-Index level) emerge from 2 approaches: either, weights are allocated by a group of experts, or, weights are directly deduced from the theoretical framework presented by Casas.
Indicator and Pillar weights are determined by a group of experts in the course of a Budget Allocation Process (BAP). The BAP is a participatory method where experts are provided a budget, e.g. N points, that they allocate to an Indicator or Pillar. Intuitively, experts "pay" more for Indicators or Pillars they want to stress (OECD, 2008, p. 32 citing Billharz, Matravers, \& Moldan, 1997). The average of the experts' allocations yields the individual Indicator or Pillar weight.

Index Area and Sub-Index weights are determined by conceptual deliberations formalized in the EQx White Paper. The resulting relative weighting between the Sub-Indices Power and Value is established as 1:2. Within each Sub-Index, the weight between the Political and Economic Index Areas is established as $1: 2$, as well.

Furthermore, the EQx applies a linear aggregation scheme. This implies a constant and full compensability between each aggregated element at the respective aggregation level (OECD, 2008, p.33). Within Pillars, Indicators are assumed to measure similar aspects of Elite Quality, and in consequence, a full compensability is intended. A similar reasoning applies for the aggregation of Pillars within Index Areas. Moreover, a linear aggregation scheme transmits the relative importance - as determined by the underlying weighting scheme - of the elements that are aggregated at the respective level to the index (Santeramo, 2017, p.131). In consequence, Index Areas and Sub-Indices are linearly aggregated as well, to ensure a full transmission of the relative weights as implied by the theoretical foundation.

$$
z_{c, i}=\frac{x_{c, i}-\mu\left(X_{i}\right)}{\sigma\left(X_{i}\right)}
$$

Indicators standardization formula (z-score), based on dataset trimmed mean $\mu\left(X_{i}\right)$ and standard deviation $\sigma\left(X_{i}\right)$

$$
x_{c, i}^{n}=\left(\frac{Z_{c, i}}{4}+0.5\right) \times 100
$$

Calculation of final Indicator Country Score, ranging from 0 to 100 


\section{Statistical Assessment (Step 8)}

The EQx Methodology Paper discussed a range of robustness tests. There are 2 reasons for this: firstly, to validate the $E Q x$ set-up, and secondly, to assess how sensitive the country ranking is, ceteris paribus, to changes in key modelling assumptions. The tests generally confirm the robustness of Country Scores and meaningfulness of the EQx Global Rank. We find that Country Score and the Global Rank are not driven by individual Indicators, different levels of data availability or the chosen normalization method. They also remain largely stable when applying a range of alternative weighting and aggregation schemes. The EQx Methodology Paper including the comprehensive sensitivity analysis is open for critical input.
Additional insight into the reliability of the $E Q x$ was obtained by replicating the entire construction process on a separate platform. Namely, the EQx is calculated using Microsoft Excel, a widely used spreadsheet software, as well as using the Index Management Platform IMP, a custom Python-based platform developed by partner dxFeed.

Visual 49: $E Q x$ weighting, overview table Note: Based on the EQx Methodology Paper

\begin{tabular}{|c|c|c|}
\hline Aggregation level & $\begin{array}{l}\text { Weighting allocation } \\
\text { method }\end{array}$ & EQx Weights \\
\hline Sub-Index weights & & within $E Q x$ \\
\hline Sub-Index I: Power & Conceptual Deliberation 1 & $34 \%$ \\
\hline Sub-Index II: Value & Conceptual Deliberation 1 & $66 \%$ \\
\hline Index Area weights & & within Sub-Index (within EQx) \\
\hline \multicolumn{3}{|l|}{ Sub-Index I: Power } \\
\hline Political Power & Conceptual Deliberation 2 & (11.6\%) \\
\hline Economic Power & Conceptual Deliberation 2 & $(22.4 \%)$ \\
\hline \multicolumn{3}{|l|}{ Sub-Index II: Value } \\
\hline Political Value & Conceptual Deliberation 3 & $(22.4 \%)$ \\
\hline Economic Value & Conceptual Deliberation 3 & $(43.6 \%)$ \\
\hline Pillar weights (within Index Areas) & Budget Allocation Process & $\begin{array}{l}\text { each Pillar receives own weight, } \\
\text { see } E Q \times \text { Methodology Paper }\end{array}$ \\
\hline Indicator weights (within Pillars) & Budget Allocation Process & $\begin{array}{l}\text { each Indicator receives own weight, } \\
\text { see } E Q \times \text { Methodology Paper }\end{array}$ \\
\hline
\end{tabular}




\subsection{EQx Continuous Development Plans}

The 2020 EQx2020 Report you have in your hands is the first ever release of the EQx Index. As a result, it has an experimental character, and while its production was guided by the perspectives and approaches of the Methodological Paper (see sections 2.4, 2.5 and 6.2), a multi-faceted review process has since commenced.

The release of the EQx2020 Report has started the first phase of the review process, which will close with the publication of the full EQx2021 Report, at which time the second phase will begin. This second review phase will be an extensive, indepth, year-long peer reviewed methodological assessment. The $E Q x$ project expects to benefit from the inputs received from academia, business practitioners and policymakers.

\section{The review process aims at diverse areas of action:}

a) Relevance. For EQx to become an accepted heuristic for Elite Quality by segments of the general public, policymakers, institutions or elites.

b) Transparency and openness. Implementation of transparency principles for $E Q x$, and open index production processes capable of incorporating critical insight and outside contributions.

c) Theoretical assessment. Continuous strengthening of the theoretical foundations for the EQx Index and its aggregated levels, as well as construct validity.

d) Statistical assessment. Continuous general validation of $E Q x$ results and the Index's robustness.

e) Macro-level research. Initiation of formal research projects in the area of economics. This includes, for instance, the development of econometric models that test the relationships and the purported predictive power of EQx over selected proximal dependent indicators (e.g. institutional quality) and distal dependent indicators (e.g. medium-term economic growth, human development).

f) Micro-level and meso-level research. Initiation of formal research projects in the areas of international business or corporate governance. This includes, for instance, testing the relationships between $E Q x$ datasets and FDI performance and internationalization models across countries, industries or firms, or assessing corporate governance in terms of firm Value Creation vs Value Extraction.

g) Indicators conceptual diligence. Theoretical evaluation of existing and candidate $E Q x$ Indicators in terms of their fit as an expression of Power and Value (Creation vs extraction), and conceptual validation of the assignment of Indicators in $\mathrm{EQx}$ Pillars.

h) Indicator dataset quality. Continuous updating of existing $E Q x$ Indicator datasets and assessment of data quality. Of importance too is the identification as well as the production of datasets for candidate Indicators that conceptually fit the Pillars.

Lastly, we emphasize that for meaningful application of the $E Q x$ methodology, the quality of the input data sources is essential. The EQx Indicators are the bedrock of the Index, and the tables in the next section 6.4 describe these in detail. 
Visual 50: $E Q x$ Indicators table

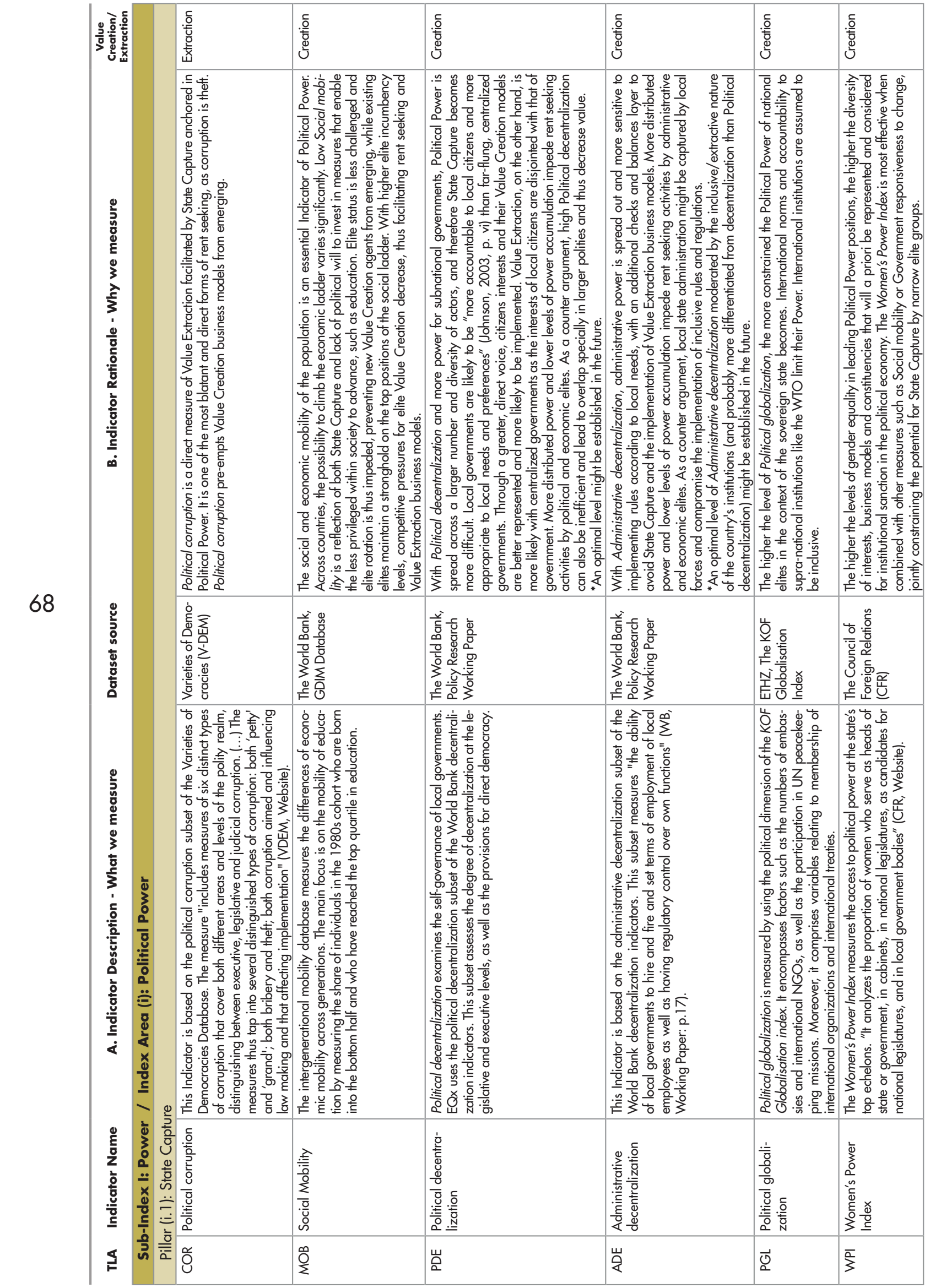




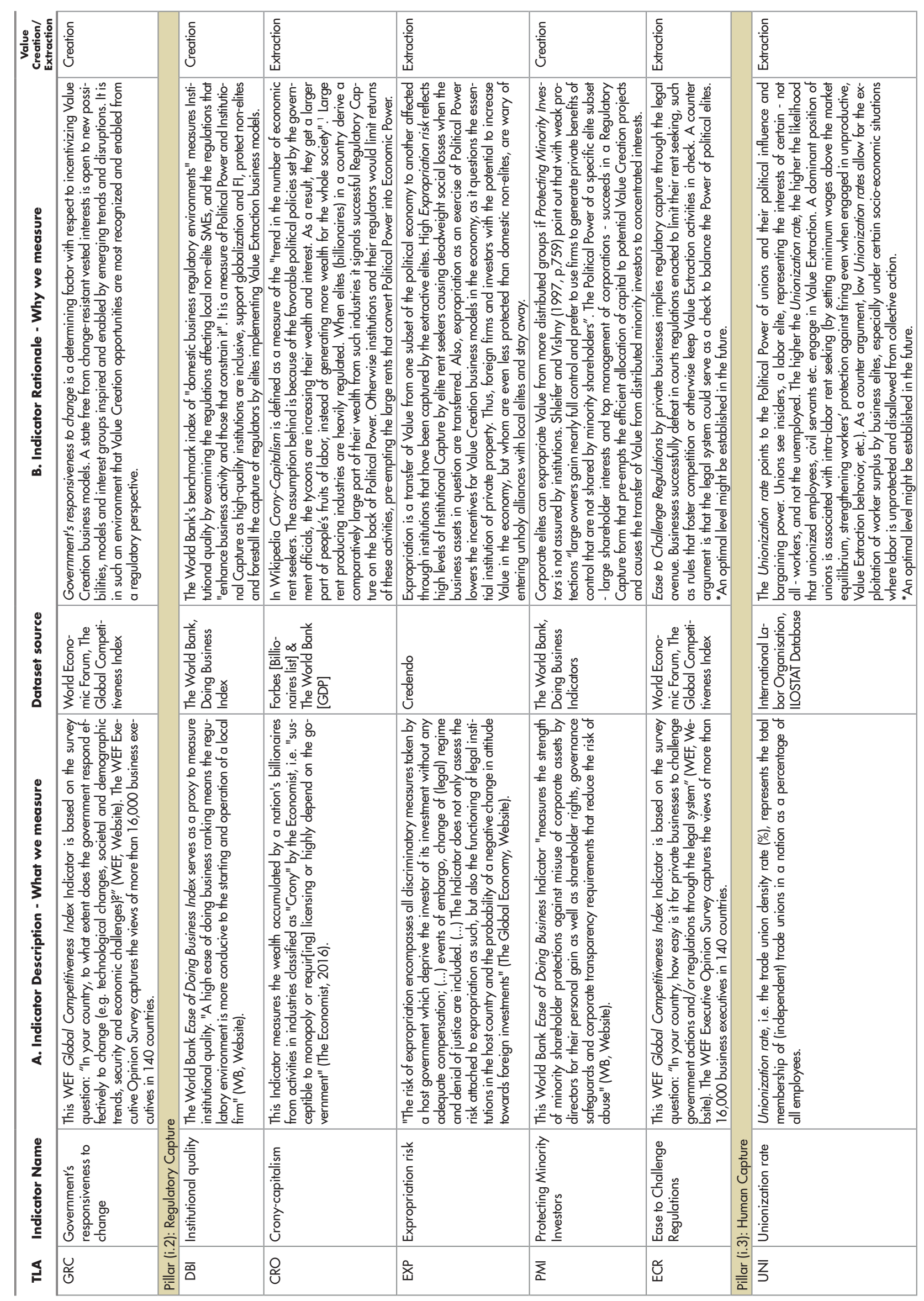




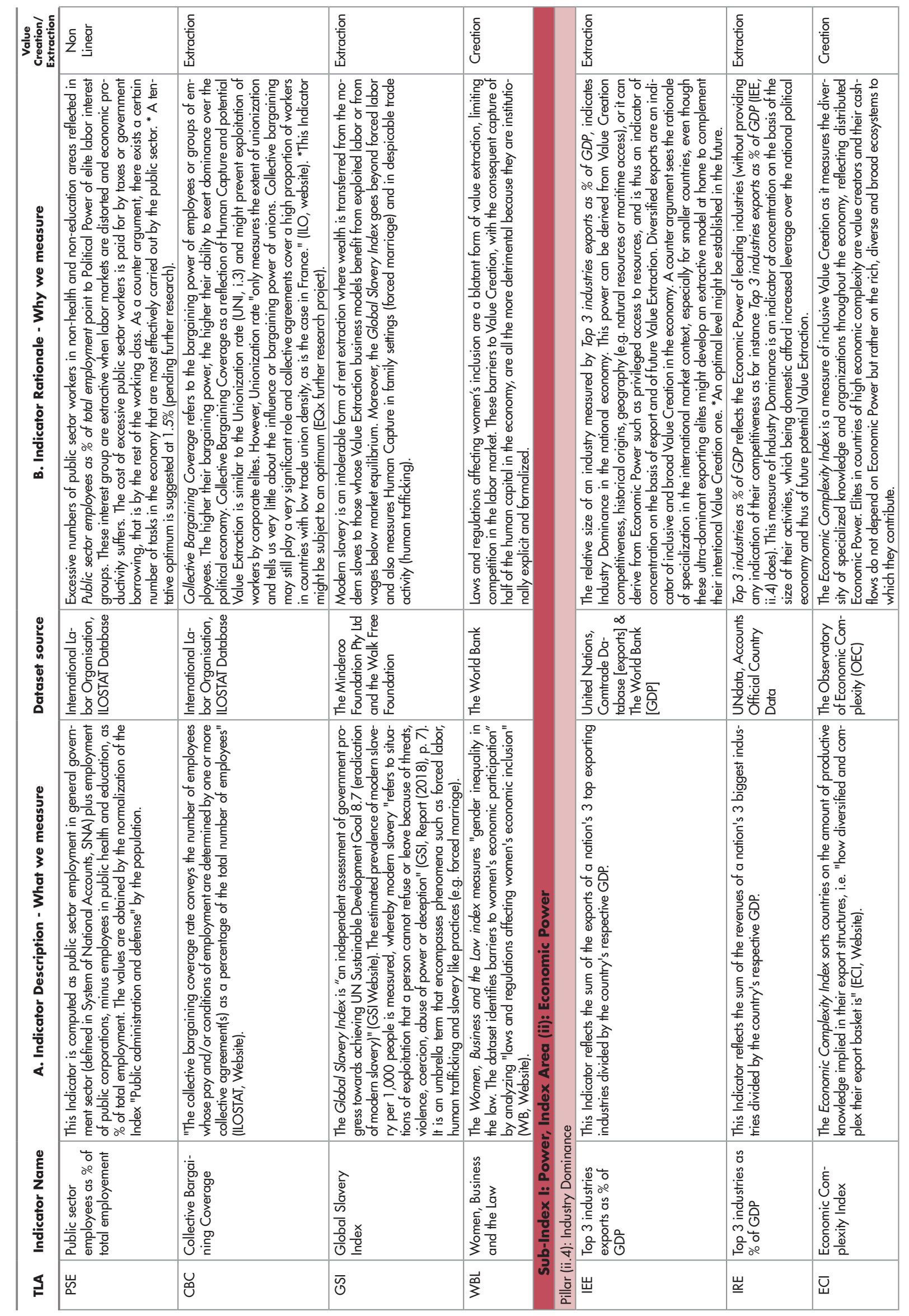




\begin{tabular}{|c|c|c|c|c|c|c|c|c|c|}
\hline & & 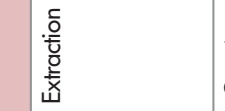 & 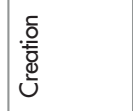 & 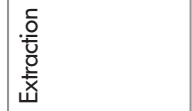 & 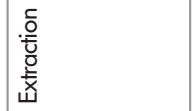 & 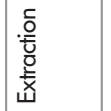 & 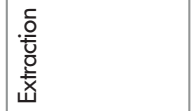 & 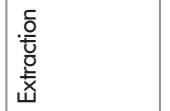 & $\begin{array}{l}\text {. } \\
\frac{D}{\bar{t}} \\
\text { 妾 } \\
\end{array}$ \\
\hline 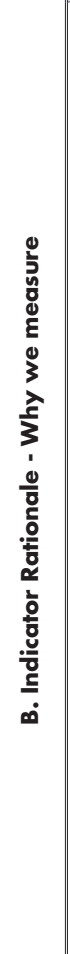 & 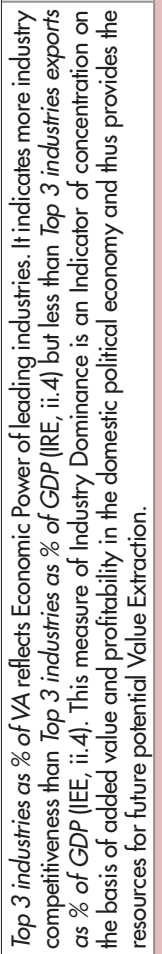 & 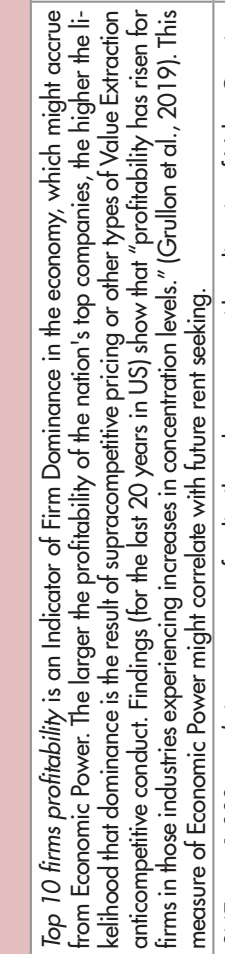 & 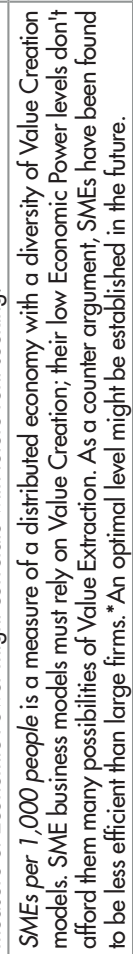 & 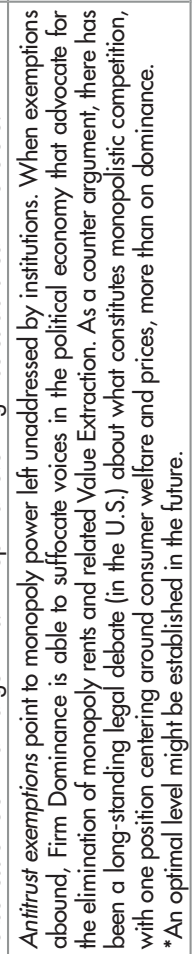 & 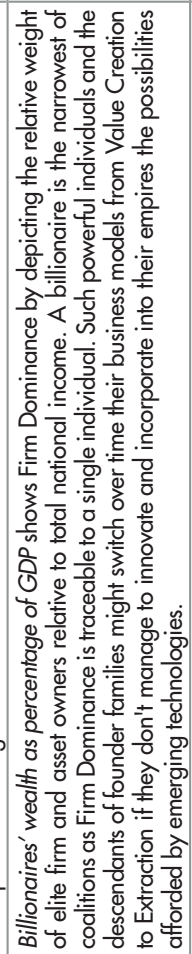 & 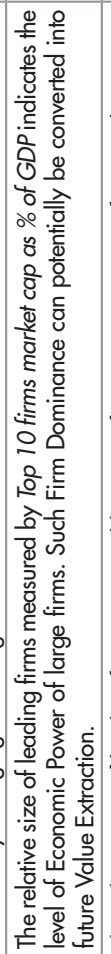 & 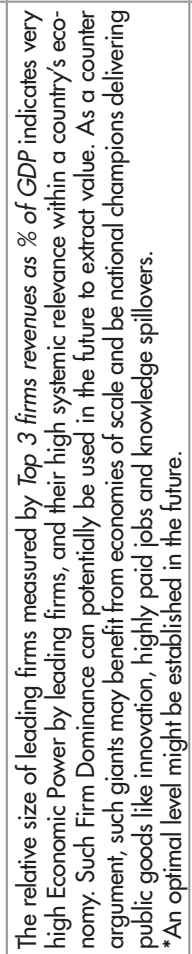 & 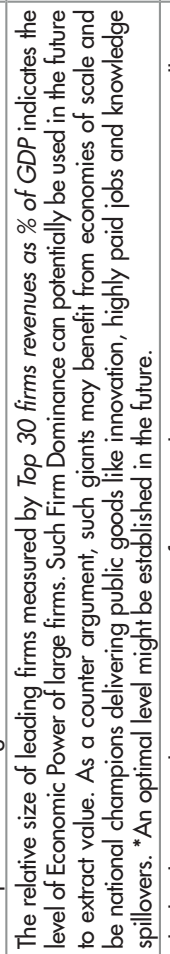 & 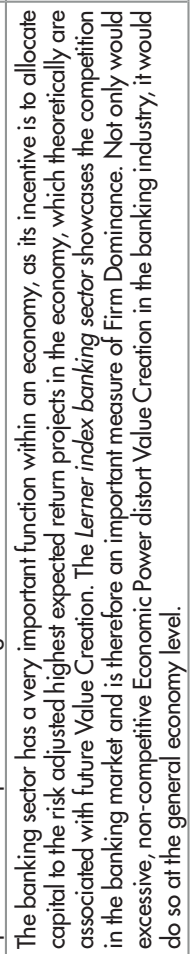 \\
\hline & 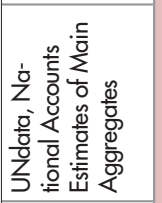 & 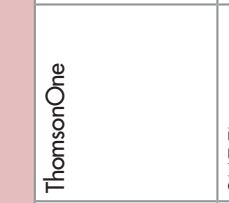 & 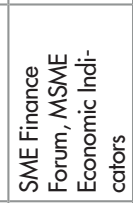 & 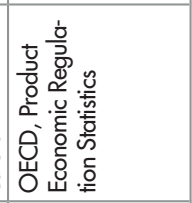 & 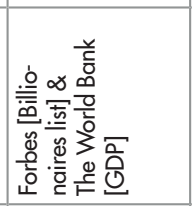 & 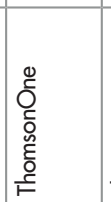 & 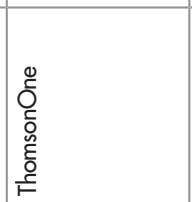 & 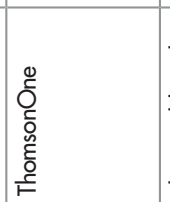 & 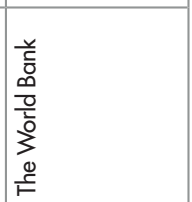 \\
\hline & 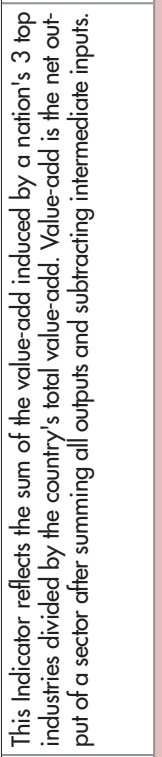 & 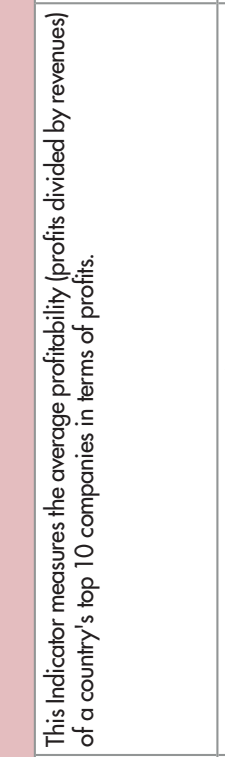 & 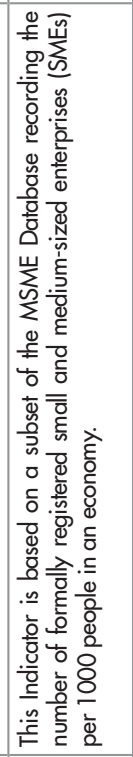 & 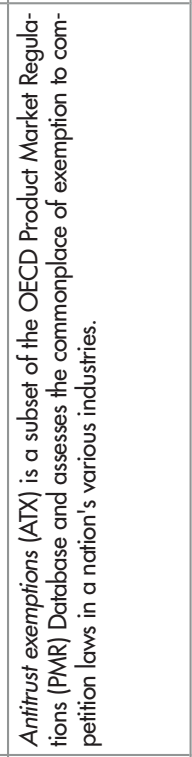 & 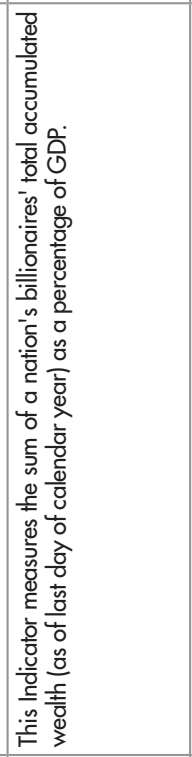 & 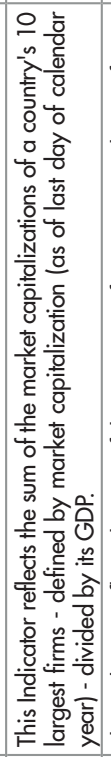 & 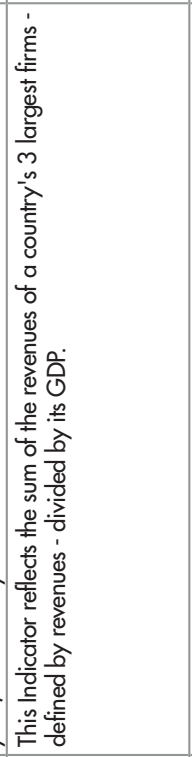 & 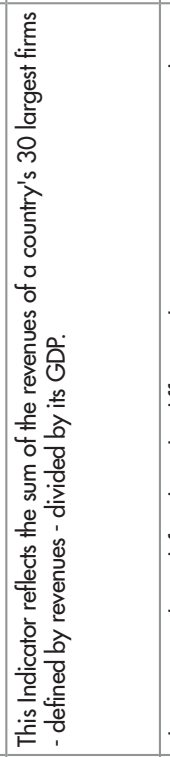 & 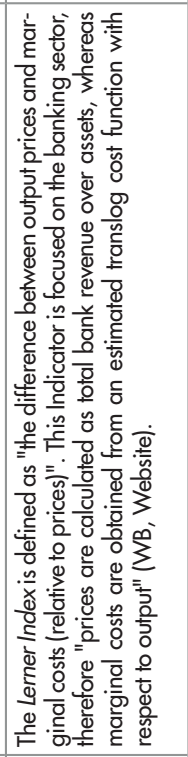 \\
\hline & 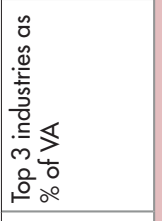 & 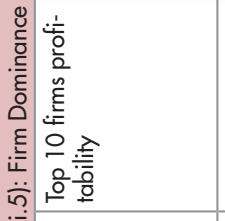 & 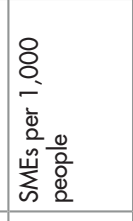 & 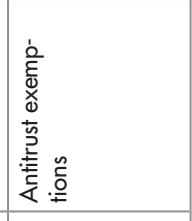 & 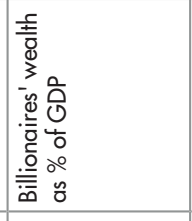 & 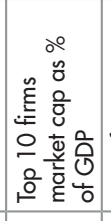 & 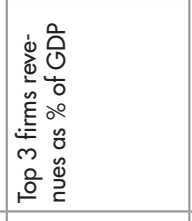 & 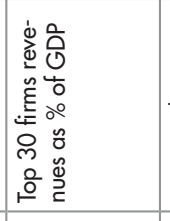 & 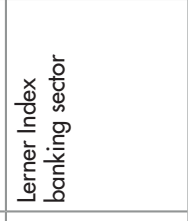 \\
\hline 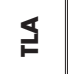 & 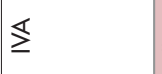 & 竞 吕 & $\sum_{w}$ & 希 & $\frac{3}{\infty}$ & 站 & 華 & 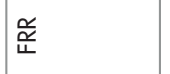 & $\stackrel{\varrho}{\exists}$ \\
\hline
\end{tabular}




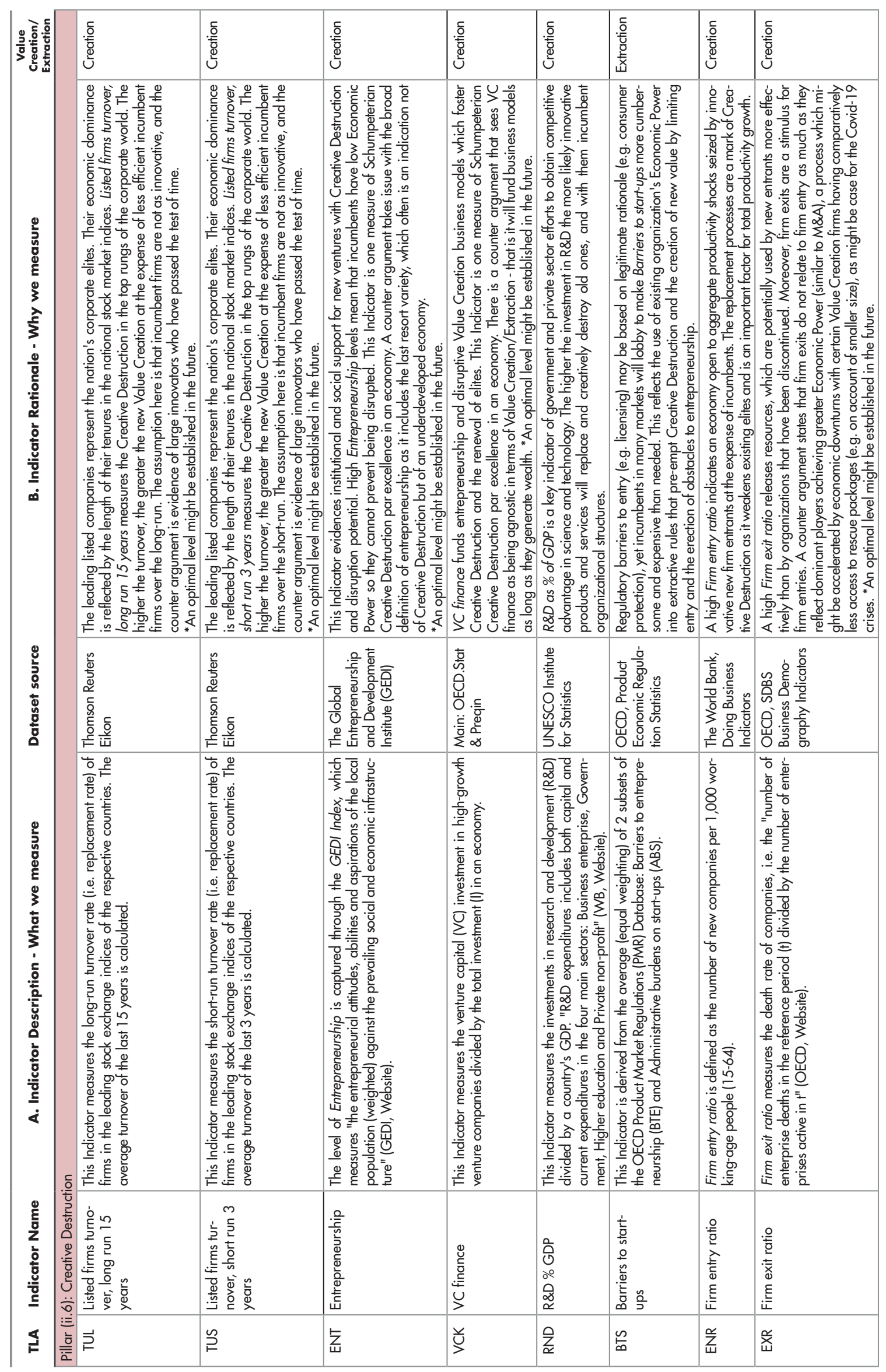




\begin{tabular}{|c|c|c|c|c|c|c|c|}
\hline & 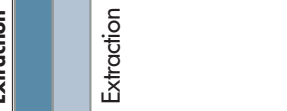 & 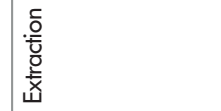 & 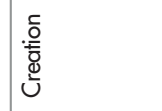 & 它. & 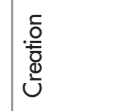 & 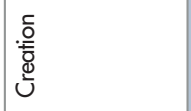 & 它. \\
\hline 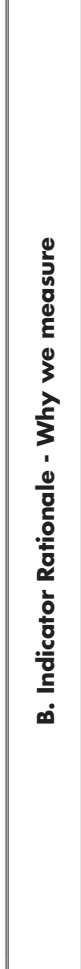 & 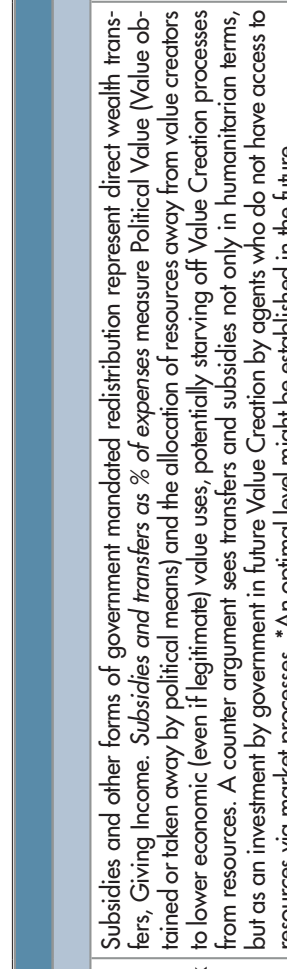 & 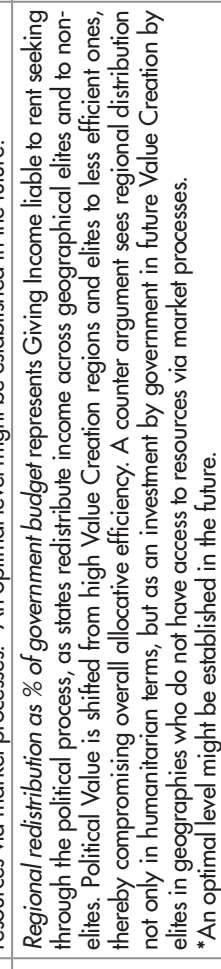 & 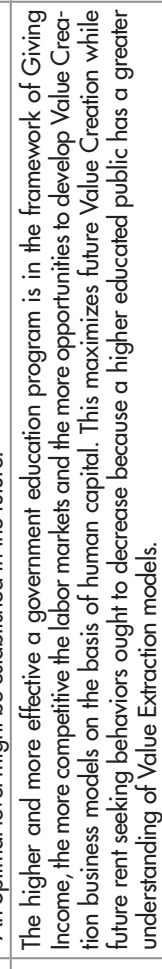 & 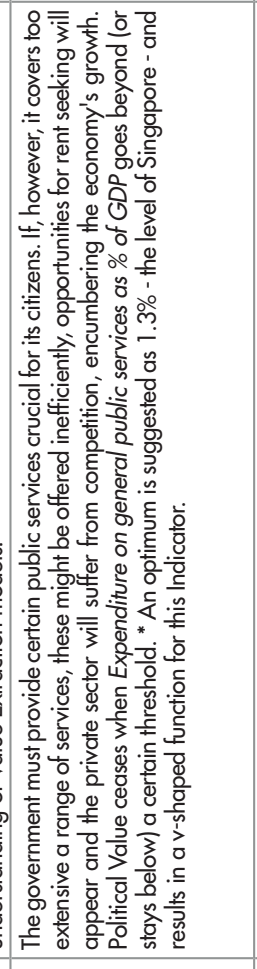 & 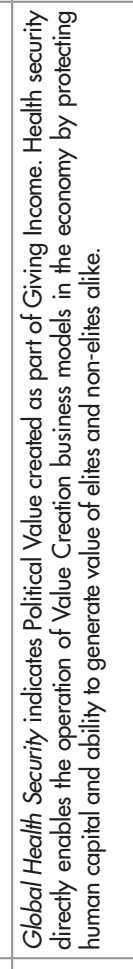 & 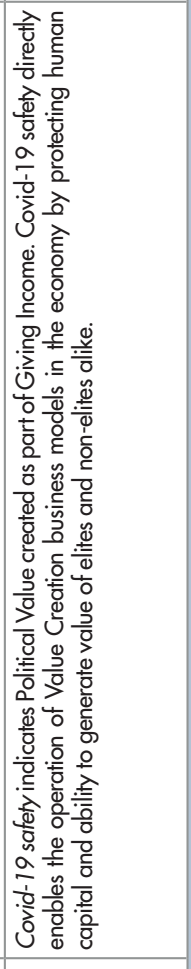 & 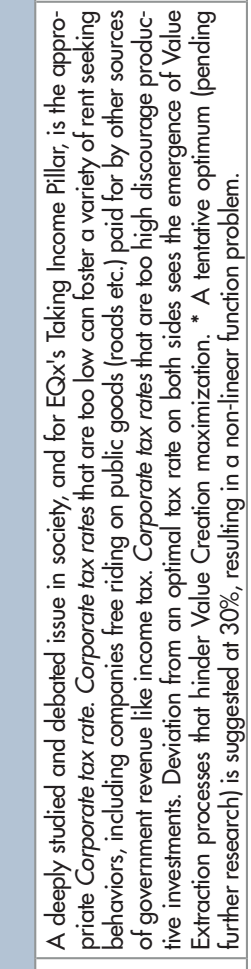 \\
\hline & 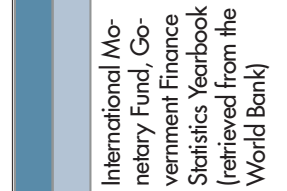 & & 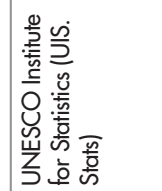 & 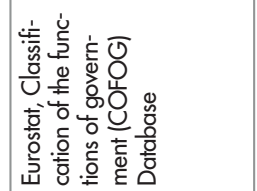 & 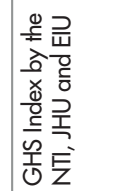 & 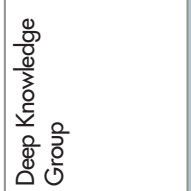 & $\sum_{\frac{1}{2}}^{0}$ \\
\hline$g$ & 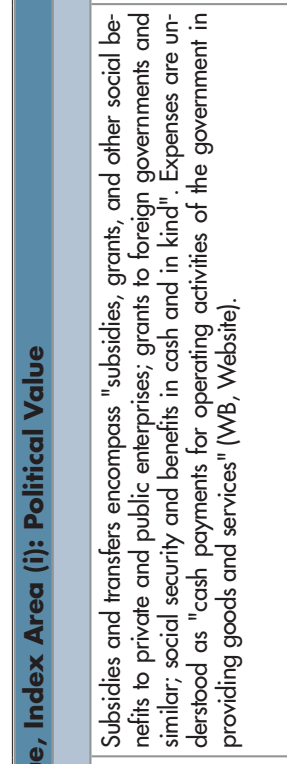 & 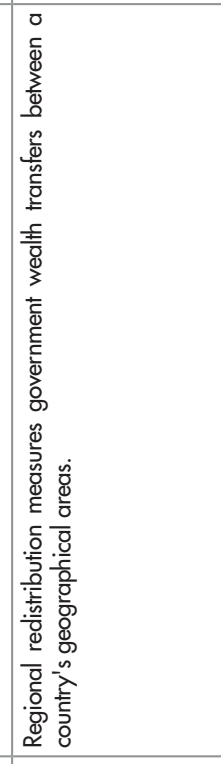 & 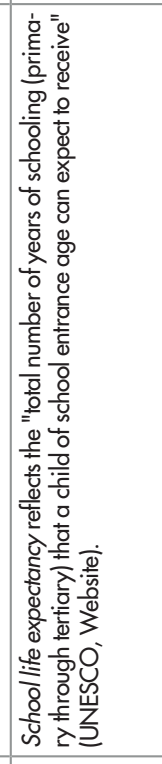 & 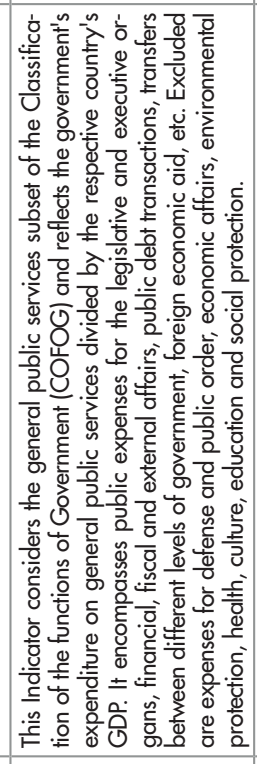 & 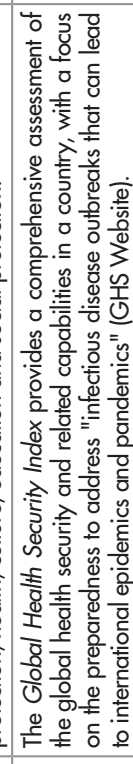 & 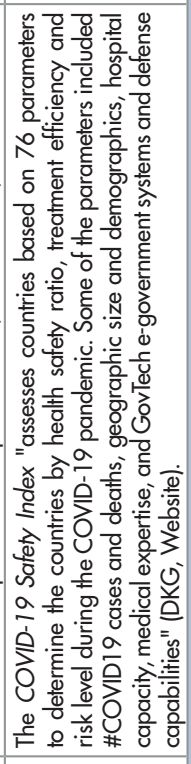 & 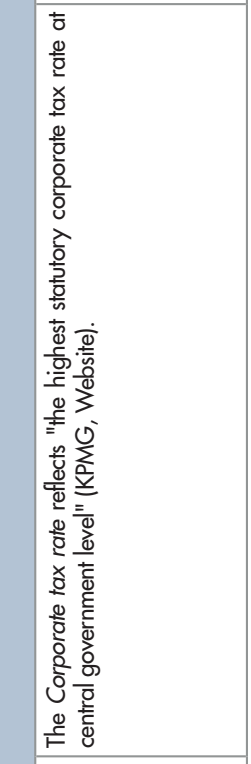 \\
\hline & 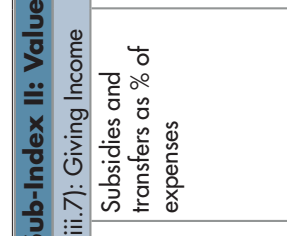 & 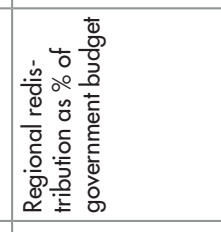 & 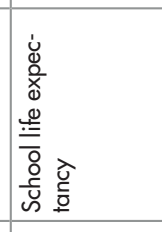 & 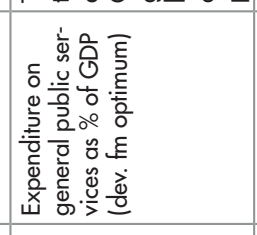 & 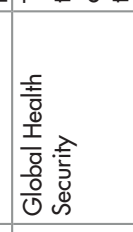 & 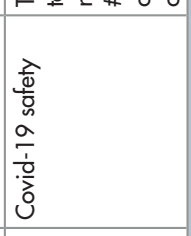 & 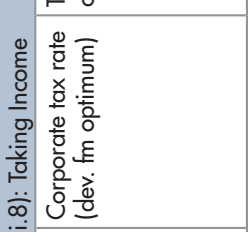 \\
\hline & 亲衮 & 岃 & 岂 & 0 & 勇 & 8 & 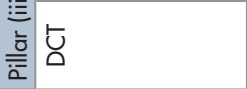 \\
\hline
\end{tabular}




\begin{tabular}{|c|c|c|c|c|c|c|c|}
\hline 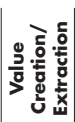 & $\stackrel{\delta}{\delta}$ 离 & 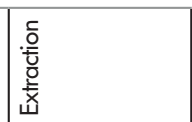 & $\begin{array}{l}\frac{\bar{c}}{\bar{t}} \\
\frac{\bar{g}}{\dot{x}}\end{array}$ & 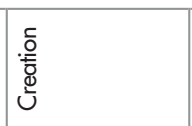 & 它. & 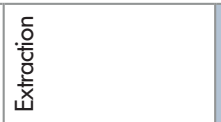 & 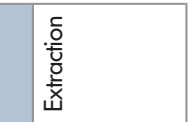 \\
\hline 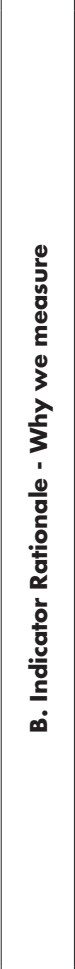 & 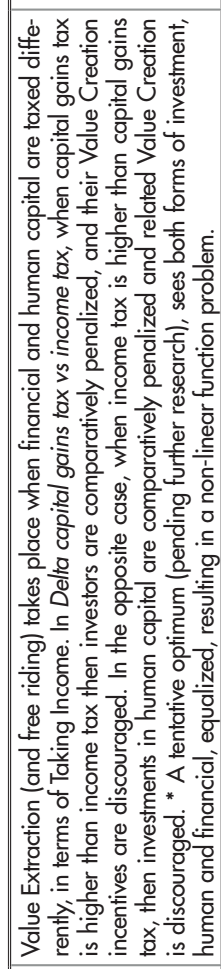 & 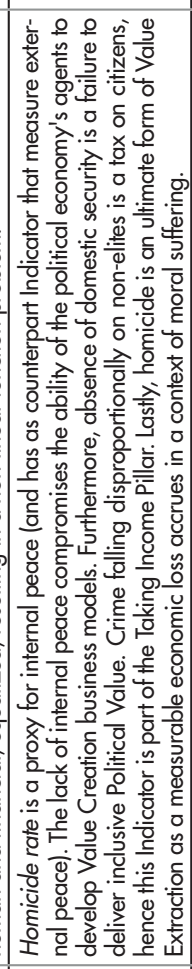 & 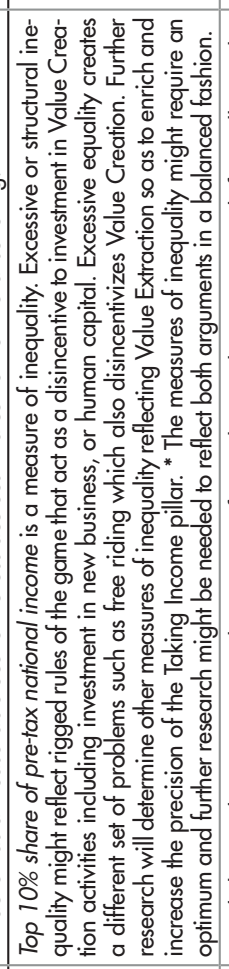 & 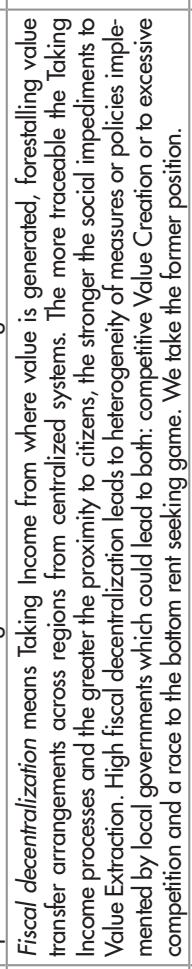 & 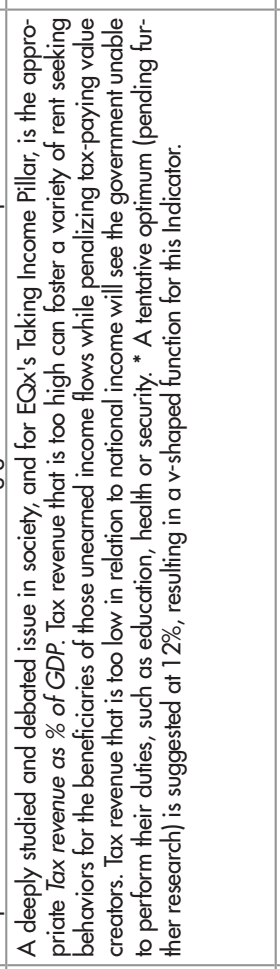 & 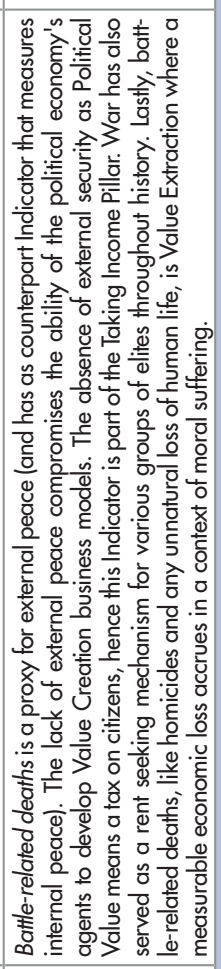 & 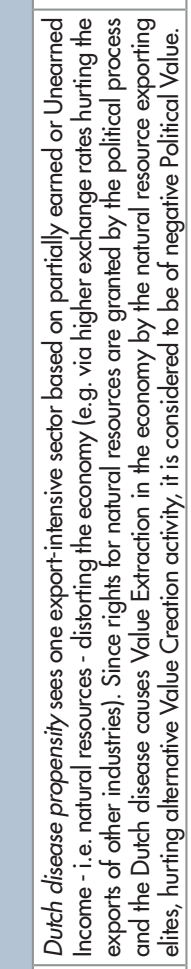 \\
\hline 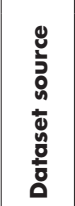 & 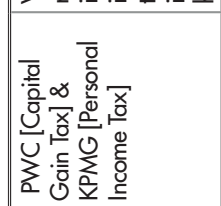 & 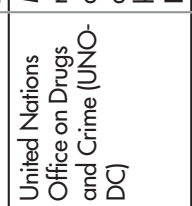 & 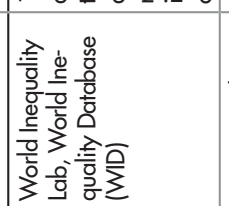 & 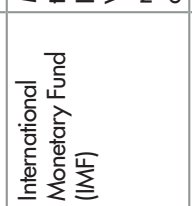 & 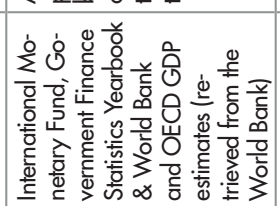 & 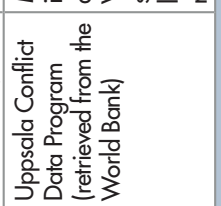 & 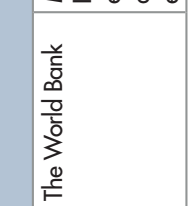 \\
\hline 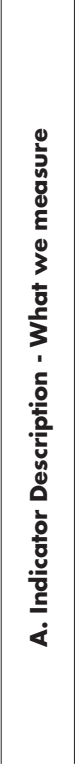 & 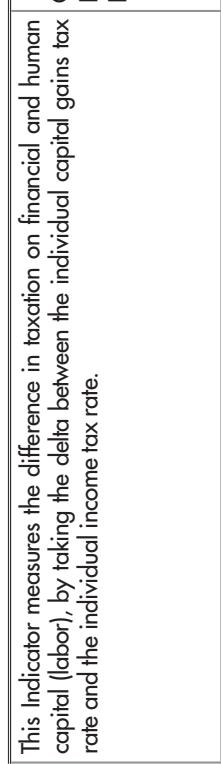 & 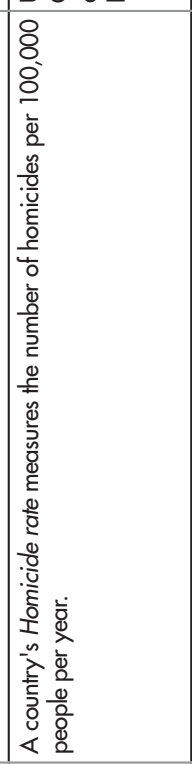 & 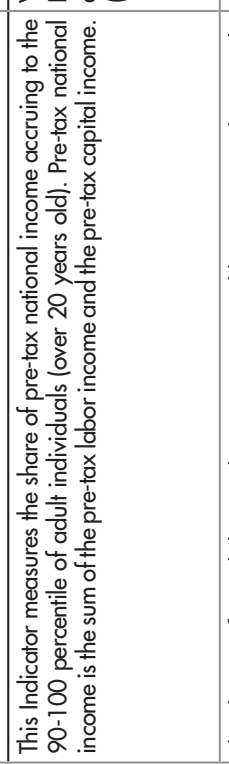 & 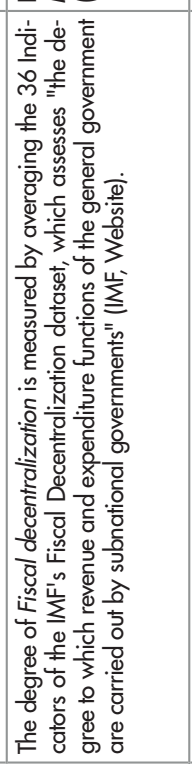 & 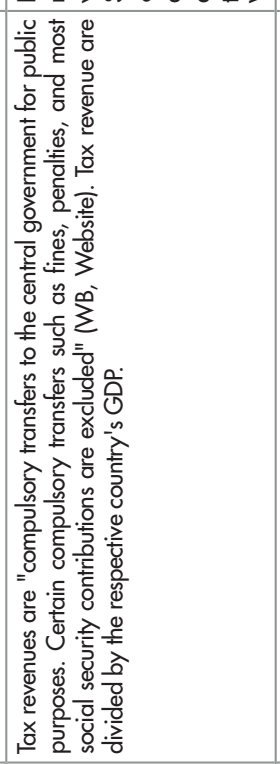 & 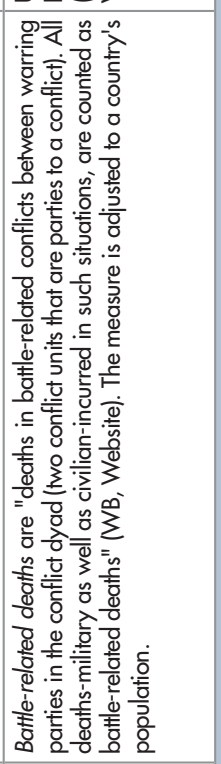 & 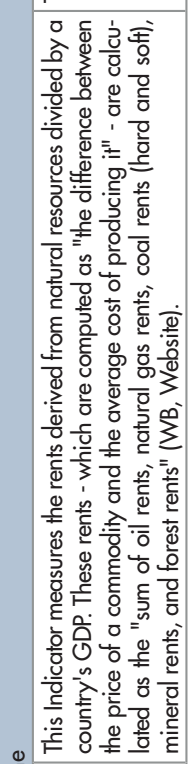 \\
\hline & 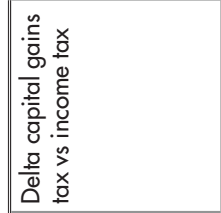 & 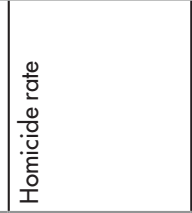 & 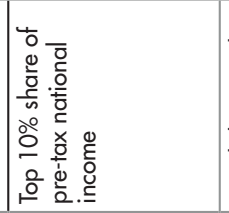 & 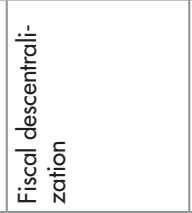 & 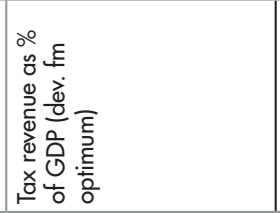 & 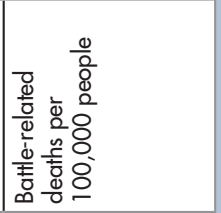 & 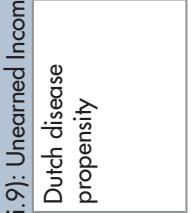 \\
\hline$\$$ & $\frac{\bar{\Delta}}{0}$ & 오 & $\underline{\underline{\mathbf{z}}}$ & 岁 & 兰 & 訔 & 5 \\
\hline
\end{tabular}




\begin{tabular}{|c|c|c|c|c|c|c|c|}
\hline & & 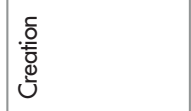 & 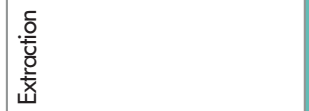 & & 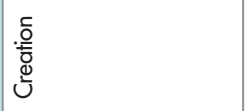 & 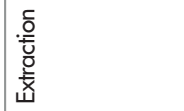 & 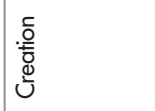 \\
\hline 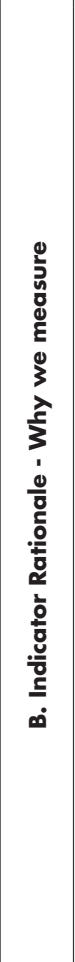 & 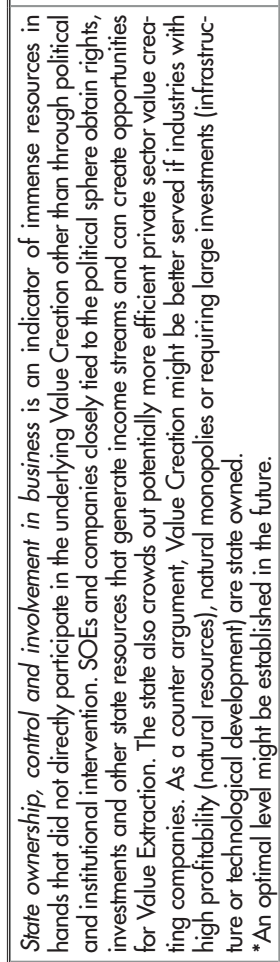 & 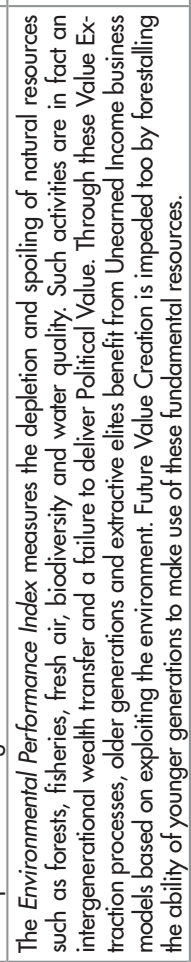 & 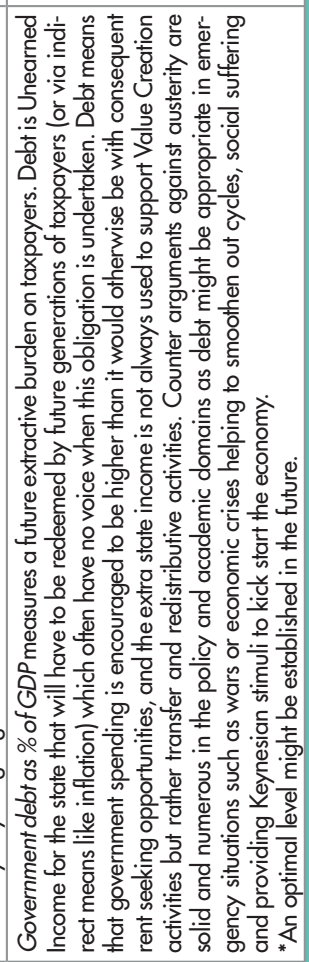 & & 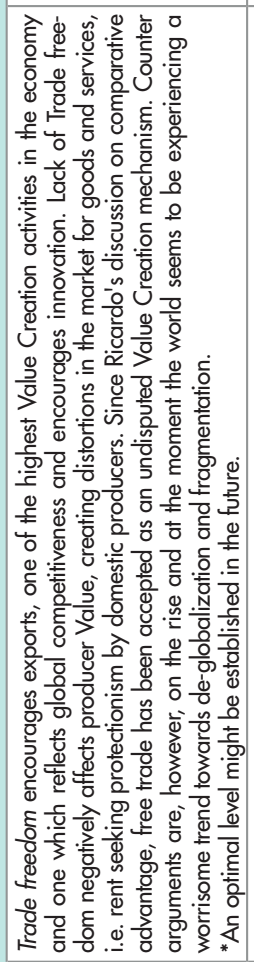 & 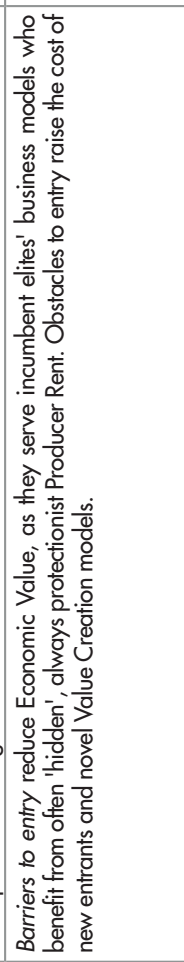 & 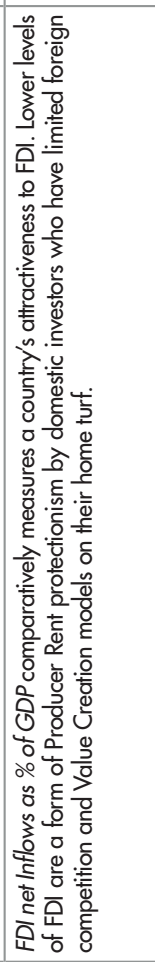 \\
\hline 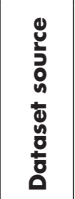 & 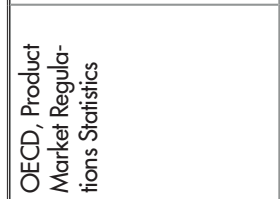 & 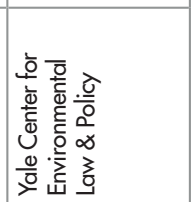 & 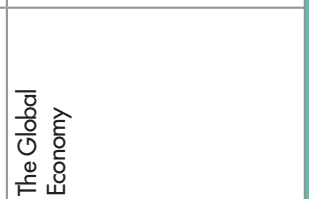 & & 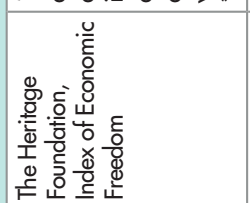 & 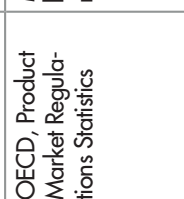 & 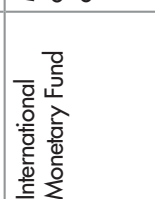 \\
\hline 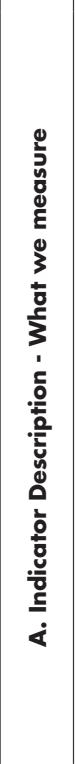 & 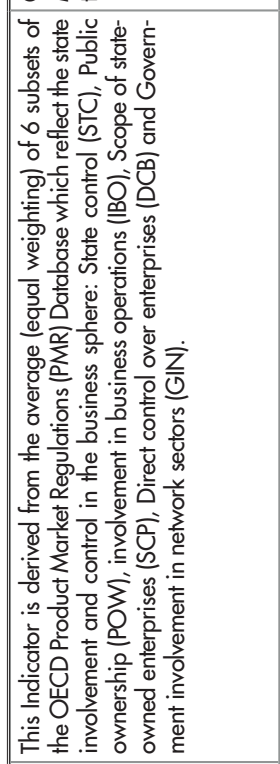 & 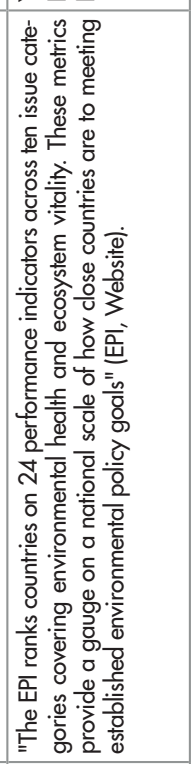 & 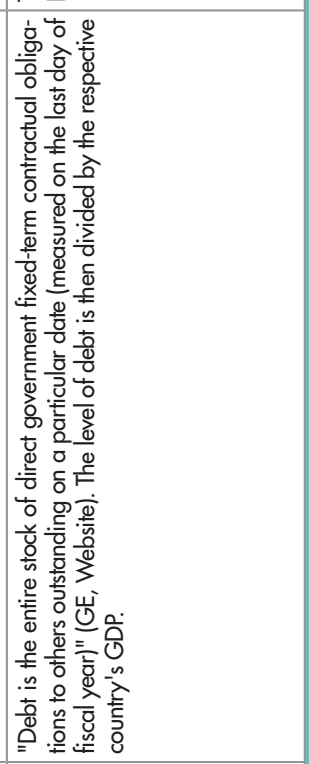 & 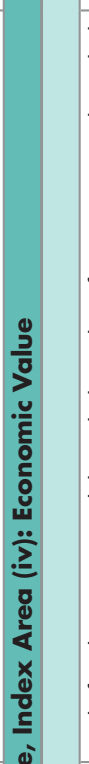 & 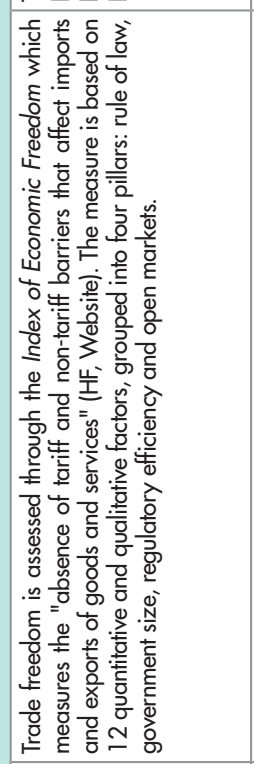 & 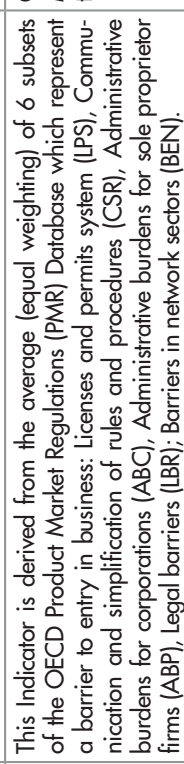 & 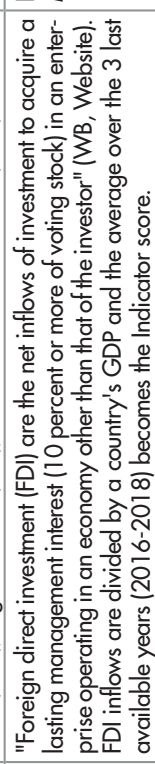 \\
\hline & 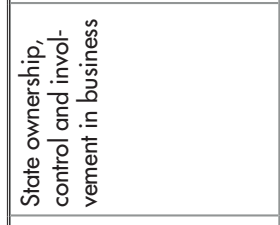 & 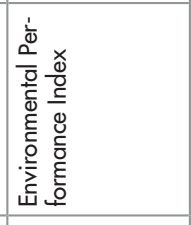 & 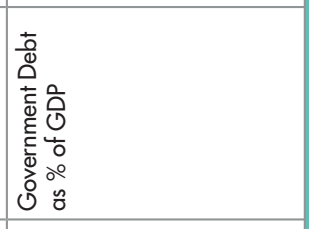 & 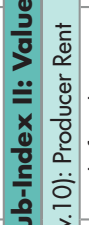 & & 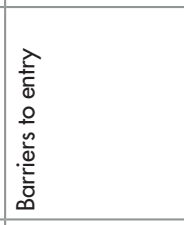 & 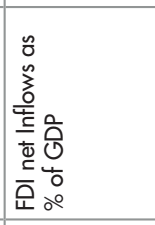 \\
\hline$\$$ & 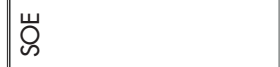 & $\overline{\bar{u}}$ & 嘀 & & & 产 & 品 \\
\hline
\end{tabular}




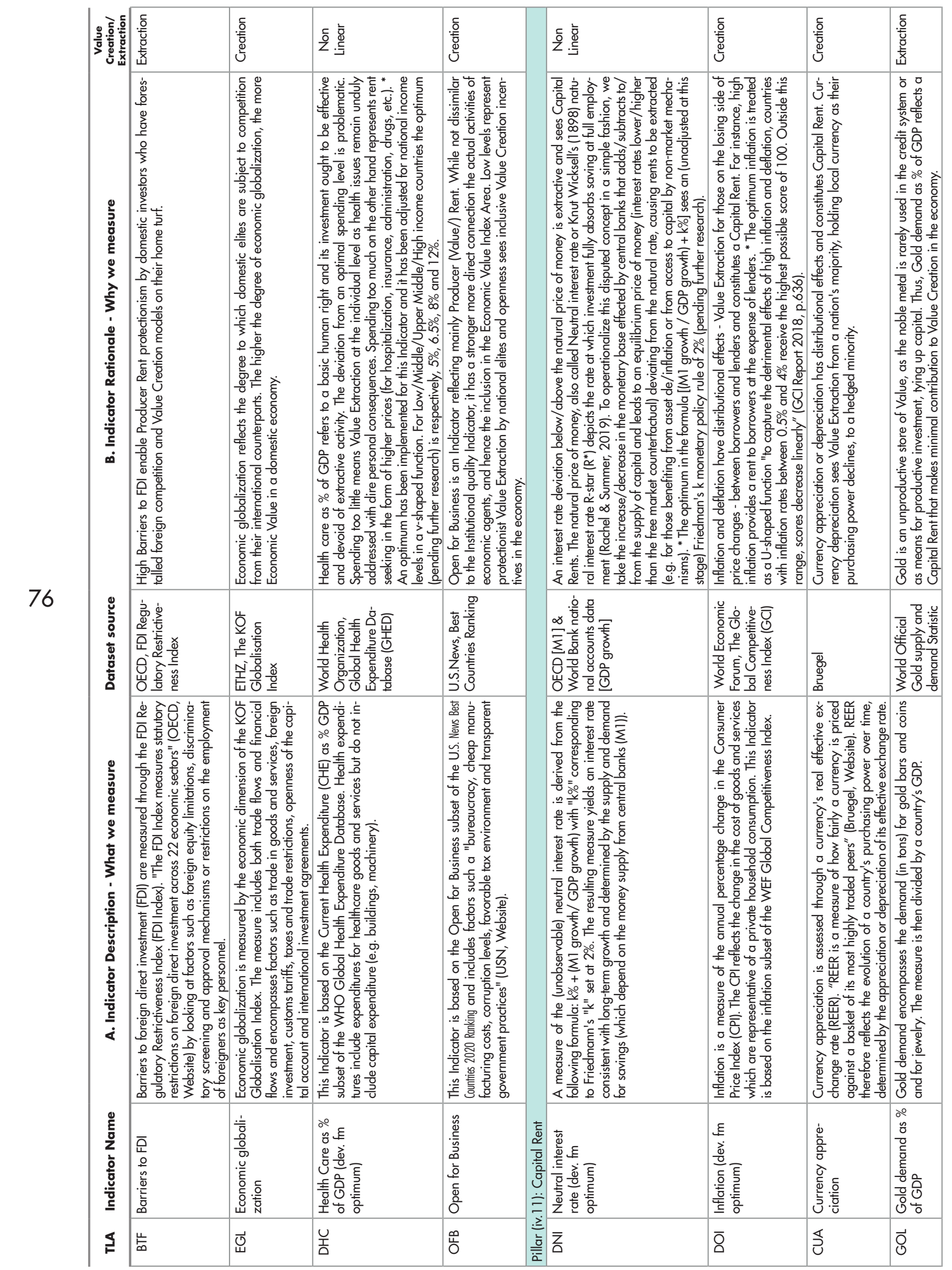




\begin{tabular}{|c|c|c|c|c|c|c|c|}
\hline & 它 & 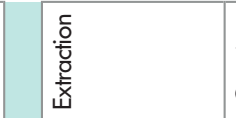 & 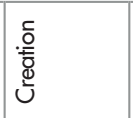 & 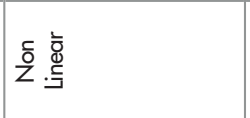 & 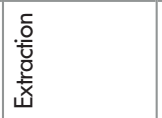 & 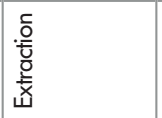 & 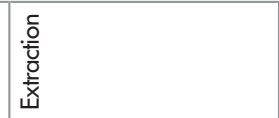 \\
\hline 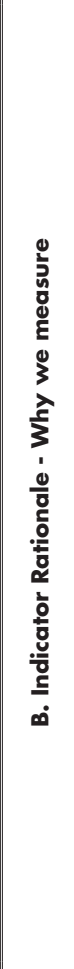 & 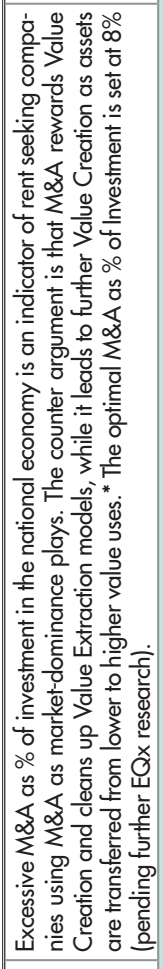 & 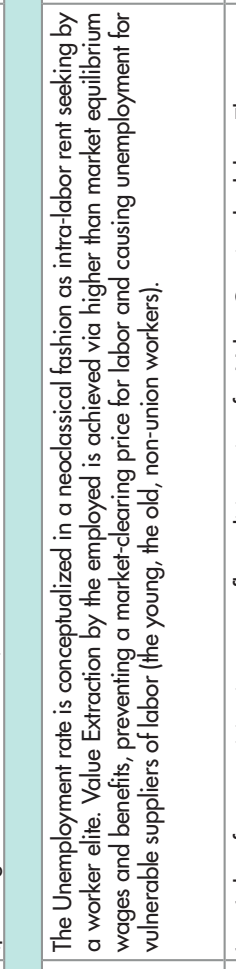 & 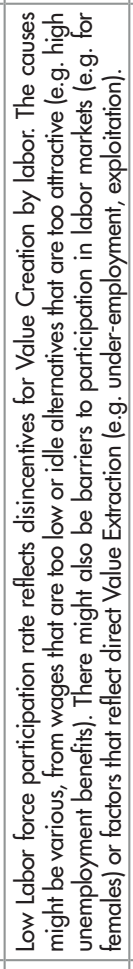 & 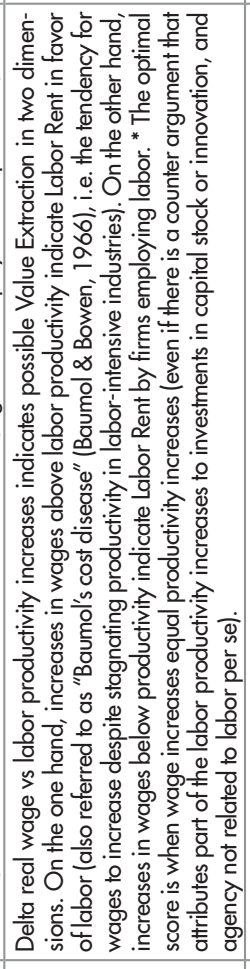 & 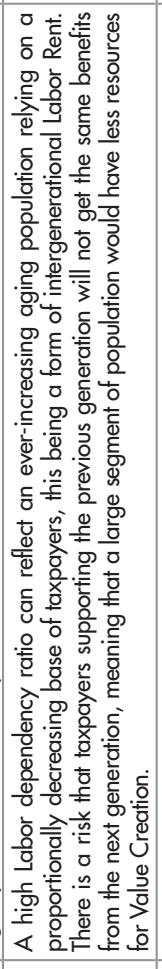 & 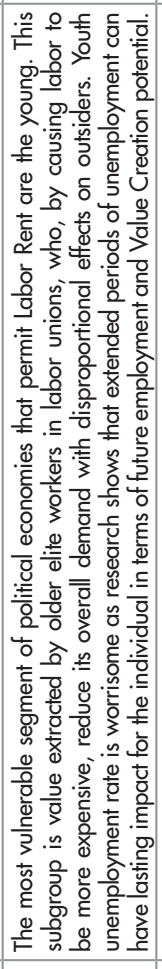 & 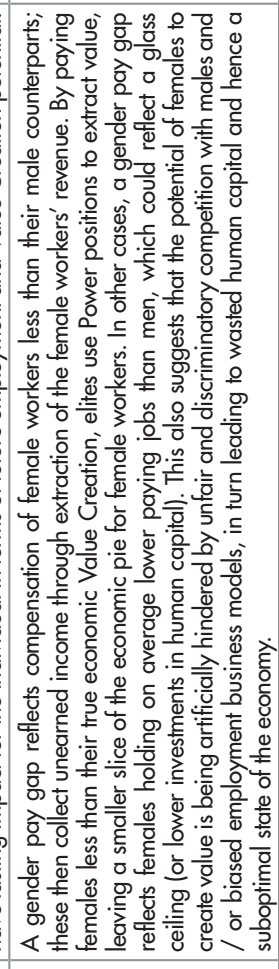 \\
\hline 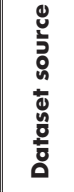 & 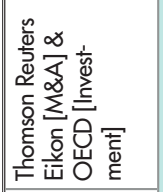 & 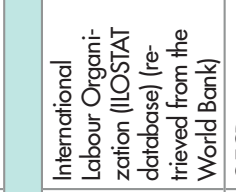 & & 0 & 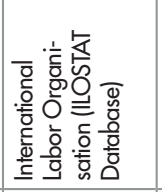 & 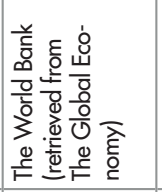 & Oి \\
\hline 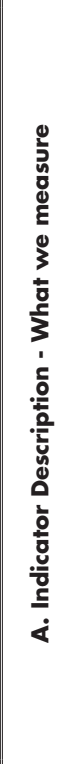 & 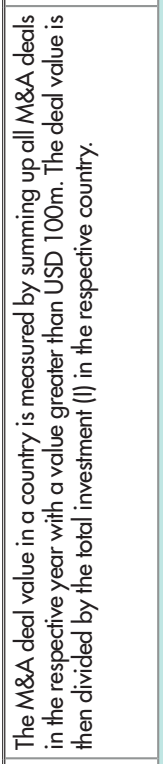 & 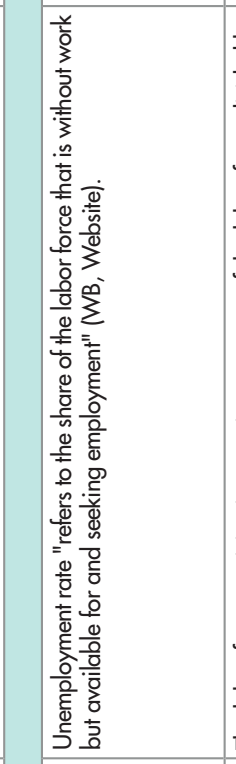 & 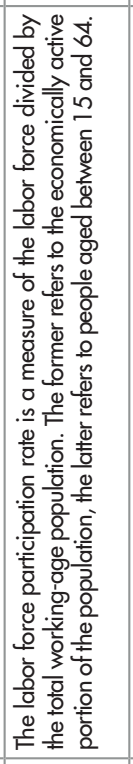 & 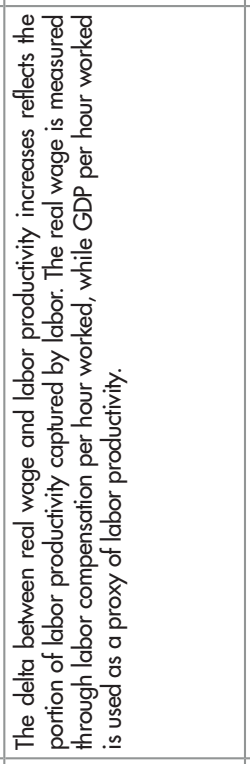 & 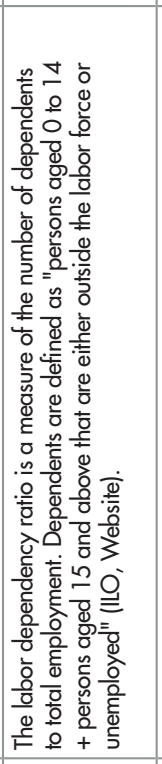 & 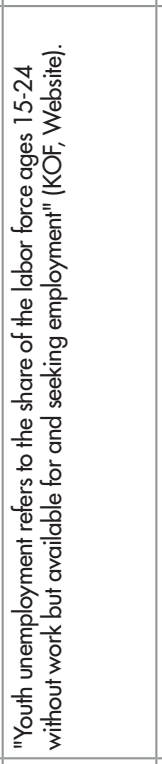 & 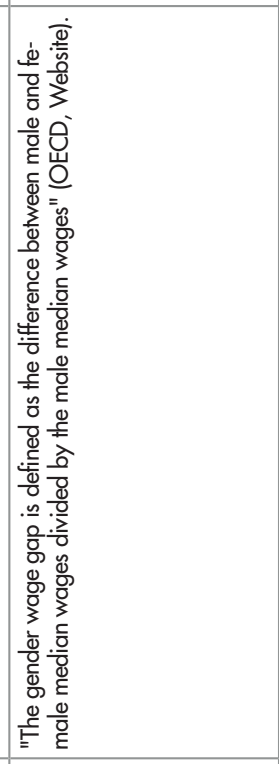 \\
\hline 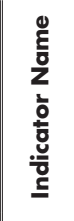 & 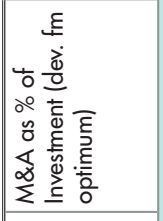 & 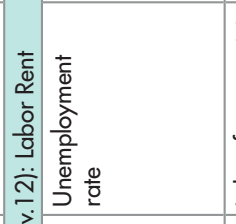 & 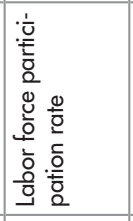 & 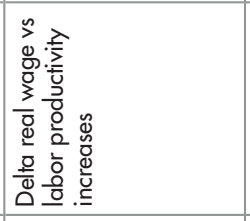 & 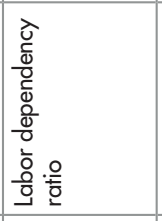 & 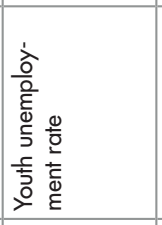 & 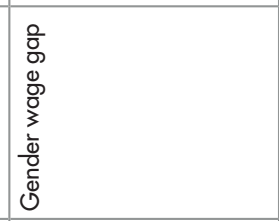 \\
\hline 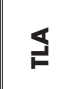 & 站 & 屁愛 & 诖 & 引 & قิ & 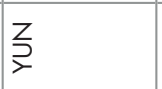 & $\sum_{0}^{2}$ \\
\hline
\end{tabular}




\subsection{Indicator Weighting Table}

Visual 5 1: EQx Indicator weighting table

\begin{tabular}{|c|c|c|c|}
\hline TLA & Variable Name & $\begin{array}{l}\text { Within } \\
\text { Pillar } \\
\text { weight } \\
\text { (BAP) }\end{array}$ & $\begin{array}{c}\text { Within } \\
\text { EQx } \\
\text { weights }\end{array}$ \\
\hline \multicolumn{4}{|c|}{ Sub-Index I: Power I Index Area (i): Political Power } \\
\hline Pillar (i.1) & State Capture & & \\
\hline COR & Political corruption & $19.5 \%$ & $0.8 \%$ \\
\hline$M O B$ & Social Mobility & $15.6 \%$ & $0.7 \%$ \\
\hline PDE & Political decentralization & $14.1 \%$ & $0.6 \%$ \\
\hline ADE & Administrative decentralization & $10.9 \%$ & $0.5 \%$ \\
\hline PGL & Political globalization & $12.7 \%$ & $0.5 \%$ \\
\hline WPI & Women's Power Index & $14.1 \%$ & $0.6 \%$ \\
\hline GRC & Government's responsiveness to change & $13.1 \%$ & $0.5 \%$ \\
\hline \multicolumn{4}{|c|}{ Pillar (i.2) Regulatory Capture } \\
\hline $\mathrm{DBI}$ & Institutional quality & $32.9 \%$ & $1.4 \%$ \\
\hline CRO & Crony-capitalism & $29.2 \%$ & $1.3 \%$ \\
\hline EXP & Expropriation risk & $19.2 \%$ & $0.8 \%$ \\
\hline PMl & Protecting Minority Investors & $11.9 \%$ & $0.5 \%$ \\
\hline ECR & Ease to Challenge Regulations & $6.8 \%$ & $0.3 \%$ \\
\hline \multicolumn{4}{|c|}{ Pillar (i.3) Human Capture } \\
\hline UNI & Unionization rate & $20.2 \%$ & $0.6 \%$ \\
\hline PSE & Public sector employees as $\%$ of total employement & $18.0 \%$ & $0.6 \%$ \\
\hline $\mathrm{CBC}$ & Collective Bargaining Coverage & $16.2 \%$ & $0.5 \%$ \\
\hline GSI & Global Slavery Index & $25.1 \%$ & $0.8 \%$ \\
\hline WBL & Women, Business and the Law & $20.4 \%$ & $0.6 \%$ \\
\hline
\end{tabular}

\section{Sub-Index I: Power I Index Area (ii): Economic Power}

\section{Pillar (ii.4) Industry Dominance}

\begin{tabular}{|c|l|c|c|}
\hline IEE & Top 3 industries exports as \% of GDP & $22.4 \%$ & $1.1 \%$ \\
\hline IRE & Top 3 industries as \% of GDP & $25.3 \%$ & $1.2 \%$ \\
\hline ECI & Economic Complexity Index & $38.4 \%$ & $1.8 \%$ \\
\hline IVA & Top 3 industries as \% of VA & $13.9 \%$ & $0.7 \%$ \\
\hline
\end{tabular}

Pillar (ii.5) Firm Dominance

\begin{tabular}{|c|l|c|c|}
\hline PRO & Top 10 firms profitability & $13.4 \%$ & $0.7 \%$ \\
\hline SME & SMEs per 1,000 people & $15.0 \%$ & $0.8 \%$ \\
\hline ATX & Antitrust exemptions & $18.0 \%$ & $0.9 \%$ \\
\hline BIW & Billionaires' wealth as \% of GDP & $15.6 \%$ & $0.8 \%$ \\
\hline FKG & Top 10 firms market cap as \% of GDP & $13.5 \%$ & $0.7 \%$ \\
\hline FRG & Top 3 firms revenues as \% of GDP & $5.9 \%$ & $0.3 \%$ \\
\hline FRR & Top 30 firms revenues as \% of GDP & $9.7 \%$ & $0.5 \%$ \\
\hline LIB & Lerner Index banking sector & $8.8 \%$ & $0.5 \%$ \\
\hline
\end{tabular}

Pillar (ii.6) Creative Destruction

\begin{tabular}{|c|l|c|c|}
\hline TUL & Listed firms turnover, long run 15 years & $7.5 \%$ & $0.9 \%$ \\
\hline TUS & Listed firms turnover, short run 3 years & $9.3 \%$ & $1.2 \%$ \\
\hline ENT & Entrepreneurship & $21.4 \%$ & $2.7 \%$ \\
\hline VCK & VC finance & $21.4 \%$ & $2.7 \%$ \\
\hline RND & R\&D \% GDP & $10.6 \%$ & $1.3 \%$ \\
\hline BTS & Barriers to start-ups & $15.1 \%$ & $1.9 \%$ \\
\hline ENR & Firm entry ratio & $10.5 \%$ & $1.3 \%$ \\
\hline EXR & Firm exit ratio & $4.3 \%$ & $0.5 \%$ \\
\hline
\end{tabular}

\begin{tabular}{|c|c|c|c|}
\hline TLA & Variable Name & $\begin{array}{l}\text { Within } \\
\text { Pillar } \\
\text { weight } \\
\text { (BAP) }\end{array}$ & $\begin{array}{l}\text { Within } \\
\text { EQX } \\
\text { weights }\end{array}$ \\
\hline \multicolumn{4}{|c|}{ Sub-Index II: Value I Index Area (iii): Political Value } \\
\hline Pillar (iii.7) & Giving Income & & \\
\hline SNT & Subsidies and transfers as $\%$ of expenses & $22.3 \%$ & $1.8 \%$ \\
\hline REG & Regional redistribution as \% of government budget & $19.4 \%$ & $1.6 \%$ \\
\hline EDU & School life expectancy & $20.4 \%$ & $1.7 \%$ \\
\hline GPS & $\begin{array}{l}\text { Expenditure on general public services as \% of } \\
\text { GDP (dev. fm optimum) }\end{array}$ & $13.7 \%$ & $1.1 \%$ \\
\hline GHS & Global Health Security & $8.6 \%$ & $0.7 \%$ \\
\hline COV & Covid-19 safety & $15.7 \%$ & $1.3 \%$ \\
\hline Pillar (iii.8) & \multicolumn{3}{|l|}{ Taking Income } \\
\hline DCT & Corporate tax rate (dev. fm optimum) & $12.7 \%$ & $1.0 \%$ \\
\hline DKI & Delta capital gains tax vs income tax & $15.7 \%$ & $1.2 \%$ \\
\hline $\mathrm{HOM}$ & Homicide rate & $22.9 \%$ & $1.9 \%$ \\
\hline INE & Top $10 \%$ share of pre-tax national income & $10.2 \%$ & $0.8 \%$ \\
\hline FDE & Fiscal descentralization & $13.5 \%$ & $1.1 \%$ \\
\hline DTR & Tax revenue as $\%$ of GDP (dev. fm optimum) & $13.3 \%$ & $1.1 \%$ \\
\hline BRD & Battle-related deaths per 100,000 people & $11.8 \%$ & $1.0 \%$ \\
\hline Pillar (iii.9) & \multicolumn{3}{|l|}{ Unearned Income } \\
\hline DUT & Dutch disease propensity & $22.1 \%$ & $1.4 \%$ \\
\hline SOE & State ownership, control and involvement in business & $17.6 \%$ & $1.1 \%$ \\
\hline EPI & Environmental Performance Index & $34.2 \%$ & $2.1 \%$ \\
\hline DBT & Government Debt as \% of GDP & $26.1 \%$ & $1.6 \%$ \\
\hline
\end{tabular}

\section{Sub-Index II: Value I Index Area (iv): Economic Value}

Pillar (iv. 10) Producer Rent

\begin{tabular}{|c|c|c|c|}
\hline TRF & Trade freedom & $20.0 \%$ & $2.5 \%$ \\
\hline BTE & Barriers to entry & $21.2 \%$ & $2.7 \%$ \\
\hline FDI & FDI net Inflows as \% of GDP & $16.8 \%$ & $2.1 \%$ \\
\hline BTF & Barriers to FDI & $10.9 \%$ & $1.4 \%$ \\
\hline EGL & Economic globalization & $12.0 \%$ & $1.5 \%$ \\
\hline $\mathrm{DHC}$ & Health Care as $\%$ of GDP (dev. fm optimum) & $13.0 \%$ & $1.7 \%$ \\
\hline OFB & Open for Business & $6.0 \%$ & $0.8 \%$ \\
\hline \multicolumn{4}{|c|}{ Pillar (iv.11) Capital Rent } \\
\hline DNI & Neutral interest rate (dev. fm optimum) & $31.31 \%$ & $4.6 \%$ \\
\hline DOI & Inflation (dev. fm optimum) & $22.81 \%$ & $3.4 \%$ \\
\hline CUA & Currency appreciation & $18.42 \%$ & $2.7 \%$ \\
\hline GOL & Gold demand as \% of GDP & $9.48 \%$ & $1.4 \%$ \\
\hline DMA & M\&A as $\%$ of Investment (dev. fm optimum) & $18.0 \%$ & $2.7 \%$ \\
\hline \multicolumn{4}{|c|}{ Pillar (iv. 12) Labor Rent } \\
\hline UEM & Unemployment rate & $23.7 \%$ & $3.8 \%$ \\
\hline LFP & Labor force participation rate & $8.7 \%$ & $1.4 \%$ \\
\hline WLP & Delta real wage vs labor productivity increases & $19.6 \%$ & $3.2 \%$ \\
\hline LDR & Labor dependency ratio & $10.1 \%$ & $1.6 \%$ \\
\hline YUN & Youth unemployment rate & $20.5 \%$ & $3.3 \%$ \\
\hline GWG & Gender wage gap & $17.3 \%$ & $2.8 \%$ \\
\hline
\end{tabular}




\section{References}

\subsection{General Literature}

Acemoglu, D. \& Robinson, J.A. (2019). The Narrow Corridor: States, Societies, and the Fate of Liberty. New York: Penguin Books

Acemoglu, D., Naidu, S., Restrepo, P., \& Robinson, J. A. (2019). Democracy does cause growth. Journal of Political Economy, 127(1), 47-100. https://doi.org/10.1086/700936

Buckup S.,\& Casas, T. (2018, November 6). Modern leaders need a powerful narrative. Management Today. Retrieved from: https://www.managementtoday.co.uk/modern-leaders-need-powerful-narrative/reputation-matters/article/1498184

Casas, T. (2020). An Inquiry into Elite Value Creation and Extraction: Conceptual Development for Political Economy Analysis and Measurement. Retrieved from SSRN: https://ssrn. com/abstract $=3660668$

Casas, T., Cozzi, G., Diebold, C.,\& Zeller, C. (2020). Measuring Elite Quality (MPRA Paper 102068). University Library of Munich, Germany. Retrieved from: https://ideas.repec.org/p/ pra/mprapa/102068.html

Clements, B. \& Parry, I. (2018, September). Subsidies: Some Work, Others Don't. Finance \& Development, 56-57. Retrieved from: https://www.imf.org/external/pubs/ft/fandd/2018/09/pdf/ what-are-subsidies-basics.pdf

Comparing crony capitalism around the world. (2016, May 5). The Economist. Retrieved from https://www.economist.com/ graphic-detail/2016/05/05/comparing-crony-capitalism-around-the-world

Federal Chancellery (2019). The Swiss Confederation - a brief guide 2019. Retrieved from https://www.bk.admin.ch/dam/bk/ en/dokumente/komm-ue/Buku2019/BUKU_2019_EN_Internet.pdf. download.pdf/BUKU_2019_EN_Internet.pdf

Hagel, J. (201 1, May 23). The Pull of Narrative - In Search of Persistent Context [Blog post]. Retrieved from: https://edgeperspectives.typepad.com/edge_perspectives/201 1/05/the-pull-of-narrative-in-search-of-persistent-context.html

Hausmann, R., Hidalgo, C., Bustos, S., Coscia, M., Chung, S., Jimenez, J.,\& Yildirim, M. (2011). The Atlas of Economic Complexity: Mapping Paths to Prosperity. Retrieved from: https://oec.world/static/pdf/atlas/AtlasOfEconomicComplexity.pdf
Hillman, A. L. \& Ursprung, H.W. (2015). Rent seeking: The idea, the reality, and the ideological resistance. Retrieved from https://www.econ.pitt.edu/sites/default/files/Hillman.Rent\%20 seeking.2015.pdf

OECD. (2008). Handbook on constructing composite indicators: Methodology and user guide. Retrieved from https://www.oecd. org/els/soc/handbookonconstructingcompositeindicatorsmethodologyanduserguide.htm

Little, R. J., \& Rubin, D. B. (2002). Statistical analysis with missing data (2 ${ }^{\text {nd }}$ ed.). Hoboken, NJ: Wiley-Interscience

Mazziotta, M., \& Pareto, A. (2013). Methods for constructing composite indices: one for all or all for one? Rivista Italiana Die Economia Demografia E Statistica, LXVII(2), 67-80. Retrieved from: https://pdfs.semanticscholar.org/2b6c/5777d49a2ddc2a6665483de36b8525f1ce08.pdf

Planet Plutocrat. (2014, March 15). The Economist. Retrieved from https://www.economist.com/news/international/21599041-countries-wherepolitically-connected-businessmen-aremostlikely-prosper-planet

Porter, M. (1990). The Competitive Advantage of Nations. New York: Free Press

Rachel, L. \& Summer, L. H. (2019). On Secular Stagnation in the Industrialized World (NBER Working Paper No. 26198). Retrieved from National Bureau of Economic Research: https:// www.nber.org/papers/w26198.pdf

Saito, T. (2012). How Do We Get Cobb-Douglas and Leontief Functions from CES Function: A Lecture Note on Discrete and Continuum Differentiated Object Models. Journal of Industrial Organization Education, 6(1). https://doi.org/10.1515/19355041.1037

Santeramo, G. S. (2017). Methodological Challenges in Building Composite Indexes: Linking Theory to Practice. In Dobrota, M., Jeremic, V., \& Radojicic, Z. (Eds.). Emerging trends in the development and application of composite indicators (pp. 127-140). Retrieved from: https://mpra.ub.uni-muenchen. de/73276/1/MPRA_paper_73276.pdf

Schumpeter, A..J. (1942). Capitalism, Socialism and Democracy. New York: Harper \& Brothers 
Shiller, R.J. (2017). Narrative Economics. American Economic Review. 107(4), 967-1004. doi: 10.1257/aer.107.4.967

Stigler, G. (1971). The Theory of Economic Regulation. The Bell Journal of Economics and Management Science, III1), 3-21. doi: $10.2307 / 3003160$

United Nations Development Programme (UNDP). (2019). Human Development Index (HDI) [Dataset]. Retrieved May 23, 2020 from: hitp://hdr.undp.org/en/data

Wolf, M. (2019, September 18). Why rigged capitalism is damaging liberal democracy. Financial Times. Retrieved from hitps://www.ff.com/content/5a8ab27ed470-1 1 e9-8367- 807ebd53ab77

World Economic Forum. (2018). The Global Competitiveness Index Dataset 2007-2017 [v. 20180712].Retrieved from: http://www3.weforum.org/docs/GCR2017-2018/GCI_Dataset_2007-2017.xlsx

The World Bank. (n.d.). GDP per capita, PPP (current international \$) [Dataset ID: NY.GDP.PCAP.PP.CD]. Retrieved May 23, 2020 from: hitps://data.worldbank.org/indicator/NY.GDP.PCAP.PP.CD 


\subsection{Data Sources, Indicators references}

The first reference is to the source that supplies the data used. A follow up reference might be provided for additional, relevant literature

* Data sources are indicated with an asterisk when the data provider requested a specific citation format:

\section{i. 1 - Political corruption (COR), uses data from: Varieties of Democracies (V-DEM)*}

[Dataset]

Coppedge, Michael, John Gerring, Carl Henrik Knutsen, Staffan I. Lindberg, Jan Teorell, David Altman, Michael Bernhard, M. Steven Fish, Adam Glynn, Allen Hicken, Anna Luhrmann, Kyle L. Marquardt, Kelly McMann, Pamela Paxton, Daniel Pemstein, Brigitte Seim, Rachel Sigman, Svend-Erik Skaaning, Jeffrey Staton, Steven Wilson, Agnes Cornell, Nazifa Alizada, Lisa Gastaldi, Haakon Gjerløw, Garry Hindle, Nina llchenko, Laura Maxwell, Valeriya Mechkova, Juraj Medzihorsky, Johannes von Römer, Aksel Sundström, Eitan Tzelgov, Yi-ting Wang, Tore Wig, and Daniel Ziblatt. 2020. "V-Dem [Country-Year/CountryDate] Dataset v10". Varieties of Democracy (V-Dem) Project. https://doi. org/10.23696/vdemds20.

[Related paper]

Pemstein, D., Marquardt, K. L., Tzelgov, E., Wang, Y., Medzihorsky, J., Krusell, J., Miri, F., \& Roemer, J. (2019). The V-Dem Measurement Model: Latent Indicator Analysis for Cross-National and Cross-Temporal Expert-Coded Data. SSRN Electronic Journal. https://doi.org/10.2139/ssrn.3395892

i. 1 - Social mobility (MOB), uses data from: The World Bank (Development Research Group), GDIM Database*

[Dataset]

GDIM. 2018. Global Database on Intergenerational Mobility. Development Research Group, World Bank. Washington, D.C.: World Bank Group

[Related paper]

Narayan, A., Van der Weide, R., Cojocaru, A., Lakner, C., Redaelli, S., Gerszon Mahler, D., Ramasubbaiah, R. G. N., \& Thewissen, S. (2018). Fair Progress?: Economic Mobility across Generations around the World. Equity and Develop ment. Washington, DC: The World Bank. https://openknowledge.worldbank. org/handle/10986/28428 License: CC BY 3.0 IGO.

i.1 - Political decentralization (PDE), uses data from:

\section{The World Bank, Policy Research Working Paper*}

[Working Paper]

Maksym Ivanyna and Anwar Shah (2014). How Close is Your Government to lts People? Worldwide Indicators on Localization and Decentralization. Economics: The Open-Access, Open-Assessment E-Journal, Vol. 8, 2014-3. http://dx.doi. org/10.5018/economics-ejournal.ja.2014-3

\section{i. 1 - Administrative decentralization (ADE), uses data from: The World Bank, Policy Research Working Paper*}

[Working Paper]

Maksym Ivanyna and Anwar Shah (2014). How Close is Your Government to Its People? Worldwide Indicators on Localization and Decentralization. Economics: The Open-Access, Open-Assessment E-Journal, Vol. 8, 2014-3. http://dx.doi. org/10.5018/economics-ejournal.ja.2014-3

\section{i. 1 - Political globalization (PGL), uses data from: ETHZ, The KOF Globalisation Index*}

[Dataset]

Gygli, Savina, Florian Haelg, Niklas Potrafke and Jan-Egbert Sturm (2019): The KOF Globalisation Index - Revisited, Review of International Organizations, 14(3), 543-574 https://doi.org/10.1007/s11558-019-09344-2

[Related Paper]

Dreher, Axel (2006): Does Globalization Affect Growth? Evidence from a new Index of Globalization, Applied Economics 38, 10: 1091-1110. i. 1 - Women's Power Index (WPI), uses data from:

The Council of Foreign Relations (CFR)

[Dataset]

Council on Foreign Relations. (2020). Women's Power Index. Retrieved April 20, 2020, from https://www.cfr.org/article/womens-power-index

i. 1 - Government's responsiveness to change (GRC), uses data from: World Economic Forum, The Global Competitiveness Index

[Report]

World Economic Forum. (2019). Global Competitiveness Report 2019. Retrieved April 20, 2020, from hitp://www3.weforum.org/docs/WEF_TheGlobalCompetitivenessReport2019.pdf

i.2 - Institutional quality (DBI), uses data from:

The World Bank, Doing Business Index

[Report]

The World Bank Group.(2019). Doing Business 2019: Training for Reform. Retrieved from https://doi.org/10.1596/978-1-4648-1326-9

i.2 - Crony-capitalism (CRO), uses data from:

Forbes [Billionaires list] \& The World Bank [GDP]

[Dataset]

Forbes. (2019). Forbes Billionaires List 2018. Retrieved from https://www. forbes.com/billionaires/list/;\#version:static;

The World Bank. (n.d.). GDP (current US\$) [Indicator ID: NY.GDP.MKTP.CD]. Retrieved June 4, 2020, from https://data.worldbank.org/indicator/ NY.GDP.MKTP.CD

i.2 - Expropriation risk (EXP), uses data from: Credendo

[Dataset]

TheGlobalEconomy.com. (n.d.). Expropriation risk by country, around the world. Retrieved from https://www.theglobaleconomy.com/rankings/Expropriation risk/

i.2 - Protecting Minority Investors (PMI), uses data from: The World Bank, Doing Business Indicators

[Report]

The World Bank Group.(2019). Doing Business 2019: Training for Reform. Retrieved from hittps://doi.org/10.1596/978-1-4648-1326-9

i.2 - Ease of Challenge Regulations (ECR), uses data from:

World Economic Forum, The Global Competitiveness Index

World Economic Forum. 2019. Global Competitiveness Index 2017-2018 - Reports - World Economic Forum. Retrieved from http://reports.weforum.org/ global-competitiveness-index-2017-2018/competitiveness-rankings/\#series=EOSQ039

i.3 - Unionization rate (UNI), uses data from:

$$
\text { International Labor Organisation, ILOSTAT Database* }
$$

International Labour Organization. (2018). ILOSTAT database Industrial Relations Data. Available from https://ilostat.ilo.org/data/.

i.3 - Public sector employees as \% of total employment (PSE), uses data from:

International Labor Organisation, ILOSTAT Database* International Labour Organization. (2019). ILOSTAT database Public Sector Employment. Available from hitps://ilostat.ilo.org/data/ 
i.3 - Collective Bargaining Coverage, (CBC) uses data from: International Labor Organisation, ILOSTAT Database*

International Labour Organization. (2018). ILOSTAT database Industrial Relations Data. Available from hitps://ilostat.ilo.org/data/

\section{i.3 - Global Slavery Index (GSI), uses data from:}

The Minderoo Foundation Pty Ltd and the Walk Free Foundation

[Report]

The Minderoo Foundation. (2018). The Global Slavery Index 2018. Retrieved from:

https://wnw.globalslaveryindex.org/resources/downloads/

i.3 - Women, Business and the Law (WBL), uses data from: The World Bank

[Dataset]

The World Bank. (2020). Women, Business and the Law Data for 1971-2020.

Retrieved from: https://wbl.worldbank.org/en/wbl-data

ii.4 - Top 3 industries exports as \% of GDP, uses data from (IEE):

United Nations, Comtrade Database \& The World Bank [GDP]

[Dataset]

United Nations.(n.d.) UN Comtrade Database. Retrieved March 13, 2019 from:

https://comtrade.un.org/

The World Bank. (n.d.). GDP (current US\$) [Indicator ID: NY.GDP.MKTP.CD] Retrieved June 4, 2020, from https://data.worldbank.org/indicator/ NY.GDP.MKTP.CD

ii. 4 - Top 3 industries as \% of GDP, (IRE) uses data from:

UNdata, National Accounts Official Country Data

[Dataset]

82 UNdata. (n.d.). National Accounts Official Country Data Table 2.4 Value added by industries at current prices (ISIC Rev. 4) [Dataset]. Retrieved April 20, 2020, from http://data.un.org/Data.aspx? $q=$ industries\&d=SNA\&f=group_ code\%3A204

ii.4 - Economy Complexity Index (ECI), uses data from: The Observatory of Economic Complexity (OEC)

[Dataset]

OEC. (n.d.). Economic Complexity Ranking of Countries (2013-2017) [Dataset] Retrieved Januar 10, 2019 from https://oec.world/en/rankings/country/eci/

ii. 4 - Top 3 industries as \% of VA (IVA), uses data from:

UNdata, National Accounts Estimates of Main Aggregates

[Dataset]

UNdata. (n.d.). National Accounts Estimates of Main Aggregates Gross Value Added by Kind of Economic Activity at current prices - U.S. dollars [Dataset]. Retrieved April 20, 2020 from hitp://data.un.org/Data.aspx?q=value+added\&d=SNAAMA\&f=grID\%3A201\%3BcurrID\%3AUSD\%3BpcFlag\%3A0

ii.5 - Top 10 firms profitability (PRO), uses data from: ThomsonOne

[Dataset]

ThomsonOne. (2020). Company-based data: Revenue, Profit, Market Capitalization [Dataset - 2018 data]. Retrieved from http://www.thomsonone. com/

ii.5 - SME per 1,000 people (SME), uses data from: SME Finance Forum, MSME Economic Indicators

[Dataset]

SME Finance Forum. (2019). MSME Economic Indicators Database 2019. Retrieved from https://www.smefinanceforum.org/data-sites/msme-country-indicators ii.5 - Antitrsut exemptions (ATX), uses data from: OECD, Product Economic Regulation Statistics*

OECD (2019), "Economy-wide regulation (Edition 2018)", OECD Product Market Regulation Statistics (database), https://doi.org/10.1787/eb1 le6de-en (accessed on 11 September 2019)

ii.5 - Billionaires' wealth as \% of GDP (BIW), uses data from: Forbes [Billionaires list] \& The World Bank [GDP]

[Dataset]

Forbes. 2019. "Forbes Billionaires List 2018 [Dataset]. Retrieved from https:// www.forbes.com/billionaires/list/;\#version:static;

The World Bank. (n.d.). GDP (current US\$) [Indicator ID: NY.GDP.MKTP.CD]. Retrieved June 4, 2020, from https://data.worldbank.org/indicator/ NY.GDP.MKTP.CD

ii.5 - Top 10 firms market cap as \% of GDP (FKG), uses data from: ThomsonOne

[Dataset]

ThomsonOne. (2020). Company-based data: Revenue, Profit, Market Capitalization [Dataset - 2018 data]. Retrieved from http://www.thomsonone. com/

ii.5 - Top 3 firms revenue as \% of GDP (FRG), uses data from: ThomsonOne

[Dataset]

ThomsonOne. (2020). Company-based data: Revenue, Profit, Market Capitalization [Dataset - 2018 data]. Retrieved from http:// $\mathrm{www}$.thomsonone. com/

ii. 5 - Top 30 firms revenue as \% of GDP (FRR), uses data from: ThomsonOne

[Dataset]

ThomsonOne. (2020). Company-based data: Revenue, Profit, Market Capitalization [Dataset - 2018 data]. Retrieved from http://www.thomsonone. com/

ii.5 - Lerner Index banking sector (LIB), uses data from: The World Bank

[Dataset]

The World Bank. (n.d.). Lerner Index [Global Financial Development database]. Retrieved May 4, 2020 from https://databank.worldbank.org/reports. aspx? source $=1250 \&$ series $=$ GFDD. 01.04

[Working Paper]*

Demirguc-Kunt, A.; Martinez Peria, M.S. (2010) . A framework for analyzing competition in the banking sector : an application to the case of Jordan (English). Policy Research working paper; no. WPS 5499. Washington, DC: World Bank. http://documents.worldbank.org/curated/

en/349041468063241 288/A-framework-for-analyzing-competition-in-thebanking-sector-an-application-to-the-case-of-Jordan

ii.6 - Listed firms turnover, long run 15 years (TUL), uses data from: Thomson Reuters Eikon

[Dataset]

Thomson Reuters Eikon. (2020). Constituents: Leavers and Joiners [Dataset]. Retrieved February 01, 2020, from hitps://eikon.thomsonreuters.com/index. $\mathrm{html}$ https://eikon.thomsonreuters.com/index.html

ii.6 - Listed firms turnover, short run 3 years, (TUS) uses data from: Thomson Reuters Eikon

[Dataset]

Thomson Reuters Eikon (2020). Constituents: Leavers and Joiners [Dataset].

Retrieved February 01, 2020, from https://eikon.thomsonreuters.com/index.html 
ii.6 - Entrepreuneurship (ENT), uses data from:

The Global Entrepreneurship and Development Institute (GEDI)

[Report]

Ács, Z.J., Lloyd, A., \& Szerb L. (n.d.). Global Entrepreneurship Index 2018.

Retrieved from https://thegedi.org/wp-content/uploads/dlm_up-

loads/2017/11/GEl-2018-1.pdf

ii.6 - VC finance (VCK), uses data from:

$$
\text { OECD.Stat \& Preqin }
$$

[Dataset]

OECD. (n.d.). OECD Entrepreneurship Financing Database. Retrieved

September 14, 2019, from https://stats.oecd.org/Index.aspx?DataSetCode $=$ VC_INVES

Preqin Pro. (n.d.). Venture Capital Database. Retrieved from: https://www. preqin.com/data/venture-capital

ii.6 - R\&D \% GDP (RND), uses data from:

UNESCO Institute for Statistics (UIS.Stats) (Retrieved from the World Bank)

[Dataset]

The World Bank. (n.d.). Research and development expenditure (\% of GDP)

[Indicator ID: GB.XP D.RSDV.GD.ZS]. Retrieved January 7, 2020 from: https:// data.worldbank.org/indicator/GB.XP D.RSDV.GD.ZS

ii.6 - Barriers to start-ups (BTS), uses data from:

OECD, Product Economic Regulation Statistics*

[Dataset]

OECD (2020), "Economy-wide regulation", OECD Product Market Regulation

Statistics (database), https://doi.org/10.1787/data-00593-en (accessed on 29 March 2020)

ii.6 - Firm entry ratio (ENR), uses data from:

[Dataset].

The World Bank, Doing Business Indicators

The World Bank. (2019). Entrepreneurship Survey and database. New business

density. Retrieved from hitps://data.worldbank.org/indicator/ic.bus.ndns.zs

ii.6 - Firm exit ratio (EXR), uses data from:

OECD, SDBS Business Demography Indicators

[Dataset].

OECD. 2018. Structural and Demographic Business Statistics (SDBS) Business Demography Indicators: Death rate of enterprises. Retrieved from hitps://stats. oecd.org/Index.aspx?Queryld=70734

iii.7 - Subsidies and transfers as \% of GDP (SNT), uses data from: International Monetary Fund, Government Finance Statistics Yearbook (Retrieved from the World Bank)

[Dataset].

The World Bank. (n.d.). Subsidies and other transfers (\% of expense) [Indicator ID: GC.XPN.TRFT.ZS]. Retrieved February 7, 2020 from https://data.worldbank. org/indicator/GC.XPN.TRFT.ZS?view=chart

iii.7 - Regional redistribution as \% of government budget (REG), uses data from:

Fraser Institute*

[Report]

James Gwartnes, Robert Lawson, Joshua Hall, and Ryan Murphy (2018)

Economic Freedom of the World: 2018 Annual Report. Fraser Institute. <https:// mww.fraserinstitute.org/studies/ economic-freedom>. iii.7 - School life expectancy (EDU), uses data from:

UNESCO Institute for Statistics (UIS.Stats)

[Dataset]

UIS.Stats. (n.d.). School life expectancy by level of education. Retrieved April 4, 2019 from: http://data.uis.unesco.org

iii.7 - Expenditure on general public services as \% of GDP (GPS), uses data from:

Eurostat, Classification of the functions of government

[Dataset] (COFOG) Database

Eurostat. (2020). General government expenditure by function of government (COFOG) [gov_10a_exp]. Retrieved from https://appsso.eurostat.ec.europa. eu/nui/submitViewTableAction.do

[Related paper]

Eurostat. (2020). Government expenditure on general public services, Statistics explained. Retrieved from hitps://ec.europa.eu/eurostat/statistics-explained/ pdfscache/42727.pdf

iii.7 - Global Health Security (GHS), uses data from:

GHS Index by the NTI, JHU and EIU

[Report]

GHS Index. 2019. Global Health Security Index: Building Collective Action and Accountability. Retrieved from hitps://www.ghsindex.org/wp-content/ uploads/2019/10/2019-Global-Health-Security-Index.pdf

iii.7 - Covid-19 safety (COV), uses data from: Deep Knowledge Group

[Dataset]

Deep Knowledge Group.(n.d.). COVID-19 Safety Ranking. Retrieved April 20, 2020, from https://www.dkv.global/safety-ranking

iii. 8 - Corporate tax rate (DCT), uses data from: KPMG

[Dataset]

KPMG. (n.d.). Corporate tax rates table. Retrieved Jan 15, 2020, from https:// home.kpmg/xx/en/home/services/tax/tax-tools-and-resources/tax-rates-online/corporate-tax-rates-table.html

iii.8 - Delta capital gains tax vs income tax (DKI), uses data from: PWC [Capital Gain Tax] \& KPMG [Personal Income Tax]

[Dataset]

PWC. (n.d.). Capital gains tax (CGT) rates. Retrieved Feb 15, 2020, from https://taxsummaries.pwc.com/quick-charts/capital-gains-tax-cgt-rates

KPMG. 2018. Individual income tax rates table. Retrieved Feb 15, 2020, from https://home.kpmg/xx/en/home/services/tax/tax-tools-and-resources/ tax-rates-online/individual-income-tax-rates-table.html

iii.8 - Homicide rate (HOM), uses data from: United Nations Office on Drugs and Crime (UNODC)

[Dataset]

United Nations Office on Drugs and Crime. (2019). Global Study on Homicide. Retrieved from https://dataunodc.un.org/GSH_app

iii.8 - Top 10\% share of pre-tax national income (INE), uses data from: World Inequality Lab, World Inequality Database (WID)

[Dataset]

WID. (n.d.). World Inequality Database. Retrieved October 17, 2019, from https://wid.world/world/\#sptinc p90p100 z/US;FR;DE;CN;ZA;GB;WO/last/ eu/k/p/yearly/s/false/25.253500000000003/80/curve/false/country 
iii.8 (g) - Fiscal decentralization (FDE), uses data from: International Monetary Fund (IMF)

[Dataset]

IMF. (n.d.). Fiscal Decentralization. Retrieved from hitps://data.imf. org/? sk=1C28EBFB-62B3-4B0C-AED3-048EEEBB684F

[Related Paper]

Hu, C., Kabanda, M., Lledó, V., Ncuti, C. \& Xiang, Y. (2018). The IMF Fiscal

Decentralization Dataset : A Primer. Retrieved from https://data.imf. org $/$ ? $\mathrm{sk}=1 \mathrm{C28EBFB}-62 \mathrm{~B} 3-4 \mathrm{~B} 0 \mathrm{C}-\mathrm{AED} 3-048 \mathrm{EEEBB} 684 \mathrm{~F}$

iii. 8 - Tax revenue as \% of GDP (DTR), uses data from: International Monetary Fund, Government Finance Statistics Yearbook \& World Bank and OECD GDP estimates (retrieved from the World Bank)

[Dataset]

The World Bank. (n.d.). Tax revenue (\% of GDP) [Indicator ID: GC.TAX.TOTL.GD.ZS]. Retrieved January 19, 2020 from hitps://data.worldbank.org/indicator/GC.TAX. TOTL.GD.ZS

iii.8 - Battlerelated deaths per 100,000 people (BRD), uses data from: Uppsala Conflict Data Program (retrieved from the World Bank)

[Dataset]

The World bank. (n.d.) Battle-related deaths (number of people) [Indicator ID: VC.BTL.DETH]. Retrieved January 4, 2020 from https://data.worldbank.org/ indicator/VC.BTL.DETH

iii.9 - Dutch disease propensity (DUT), uses data from The World Bank

[Dataset]

World Bank. (n.d.). Total natural resources rents (\% of GDP) [Indicator ID: NY. GDP.TOTL.RT.ZS]. Retrieved in July 2019 from : https://data.worldbank.org/ indicator/NY.GDP.TOTL.RT.ZS

[Related paper]

World Bank. (2011). The Changing Wealth of Nations: measuring sustainable development in the New Millennium. Washington DC: World Bank.

iii.9 - State ownership,control and involvement in business (SOE), uses data from:

OECD, Product Market Regulations Statistics*

\section{[Dataset]}

OECD (2019), "Economy-wide regulation (Edition 2018)", OECD Product Market Regulation Statistics (database), https://doi.org/10.1787/ebl le6de-en (accessed on 11 Sept 2019)

iii.9 - Environmental Performance Index (EPI), uses data from: Yale Center for Environmental Law \& Policy *

[Report]

Wendling, Z. A., Emerson, J. W., Esty, D. C., Levy, M. A., de Sherbinin, A., et al. (2018). 2018 Environmental Performance Index. New Haven, CT: Yale Center for Environmental Law \& Policy. https://epi.yale.edu/

iii.9 - Government Debt as \% of GDP (DBT), uses data from: The Global Economy

[Dataset]

TheGlobalEconomy.com. (n.d.). Government debt by country, around the world. Retrieved May 17, 2020 from hitps://mww.theglobaleconomy.com/rankings/ Government_debt/

iv. 10 - Trade freedom (TRF), uses data from:
The Heritage Foundation, Index of Economic Freedom

[Website]

The Heritage Foundation. (n.d.). Country Rankings. Index of Economic Freedom. Retrieved December 13, 2019 from https://www.heritage.org/index/explore

iv. 10 - Barriers to entry (BTE), uses data from:

OECD, Product Market Regulations Statistics*

[Dataset]

OECD (2019), "Economy-wide regulation (Edition 2018)", OECD Product Market Regulation Statistics (database), https://doi.org/10.1787/ebl le6de-en (accessed on 11 September 2019)

iv. $10-\mathrm{FDI}$ net Inflows as \% of GDP (FDI), uses data from: International Monetary Fund, International Financial Statistics and Balance of Payments databases and various others (retrieved from the World Bank)

[Dataset]

The World Bank. (n.d.). Foreign direct investment, net inflows (\% of GDP) [Indicator ID: BX.KLT.DINV.WD.GD.ZS]. Retrieved February 6, 2020 from https://data.worldbank.org/indicator/BX.KLT.DINV.WD.GD.ZS

iv. 10 - Barriers to FDI (BTF), uses data from:

OECD, FDI Regulatory Restrictiveness Index

[Dataset]

OECD.(n.d.). FDI Regulatory Restrictiveness Index. Retrieved May 15, 2020

from: https://stats.oecd.org/Index.aspx?datasetcode=FDIINDEX\#

iv. 10 - Economic globalization (EGL), uses data from:

ETHZ, The KOF Globalisation Index*

[Dataset]

Gygli, Savina, Florian Haelg, Niklas Potrafke and Jan-Egbert Sturm (2019): The KOF Globalisation Index - Revisited, Review of International Organizations, 14(3), 543-574 https://doi.org/10.1007/s1 1558-019-09344-2

[Related Paper]

Dreher, Axel (2006): Does Globalization Affect Growth? Evidence from a new Index of Globalization, Applied Economics 38, 10: 1091-1110.

iv. 10 - Health care as \% of GDP (DHC) uses data from: World Health Organization, Global Health Expenditure Database

[Dataset]

World Health Organisation. (n.d.). Global Health Expenditure Database [Indicator ID: che_gdp]. Retrieved March 16, 2020, from https://apps.who.int/ nha/database/Select/Indicators/en

iv. 10 - Open for Business (OFB), uses data from:

U.S.News, Best Countries Ranking

[Report]

U.S. News. (2020). Best Countries 2020: Global rankings, international news and data insights. Retrieved from https://www.usnews.com/media/best-countries/overall-rankings-2020.pdf?int=top_nav_Download\%202020\%20Rankings

iv. 11 - Neutral interest rate (DNI), uses data from:

[Dataset] OECD* $[\mathrm{MI}]$ \& The World Bank [GDP growth]

OECD. 2020. Main Economic Indicators. doi: 10.1787/7a23d68b-en (Accessed on 31 March 2020)

The World Bank. (n.d.). GDP growth (annual \%) [Indicator ID: NY.GDP.MKTP. KD.ZG]. Retrieved June 4, 2020, from https://data.worldbank.org/ indicator/NY.GDP.MKTP.KD.ZG

iv. 11 - Inflation (DOI), uses data from: 
[Report]

World Economic Forum, The Global Competitiveness Index

World Economic Forum. 2019. Global Competitiveness Report 2019. Retrieved from http://www3.weforum.org/docs/WEF_TheGlobalCompetitivenessReport2019.pdf

iv. 1 - Currency appreciation (CUA), uses data from: Bruegel

[Dataset]

Bruegel. 2019. Real effective exchange rates for 178 countries: a new database

I Bruegel. Retrieved April 20, 2020, from https://www.bruegel.org/

publications/datasets/real-effective-exchange-rates-for-178-countries-a-new-

database/

[Related papers]*

Darvas, Z. (2012a). Real effective exchange rates for 178 countries: a new

database. Working Paper 2012/06, Bruegel, 15 March 2012

Darvas, Z. (2012b). Compositional effects on productivity, labour cost and export adjustment. Policy Contribution 2012/11, Bruegel, 22 June 2012

iv. 11 - Gold demand as \% of GDP (GOL), uses data from: World Official Gold supply and demand Statistic

[Dataset]

World Gold Council. (n.d.) Gold Demand and Supply Statistics [Goldhub]

Retrieved October 19, 2019 from hitps://mmw.gold.org/goldhub/data/

gold-supply-and-demand-statistics

iv. 11 - M\&A as \% of Investment (DMA), uses data from:

Thomson Reuters Eikon [M\&A]

[Dataset]

Thomson Reuters Eikon. (2020). M\&A Transaction Data, 1970-2019 [Dataset].

Retrieved February 3, 2020 from https://eikon.thomsonreuters.com/index.html

iv. 12 - Unemployment rate (UEM), uses data from: International Labour Organization (ILOSTAT database) (retrieved from the World Bank)

[Dataset]

The World Bank. (n.d.). Unemployment, total (\% of total labor force) (national estimate) [Indicator ID: SL.UEM.TOTL.NE.ZS]. Retrieved September 19, 2019 from hitps://data.worldbank.org/indicator/SL.UEM.TOTL.NE.ZS

iv. 12 - Labor foce participtation rate (LFP), uses data from:

$$
\text { OECD* }
$$

[Dataset]

OECD, (2019), Labour force participation rate (indicator) doi:

10.1787/8a801325-en (Accessed on 14 September 2019)

iv. 12 - Delta real wage vs labor productivity increases (MLP), uses data from:

$$
\text { OECD* }
$$

[Dataset]

OECD (2020), Labour compensation per hour worked (indicator). doi:

10.1787/25lec2da-en (Accessed on 20 April 2020)

OECD (2020), GDP per hour worked (indicator). doi: 10.1787/1439e590-en (Accessed on 20 April 2020)

iv. 12 - Labor dependeny ratio (LDR), uses data from:

$$
\text { International Labor Organisation (ILOSTAT Database) }
$$

[Dataset]

International Labour Organisation. (n.d.) Labour Dependency ratio [LO modelled estimates]. Retrieved September 5, 2019: from https://www.ilo.org/ shinyapps/bulkexplorer32/? lang=en\&segment=indicator\&id=POP_2LDR_ NOC_RT_A iv. 12 - Youth unemployment rate (YUN), uses data from: The World Bank (retrieved from The Global Economy)

[Dataset]

TheGlobalEconomy.com. (n.d.). Youth unemployment rate. Retrieved December 28, 2019 from hitps://www.theglobaleconomy.com/download-data.php

iv. 12 - Gender wage gap (GWG), uses data from: OECD

[Dataset]

OECD. (n.d.). OECD.Stat Employment Database. Retrieved April 18, 2020 from https://stats.oecd.org/index.aspx?queryid=54751 


\section{Chapter 1: Introduction}

${ }^{1}$ Narratives are increasingly becoming objects of study in economics, partially as a result of Robert J. Shiller's 2017 seminal Narrative Economics article; in the areas of management and leadership their relevance for effective collective action is increasingly discussed (e.g. Hagel, 2011; Buckup \& Casas, 2018)

2 The analogy between Value Creation vs rent seeking behavior and the 'pie' comes from "Planet Plutocrat" (The Economist, 2014)

\section{Chapter 4: EQx Country analysis, Authors}

The EQx country analysis and special regional analysis presented in chapter 4 are the result of the valuable contribution of several authors. A suggested citation format is presented with the example of France. The individual DOI of each contribution can be found below.

France: Diebold, C., \& van der Watt, D. (2020). Country Scorecards, Deep Dive Analysis: France, Able to increase Elite Quality - but no signs it will do so across the board. In Casas i Klett, T., \& Cozzi, G. (Eds). Elite Quality Report 2020: 32 Country Scores and Global Rank (pp.34-35). Seismo. doi: $10.33058 /$ seismo.30750.01

Germany, doi: 10.33058/seismo.30750.02

Italy, doi: 10.33058/seismo.30750.03

Japan, doi: 10.33058/seismo.30750.04

Norway, doi: 10.33058/seismo.30750.05

Portugal, doi: 10.33058/seismo.30750.06

Russia, doi: 10.33058/seismo.30750.07

Turkey, doi: 10.33058/seismo.30750.08

United States, doi: 10.33058/seismo.30750.09

Special Regional Analysis: North East Asia, doi: 10.33058/seismo.30750.10

Chapter 4: EQx Country analysis, in-text references

${ }^{1}$ Mallet, V. (2019, September 10). France says budget deficit being cut 'less rapidly than predicted'. The Financial Times. Retrieved from https://www.ff. com/content/3c29c91c-d3af-1 1e9-a0bd-ab8ec6435630

${ }^{2}$ Chrisafis, A. (2019, April 25). Macron responds to gilets jaunes protests with EUR 5bn tax cuts. The Guardian. Retrieved from https://www. theguardian.com/world/2019/apr/25/emmanuel-macron-significant-tax-c ut-gilets-jaunes-speech

${ }^{3}$ France sinks deeper into debt. (2019, June 28). France 24. Retrieved from https://www.france24.com/en/20190628-france-sinks-deeper-debt

${ }^{4}$ Rickman, C. (2020, March 3). Here's What France Is Actually Doing to Fight Climate Change. Frenchly. Retrieved from https://frenchly.us/ what-is-france-actually-doing-to-fight-climate-change/

${ }^{5}$ Women 7 (W7). (2019, January 1). Elysee.fr. Retrieved from https://www. elysee.fr/en/g7/2019/01/01/women-7-w7

${ }^{6}$ Winter, C. (2019, August 21). Germany: 29.8 million people with immigrant background. Dw.com. Retrieved from https://www.dw.com/en/ germany-208-million-people-with-immigrant-background/a-50108141

7 Thelen, F. (2020, January 22). Tesla wird Marktkapitalisierung verdoppeln, VW und BMW werden bedeutungslos. Handelsblatt. Retrieved from https:// www.handelsblatt.com/meinung/gastbeitraege/gastbeitrag-von-frank-thelen-tesla-wird-marktkapitalisierung-verdoppeln-vw-und-bmw-werden-bedeutungslos $/ 25462604 . \mathrm{html}$

${ }^{8}$ Kupferschmidt, K., \& Vogel, G. (2020, April 27). Reopening puts Germany's much-praised coronavirus response at risk. Sciencemag.org. Retrieved from https://www.sciencemag.org/news/2020/04/reopening-puts-germany-s-much-praised-coronavirus-response-risk

9 Collman, A. (2020, April 27). Germany's coronavirus lead said the country's restrictions worked so well that people are now angry because they think the government overreacted. Business Insider. Retrieved from https:// www.businessinsider.com/germany-coronavirus-restrictions-so-effective-people-think-overreaction-2020-4? $r=U S \& I R=T$
${ }^{10}$ McGrath, M. (2019, December 12). The World's 100 Most Powerful Women. Forbes. Retrieved from hitps://www.forbes.com/power-women/\#50cd2bdc5e25

11 Neinaber, M. \& Macfie, N. (2019, December 31). I'm using all my strength to fight climate change, says Merkel. Reuters. Retrieved from https://www.reuters.com/article/us-germany-climatechange/im-using-allmy-strength-to-fight-climate-change-says-merkel-idUSKBNIYYIIF

12 Yamaguchi, T., Kajimoto, T. \& Kim, C-R. (2019, June 26). Japan tax revenue hit record in FY2018/19, exceeding bubble era: government sources. Reuters. Retrieved from hitps://www.reuters.com/article/ us-japan-economy-tax/japan-tax-revenue-hit-record-in-fy2018-19-exceeding-bubble-era-government-sources-idUSKCNITROKB

${ }^{13}$ McCurry, J. (2015, November 26). Japan under pressure to accept more immigrants as workforce shifts. The Guardian. Retrieved from https://www. theguardian.com/world/2015/nov/26/japan-under-pressure-to-acceptmore-immigrants-as-workforce-shrinks

${ }^{14}$ LaMagna, M. (2018, August 22). The American Dream may be dead. The New York Post. Retrieved from https://nypost.com/2018/08/22/ the-american-dream-may-be-dead/

${ }^{15}$ Meixler, E., Smith, G. \& Goldberg, E. (2019, December 23). FirstFT: 2019 in review. The Financial Times. Retrieved from https://www.ft.com/ content/0591 e3c0-2518-1 lea-9a4f-963f0ec7e134

\section{Indicators list}

${ }^{1}$ Crony-capitalism index. (n.d.). In Wikipedia. Retrieved June 29, 2020 from: https://en.wikipedia.org/wiki/Crony-capitalism_index

\section{Pictures credit}

p.vi: Luca Zanier Photography, with permission Corridors of Power Project, Stiftsbibliothek I St.Gallen

p.2: Visual 1: Joe Tabacca, Shutterstock.com (right) \& Alexandre Salama, with permission (left)

p.7: Luca Zanier Photography, with permission

Corridors of Power Project, CGT General Labour Confederation I Paris 2010

p. 11: Luca Zanier Photography, with permission

Corridors of Power Project, EU Parliament Strasbourg III Plenary Chamber 2015

p. 18-19: Luca Zanier Photography, with permission

Corridors of Power Project, EU Parliament Strasbourg III Plenary Chamber 2015

p.25: Luca Zanier Photography, with permission

Corridors of Power Project, WIPO New Conference Hall I Geneva

p.57: Matej Kastelic, Shutterstock

P.60: Luca Zanier Photography, with permission

Corridors of Power Project, Humboldt University Library I Berlin 2014

p.91: Luca Zanier Photography, with permission

Corridors of Power Project, WIPO New Conference Hall I Geneva

\section{Style note}

All the terms original to EQx such 'Elite Quality' or 'enlightened elites' when introduced will have single quotation marks. Thereafter the marks will disappear, but the term might be rendered in italics. Terms that depict a component of the EQx index are capitalized as for example Power Sub-Index, Economic Dimension, Political Value Index Area, Creative Destruction Pillar or Indicator. The Pillars are followed by their Pillar Code as in Creative Destruction (ii.6). The Indicators themselves are referred to in italics and are followed by their Indicator Code in brackets as in Currency appreciation (CUA, iv. 11). Terms that represent proprietary frameworks such as State of Elites framework or Index Area matrix will be capitalized. This Report's citations are based on APA $6^{\text {th }}$ edition standard.All references to indices in the Report are italicized (e.g. Environmental Performance Index). 


\section{Forthcoming, EQx2021}

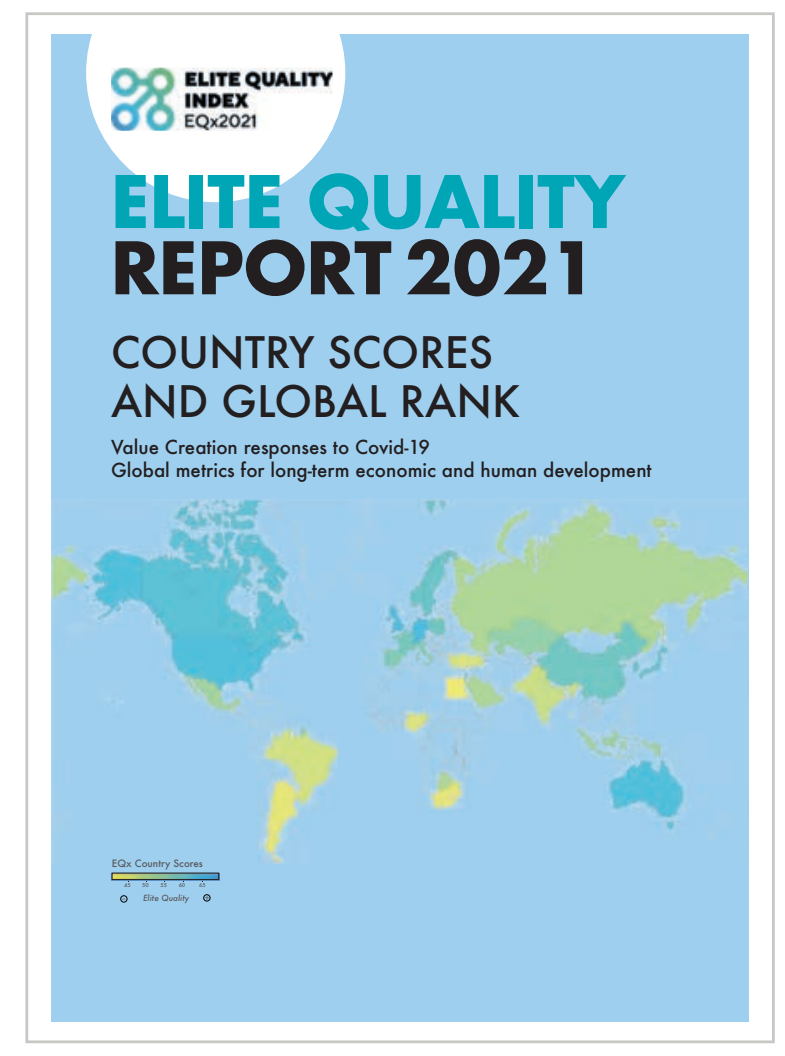

The Elite Quality Report 2021: Country Scores and Global Rank (EQ×2021) is under development and planned for release in 2021 . It will feature:

- Value Creation responses to Covid-19: Analysis of long-term economic prospects through the unique Elite Quality framework

- New Indicators will expand the existing 72 datasets to capture additional evidence of Value Creation in the political economy

$100+$ Countries, up from the initial 32 country coverage in the $E Q \times 2020$ 


\section{Acknowledgements}

The Foundation for Value Creation is in deep gratitude to its partners and supporters for their insights, resources and valuable guidance during the conception and production of this report. The team that participated in this year's Elite Quality Index $(E Q \times 2020)$ is acknowledged below:

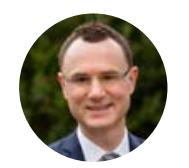

Tomas Casas

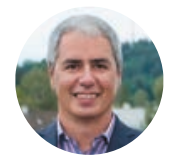

Guido Cozzi

Index Director

Chief Economist

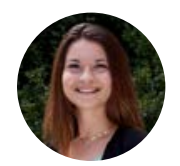

Camille Zeller

Data Manager

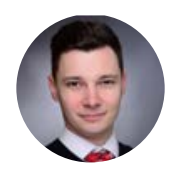

Anton Antonov

Index Plafform Manager

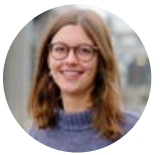

Céline Diebold

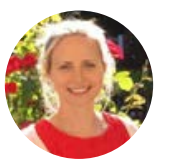

Diana van der Watt

Research Analyst

We express our gratitude to the expert advisors for their valuable guidance and original insight:

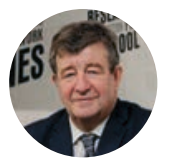

Shlomo Weber

Senior Economics Advisor

and Eurasia Advisor

Michael Hilb

Foundation Governance

Advisor 
This report's original content was made possible by the intellectual contributions and critical suggestions of committed partner institutions as well as many individuals worldwide. The index development and academic leadership rests with two institutes at the University of St.Gallen: the Research Institute for International Management (FIM-HSG) and the Institute of Economics (FGN-HSG). EQx has benefited from the data, methodological inputs and analysis from a network of international partners. The SKOLKOVO Moscow School of Management, the EQx partner for Russia and the Commonwealth of Independent States (CIS), has supported the index from its early conceptualization stages. The academic partner for Portugal, the School of Economics and Management, University of Porto, has made significant and committed contributions to EQx. At the individual level, we are profoundly indebted to the authors of the deep dive country analyses and their institutional supporters: To Freya Beamish of Pantheon Macroeconomics; to Prof. Etsuro Shioji of Hitotsubashi University; to Prof. Claudia Ribeiro and Prof. Óscar Afonso of the School of Economics and Management, University of Porto; to President Andrei Sharonov and Prof. Evgeny Kaganer of the SKOLKOVO Moscow School of Management and to Rector Ruben Enikolopov of the New Economic School; to Prof. Jan Ketil Arnulf, Prof. Dag Morten Dalen and Prof. Janicke Rasmussen of the BI Norwegian Business School. We express our deep thanks to Prof. Sasha Shapoval for methodological discussions and original ideas, many of which will reach fruition in future versions of the index. The leadership at FIM-HSG of Prof. Winfried Ruigrok is essential to this project, as are his sharp inputs and valuable insight. We appreciate the counsel of Beat Ulrich, CEO of the St.Gallen Symposium (www.symposium. org), for his suggestion to take the perspective of the next generation when developing the Index and its public discourse approaches positioning the EQx project as a platform for inter-generational dialogue. Prof. Martin Hilb's continuous encouragement and kindness have imbued the project with unique momentum and opened original avenues of future inquiry. We also would like to extend our thanks to all those who have supported the EQx work in diverse areas of engagement for their professionalism and trust. We acknowledge the various inputs of the students of the University of St.Gallen, Jason Tran, Lone Myrtue, Malte Traenkle, Marc Hew, Philip Scheu and Sebastian Baumann. The creative work of Chloe Dikotter, Massimo Rahmim, Hannah Kyburz and Gabriel Hafner have made the report an easier and more enjoyable read, including its online version. The media relations team at the University of St.Gallen with Gordon Langlois and Annkathrin Heidenreich have provided access to the report and its findings to wider audiences in Europe and globally. The team at Seismo AG led by Franziska Doerig, Christine Hirzel and Franziska Hasler has contributed to many aspects of this work's design, visualization and production process. Gallus Niedermann and the printer team at www. NiedermannDruck.ch undertook outmost care to realize a printed version of the report to Swiss quality standards. Daniel Fafula and his Friedrichshafen and Budapest teams at www.apicore have conscientiously executed the www.elitequality.org website. Luca Zanier has made an important artistic contribution to this work by licensing the pictures of his "Corridors of Power" photography project. Of strategic importance for this project is the development of a capable, robust and user-friendly Index Management Platform (IMP-EQx); our recognition here goes to the teams of dxFeed in Munich and St. Petersburg under the leadership of Dmitri Parilov and Oleg Solodukhin as well as the most efficient and creative technology management of Anton Antonov, Sergey Titov and his colleagues. The Foundation for Value Creation is also deeply indebted to the generous benefactors and supporting organizations whose resources have made this report possible. 


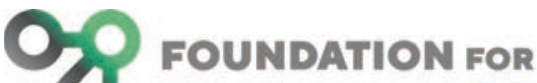

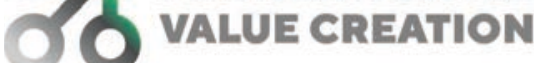

\section{The relationship between the Foundation for Value Creation (FVC) and the Index (EQx):}

The Foundation for Value Creation (FVC or Foundation) is a Switzerland-based, non-profit foundation, supervised by the Swiss Federal Supervisory Board for Foundations (Eidgenössische Stiffungsaufsicht, ESA) (application pending). The Foundation's vision and its purpose (Stiftungssweck) articulated in its statutes (Satzung) includes the generation of innovative, evidence-based insights on Value Creation. The Foundation's resources are allocated and audited in compliance with its purpose and applicable Swiss laws.

Measuring the degree of Value Creation in an economy is the objective of the Elite Quality Index (EQx) project. The underlying assumption of $E Q x$, shared by the Foundation, is that the extent to which elite business models create value, rather than extract value, significantly contributes to the country's economic growth and human development. The Foundation realizes its purpose by supporting EQx along three dimensions.

Firstly, the Foundation makes the development of EQx possible, by coordinating the international partner network, providing support for research initiatives and by assisting in the publication and dissemination of the results. Dissemination activities include the participation in and organization of international, local and digital events, as well as establishing a collaborative platform for partners to work on and share EQx data. Secondly, the Foundation sees $E Q x$ as a unique intellectual asset for a wide range of educational initiatives. These include university courses for new generations of students, innovative formats for the broader public, as well as custom programmes for the top leadership of organizations, governments and institutions. Thirdly, EQx provides a distinct practice oriented analytical toolset to be leveraged for the inside-out transformation and renewal of elite business models towards inclusive Value Creation and away from Value Extraction. EQx results and interpretation lend themselves to the reflection and analysis that precedes transformative action, and the international and open plafform collaboration approach of the Foundation enables the impact, aiming deep into societies and into the core of political economies.

If you are interested in knowing more about the FVC or having conversation with the foundation's associates, you can email us at: foundation@elitequality.org 


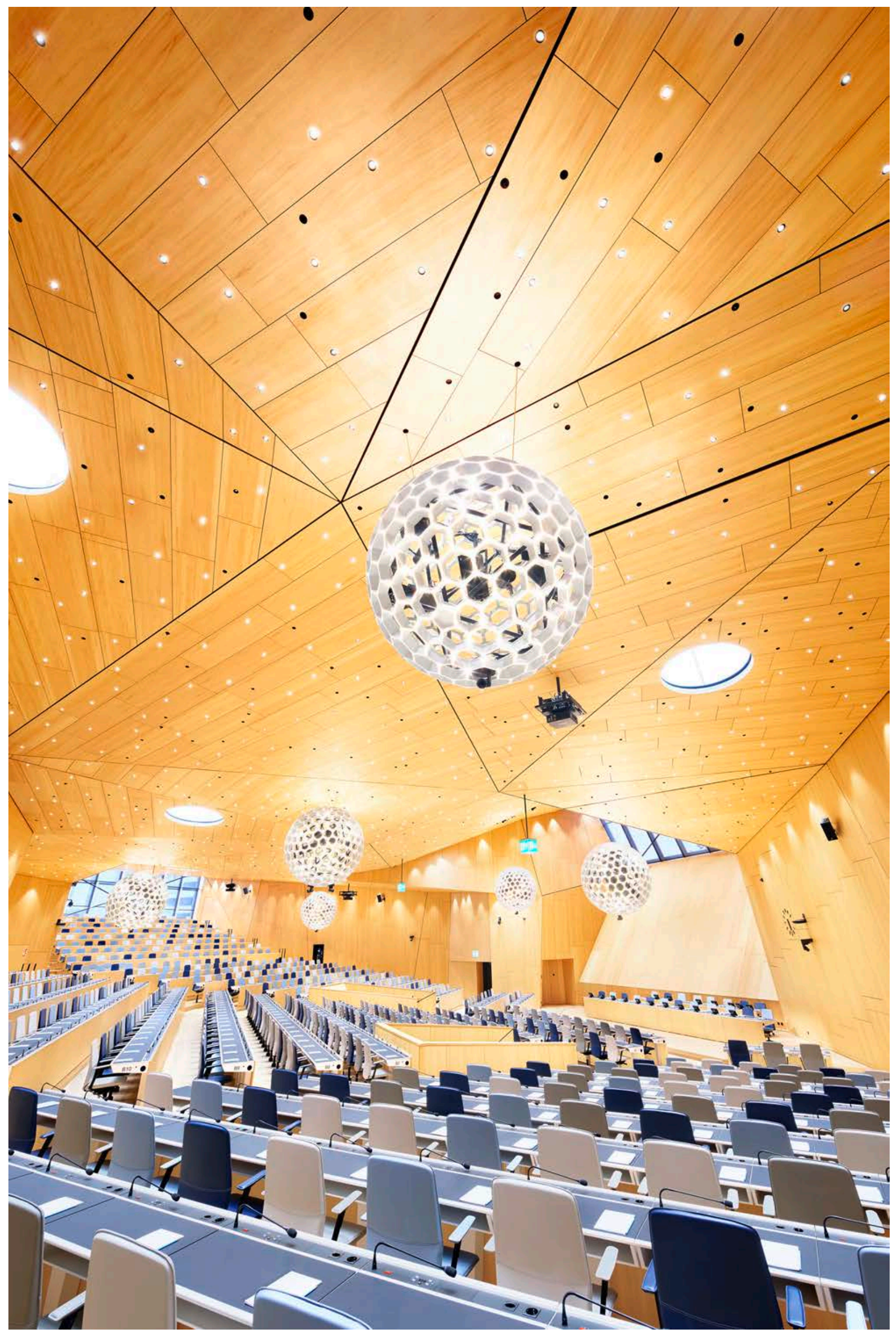




\section{Purpose}

The global Elite Quality Index (EQx) is a flagship project. We aim to produce innovative and academically grounded insights on the subjects of value creation and elite quality. Through research projects and our partner network, we identify causes of medium-term economic growth and human development, including the rise and fall of nations and organizations. We seek to contribute original ideas and evidence-based understanding to policy and public debates on these topics, and ultimately aim to identify and initiate ways of transforming leading business models from value extraction to value creation. We encourage international dialogue across generations and social groups, novel educational and knowledge dissemination formats, and the construction of value-oriented, inclusive narratives for societies. 